

\title{
Movilidad, elementos esenciales y riesgos en el distrito metropolitano de Quito
}

\author{
Florent Demoraes
}

\section{To cite this version:}

Florent Demoraes. Movilidad, elementos esenciales y riesgos en el distrito metropolitano de Quito.

Colección Quito Metropolitano, 2005, 10.4000/books.ifea.5102 . halshs-00102770

\section{HAL Id: halshs-00102770 \\ https://shs.hal.science/halshs-00102770}

Submitted on 18 Dec 2009

HAL is a multi-disciplinary open access archive for the deposit and dissemination of scientific research documents, whether they are published or not. The documents may come from teaching and research institutions in France or abroad, or from public or private research centers.
L'archive ouverte pluridisciplinaire HAL, est destinée au dépôt et à la diffusion de documents scientifiques de niveau recherche, publiés ou non, émanant des établissements d'enseignement et de recherche français ou étrangers, des laboratoires publics ou privés. 




Municipio del Distrito Metropolitano de Q uito Dirección Metropolitana de Planificación Territorial
Institut de Recherche pour le Développement 

Municipio del Distrito Metropolitano de Quito - Dirección Metropolitana de Planificación Territorial Institut de Recherche pour le Développement

\title{
WOOVIDDAD, ELENMENTOS ESENCIALES Y PIESGOS EN EL DISTPITO A METROPOLJTANO DE QUJTO
}

\author{
Florent Demoraes
}


Paco Moncayo Gallegos

Alcalde Metropolitano de Quito

Diego Carrión

\section{Secretario Metropolitano de Desarrollo Territorial}

René Vallejo

Director Metropolitano de Planificación Territorial

Nury Bermúdez

\section{Coordinadora de la Unidad de Estudios e Información Metropolitana}

\section{Autor}

Florent Demoraes - Laboratoire EDYTEM (Université de Savoie) - UR 029 "Environnement Urbain" (IRD)

\section{Mapas y gráficos}

Florent Demoraes, utilización SIG "Savane"

\section{Edición}

Florent Demoraes, Tania Serrano, Mónica Pabón

\section{Traducción}

Florent Demoraes, Tania Serrano

\section{Portada}

Triumphal Arch, 2001

Miguel Betancourt

\section{Diagramación e Impresión}

AH/editorial

(C) Municipio del Distrito Metropolitano de Quito Dirección Metropolitana de Planificación Territorial

García Moreno 1130 y Chile. Quito, Ecuador.

Telf: 2584345, 2957751 Fax 2580813. dgp@quito.gov.ec www.quito.gov.ec

(c) Institut de Recherche pour le Développement (IRD)

Representación en Ecuador

Whymper 442 y Coruña - Quito

Tef: 25039 44, 2504856 - Fax: 2504020 - correo electrónico: repquito@ird.fr www.ec.ird.fr

(c) Instituto Francés de Estudios Andinos (IFEA)

Av. Arequipa 4595 - Miraflores. Lima 18 - Perú

Tel: (511) 7026070 Fax: (511) 70260 73. E-mail: postmaster@ifea.org.pe

Pág. web: http:// www.ifeanet.org

Este volumen corresponde al tomo 210 de la colección

"Travaux de I'Institut Français d'Études Andines" (ISSN 0768-424X)

Movilidad, elementos esenciales y riesgos en el Distrito Metropolitano de Quito, Ecuador

ISBN: 9978-970-53-3

Quito, Ecuador, Noviembre de 2005 


\section{PRESENTACIÓN}

En la concepción de la ciudad como una organización particular de interacciones entre individuos, grupos y actividades la movilidad se constituye en elemento esencial de los sistemas urbanos, de la estructuración de las redes urbanas y de la accesibilidad y por lo tanto fundamental y necesaria para el desenvolvimiento de las actividades urbanas cotidianas.

En el caso del DMQ en una estructura urbana altamente condicionada por las limitaciones de la geografía y vulnerable ante las amenazas naturales, los problemas cotidianos y las perturbaciones episódicas de la movilidad dificultan el funcionamiento de la ciudad y pueden llegar a limitar las expectativas de su desarrollo por lo que constituyen motivo de preocupación de sus autoridades, de las instituciones y dependencias gestionadoras y de sus propios actores.

En este contexto y en el marco del programa "Sistemas de Información y Riesgos en el DMQ" que desarrollan la Dirección Metropolitana de Planificación Territorial y el Institut de Recherche pour le Développement (IRD) se realizo la investigación "Movilidad, elementos esenciales y riesgos en el Distrito Metropolitano de Quito" que tiene como objetivo el evaluar los riesgos a los que está expuesto el Distrito Metropolitano de Quito toman do en cuenta los problemas de movilidad habituales de las personas y la accesibilidad como un aporte al conocimiento de la problemática y a los fines de una práctica institucional de planificación estratégica y preventiva del territorio metropolitano.

Esta obra que se halla estructurada a partir del estudio de los flujos y movimientos de personas y el sistema de transporte, de la identificación y localización de los elementos esenciales de la movilidad, del análisis de la vulnerabilidad de los elementos esenciales de la movilidad y de la evaluación de los riesgos construye una base de reflexión para los diferentes gestores urbanos y entrega directrices para la reducción de la vulnerabilidad y medidas encaminadas a orientar la gestión de crisis de la movilidad urbana.

Al presentar esta publicación que sin duda abre nuevas pistas metodológicas para un mejor entendimiento de las dinámicas territoriales quiero resaltar el virtuosismo académico de su autor Florent Demoraes y el compromiso que para la ciudad de Quito han demostrado (i) el Institut de Recherche pour le Développement (IRD, ex ORSTOM) al promover y participar en la investigación geográfica sobre las problemáticas urbanas, y (ii) el Instituto Francés de Estudios Andinos (IFEA) al coauspiciar esta edición.

\section{Arq. René Vallejo Aguirre}

Director Metropolitano de Planificación Territorial 



\section{Agradecimientos}

Agradezco la colaboración de las numerosas instituciones que facilitaron valiosa información y datos para la realización de esta investigación, entre ellas:

Consejo Nacional de Tránsito (CNT)

Consejo Provincial de Tránsito de Pichincha (CPTP)

Cuerpo de Bomberos del Distrito Metropolitano de Quito

Departamento de Seguridad e Higiene Industrial, MDMQ

Dirección de Avalúos y Catastros, MDMQ

Dirección de Emergencias 911

Dirección Metropolitana de Transporte y Vialidad (DMT)

Empresa Metropolitana de Senvicio y Administración del Transporte (EMSAT)

Empresa Eléctrica Quito (EEQ)

Empresa Metropolitana de Obras Públicas de Quito (EMOP-Q)

Empresa Municipal de Transporte, MDMQ

Facultad de Ingeniería Civil, Escuela Politécnica Nacional

Honorable Consejo Provincial de Pichincha (HCPP)

Instituto Nacional de Estadísticas y Censos (INEC)

Ministerio de Obras Públicas (MOP)

Servicio de Investigación de Accidentes de Tránsito (SIAT - Policía Nacional)

Unidad Operadora del Sistema Trolebus (UOST)

$Y$ en especial mi sincero reconocimiento a todas aquellas personas que hicieron posible, gracias a su colaboración científica, sus consejos, su tiempo y su apoyo, la culminación de este trabajo, en particular:
Dr. Robert D'Ercole
Dr. Alain Mamézy
Dra. Pascale Metzger
Arq. Hidalgo Núñez

Dr. Fabricio Yépez Ing. Jairo Estacio Ing. Marcelo Narváez Ing. Ivan Parreño
Arq. Nury Bermúdez

Lic. Tania Serrano

Sr. Joe Tupiza

Ing. Marco Vinicio Tupiza

Ing. Alexandra Mena

Arq. Patricia Mena

Arq. René Vallejo

Dr. Marc Souris

Dra. Dominique Couret

Ing. Agustín Rivadeneira

Eco. Alex Tupiza

Ing. Marcelo Yánez

Ing. Vinicio Marroquí

Ing. Galo Atiaga

\author{
Arq. Julio Arteaga \\ Arq. Gerardo Viteri \\ Sr. Orlando Vaca \\ Sra. Miriam Duque \\ Ing. Wladimir Aguirre \\ Ing. Carlos Nielsen \\ Ing. Carlos Poveda \\ Ing. Damien Golbin \\ Ing. David Vargas \\ Ing. Hugo Miller \\ Sr. Fabián Veintimilla \\ Ing. Masapanta \\ Ing. Roberto Cóndor \\ Ing. Romeo Santillán
}

Y a todo el personal de la DMPT y DMT; investigadores, doctorantes y personal administrativo del laboratorio EDYTEM de la Universidad de Saboya (Francia) y personal de la representación del IRD en Ecuador, que, de una u otra manera, me brindó su apoyo. Este trabajo no hubiese sido posible sin el aporte financiero de los Ministerios franceses de Educación e Investigación (programa Aires Culturelles), de Relaciones Exteriores (beca Lavoisier) y del Departamento de Geografía de la Universidad de Saboya.

Finalmente quiero agradecer a mis padres que creyeron en mí, a Tania por haberme alentado, reconfortado y quien supo tener paciencia; a mis amigos de siempre (Foued, J aguer, Bérane, Ouavur, Naguev, Jean-Fred... ) y a mis compañeros "chéveres" de Quito (Don Luis y Finette) quienes estuvieron expuestos a mis angustias y cambios de humor. 

En este libro se presenta una reflexión sobre los riesgos a los cuales está expuesto el Distrito Metropolitano de Quito -DMQ - considerando la cuestión de la movilidad cotidiana de las personas y la cuestión de la accesibilidad. Este análisis se funda en un método elaborado en el marco del programa "Sistema de información y riesgos en el DMQ" llevado a cabo por la Dirección Metropolitana de Territorio y Vivienda del Municipio de Quito y el Institut de Recherche pour le Développement (IRD, ex ORSTOM).

Para prevenir eficazmente los riesgos a los cuales está expuesta la capital ecuatoriana por problemas de movilidad habituales o excepcionales, es imprescindible enfocar el análisis en las obras viales claves y los equipamientos de transporte esenciales. En efecto, la pérdida de su operatividad podría dificultar gravemente las comunicaciones y reducir fuertemente la accesibilidad de algunos sectores lo que causaría perjuicios muy severos al territorio metropolitano. La situación es tanto más crítica cuanto que las obras claves son vulnerables y tanto más problemática cuanto que los sectores en cuestión cuentan con funciones urbanas estratégicas (grandes equipamientos de la logística urbana, grandes centros hospitalarios,...).

En primer lugar se estudia los flujos y movimientos de personas y el sistema de transporte vigente. Se identifica y localiza en la segunda parte las infraestructuras claves de la movilidad. En una tercera fase se analiza los factores de vulnerabilidad de estas infraestructuras claves, vulnerabilidad que las predisponen a fallos o daños. Por último se aborda los riesgos a los cuales está expuesto el Distrito dada la reducción de la accesibilidad de los diferentes espacios metropolitanos que puede resultar del cierre de las vías claves.

En una perspectiva de planificación urbana preventiva, el libro proporciona una base de reflexión para los gestores, pistas para la reducción de la vulnerabilidad y medidas encaminadas a orientar la gestión de crisis. Si bien se dirige a los encargados del manejo del transporte o riesgos, este libro está destinado a los planificadores urbanos y de manera general a todo público interesado en comprender el funcionamiento de la movilidad de las personas y la vulnerabilidad de la capital ecuatoriana.

Palabras claves: elementos esenciales, movilidad y transporte urbanos, vulnerabilidad, accesibilidad, riesgos, planificación urbana preventiva, Quito.

Una versión más detallada de esta investigación en francés está disponible en formato pdf en la siguiente dirección: http://edytem.univ-savoie.fr/membres/demoraes/these/ these.html 


\section{Résumé}

Ce livre présente une réflexion sur les risques encourus par le District Métropolitain de Quito -DMQ- en considérant la question de la mobilité quotidienne des personnes et la question de l'accessibilité. Cette analyse s'appuie sur une méthode mise au point dans le cadre du programme «Système d'information et risques dans le DMQ » mené par la Direction Métropolitaine du Territoire et du Logement de la Municipalité de Quito et l'Institut de Recherche pour le Développement (IRD).

Pour prévenir de façon efficace les risques auxquels est exposée la capitale équatorienne compte tenu des problèmes de mobilité habituels ou exceptionnels, il est indispensable de cibler l'analyse sur les infrastructures routières enjeux et sur les équipements de transport enjeux. En effet, la perte de leur opérationnalité pourrait compromettre sérieusement les communications et réduire fortement l'accessibilité de certains secteurs, situation qui handicaperait gravement le territoire métropolitain. La situation est d'autant plus critique que les enjeux sont vulnérables et d'autant plus problématique que les secteurs en question rassemblent des fonctions urbaines stratégiques (grands équipements de la logistique urbaine, grands centres hospitaliers...).

En premier lieu, sont étudiés les flux et de personnes et le système de transport actuel. En second lieu, sont identifiées et localisées les infrastructures enjeux de la mobilité. En troisième lieu, les vulnérabilités déplacements enjeux, les prédisposant aux défaillances ou à l'endommagement, sont analysées. Enfin sont évalués les risques encourus par le District compte tenu de la réduction de l'accessibilité des différents espaces métropolitains pouvant découler de la fermeture des routes enjeux.

Dans une perspective de planification urbaine préventive, le livre propose une base de réflexion utile aux gestionnaires, fournit des pistes pour la réduction des vulnérabilités et apporte des orientations pour la préparation aux crises. S'il s'adresse aux responsables de la gestion des transports ou des risques, ce livre est aussi destiné aux planificateurs urbains et de manière générale à quiconque désire comprendre le fonctionnement de la mobilité des personnes et la vulnérabilité de la capitale équatorienne.

Mots-clefs : enjeux, mobilité des personnes, transports urbains, vulnérabilités, accessibilités, nisques, planification urbaine préventive, Quito.

Une version plus détaillée de cette recherche est consultable au format pdf à l'adresse suivante :

http://edytem.univ-savoie.fr/membres/demoraes/these/ these.html 


\section{Abstract}

The objective of this book is to offer reflections on the risks incurred by the Metropolitan District of Quito -DMQ(Ecuador) regarding the people's daily mobility and accessibility issues. The analysis is based on a method elaborated in the framework of a research programme called "Information System and Risks within the Metropolitan District of Quito" carried out by the Municipality of Quito in partnership with the Development Research French Institute (IRD).

In order to prevent efficiently the risks incurred by the Ecuadorian capital due to usual or exceptional mobility problems, it is essential to focus the analysis on the critical urban road infrastructures and on the critical urban transportation facilities. Indeed, the loss of their serviceability is likely to hamper interchanges and to limit severely the accessibility of certain zones, which could be highly detrimental to the metropolitan territory. The situation may be even worse if the critical infrastructures are vulnerable and even more problematic if the concerned zones gather strategic urban functions (important urban facilities, such as large hospitals, main electricity factories...).

The first part presents the current daily interchanges and movements of people in the District and also an analysis of the transport system. In the second part the critical infrastructures of transportation are identified and localised. In the third part the vulnerabilities of these critical infrastructures, predisposing them to failures and damages, are analysed. The fourth part puts forward an assessment of the risks incurred by the District, taking into account the limitations of accessibility resulting from possible disruptions of the critical roads.

Taking a preventive planning perspective, this book suggests reflections that could be useful to different urban stakeholders; it provides ways of reducing vulnerabilities and presents orientations toward crisis preparedness. While intended for the authorities in charge of transportation and risk management, this book is also meant for urban planners and for any of the public interested in understanding the organisation of people's mobility and the vulnerability of the Ecuadorian capital.

Key words: urban transportation, people's mobility, critical infrastructures, vulnerability, accessibility, risks, urban preventive planning, Quito.

A more detailed version of this research (in French) is downloadable at the following website:

http://edytem.univ-savoie.fr/membres/demoraes/these/these.html 
D 


\section{Contenido}

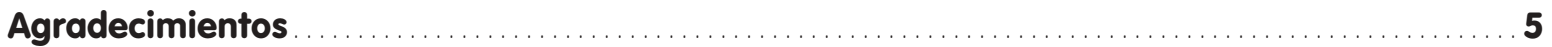

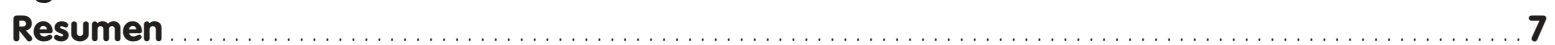









1 La movilidad en el funcionamiento de la ciudad ........................................ 20

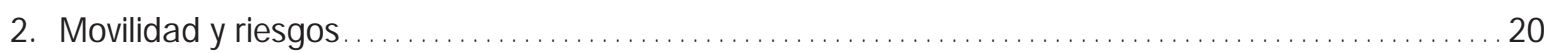

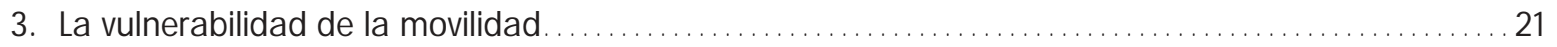

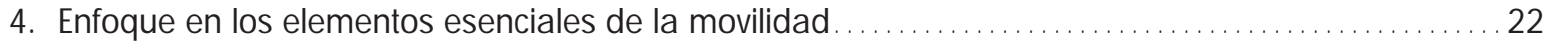

5. La necesaria utilización de la noción de accesibilidad ..................................... 23

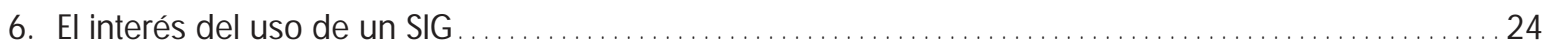

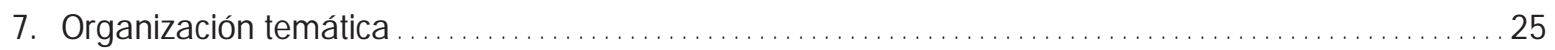

MOVILIDAD DE LAS PERSONAS, ESTRUCTURA Y FUNCIONAMIENTO

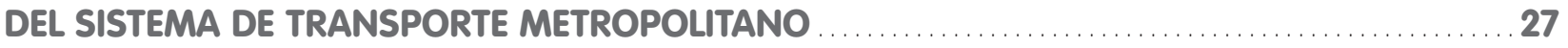

1. El 80 por ciento de los desplazamientos realizados a diario en bus . ................... 29

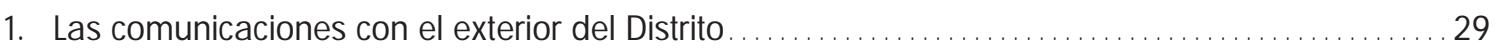

Quito, metrópoli andina ubicada en la sierra centro norte del país..................... 29

Flujos mayoritarios hacia el sur del país .......................................... 30

El Distrito Metropolitano de Quito: un nodo importante en la red vial nacional . ............... 35

Desplazamientos de personas entre el DMQ y los cantones vecinos ....................... 35

2. Las comunicaciones metropolitanas centro-periferia ................................... 37

La periferia: desigual e insuficientemente provista de funciones urbanas .................. 39

La ciudad de Quito: alta concentración de las funciones urbanas ........................ 43

Desplazamientos entre la ciudad de Quito y la periferia .............................. 45

3. Las comunicaciones intra-urbanas ................................................. 49

La hipercentralidad funcional de la ciudad .................................... 49

La frecuentación del espacio central . ............................................. 52

Frecuentación y motivos de viaje dentro de la ciudad: situaciones muy heterogéneas ......... 53 
2. Estructura, organización y funcionamiento del sistema de transporte

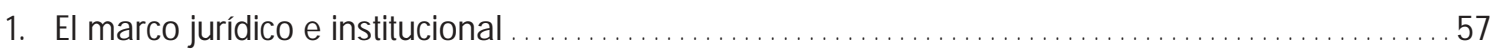

Actores involucrados en la vialidad ............................................ 57

Los organismos tutelares del transporte colectivo .................................. 60

Organismos encargados del parque automovilístico y del tráfico ....................... 61

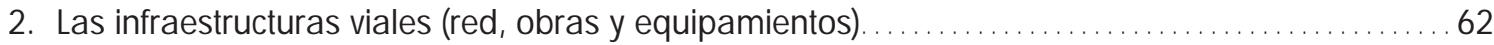

Función y frecuentación de los ejes viales ......................................... 62

Las obras viales: últimas construcciones y su repartición en la ciudad ....................66 66

Otros equipamientos e instalaciones necesarios para la movilidad .....................69 69

3. El sistema de transporte: particularidades, funcionamiento, utilización y evolución .............. 72

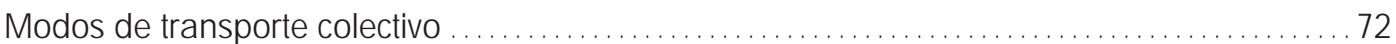

La oferta privada del transporte colectivo público ................................... 73

La oferta municipal de transporte colectivo público ................................. 77

Crecimiento del parque automovilístico en el Distrito Metropolitano de Quito ................. 85

\section{ELEMENTOS ESENCIALES DEL FUNCIONAMIENTO DEL SISTEMA}

3. El uso de la noción de "elemento esencial" en los análisis de riesgo urbano: un enfoque reciente.

1 Niza y Annecy: enfoque en los elementos esenciales en

un contexto de amenaza sísmica.

2. El uso de la noción de elemento esencial en el programa

"Sistema de información y riesgos en el Distrito Metropolitano de Quito"...................... 92

Enfoque en los elementos esenciales, independientemente de las amenazas.............. 92

Elementos esenciales: una noción relativa .......................................... 92

4. Los elementos esenciales de la movilidad a escala del Distrito ........................ 95

1 Los ejes viales esenciales: método de identificación y cartografía .......................... 95

Los accesos al Distrito ....................................................... 95

Los ejes centro periferia................................................... 97

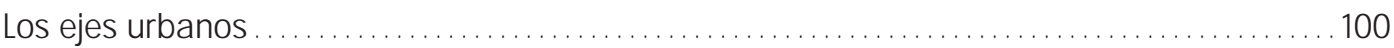

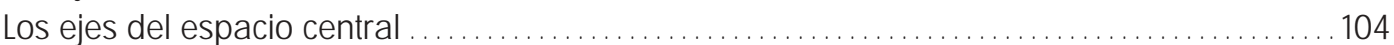

Síntesis: ejes importantes, esenciales y tramos funcionales homogéneos .................. 105 
2. Las infraestructuras viales esenciales: método de identificación y cartografía ................. 106

3. Los equipamientos de transporte esenciales: método de identificación y cartografía............112

LA VULNERABILIDAD DEL SISTEMA DE MOVILIDAD METROPOLITANA

5 - La vulnerabilidad de los elementos esenciales de

la movilidad y factores de compensación: presentación y aplicación

1 El riesgo, un juego entre factores de vulnerabilidad y fortalezas . ........................... 119

2. Análisis de la vulnerabilidad en el marco del programa

"Sistema de información y riesgos en el DMQ"....................................... 120

Las seis formas de vulnerabilidad consideradas................................. 120

La exposición a las amenazas como una de las formas de vulnerabilidad ................. 121

3. Análisis de la vulnerabilidad de los elementos esenciales del sistema

de movilidad: procedimiento e implementación...................................... 122

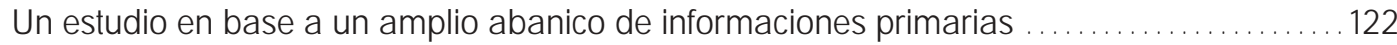

Procedimiento y criterios de evaluación de la vulnerabilidad .......................... 124

El uso de un SIG para analizar ciertas formas de vulnerabilidad . . . . . . . . . . . . . . . . . 128

Método de ponderación y valoración de las formas de vulnerabilidad:

enfoque cualitativo y cuantitativo.

6 - Análisis de vulnerabilidad de los elementos esenciales del sistema de movilidad: resultados cartográficos

1 Representación cartográfica de la vulnerabilidad de los elementos esenciales................. 149

Los ejes viales: vulnerabilidad heterogénea ........................................... 149

Los puentes: entre una vulnerabilidad nula y una máxima ........................... 150

Los centros de transporte y los túneles: un balance moderado ......................... 153

2. Síntesis: los accesos a la ciudad y las comunicaciones intra urbanas norte-sur altamente vulnerables...................................... 159

La noción de vulnerabilidad acumulada ........................................... 159

El cálculo de la vulnerabilidad acumulada ........................................ 159

Vulnerabilidad acumulada de los elementos esenciales

de la movilidad: ensayo cartográfico. 
7. Interés del uso de la noción de accesibilidad para la comprensión de los riesgos

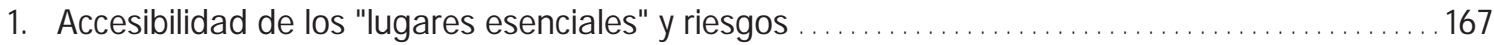

La accesibilidad de los lugares esenciales........................................... 167

...accesibilidad cuya reducción conllevaría riesgos ................................... 167

2. Las comunicaciones en tiempo habitual al interior de la aglomeración ....................... 168

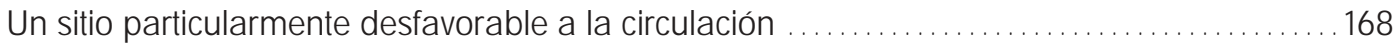

3. Definición y método de evaluación de la accesibilidad de los lugares. ...................... 172

8. Evaluación de la accesibilidad de los diferentes subespacios geográficos del Distrito: procedimiento y cartografía . . . . . . . . . . . . . . 177

1 La accesibilidad en tiempo habitual . . . . . . . . . . . . . . . . . . . . . . . . . . . . . . . . . . . . . . . . . . 177

2. Accesibilidad de las zonas, en caso de fallo en los elementos esenciales de la movilidad más vulnerables........................................ 180

Análisis de reducción de la accesibilidad ......................................... 180

Reducción de la accesibilidad según la lógica endótropa de proximidad .................. 180

Reducción de la accesibilidad según la lógica centrípeta .............................. 181

9. Vulnerabilidad de la accesibilidad,

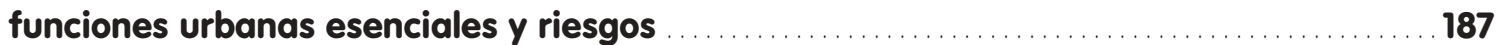

1 Principio y método de evaluación de los riesgos ...................................... 187

Actividades e instalaciones urbanas esenciales

de funcionamiento, crisis y recuperación . . . . . . . . . . . . . . . . . . . . . . . . . . . . . . . . . . . 187

Localización de los elementos esenciales y accesibilidad .............................. 188

2. Aislamiento, funciones vitales de proximidad y riesgos para el DMQ $\ldots \ldots \ldots \ldots \ldots \ldots \ldots \ldots . \ldots 18$

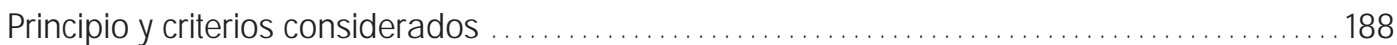

Método de análisis y cartografía ............................................... 189

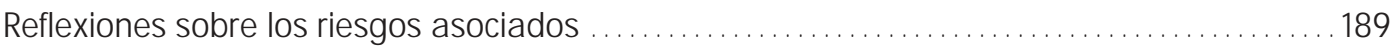


3. Aislamiento, instalaciones esenciales para el funcionamiento

del DMQ y riesgos asociados ..................................................... 191



Reflexiones sobre los riesgos asociados . . . . . . . . . . . . . . . . . . . . . . . . . . . . . . . . . 192

4. Desvíos, instalaciones urbanas esenciales, dependencia de

las comunicaciones y riesgos para el DMQ ....................................... 196



Reflexiones sobre los riesgos asociados ....................................... 196



1 Recapitulación de los principales resultados del análisis ................................ 203

Movilidad de las personas en el DMQ ......................................... 203

Sistema de transporte metropolitano (actores, red, oferta) ........................... 203

Identificación de los elementos esenciales de la movilidad.............................. 204

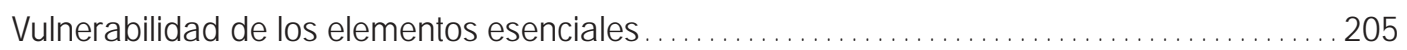

Accesibilidad y riesgos .......................................................... 205

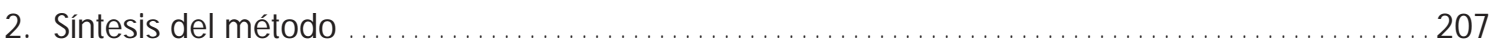

3. Aportes para los gestores ...................................................... 207

4. Limitaciones del estudio ................................................... 210

5. Reproductibilidad del método ................................................. 211

6. Elemento esencial, vulnerabilidad y accesibilidad: tres nociones esenciales para la evaluación de los riesgos ....................................... 212





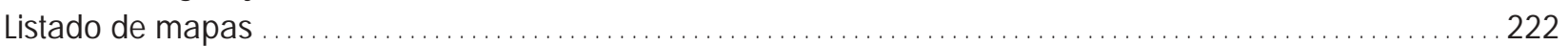



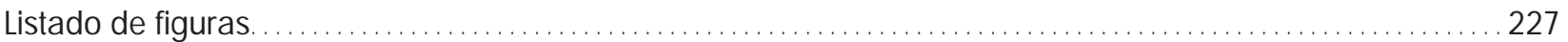


b 
INTRO DUCCIÓN 

Frente a los problemas que tiene que afrontar la ciudad de Quito por su exposición a una gran variedad de amenazas de origen natural y antrópico (terremoto, inundación, explosión de productos peligrosos), surgió una colaboración científica entre la Dirección Metropolitana de Planificación Territoral del Municipio de Quito (DMPT) y el Institut de Recherche pour le Développement (IRD). El programa de investigación denominado "Sistema de información y riesgos en el Distrito Metropolitano de Quito" iniciado en 1999' tiene cuatro objetivos principales:

- Profundizar el conocimiento de la vulnerabilidad y los riesgos en Quito.

- Desarrollar un método de análisis de los riesgos en medio urbano.

- Desarrollar una herramienta destinada a apoyar las decisiones de los actores locales en el marco de una política de prevención de riesgos y de acciones a tomar en caso de crisis.

- Reflexionar sobre los conceptos y sobre los vínculos entre investigación y aplicación en el ámbito de los riesgos en medio urbano.

Este trabajo requirió la evolución de una base de datos urbanos preexistente, desarrollada desde finales de la década de los ochenta por la Unidad de Estudios e
Información Metropolitana (UEIM-DMPT) y el ORSTOM, actual IRD. Esta base fue diseñada inicialmente para la planificación de la aglomeración capitalina y la gestión urbana cotidiana. Además, un enorme trabajo de actualización y esfuerzo para enriquecer esta base se llevó a cabo en varios temas, en especial en el de la movilidad urbana. Esta evolución era indispensable para poder identificar los elementos esenciales de la ciudad, analizar la vulnerabilidad y evaluar los riesgos. La estructuración de los datos y su explotación en el Sistema de Información Geográfica Savane², fue concebida según una metodología de tal manera que pueda ser reproducida en otras ciudades. Esta investigación se basa en información recopilada entre 2000 y 2002 por lo que puede resultar desactualizada en ciertos aspectos.

1. Inicialmente manejado bajo la supervisión de Pascale Metzger, investigadora en el IRD, fue dirigido desde octubre de 2000 por Robert D'Ercole, geógrafo de la Universidad de Saboya Francia.

2. Diseñado y desarrollado por Marc Souris, Director de Investigación en el IRD. 


\section{La movilidad en el funcionamiento de la ciudad}

Entre los temas analizados en el marco del programa, el de la movilidad ocupa una posición central.

Las ciudades son el reflejo y el resultado de intercambios. Muchos autores destacan la importancia de la movilidad sea por la constitución de los sistemas urbanos o por la estructuración de las redes urbanas. En Quito, como en las demás urbes, la movilidad revela ser fundamental y necesaria para el desenvolvimiento de las actividades cotidianas. La movilidad es tan imprescindible que sus perturbaciones afectan de una manera grave el funcionamiento de los sistemas territoriales. En Quito, en los últimos seis años, varios fenómenos de origen natural y antrópico perturbaron los desplazamientos. Se puede mencionar entre otros, el cierre de uno de los principales accesos a la ciudad de Quito (vía Interoceánica) en mayo de 1998, luego de un deslizamiento de tierra y la paralización del tráfico después de la caída de ceniza del volcán El Reventador, en noviembre de 2002.

Los problemas cotidianos y perturbaciones ocasionales de la movilidad preocupan a las autoridades encargadas de la toma de decisiones, porque perjudican 0 dificultan el funcionamiento de la ciudad y pueden contrarrestar su desarrollo. Por eso, el empeño en evaluar los riesgos a los que está expuesto el DMQ tomando en cuenta sus problemas de movilidad habituales y excepcionales, con el fin de proponer ideas concretas destinadas a reducir la vulnerabilidad y los riesgos.

\section{Movilidad y riesgos}

A la movilidad urbana se la define en esta investigación como el conjunto de desplazamientos de personas realizados cada día por obligación (trabajo, escuela) o de manera libre (distracción, visitas) a través de distintos modos de transportación que circulan sobre redes generalmente interconectadas.

El riesgo es un concepto cuyas definiciones han cambiado mucho. Es sobre todo a partir de la década de los noventa, promulgada como Década Internacional para la Prevención de los Desastres Naturales por las Naciones Unidas que el riesgo empezó a ser analizado en toda su complejidad. Actualmente, el riesgo integra comúnmente varias dimensiones: amenazas o peligros, probabilidades, elementos expuestos, debilidades y consecuencias. Sin embargo, entre los elementos expuestos, no todos tienen la misma importancia. En el marco del programa se consideró que: "el riesgo para una ciudad o para cualquier otra entidad espacial es la posibilidad de perder lo que es esencial para su funcionamiento y desarrollo. Es ante todo el elemento esencial que se encuentra en posición central en la definición del riesgo. El riesgo es aún mayor si los elementos esenciales de la ciudad son vulnerables, y la vulnerabilidad puede depender de la exposición a las amenazas o del propio funcionamiento de los elementos esenciales ${ }^{3 \prime \prime}$.

3 R. D'Ercole, P. Metzger, 2004. 


\section{La vulnerabilidad de la movilidad}

Si bien es cierto que la amenaza puede generar perturbaciones de tráfico (deslizamiento de tierra), desórdenes en la circulación de automotores (apagón eléctrico poniendo fuera de servicio los semáforos) existen otros factores ligados a las características del propio funcionamiento del sistema de transporte, a las modalidades del ordenamiento urbano y los procesos de urbanización que condicionan el advenimiento del peligro, la susceptibilidad de daño y/o consecuentemente problemas de transporte. Se observa diariamente muchos disfuncionamientos sin que intervenga ningún fenómeno perturbador o destructivo. Sin embargo, el impacto de un fenómeno es aún más grave cuando el elemento expuesto es frágil. Ello ha orientado el análisis sobre la identificación de los factores de vulnerabilidad de la red vial y del sistema de transporte.

Algunos estudios ya han sido llevados a cabo en este ámbito y abarcan la variabilidad del rendimiento óptimo de las redes viales (M. Appert, L. Chapelon, 2003), la confiabilidad de las redes viales, (Y. Iida, 1999), la vulnerabilidad de las vías (G. Lleras-Echeverri, M. Sánchez-Silva, 2001; K. Berdica, 2002; M. Taylor, G. D’Este, 2003; J. Husdal, 2004), los daños generados por la ruptura de tramos viales (J.F. Gleyze, 2001) e incluso el impacto de los "fenómenos ambientales" sobre los sistemas de transporte (T.J. Cova, S. Conger, 2004). Esos estudios tratan esencialmente de los países industrializados (Francia, Suecia, Noruega, Australia, Estados Unidos), cuyas redes viales y sistemas de transporte son bastante complejos. Dichos análisis se fundamentan sobre bases de datos extensas, de las cuales no se dispone en Quito.

En el marco del programa "Sistema de información y riesgos en el Distrito Metropolitano de Quito"4 , la vulnerabilidad de los sistemas de transporte y de la red vial fue analizada considerando seis formas determinadas por el equipo de investigación. Esas seis formas toman en cuenta tanto las fragilidades de los sistemas (las tres primeras) como también unos factores de compensación (tres últimas). Se trata de las seis formas siguientes:

- La vulnerabilidad intrínseca: corresponde a las debilidades internas, a las propias fragilidades, a las debilidades estructurales del elemento estudiado.

- La dependencia: considera las relaciones de dependencia del elemento frente a otros sistemas, relaciones que son necesarias para su funcionamiento.

- La exposición a los peligros y la susceptibilidad de daño: abarca los diferentes tipos de amenazas de origen natural y antrópico a las cuales están expuestos los elementos. Permite también evaluar si estos últimos son susceptibles de experimentar disfuncionamientos o daños.

- La capacidad de control: entiende la posibilidad de controlar el elemento. En otros términos se analiza si es fácil o no intervenir a nivel del elemento, directamente o a distancia, en caso de problema.

- Las alternativas: consideran las posibilidades de reemplazo, de sustitución de un elemento asegurando una función, en caso de fallo.

4. Otros temas abordados en el programa (red eléctrica, red de abastecimiento en agua, empresas, establecimientos de salud, etc.) fueron analizados de la misma manera. 
- La preparación a las crisis: comesponde a las medidas preventivas, a las diversas formas de preparación, a la existencia de planes previstos por los gestores para afrontar las crisis.

La vulnerabilidad de las redes y del transporte permite entonces entender su predisposición a fallos, los problemas de transporte que pueden ocurrir y los riesgos asociados.

\section{Enfoque en los elementos esenciales de la movilidad}

Todos los elementos de una red vial, de un sistema de transporte no tienen la misma importancia. Algunos poseen un carácter primordial para el funcionamiento de una ciudad. Es así como se decidió enfocar el análisis de la vulnerabilidad sobre los elementos esenciales del funcionamiento del sistema urbano. De hecho, con el fin de optimizar la reducción de riesgos tomando en cuenta los pocos recursos financieros de la ciudad de Quito, fue pertinente enfocar el análisis en las estructuras principales, es decir, sobre aquellas cuyo fallo o daño perjudicaría gravemente el sistema urbano, aquellas que los responsables de la toma de decisión deben reforzar, proteger o resguardar prioritariamente. Por otro lado, analizar la vulnerabilidad de los elementos esenciales de un sistema urbano presenta una ventaja metodológica en el sentido que es imposible analizar de manera exhaustiva las innumerables actividades e infraestructuras urbanas, en especial cuando se trabaja en una ciudad grande en el marco de un programa de investigación cuya duración es limitada en el tiempo. Por último, los elementos esenciales son unos objetos de interés común (vía, túnel, terminal terrestre, estación de transferencia), sobre los cuales los actores municipales pueden actuar tanto para su administración en tiempo normal como también para su gestión en caso de emergencia.

Varios estudios de riesgos llevados a cabo por geógrafos de la Universidad de Saboya (C. Lutoff, 2000; R. D’Ercole, P. Pigeon, O. Baussart, et al., 2000) en las ciudades de Niza y Annecy, ya permitieron validar la pertinencia de una evaluación de los riesgos en medio urbano, partiendo de un análisis de vulnerabilidad enfocada en los elementos esenciales. Sin embargo, en esos estudios, los elementos esenciales han sido determinados en relación con una amenaza específica (terremoto), mientras en este trabajo se identifica los elementos esenciales de manera independiente de las amenazas.

Este procedimiento es innovador e implica una metodología de análisis peculiar. La idea es analizar en primer lugar la ciudad y sus elementos esenciales de funcionamiento sobre cualquier otra consideración. Esa orientación estuvo influenciada por el Municipio de Quito, organismo clave encargado de la gestión y planificación urbana. Tomando en cuenta el gran número de amenazas a las cuales está expuesto el Distrito y conociendo que no se puede prever la contingencia, los lugares en donde van a ocurrir, así como su extensión espacial, parece oportuno enfocar primero en los pilares del funcionamiento del sistema urbano más tangibles, para luego analizar su vulnerabilidad y exposición eventual a amenazas.

La investigación identificó los elementos esenciales de la movilidad a nivel de todo el Distrito (y no solo de un barrio o un sector de la ciudad). Esta escala permite abarcar los rasgos generales del funcionamiento de la aglomeración en su conjunto, funcionamiento que 
depende mucho de la ciudad de Quito ${ }^{5} \mathrm{y}$, en especial, de su zona central asociada a una posición de centralidad metropolitana. Esta escala presenta la ventaja de estar en adecuación con la escala de acción de los gestores municipales en el ámbito de vialidad, de transporte y también de gestión de riesgo. La cuestión es saber cuáles son los elementos esenciales de la movilidad en el DMQ y cómo identificarlos. Hubo empeño en descubrir los elementos materiales estratégicos y los lugares donde se ubican para evaluar posteriormente su vulnerabilidad que integra, entre otros, la exposición eventual a amenazas y su grado de accesibilidad. El discernimiento de los elementos materiales esenciales se fundamenta en un método peculiar que consiste en jerarquizar y categorizar los objetos en función de distintos criterios según los espacios estudiados (ciudad, periferia y resto del Distrito).

Conociendo las infraestructuras más relevantes, se llevó a cabo un análisis de vulnerabilidad, en base al cual se resaltaron los elementos más vulnerables, es decir los más susceptibles de quedar fuera de servicio. Ello permite seleccionar los tramos viales sobre los cuales la circulación corre el mayor riesgo de resultar interumpida y las zonas que quedarían poco accesibles.

5. En este libro se considera como "ciudad de Quito" al conjunto de las siguientes parroquias: Turubamba, La Ecuatoriana, Quitumbe, Chillogallo, La Mena, San Bartolo, Solanda, La Argelia, La Ferroviara, Chilibulo, La Magdalena, Chimbacalle, Puengasí, La Libertad, Centro Histórico, San Juan, Belisario Quevedo, Mariscal Sucre, Rumipamba, Kennedy, Concepción, Cochapamba, Cotocollao, Ponceano, Comité del Pueblo, Carcelén, San Isidro del Inca, El Condado, Jipijapa, Iñaquito, Itchimbía, Guamaní.

\section{La necesaria utilización de la noción de accesibilidad}

El cierre de un eje vital, la suspensión de un servicio de transporte en una vía principal afectarán aún más a la ciudad si estos elementos de gran importancia permiten el acceso a los lugares esenciales para su funcionamiento y desarrollo.

Los lugares esenciales son espacios que concentran muchas funciones urbanas con un papel fundamental en varios ámbitos (salud, educación, economía) y que deben ser accesibles para desempeñar normalmente actividades y servicios. Estos lugares esenciales pueden corresponder a centralidades que cuentan con funciones urbanas de primera relevancia. En las periferias de la ciudad otros sectores en los que se encuentran las grandes instalaciones de la logística urbana (planta eléctrica, planta de almacenamiento de combustible, antenas de telecomunicación) pueden también ser asociados como lugares esenciales. La limitación y/o el cierre de los accesos a los lugares esenciales implican riesgos. En efecto, la imposibilidad de acceder a los lugares esenciales puede afectar el funcionamiento mismo de los elementos esenciales, consecuentemente el sistema territorial en su conjunto corre el riesgo de resultar gravemente afectado. En el caso del DMQ, los elementos esenciales fueron identificados, localizados y presentados en el libro: "Los lugares esenciales del Distrito Metropolitano de Quito" (R. D’Ercole, P. Metzger, 2002). Es a partir de esa información que se pudo evaluar los riesgos.

$\mathrm{Si}$ un sector resulta poco accesible por los daños ocasionados en sus vías de acceso (destrucción de un puente, derrumbe sobre una calzada), se puede ya observar varios problemas de comunicación en tiem- 
po normal, problemas que pueden dificultar el funcionamiento del sistema territorial. Por eso, en primer lugar se midió y cartografió la accesibilidad habitual, que es muy heterogénea al interior del Distrito, para luego analizar los problemas de accesibilidad posibles, en caso de fallo de las infraestructuras viales de mayor importancia.

Una mala accesibilidad habitual u ocasional permite poner énfasis sobre los elementos urbanos esenciales para el funcionamiento del sistema territorial, que corren el riesgo más grave, de encontrarse inoperantes debido a su ubicación. Por otro lado, todos los elementos urbanos esenciales no tienen la misma escala de influencia. Algunos ejercen una función sobre la región metropolitana, otros tienen un efecto mucho más localizado. Por ejemplo, la fama de una universidad sobrepasa a menudo la simple escala de la ciudad; de su lado, ciertos centros hospitalarios especializados son asociados a una zona de influencia muy amplia, mientras un dispensario médico asegura un servicio únicamente sobre la vecindad cercana. Ello permite entender que la reducción de la accesibilidad puede estar asociada a impactos espaciales muy variados.

Para sintetizar, el riesgo se mide a partir de las consecuencias negativas previsibles, considerando los problemas de acceso a los lugares esenciales. Se puede atribuir estos problemas a una pérdida de operatividad de un tramo vial esencial o de un elemento principal de transporte debido a su alta vulnerabilidad. El análisis espacial necesario para la determinación de la accesibilidad habitual y, en caso de emergencia, permite contribuir a la evaluación de los riesgos.

\section{El interés del uso de un SIG}

Este planteamiento de la evaluación de riesgos no sería factible sin los tratamientos realizados gracias a un Sistema de Información Geográfica (SIG). En cada etapa de la evaluación el SIG es imprescindible.

El SIG permite identificar los elementos esenciales mediante consultas y tratamientos. Si se trata de variables cuantitativas, selecciona objetos en función de un valor límite; tratándose de variables cualitativas elige solamente ciertas modalidades. También permite identificar los corredores esenciales de transporte mediante el cálculo del número de líneas de buses que transitan por las vías, etc.

En el ámbito de la vulnerabilidad, el SIG ofrece muchas posibilidades. Por ejemplo, permite medir las características de las redes y así distinguir los sectores poco accesibles, los tramos viales muy empinados, muy sinuosos. Permite obviamente medir la exposición de los elementos frente a las amenazas y brinda la posibilidad de superposición de los elementos esenciales con otros fenómenos que tienen una dimensión espacial (zona de congestión vehicular, recorridos de transporte de productos peligrosos). Gracias a un SIG, se calculan también las distancias (alejamiento en relación con la ubicación de las compañías de bomberos, evaluación de los desvíos necesarios en caso de cierre de una vía) y se puede determinar la accesibilidad de los elementos esenciales respecto a la red vial. Finalmente, posibilita la evaluación de riesgos al identificar, dentro de una zona que queda aislada, la cantidad de población, las actividades y funciones urbanas presentes. Con esa información es posible medir las consecuencias previsibles. 
Todos los tratamientos y análisis efectuados en la investigación se fundamentan en el SIG "Savane" al cual se añadieron nuevas funcionalidades para responder a las necesidades requeridas, en particular para calcular la conexidad ${ }^{6}$ de las redes, la pendiente de los tramos viales a partir de un Modelo Numérico de Terreno, su orientación, etc.

\section{Organización temática}

La primera parte, trata sobre la movilidad de las personas en el Distrito, examina sus fundamentos respecto a la repartición de las funciones urbanas y detalla el sistema de transporte (actores, redes, oferta) en el cual se funda.

La segunda parte, presenta los elementos materiales esenciales de la movilidad y las infraestructuras de mayor relevancia, gracias a un método de identificación elaborado en el marco del programa "Sistema de información y riesgos en el Distrito Metropolitano de Quito". Los elementos esenciales son cartografiados.
La tercera parte, abarca las distintas formas de vulnerabilidad de los elementos esenciales, vulnerabilidad que los predisponen a fallos o daños. El método de evaluación de la vulnerabilidad en seis formas (intrínseca, dependencia, exposición a las amenazas y susceptibilidad a daños, capacidad de control, alternativas y preparación para afrontar la crisis) es detallado. Se presenta también la vulnerabilidad de los elementos esenciales bajo la forma de mapas.

La cuarta parte analiza los riesgos. Se fundamenta en un análisis espacial que permite medir la accesibilidad habitual de los lugares y sobre todo las posibilidades de limitación de su accesibilidad en caso de fallo de un tramo vial esencial debido a su alta vulnerabilidad. Gracias a este procedimiento, se miden las consecuencias previsibles de los fallos a nivel de todo el Distrito.

6. La conexidad se refiere a la capacidad de llegar, a partir de cualquier nodo, a los otros nodos de una red. (P, Baud, et al., 1997). 



\section{MOVILIDAD DE LAS PERSONAS, ESTRUCTURA Y FUNCIONAMIENTO DEL SISTEMA DE TRANSPORTE METROPOLITANO}

Para entender los riesgos a los cuales está expuesto el DMQ partiendo de las perturbaciones y disfuncionami entos previsibles de la movilidad de las personas, se debe conocer cuáles son las principales características y problemas de la movilidad cotidiana en el Distrito y el sistema de transporte en el cual se funda. Este análisis es necesario para destacar posteriormente las conexiones y corredores de transporte de mayor relevancia y las infraestructuras esenciales asociadas, así como su vulnerabilidad. 



\section{1 - El 80 por ciento de los desplazamientos realizados a diario en bus}

El objetivo de este capítulo es determinar las necesidades que tiene el 1.8 millón de capitalinos para trasladarse en el marco de las actividades nacionales y metropolitanas. Se presentan las principales características de los desplazamientos cotidianos de personas sobretodo en transporte colectivo a distintas escalas. Se intenta explicar los motivos de viaje así como su origen y destino considerando la repartición de las funciones urbanas y las centralidades?

La importancia del transporte colectivo es capital en la aglomeración. Según la Empresa Metropolitana de Administración y Servicio de Transporte (EMSAT), este modo de transporte aseguraba en el 2001 cerca del 80 por ciento de los desplazamientos motorizados cada día. Por esta razón se analiza ante todo la movilidad de las personas en transporte colectivo, en el DMQ, y según qué lógica se articulan los desplazamientos. El análisis abarca a continuación tres escalas: (1) comunicaciones con el exterior del Distrito, (2) comunicaciones entre el centro urbano y periferia metropolitana y (3) comunicaciones intra-urbanas.

\section{Las comunicaciones con el exterior del Distrito}

\section{Quito, metrópoli andina ubicada en la sierra centro norte del país}

El DMQ se ubica en el tercio norte del país, en la cordillera de los Andes, entre la región costanera al oeste y la cuenca amazónica al este. Esta situación implica que se encuentran al sur del Distrito los dos tercios de los principales centros urbanos, entre los cuales la aglomeración portuaria de Guayaquil, la más poblada y económicamente más activa, con la cual Quito mantiene intercambios intensos. Quito está conectada directamente, sin necesidad de hacer trasbordo, con casi la totalidad del país en bus interprovincial (Véase mapa 1-1). De su lado, las provincias orientales amazónicas son, de modo general, menos accesibles por vía terrestre debido al escaso número de ejes viales y

7. No obstante, los datos referentes a los flujos interprovinciales son escasos o desactualizados. Del mismo modo, ninguna encuesta de movilidad ha sido llevada a cabo en los hogares del DMQ. En cambio, una encuesta origen-destino que evaluó cerca de 1.5 millón de desplazamientos diarios en buses y varios conteos vehiculares fueron realizados por el Municipio de Quito, el Honorable Consejo Provincial de Pichincha (HCPP) y el Ministerio de Obras Públicas (MOP). 
los intercambios son menos frecuentes ya que las densidades poblacionales son bajas ${ }^{8}$.

Se observa entonces una cierta preponderancia de las comunicaciones entre Quito y los dos tercios sur del país y un acceso relativamente fácil a la capital en tiempo normal ${ }^{9}$ desde cualquier provincia, gracias a una red de transporte interprovincial organizada en un territorio poco extenso $\left(270.670 \mathrm{Km}^{2}\right)$. Esta red de transporte interprovincial es muy importante debido a que la tasa de motorización de los hogares es bastante baja (en promedio, 5 vehículos cada 100 habitantes a nivel nacional en el 2001 (Véase capítulo 2, sección 3.4). Adicionalmente, dos conexiones terrestres internacionales son posibles desde Quito hacia Colombia, al norte y hacia Perú, al sur.

\section{Flujos mayoritarios hacia el sur del país}

Se evaluó el volumen de desplazamientos de personas tomando en cuenta la red urbana nacional, las conexiones interprovinciales en bus y la circulación en automóvil. Se consideró el número de líneas de buses oficiales que prestan un servicio de transporte interprovincial desde la terminal terrestre del Cumandá, de donde salen todos los días 51 compañías, es decir más del 90 por ciento del total. Se hizo una fusión de las provincias en grandes conjuntos geográficos homogéneos con el fin de simplificar la representación cartográfica (mapa 1-2). Considerando que el volumen de pasajeros es proporcional al número de líneas de bus, al número de buses ${ }^{10} \mathrm{y}$ también al tráfico de vehículos livianos (Véase mapa 1-5), se puede observar que la provincia de Pichincha mantiene vínculos densos:

- en primer lugar, con la sierra central ${ }^{11}$ (23 líneas, 970 buses y 3.800 vehículos diarios)
- en segundo lugar, con la región costanera ${ }^{12}$ (21 líneas, 410 buses y 1.910 vehículos diarios ${ }^{13}$ ),

- en tercer lugar, con la sierra norte ${ }^{14}$ (13 líneas, 250 buses y 1.260 vehículos diarios)

- finalmente, en una proporción inferior, con la amazonía (7 líneas, 140 buses y 160 vehículos diarios).

En el primer caso (intercambios con la sierra central), la importancia de los flujos se debe a la presencia de centros urbanos relativamente importantes como Ambato, Latacunga, Riobamba (Véase mapa 1-3) y al hecho de que la sierra central, punto de gravedad geográfico del país, es un verdadero eje de tránsito por el cual circulan muchas compañías con destino a la sierra sur y la amazonía (Puyo, Macas).

En el caso de las comunicaciones con la región costanera, la mayoría de las compañías pasan por la ciudad intermedia de Santo Domingo, polo urbano en plena expansión. Los mayores intercambios se realizan con

8. En cambio, los flujos aéreos son relativamente numerosos para llegar, entre otros, a los campos de extracción de petróleo y el transporte fluvial asegura un papel cada vez más importante mientras más se va al este.

9. Cuando las vías son transitables, es decir fuera de las épocas del fenómeno El Niño, de erupción volcánica, de levantamiento indígena.

10. Estos criterios no son suficientes, se debería adicionalmente considerar el tamaño de los buses, su tasa de ocupación, pero no se tiene esa información.

11. Fusión de las provincias de Bolívar, Cañar, Cotopaxi, Chimborazo, Tungurahua.

12. Juntando la costa norte (Esmeraldas), centro (Manabí, Los Ríos) y sur (Guayas, El Oro).

13. Sumando el tráfico de los dos itinerarios posibles desde Quito (por Aloag y Calacalí).

14. Fusión de las provincias de Carchi e Imbabura. 
Mapa 1-1

Principales ciudades de destino desde Quito en bus sin trasbordo




Mapa 1-2

Conexiones interprovinciales en bus desde Quito




Mapa 1-3

Red vial principal del Ecuador



(Fuente: M OP) 
la costa sur (10 líneas desde Quito) en donde se encuentra Guayaquil y más al sur Machala, centro de negocio regional ligado a la actividad de exportación de banano. En el caso de la sierra norte, la mayonía de los flujos, en comparación moderados, se deben a la presencia de ciudades intermedias dinámicas tales como Otavalo, Cayambe, Ibarra, Tulcán ubicadas en un amplio corredor de tránsito hacia Colombia.

Por último, el tráfico mínimo observado en dirección a la amazonía se debe a que esta región es poco poblada y una parte no despreciable de desplazamientos de personas (trabajadores de las compañías petroleras, en la mayonía de los casos) los realizan por vía aérea.

La importancia de los flujos entre las provincias y la capital se mide también por la magnitud de los movimientos migratorios, en el sentido de que las personas que no son originarias del lugar, viajan a menudo para visitar a su familia ${ }^{15}$, especialmente en los feriados y de vez en cuando para votar ${ }^{16}$. Según el último censo (INEC, 2001), de un total de 1'840.000 habitantes en el $\mathrm{DMQ}^{17}$, cerca de una tercera parte nació fuera del cantón de Quito y alrededor del ocho por ciento se instaló en la capital durante los últimos cinco años. Entre estos nuevos inmigrantes, el 26,3 por ciento proviene de la sierra central (Véase figura 1-1), el 14,6 por ciento de la costa central, el 13,2 por ciento de la siera norte y el 12,5 por ciento son extranjeros (colombianos, europeos, estadounidenses, en su mayoría).

15. El núcleo familiar en el Ecuador sigue siendo todavía muy sólido. Esta solidaridad se evidencia por ejemplo a través del sistema de remesas enviadas por los ecuatorianos residentes en el extranjero, que representa la segunda fuente de ingresos para el estado ecuatoriano, después de la exportación del petróleo.
Figura 1-1

Procedencia de los inmigrantes instalados en Quito entre 1996 y 2001



(Fuente: INEC, 2001) 
El DMQ representa un verdadero polo de atracción asociado a su situación económica a nivel nacional. "La especificidad del papel de Quito en la economía ecuatoriana proviene de su estatus de capital, de su función de redistribución de los recursos financieros del país y de su notable nivel de industrialización" ( $\mathrm{R}$. D'Ercole, P. Metzger, 2002). El sector manufacturero del Distrito representa el 20 por ciento del PIB nacional ecuatoriano. El Distrito cuenta también con alrededor del 25 por ciento de los empleos nacionales del sector secundario y el 22,5 por ciento de los empleos nacionales del sector terciario (INEC, 2001).

\section{El Distrito Metropolitano de Quito: un nodo importante en la red vial nacional}

Estas comunicaciones interprovinciales se fundan en una red vial relativamente densa cubriendo de manera globalmente homogénea el territorio nacional, excepto la amazonía (Véase mapa 1-3). La carretera Panamericana cruza el país de norte a sur pasando por Quito y Guayaquil en el itinerario costanero. El Distrito es un nodo relevante en la red vial nacional ya que corresponde a un punto de convergencia entre las comunicaciones norte-sur y este-oeste (mapa 1-4). El DMQ, sede de la capital administrativa y política del Ecuador, se encuentra en una situación "privilegiada" respecto a la red vial nacional.

\section{Desplazamientos de personas entre el DMQ y los cantones vecinos}

A una escala más local, los desplazamientos de personas son también muy numerosos entre el DMQ y los cantones vecinos (Véase mapa 1-5). Los intercambios son importantes por la localización de tres centros ur- banos secundarios (Otavalo, Cayambe, Machachi) ubicados a menos de dos horas del centro de Quito. Cada centro (que cuenta con una población de 20 mil a 40 mil habitantes) tiene sus propias características que lo singularizan de los demás y que explica el tipo peculiar de relación que mantiene con el DMQ. Este enfoque cualitativo y semi cuantitativo evidencia varios tipos de intercambios.

\section{Los intercambios turísticos}

\section{y de negocios entre Otavalo y el DMQ}

Se trata de viajes para el negocio (artesanos) y de flujos turísticos que aumentan el día de mercado (sábado) y durante las fiestas (el 24 de junio, día de San Juan y en septiembre, la quincena folclórica). Otavalo es un centro de negocios y de producción de artesanías (textiles, vasijas, esculturas) conocido en el mundo entero. Adicionalmente, muchos otavaleños viajan de vez en cuando a Quito para vender su producción, hacer compras y tener acceso a determinados servicios (salud). Otavalo, ubicada en la carretera Panamericana norte, es accesible cada día por 13 líneas de bus directamente desde Quito (la mayoría va más al norte).

Los intercambios de mano de obra y de negocios entre Cayambe y el DMQ

Se trata, en primer lugar, de los flujos cotidianos de mano de obra agrícola (sobre todo femenina) y en segundo lugar, de desplazamientos para los negocios (gerentes de floricultoras). Estos últimos viajan a me-

16. El sufragio es una obligación en el Ecuador y durante los días de elección las personas suelen regresar a su circunscripción (generalmente, su lugar de nacimiento).

17. Es decir el 15 por ciento de la población total del Ecuador (12'156.600 habitantes). 


\section{Mapa 1-4}

Red vial principal de la provincia de Pichincha y del Distrito Metropolitano de Quito

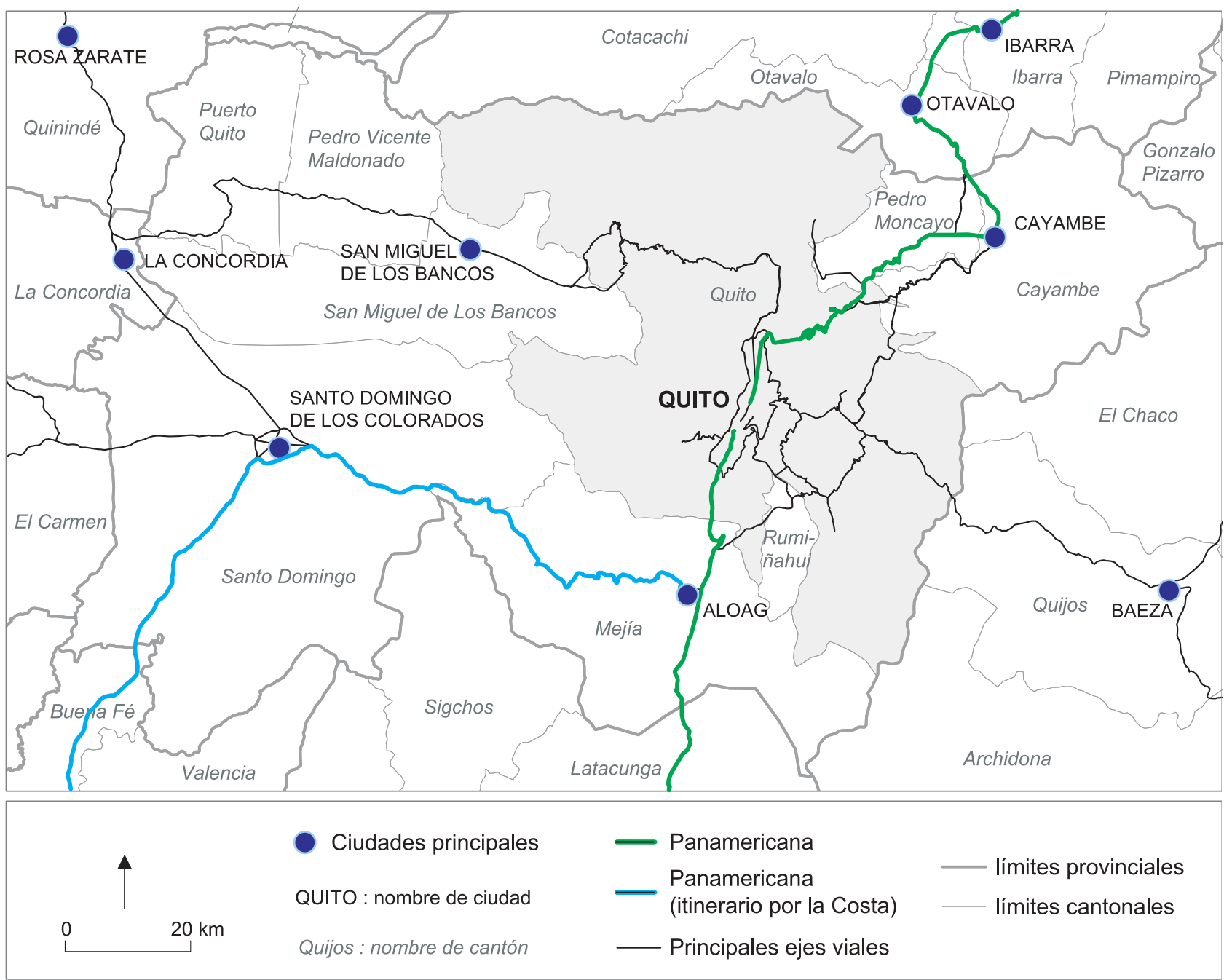

(Fuente: M OP) 
nudo a Quito, por la ubicación del aempuerto Mariscal Sucre, desde donde se exporta la producción. En efecto, el cantón de Cayambe es una zona de floricultura (900 ha), en particular de rosas, que genera empleos y que explica el gran volumen de desplazamientos, evaluado en cerca de 800 personas (F. Bondoux, F. Demoraes, 2002) procedentes de las parroquias suburbanas orientales de Quito. Estos trayectos son realizados muy temprano en la mañana (de las $5 \mathrm{~h} 30$ a las 6h30) y en sentido contrario, en la tarde (de las $15 \mathrm{~h} 00$ a las 16h00). Este transporte exclusivo, adecuado a los horarios de los obreros agrícolas, es financiado por las plantaciones florícolas. En paralelo, muchos habitantes de Cayambe viajan esporádicamente a Quito para hacer compras y acceder a algunos servicios (salud). Una sola línea de bus regular oficial asegura el servicio cada día entre Cayambe y Quito ${ }^{18}$.

Los intercambios entre Machachi, centro regional agrícola y el DMQ

Se trata de flujos esporádicos para el negocio (agricultores, ganaderos, productores de leche) y para las compras de productos frescos (carne, legumbres, frutas, papas) durante el gran mercado del sábado. Machachi es en efecto un centro regional agrícola importante situado en un tramo de la carretera Panamericana sur.

El análisis previo permitió entender la posición de la capital del Ecuador en la red de transporte de personas a nivel nacional y regional. Los buses viajan cada día desde la terminal terrestre Cumandá hacia más de 70 destinos diferentes. Cerca de 11.000 autos y 2.300 buses entran todos los días en la aglomeración. A continuación se trata de averiguar cómo se organizan los desplazamientos al interior del Distrito y más específi- camente en la aglomeración. Se considera las dos escalas siguientes: (1) las comunicaciones entre el centro y la periferia y (2) las comunicaciones intra-urbanas.

\section{Las comunicaciones metropolitanas centro-peniferia}

El objetivo de esta sección es entender cuáles son los principales desplazamientos entre la periferia y la ciudad de Quito respecto a la repartición de las funciones urbanas y de población, las distintas centralidades que coexisten en el DMQ, su nivel de influencia y las características de los desplazamientos que se articulan alrededor de ellas.

"La centralidad urbana es uno de los elementos que estructura fuertemente los ritmos de frecuentación y las estrategias de localización, delocalización y relocalización de los actores económicos y también el sistema de relaciones de los habitantes con su territorio (...). Los centros de las aglomeraciones siguen siendo el principal elemento estructurante debido a la dimensión de sus efectos de polarización y la densidad de sus lazos con los centros secundarios o las diferentes zonas funcionales $(. . .)^{\prime \prime 19}$.

"El estudio de las funciones urbanas, es decir, el conjunto de actividades administrativas, políticas, comerciales, industriales y de servicio, ubicadas en la ciudad, permite definir los lazos específicos entre una ac-

18. Entre las demás compañías que circulan desde Quito rumbo el norte, la mayoría pasan por Cayambe para recoger a pasajeros únicamente cuando la demanda es baja.

19. M. Cosinschi, J.B. Racine, 1995. 
Mapa 1-5

Principales desplazamientos de personas entre el DMQ y los cantones vecinos

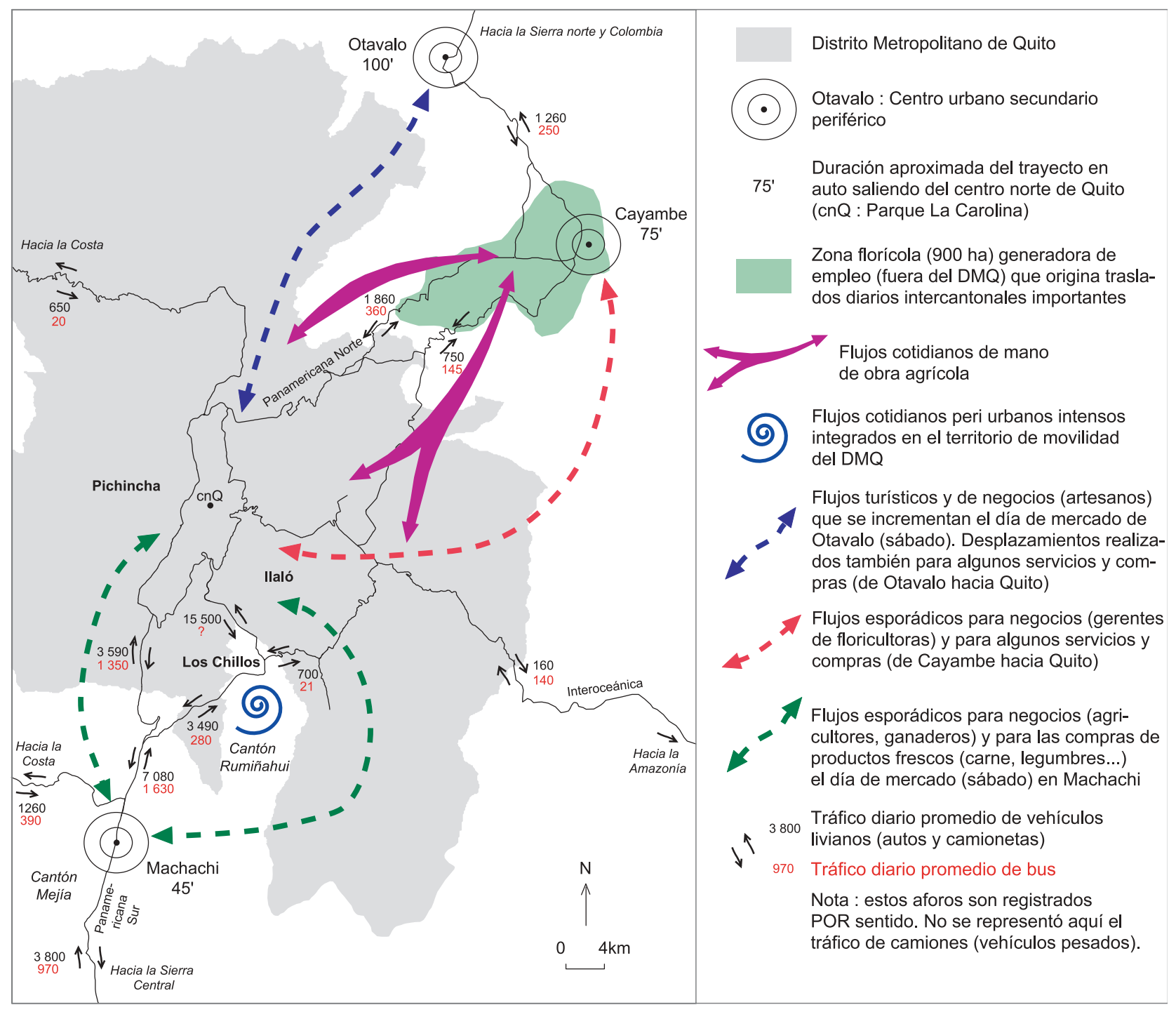

(Fuentes: DM T, investigación personal) 
tividad dada y su proyección en el espacio urbano" (D. Pumain, Th. Saint-Julien, 1997). Es entonces a través del análisis de la repartición de las funciones urbanas que se empieza el estudio de los desplazamientos en el Distrito.

\section{La periferia: desigual e insuficientemente provista de funciones urbanas}

Si bien no fue posible conocer la organización de los desplazamientos de personas al interior de los espacios periféricos suburbanos por la ausencia de una encuesta de movilidad, fue en cambio factible resaltar la existencia de unas centralidades locales con múltiples funciones urbanas que a pesar de todo, no son suficientes para que los habitantes de dichos sectores puedan cumplir con sus obligaciones y responder a sus necesidades. Se sabe que los desplazamientos de proximidad realizados al interior de los espacios suburbanos ocupan solamente una muy baja proporción de los desplazamientos metropolitanos en transporte colectivo (TC). Según la encuesta origen-destino de $1998^{20}$, unos 36.500 viajes son efectuados cada día dentro de los sectores suburbanos mientras más de 150.000 habitantes de las periferias se trasladan cada día a la ciudad. Los desplazamientos locales suburbanos representan únicamente el 2,5 por ciento del total de los desplazamientos realizados en TC urbano e interparroquial. Sin embargo, cabe tomar precaución con este valor. El bajo número de desplazamientos de proximidad es sin lugar a duda subestimado por la ausencia de datos sobre el transporte colectivo al interior del Valle de Los Chillos, por la ausencia de datos sobre el transporte intercantonal, de datos relativos al transporte escolar suburbano, y también por el uso bastante frecuente del transporte informal.
Se dividió la periferia de la aglomeración ${ }^{21}$ en cuatro conjuntos geográficos "homogéneos". Se trata de:

- al norte el valle de Pomasqui (A),

- al nor-este la zona de Carapungo, Calderón y Guayllabamba (B),

- al este el valle de Cumbayá, Tumbaco y El Quinche $(\mathrm{C})$,

- y al sur-este el valle de Los Chillos (D).

En el caso de este último valle, se llegó únicamente a una estimación de las funciones urbanas existentes debido a que una gran parte pertenece al cantón Rumiñahui y por tanto se tiene escasa información en el Municipio de Quito. La cartografía de las principales funciones urbanas y actividades polarizadoras en los valles suburbanos se fundamenta en la información colectada y analizada en el marco del programa "Sistema de información y riesgos en el Distrito Metropolitano de Quito". A pesar de que el conjunto de variables utilizadas no es exhaustivo ${ }^{22}$, permite entender la repartición de las funciones y su insuficiencia respecto a la población residente, también la comparación entre los valles, útil para resaltar los niveles de dependencia entre la ciudad y su periferia.

20. Esta encuesta fue llevada a cabo por la Unidad de Planificación y Gestión del Transporte (UPGT) los días martes 10, miércoles 11 y jueves 12 de noviembre de 1998, en casi todas las líneas de bus legales que prestan un servicio en la aglomeración urbana. Un poco más de 40.000 encuestas válidas fueron colectadas gracias a las respuestas de los usuarios en los buses urbanos e ínter parroquiales, entre las $6 \mathrm{~h} 00$ y las $20 \mathrm{~h} 00$.

21. Se profundizará esta división en la cuarta parte en el capítulo sobre la evaluación de la accesibilidad.

22. Se podría igualmente considerar otros servicios (establecimientos bancarios), los lugares de recreación, etc. 
El mapa 1-6 representa las funciones urbanas y los sectores de concentración de empleo en las parroquias suburbanas del DMQ y el mapa 1-7 muestra la repartición de la población y el uso dominante de suelo. El análisis del uso del suelo se funda en la información proporcionada por la Empresa Eléctrica de Quito (EEQ) $)^{23}$. Se asoció de una manera esquemática los tres diferentes consumos residenciales de electricidad a tres categonías sociales (hogares de bajos ingresos, de medianos ingresos y de altos ingresos) ${ }^{24}$. A pesar de que todos los medidores no constan en la base de la EEQ (lo que representa un sesgo), tiene como ventaja abarcar también el cantón Rumiñahui.

Los siguientes mapas resaltan las múltiples disparidades entre los cuatro conjuntos geográficos periféricos de la aglomeración que se sintetizó a continuación:

Valle de Pomasqui: cuenta con la menor población (44.000 habitantes, véase tabla 1-1). Salvo una proporción relativamente alta de industrias (el tres por ciento de los medidores, valor más alto en comparación con los demás valles, véase figura 1-2), las otras funciones locales son muy limitadas. No hay un centro comercial grande, tampoco centro médico con capacidad de hospitalización y ninguna universidad.

Corredor de Carapungo, Calderón: 97.000 personas viven en este sector. La población es esencialmente de bajos ingresos (el 60 por ciento de los hogares tiene un consumo de electricidad bajo). Las actividades locales son un poco más desarrolladas con algunas industrias y una administración zonal. No hay un centro comercial grande, tampoco centro médico con capacidad de hospitalización, ninguna universidad.

Valle de Cumbayá, Tumbaco: el conjunto de este valle cuenta con 120.000 habitantes. Reúne un mayor número de servicios, actividades y comencios (el 7,4 por ciento de los medidores), en especial a nivel de dos centralidades locales (Cumbayá y Tumbaco) que polarizan los desplazamientos de proximidad. Posee 62 establecimientos escolares, una clínica, una universidad (San Francisco) y sus empresas contratan a más de 3.000 personas. Los barrios residenciales de altos ingresos son numerosos (el 9,3 por ciento de los medidores eléctricos es de tipo residencial de alto consumo, valor en comparación más alto). Esta singularidad es sin lugar a duda asociada a prácticas de movilidad fundadas en un mayor uso del automóvil.

Valle de Los Chillos: a pesar de ser más poblado (182.500 habitantes repartidos en ambos cantones), la configuración de este valle con dos centralidades (Conocoto y Sangolquí) se parece a la del valle de Cumbayá y Tumbaco. Cuenta con un gran número de servicios y actividades. El cantón Rumiñahui resalta como un lugar de concentración importante del comercio local (el 10\% de los medidores eléctricos corresponden a uso comercial). Los hogares de bajos ingresos de este cantón son en comparación menos numerosos (48,3 por ciento de los hogares tiene un consumo bajo de electricidad), mientras que el resto del va-

23. Empresa que administra una base de datos georeferenciados de más de 485.000 medidores eléctricos por categoría: establecimientos sociales, comerciales, entidades oficiales, industrias, viviendas residenciales divididas en tres subcategorías: (1) bajo consumo (menos de $120 \mathrm{KW} / \mathrm{h}$ por mes), (2) consumo promedio (entre 120 y $400 \mathrm{KW} / \mathrm{h}$ por mes) y (3) consumo alto (más de $400 \mathrm{KW} / \mathrm{h}$ por mes).

24. Obviamente, este criterio no es suficiente para determinar en forma precisa las categorías sociales. Sin embargo, el consumo eléctrico está fuertemente correlacionado a la riqueza de los hogares, ya que permite evaluar el uso de aparatos electrodomésticos. 
Mapa $1-6$

Principales funciones urbanas y sectores de concentración del empleo en las parroquias suburbanas del DMQ

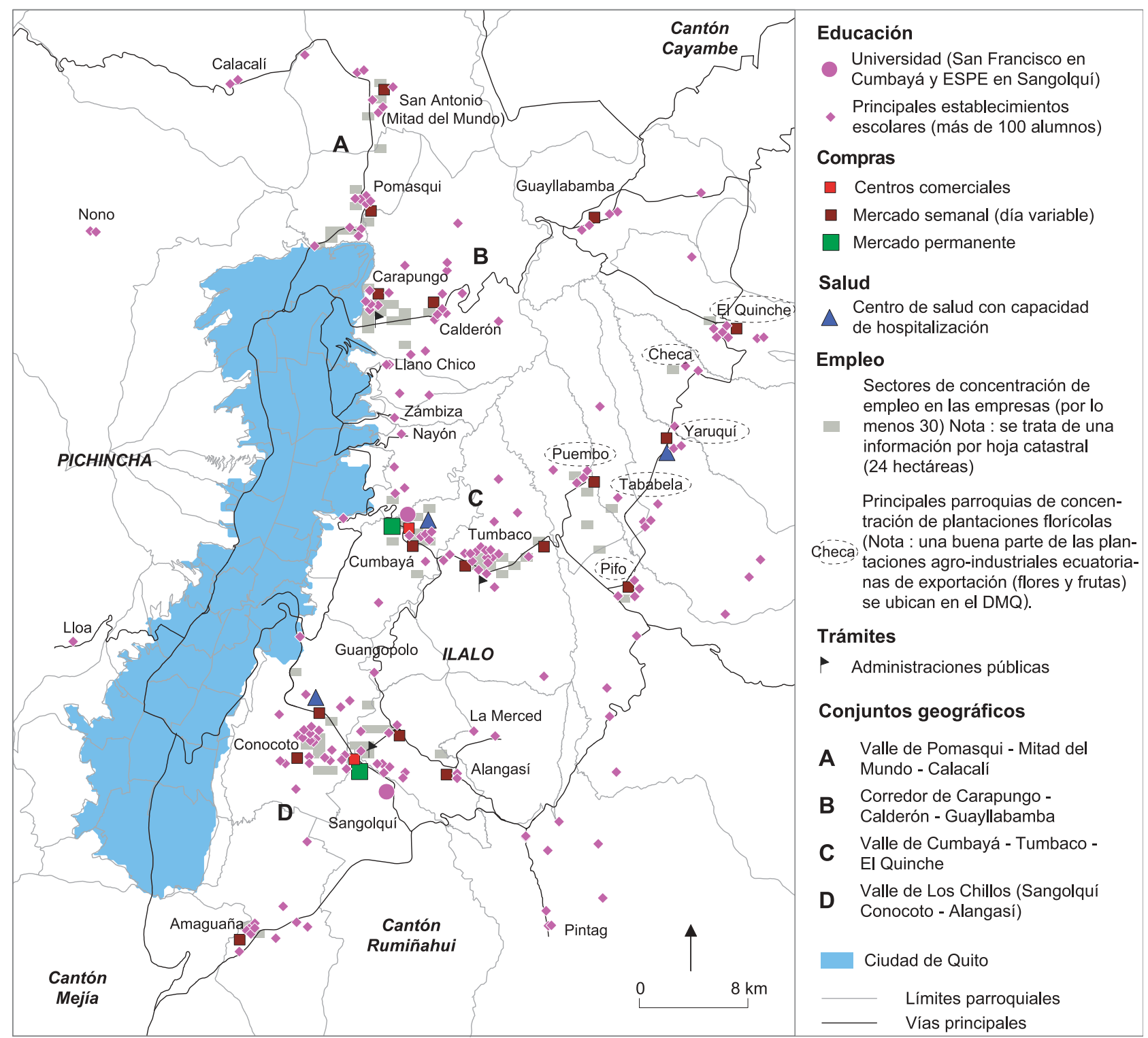

(Fuentes: M DM Q, encuestas IRD) 
Mapa $1-7$

Densidad de población y uso dominante del suelo en las parroquias suburbanas de la aglomeración de Quito en 2001
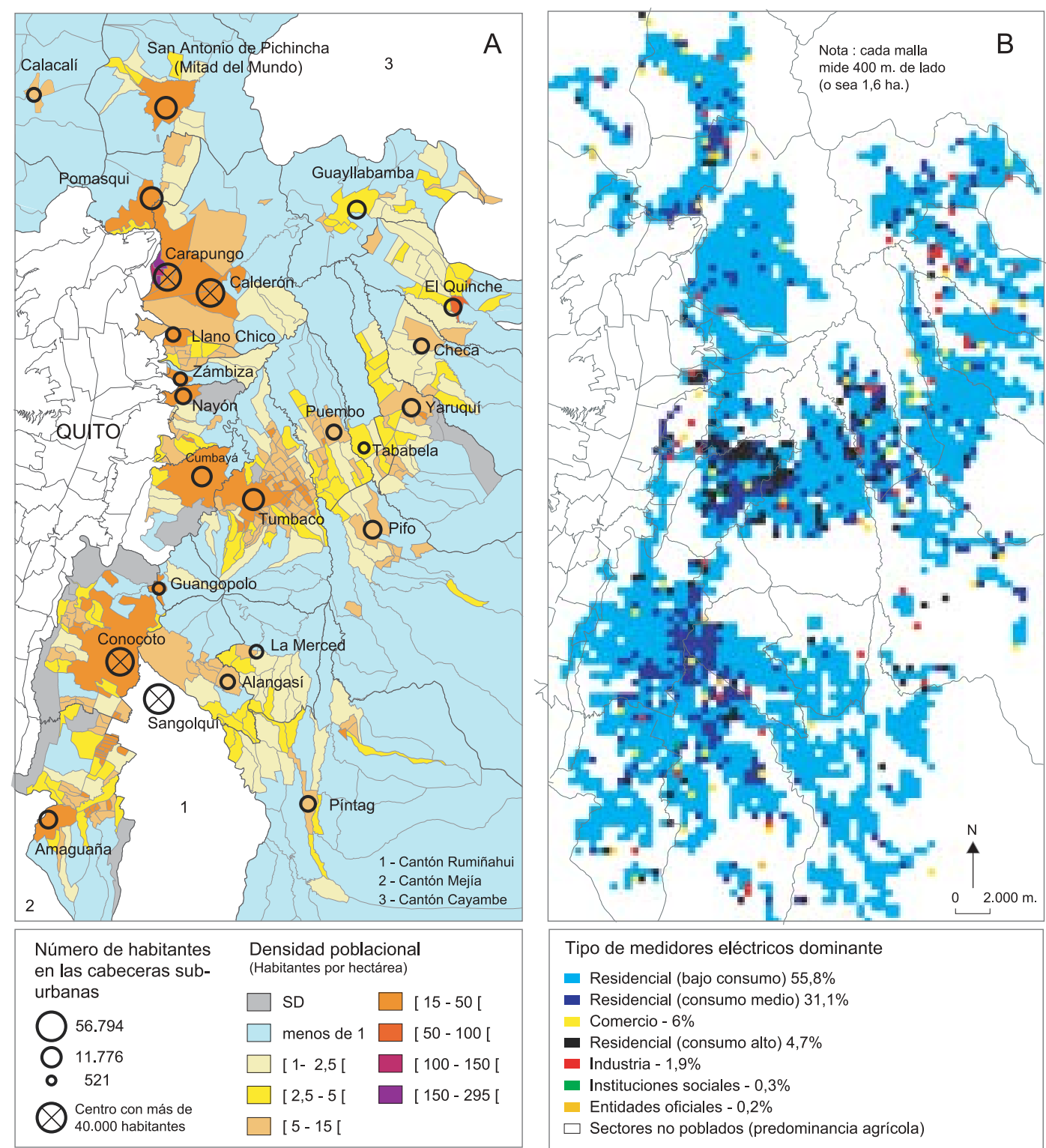

Tipo de medidores eléctricos dominante

- Residencial (bajo consumo) $55,8 \%$

- Residencial (consumo medio) $31,1 \%$

Comercio - 6\%

- Residencial (consumo alto) $4,7 \%$

- Industria - 1,9\%

- Instituciones sociales - 0,3\%

- Entidades oficiales - $0,2 \%$

$\square$ Sectores no poblados (predominancia agrícola) 
Tabla 1-1

Repartición de la población, del empleo y de las funciones urbanas por conjunto geográfico suburbano

\begin{tabular}{|c|c|c|c|c|c|c|c|c|c|c|c|c|c|c|}
\hline Conjuntos & \multicolumn{2}{|c|}{ Población } & \multicolumn{2}{|c|}{$\begin{array}{c}\text { Superficie } \\
\mathrm{km}^{2}\end{array}$} & \multicolumn{2}{|c|}{$\begin{array}{l}\text { Empleados en } \\
\text { las empresas }\end{array}$} & \multicolumn{2}{|c|}{$\begin{array}{c}\text { Establecimientos } \\
\text { escolares y } \\
\text { universitarios }\end{array}$} & \multicolumn{2}{|c|}{$\begin{array}{c}\text { Centros médicos } \\
\text { con capacidad } \\
\text { de hospitalización }\end{array}$} & \multicolumn{2}{|c|}{$\begin{array}{c}\text { Principales } \\
\text { lugares de venta } \\
\text { de alimentos }\end{array}$} & \multicolumn{2}{|c|}{$\begin{array}{c}\text { Administraciones } \\
\text { públicas }\end{array}$} \\
\hline A - Valle de Pomasqui & \multicolumn{2}{|c|}{44.000} & \multicolumn{2}{|c|}{324} & \multicolumn{2}{|c|}{1.300} & \multicolumn{2}{|l|}{17} & \multicolumn{2}{|c|}{-} & \multicolumn{2}{|c|}{2} & \multicolumn{2}{|c|}{0} \\
\hline B - Carapungo, Calderón & \multicolumn{2}{|c|}{97.100} & \multicolumn{2}{|c|}{135} & \multicolumn{2}{|c|}{1.570} & \multicolumn{2}{|l|}{24} & \multicolumn{2}{|c|}{ 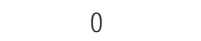 } & \multicolumn{2}{|c|}{3} & \multicolumn{2}{|c|}{1} \\
\hline C - Cumbayá, Tumbaco & \multicolumn{2}{|c|}{120.000} & \multicolumn{2}{|c|}{643} & \multicolumn{2}{|c|}{3.060} & \multicolumn{2}{|c|}{$62+1$ universidad } & \multicolumn{2}{|c|}{1} & \multicolumn{2}{|c|}{9} & \multicolumn{2}{|c|}{1} \\
\hline \multirow[t]{2}{*}{ D - Valle de Los Chillos } & 65.880 & 116.630 & 135 & 675 & $?$ & 2.340 & $?+1$ universidad & 70 & $?$ & 1 & $?$ & 7 & $?$ & 1 \\
\hline & $\begin{array}{l}\text { Rumi- } \\
\text { ñahui }\end{array}$ & $\mathrm{DMQ}$ & & & & & & & & $C D M T$ & DTN & rOMUE & ncuestas & SP, DMC \\
\hline
\end{tabular}

lle alcanza el valor más alto (cerca del 63 por ciento) en comparación con los tres conjuntos geográficos periféricos anteriormente descritos.

A pesar de las disparidades entre los cuatro conjuntos geográficos, todos tienen un carácter residencial muy marcado; cerca del 92 por ciento de los medidores eléctricos ubicados en estos espacios periféricos son de tipo residencial. Este carácter residencial es más acentuado que en la ciudad (84 por ciento).

El previo análisis evidencia que los espacios periféricos de la ciudad de Quito, respecto a su población, son a distintos niveles insuficientemente provistos de funciones urbanas y no permiten responder totalmente a las necesidades básicas u ocasionales de sus habitantes. También evidencia diferentes niveles de dependencias dentro de la aglomeración (Pomasqui y Calderón parecen más dependientes con respecto a la ciudad) y explica en parte la importancia diaria de los desplazamientos entre el centro y la periferia.

\section{La ciudad de Quito: alta concentración de las funciones urbanas}

Muchos estudios muestran la muy marcada concentración de las actividades urbanas al interior de la ciudad de Quito. Se menciona este flagrante desequilibrio en el Plan General de Desarrollo Territorial (MDMQ/DMTV, 2000) como uno de los mayores problemas actuales. Se añade a esta primera distorsión un desequilibrio demográfico entre Quito y su periferia (F. Carrión, R. Vallejo, 2000). El libro Los lugares esenciales del Distrito Metropolitano de Quito (R. D'Ercole, P. Metzger, 2002) pone énfasis también sobre la situación de hipercentralidad metropolitana en base a un amplio panel de variables actualizadas. Estos trabajos preliminares sirven de punto de partida para comprender las características de movilidad cotidiana entre las cuales se destaca la magnitud de los movimientos entre el centro y la periferia.

Alrededor del 77 por ciento de la población del Distrito vive en la ciudad de Quito en una superficie que cubre menos del 5 por ciento del territorio metropolitano (véase tabla 1-2, mapas 1-8 y 1-9). Este espacio reúne cerca del 92 por ciento de los empleos censa- 
Figura $1-2$

Repartición del número de medidores eléctricos por categoría y por conjunto suburbano en porcentaje

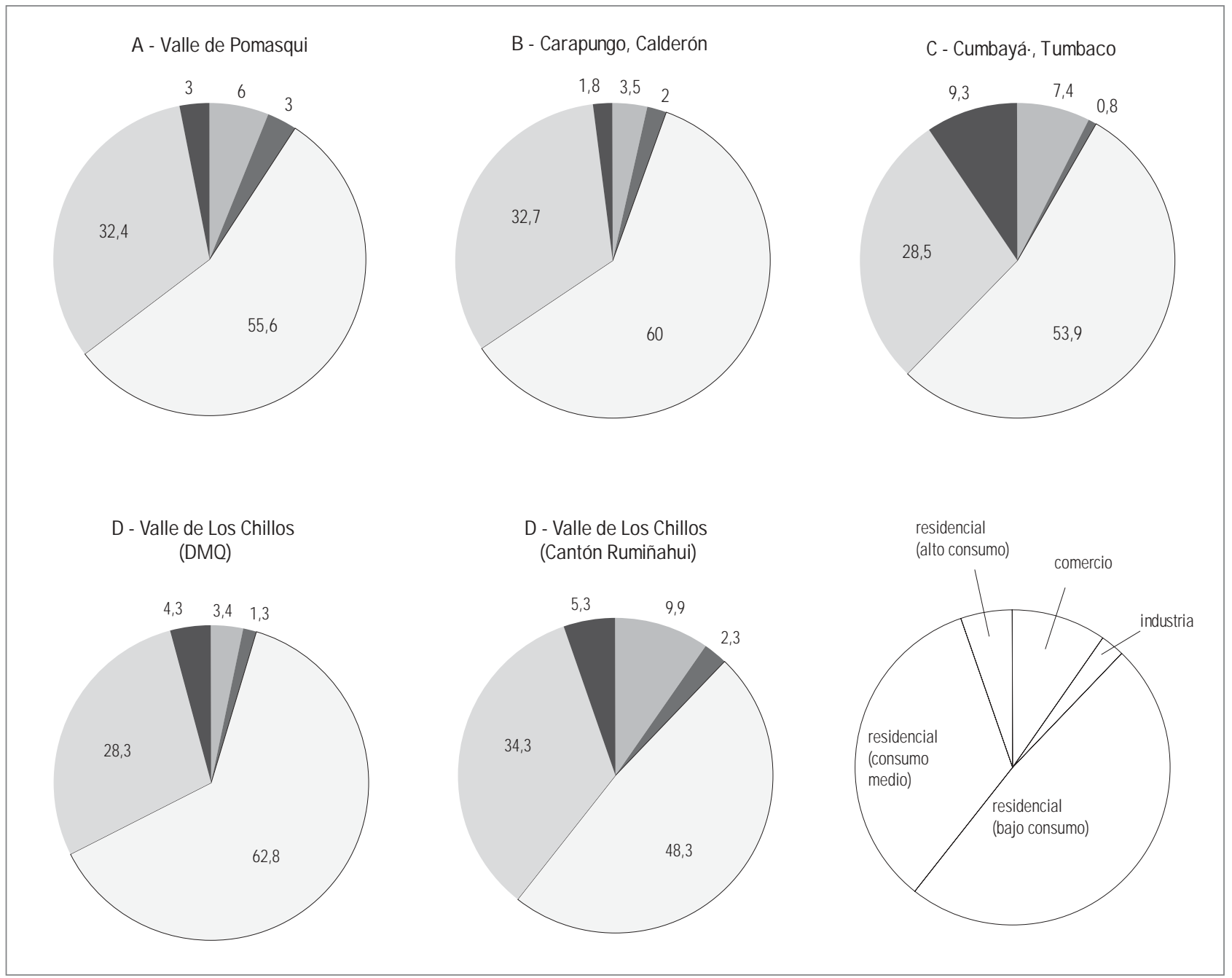

(Fuente: EEQ, 2001) 
Tabla 1-2

Repartición de la población, del empleo y de las funciones urbanas entre la ciudad de Quito y su periferia

\begin{tabular}{|c|c|c|c|c|c|c|c|c|c|c|c|c|c|c|}
\hline & \multicolumn{2}{|c|}{ Población } & \multicolumn{2}{|c|}{ Superficie km² } & \multicolumn{2}{|c|}{$\begin{array}{l}\text { Empleado } \\
\text { en las } \\
\text { empresas }\end{array}$} & \multicolumn{2}{|c|}{$\begin{array}{l}\text { Población } \\
\text { escolar y } \\
\text { universitaria }\end{array}$} & \multicolumn{2}{|c|}{$\begin{array}{c}\text { Número de } \\
\text { camas en los } \\
\text { centros médicos }\end{array}$} & \multicolumn{2}{|c|}{$\begin{array}{l}\text { Principales } \\
\text { lugares de venta } \\
\text { de alimentos }\end{array}$} & \multicolumn{2}{|c|}{$\begin{array}{c}\text { Administraciones } \\
\text { públicas }\end{array}$} \\
\hline & & $\%$ & & $\%$ & & $\%$ & & $\%$ & & $\%$ & & $\%$ & & $\%$ \\
\hline Ciudad de Quito & $1^{\prime} 413.694$ & 76.8 & 188 & 4.4 & 248.468 & 91.6 & 229.643 & 82.4 & 4.239 & 95.6 & 92 & 80.7 & 107 & 97.3 \\
\hline Resto DM Q & 427.506 & 23.2 & 4.067 & 95.6 & 22.839 & 8.4 & 48.999 & 17.6 & 196 & 4.4 & 22 & 19.3 & 3 & 2.7 \\
\hline Total & $1^{\prime} 841.200$ & 100 & 4.255 & 100 & 271.307 & 100 & 278.642 & 100 & 4.435 & 100 & 114 & 100 & 110 & 100 \\
\hline
\end{tabular}

(Fuentes: INEC, DM TV, IESS, DTM, M EC, CONUEP, encuestas IRD, M SP, DM C)

dos en las empresas ${ }^{25}$, el 83 por ciento de la población escolar, más del 87 por ciento de los docentes (17.670 profesores), más del 95 por ciento de las capacidades de hospitalización, más del 80 por ciento de los lugares más grandes de venta de alimento ${ }^{26}$ y el 97,3 por ciento de las instituciones públicas en las cuales trabajan 22.660 personas (es decir casi el 99 por ciento de los empleos públicos).

$\mathrm{Si}$ bien es cierto que estos valores pueden padecer de varios emres e imprecisiones, no cabe duda en cuanto a la hipercentralidad socio económica metropolitana de la ciudad de Quito.

Los siguientes mapas ilustran la marcada concentración espacial de población, de funciones urbanas y de empleo en la ciudad de Quito. La concentración de las actividades explica en parte la magnitud de los movimientos pendulares.

\section{Desplazamientos entre la ciudad de Quito y la periferia}

Según la encuesta origen-destino de 1998, unos 148.150 desplazamientos cotidianos fueron censados en los buses entre Quito y la periferia suburbana, es decir cerca del 10 por ciento del total de desplaza- mientos en transporte colectivo observados cada día en la aglomeración. Estos valores son subestimados porque la encuesta no toma en cuenta el transporte intercantonal, cuyo papel es muy importante para las conexiones con el sur de la aglomeración (cantón Mejía) y con el valle de Los Chillos. No es fácil evaluar el número exacto de movimientos pendulares entre el valle de Los Chillos y la ciudad de Quito, pero se sabe que son intensos. En efecto, más de 18.000 vehículos transitan por la autopista Rumiñahui cada día desde el valle de Los Chillos con dirección a Quito. Si bien el cantón Rumiñahui no pertenece al Distrito, forma parte integrante del territorio de movilidad metropolitana. Ello se evidencia a través de la configuración de su red vial principal, estrechamente enlazada con la del DMQ, y a través del gran número de líneas de buses interparroquiales e intercantonales que co-

25. Se debe considerar este valor con precaución en la medida en que el número de empleados se registra en el lugar oficial de la empresa (sede social) que no corresponde siempre al lugar de actividad real. Además el INEC evalúa en unos 240.000 el número de empleos informales (muy difícil de localizar). Por último, el número de personas activas en el sector primario no es despreciable en las parroquias suburbanas.

26. Se consideraron los mercados, plataformas, ferias y supermercados. No se consideraron las tiendas barriales. 


\section{Mapa 1-8}

Concentración de la población y del empleo en la zona urbana consolidada de Quito
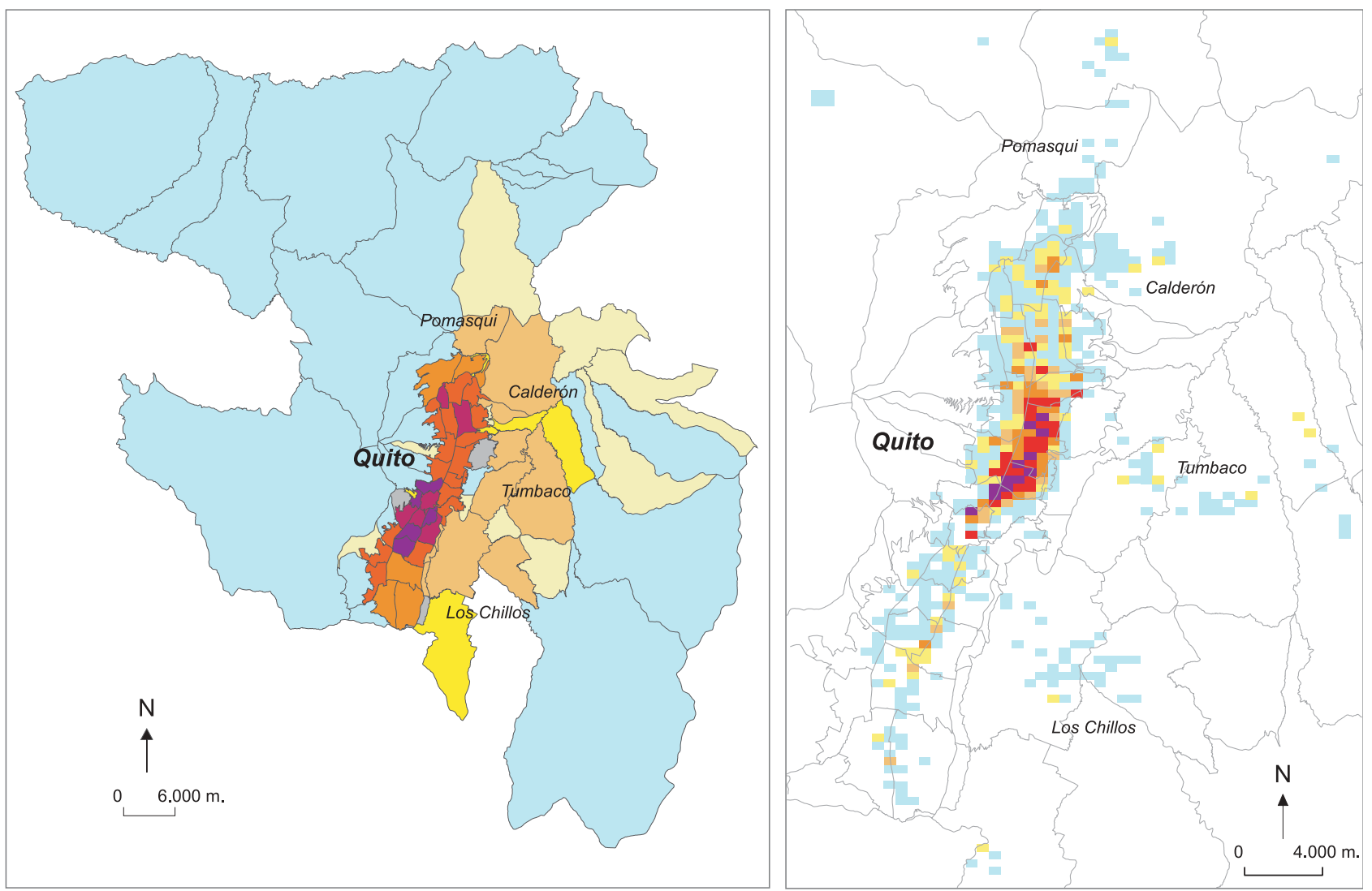

Densidad poblacional (Habitantes por hectárea)

$\begin{array}{lll}\square \text { sd } & \square \text { [2,5-5 [ } & \square \text { [50 - 100 [ } \\ \square \text { menos de } 1 & \square \text { [5-15 [ } & \square \text { [100 - 150 [ } \\ \square \text { [1 - 2,5 [ } & \square \text { [15-50 [ } & \square \text { [150 - 185] }\end{array}$

Número de empleados en las empresas (por hoja catastral)

$\square$ [1 -200[ $\square[500-1.000$ [ $\square[2.000-5.000$ [
$\square$ [200-500 [ $\square$ [1.000-2.000[ $\square[5.000-13.427$ ]

(según R. D'Ercole, P. M etzger, 2002, Fuentes: INEC, IESS, DTM) 


\section{Mapa 1-9}

Concentración de las funciones urbanas y de los servicios a favor de la ciudad de Quito

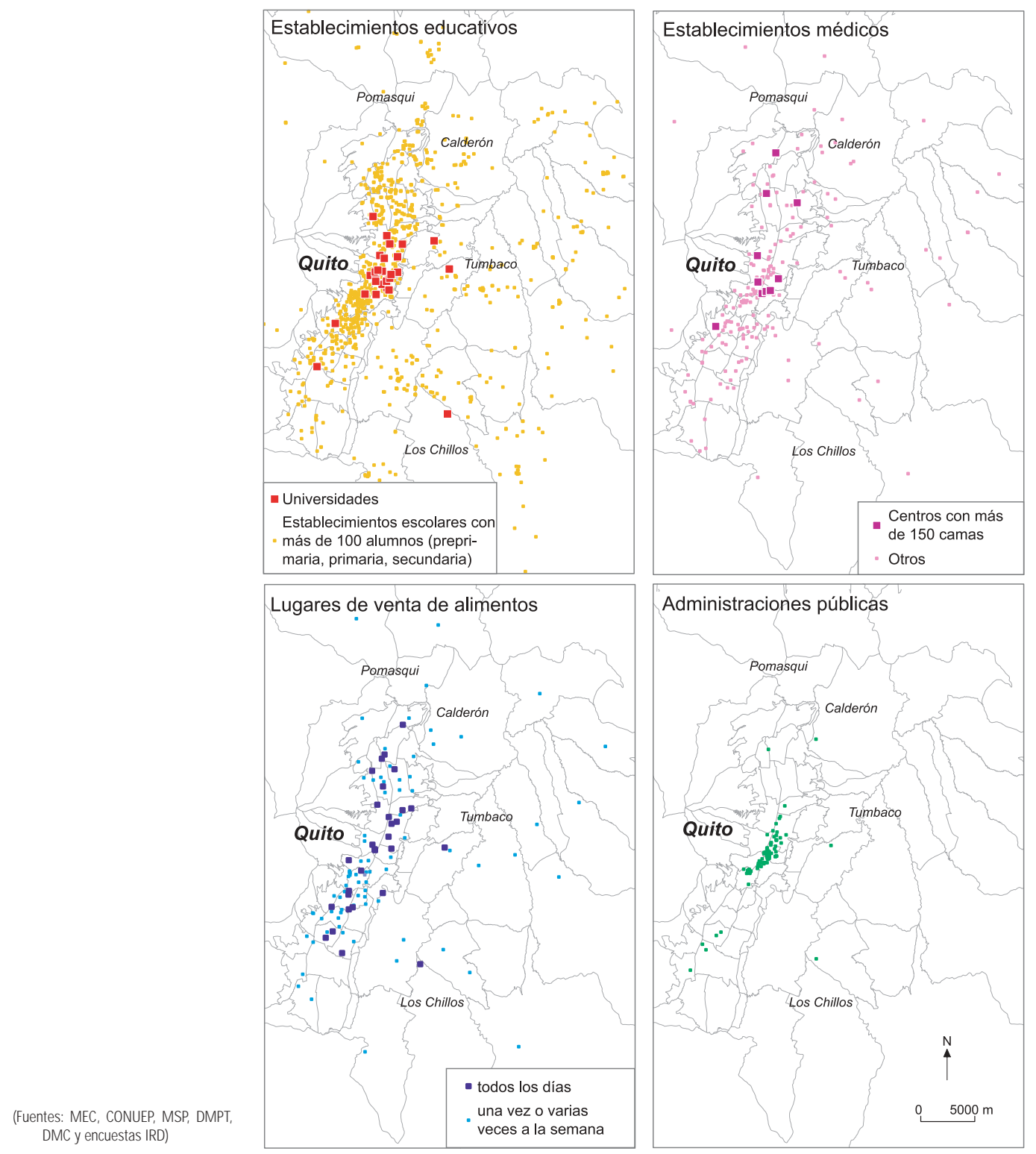


Figura 1-3

Motivos de los viajes diarios realizados en bus entre el centro y la periferia

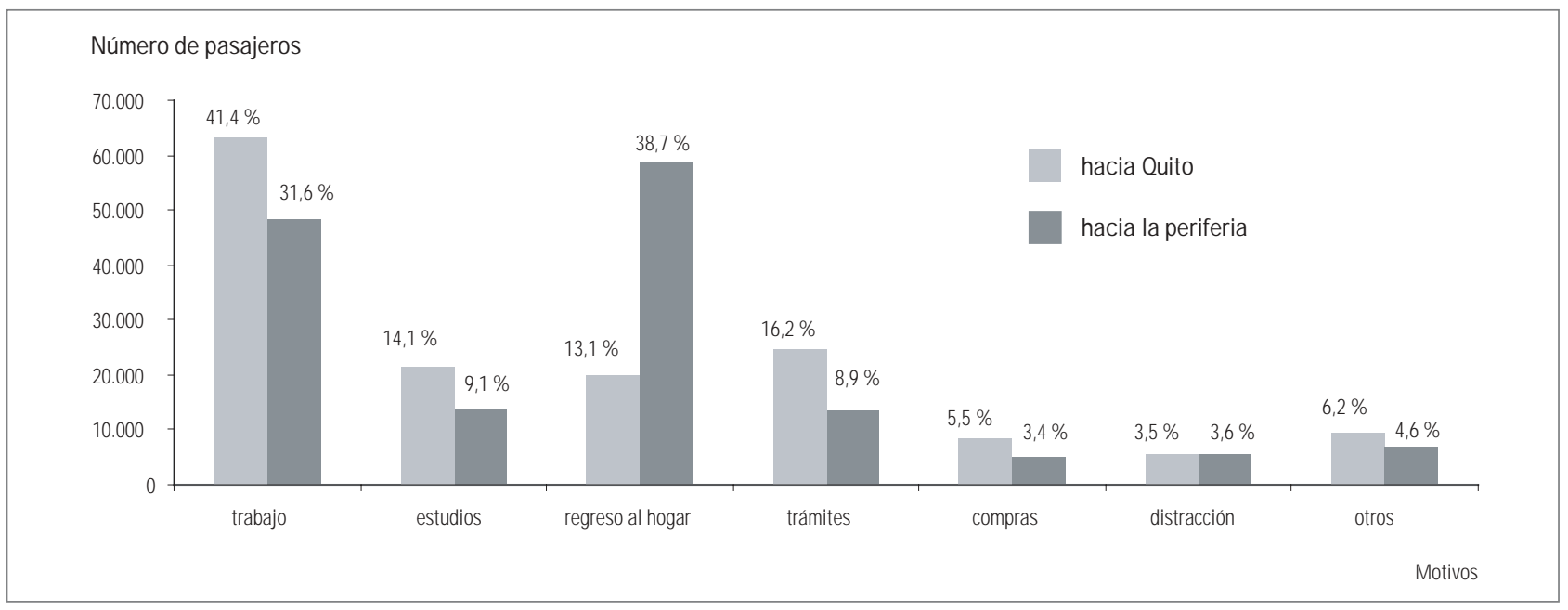

(Fuente: Encuesta OD, 1998, UPGT)

nectan Quito con Los Chillos. Por último, al interior del valle de Los Chillos no se observa una discontinuidad marcada en la mancha urbana en el límite de ambos cantones (mapa 1-7, cuadro B).

En lo que se refiere a la repartición horaria de los movimientos pendulares en transporte colectivo interparroquial, cabe destacar que la mayoría se realiza en la mañana. Más del 67 por ciento de los desplazamientos hacia Quito son efectuados antes de las 13h00. En sentido contrario, los viajes son también mayoritarios en la mañana pero en menor magnitud (57 por ciento del total). Desde un punto de vista de los motivos, el 42 por ciento de los desplazamientos hacia Quito se realizan para ir al trabajo, el 16 por ciento para trámites, el 14 por ciento para estudios, el 13 por ciento pa- ra regresar al hogar y el 5 por ciento para las compras (figura 1-3). En sentido contrario, el 39 por ciento de los viajes con destino a los valles se realiza para regresar al hogar, el 32 por ciento para ir al trabajo, el 9 por ciento para los estudios y los trámites.

Los porcentajes expresan la proporción de los viajes por motivo en relación con el total de los viajes diarios por sentido (Fuente: Encuesta OD, 1998, UPGT).

Los mayores movimientos pendulares parecen aquellos censados entre Quito y el corredor "B" de Carapungo-Calderón (mapa 1-10). En efecto, se observa cerca de 58.000 viajes cada día entre estas dos zonas. El valle de Cumbayá-Tumbaco ocupa el segundo lugar con cerca de 52.000 movimientos pendulares. Entre Quito y el valle de Pomasqui, al norte, se censa 
cerca de 20.000 viajes. Sin embargo, debido al carácter parcial de la información disponible sobre los movimientos pendulares de personas procedentes de Los Chillos y del sur de la aglomeración (cantón Mejía), estas cifras comparativas son muy relativas. De su lado, el corredor "B", a pesar de contar con una población menor que la del valle de Tumbaco, mantiene proporcionalmente lazos más intensos con la ciudad. Ello se debe a que en el comedor "B" existen pocas actividades y funciones urbanas. Desde esta zona hacia Quito, la mayonía de los viajes son realizados esencialmente para ir al trabajo a lo largo de todo el día (desde las 6 h00 hasta las 16h00). En sentido contrario, a partir de las 9h00 los viajes hacia Carapungo-Calderón se realizan mayoritariamente con el fin de regresar al hogar. Este corredor presenta entonces muchas características de una ciudad dormitorio.

El mapa 1-11 indica dentro de la ciudad los dos sectores de principal destino de los movimientos pendulares por zona de procedencia. De modo general, la mitad norte de la ciudad recepta la mayoría de estos flujos: La Marín (sector 28), el centro Norte (sectores 39, 40 y 41), el nor-este (sectores 47 y 51) y por último Cotocollao (sector 57). La Marín corresponde a la centralidad asociada al centro histórico que congrega múltiples administraciones y comercios. El centro-norte reúne universidades (Central, Católica, Politécnica), muchos comercios (mercado de Santa Clara) y numerosas oficinas y restaurantes. Cuenta también con los más grandes centros comerciales (Quicentro, Megamaxi, El Jardín), muchos bancos y sedes sociales de empresas. Por último, Cotocollao es un antiguo pueblo rural hoy en día integrado en la mancha urbana y engloba varios hospitales públicos, múltiples comercios y empresas.
La hipercentralidad de la ciudad de Quito explica la magnitud de los desplazamientos centro-periferia. Por otro lado, la configuración de la ciudad $(40 \mathrm{~km}$. de largo y entre 3 y $5 \mathrm{~km}$. de ancho) así como la desigual repartición de las funciones dentro de la mancha urbana origina también un volumen considerable de movimientos intra-urbanos.

\section{Las comunica ciones intra-urbanas}

Se aborda en esta sección la repartición de las funciones al interior de la ciudad, la magnitud de los movimientos intra-urbanos y los principales lugares de destino dentro de la ciudad.

\section{La hipercentralidad funcional de la ciudad}

Si bien a escala del Distrito existe hiperconcentración de las funciones urbanas en la ciudad de Quito, se evidencia que los espacios al interior de ésta no están equitativamente provistos. Por lo tanto, las distintas zonas urbanas no son igualmente atractivas. Un espacio central es sumamente atractivo debido a la concentración de empresas (Mapa 1-12, cuadro A), administraciones, establecimientos educativos, centros de salud y lugares de venta de alimentos (Mapa 1-12, cuadro B). Este espacio central está conformado por 25 sectores de referencia contiguos de la encuesta origen-destino de 1998. Este espacio es el destino de cerca del 50 por ciento de los viajes registrados en la ciudad en transporte colectivo urbano e interparroquial. Este espacio central es delimitado al sur por el cerro de El Panecillo, y al norte por el aeropuerto. Agrupa 132 barrios urbanos (de un total de 668 que cuenta la ciudad de Quito) y 7 parroquias urbanas ${ }^{27}$ (de un total de 32). Se extiende en una superficie de 3.360 ha., 


\section{Mapa 1-10}

Volumen y motivos de los desplazamientos de personas realizados a diario en transporte colectivo interparroquial entre la ciudad y los espacios periféricos metropolitanos

Motivos (se trata del motivo

más representado por hora):

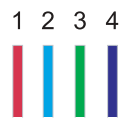

1 - trabajo

2 - estudios

3 - regreso al hogar

4 - trámites
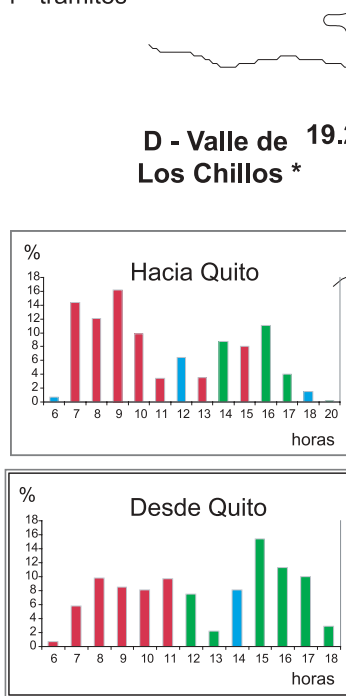

mbayá y Tumbaco

Nota : los histogramas representan el volumen horario de pasajeros (de las 6:00 a las 19:00) expresados en porcentaje, en relación con el total diario de personas que se trasladan desde / hacia cada uno de los 4 sectores suburbanos.

* : El volumen horario es subestimado debido a que una proporción significativa de los viajes se realiza gracias al transporte intercantonal no representado en este mapa.
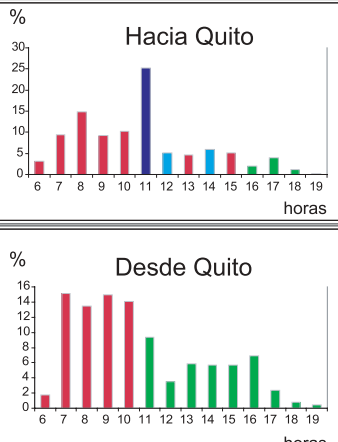

9.610

A - Pomasqui Mitad del Mundo

51.680

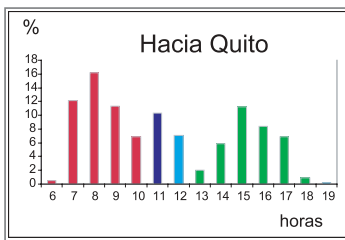

\section{B - Carapungo} y Calderón
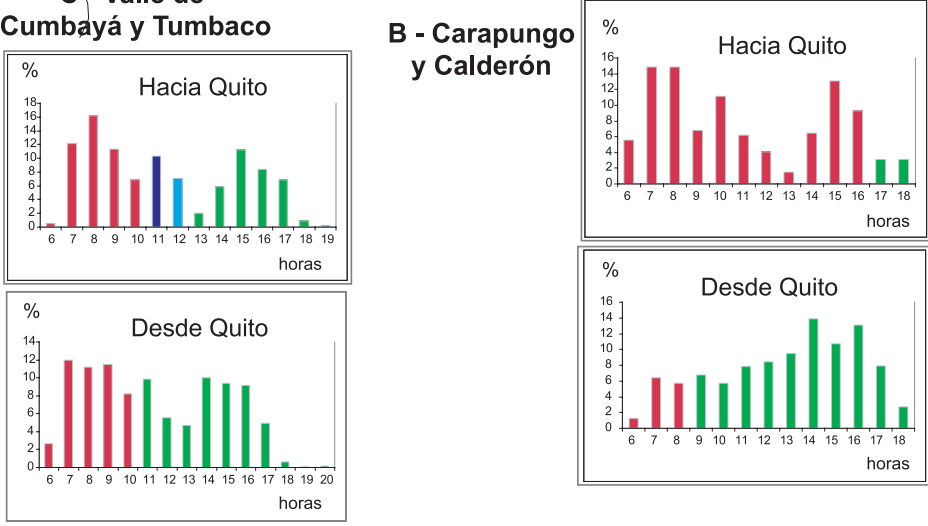

(Fuente: encuesta UPGT, 1998) 
Representación de los dos principales sectores de destino de los movimientos pendulares por zona de procedencia (Transporte colectivo interparroquial únicamente)

\section{Nombres de los sectores}

28 : San Marcos, Plaza Marín

39 : Girón, La Floresta, U Católica, Politécnica

40 : La Mariscal, La Colón, Hosp Baca Ortiz, Sta Teresita

41 : Santa Clara, U Central, Belisario Quevedo

47 : Batán, Bellavista, CC Quicentro, Colegio 24 de Mayo, Tribunal Supremo Electoral

57 : San Carlos, Andalucía, Cotocollao, Quito Norte, Tulipanes
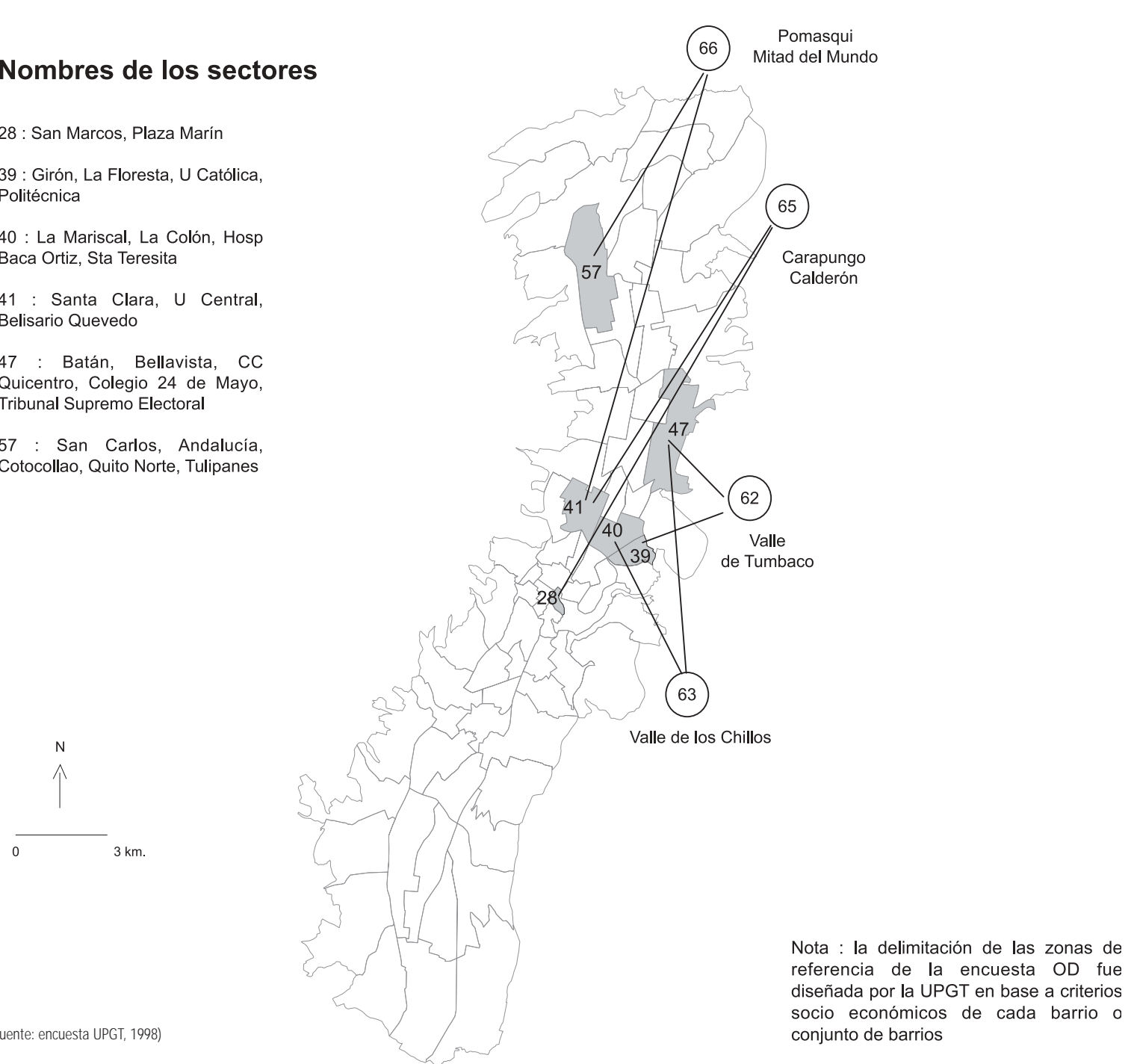
es decir en el 17,5 por ciento del área urbana. El espacio central cuenta con más de los dos tercios de las empresas (Mapa 1-12, cuadro A) ${ }^{28}$. Fuera de este espacio, la concentración de empresas es reducida. En su gran mayoría se encuentran de cada lado del aeropuerto (6), en el sector del Ponceano (7) y en el sur en el sector de la Villa Flora (8). En lo que se refiere a las demás funciones urbanas (Mapa 1-12, cuadro B), al interior del espacio central, más de una cuarta parte se concentra en dos barrios (Centro histórico y Mariscal) en donde las administraciones son dominantes en número. Dentro del espacio central, las administraciones están en segunda posición después de los establecimientos educativos. Los centros de salud son mayoritarios en los barrios de Miraflores (9), Santa Clara (10), Guangacalle (11). Los lugares de venta de alimentos son dominantes en número al oeste del centro histórico en San Roque (13) y en la parte norte del espacio central en el barrio de El Inca (14).

La repartición de las categonías de medidores eléctricos por manzana (Mapa 1-12, cuadro C) indica que la mitad sur de la ciudad es mayoritariamente constituida por barrios residenciales de bajos ingresos. De su lado, la mitad norte, sin tomar en cuenta sus periferias, cuenta esencialmente con barrios de clase media y alta (barrios Quito Tennis, El Bosque, Bellavista, El Condado). Cerca del 84 por ciento de los medidores ubicados en la ciudad (384.000) son de tipo residencial sin importar su categoría. Un amplio corredor longitudinal en el cual predominan los comercios, se extiende desde el centro histórico, pasando por el centro moderno hasta el aeropuerto. La actividad industrial es mayoritaria en algunos sectores al nor-este (bamios Ponceano y Santa Lucía) y en algunas manzanas ubicadas a lo largo de la Panamericana sur (barrios
San Bartolo, Plywood y Turubamba). Por último, en la ciudad 1.820 manzanas siguen baldías en especial en el sur de la ciudad.

Según el último censo de 2001, alrededor de 283.700 personas viven en el espacio central, lo que representa el 20 por ciento de la población urbana, valor bajo con respecto a la multiplicidad y el gran número de funciones que concentra. Este desequilibrio implica una necesaria movilización de los ciudadanos hacia este espacio y asimismo una gran cantidad de movimientos en su interior.

\section{La frecuentación del espacio central}

El mapa 1-13 muestra que el espacio central registra cotidianamente cerca de 690.000 desplazamientos de personas (suma de los 326.700 viajes realizados al interior del espacio central y de las afluencias desde el resto de la metrópoli evaluadas en 362.580 viajes). Estos 690.000 desplazamientos representan el 46 por ciento del 1.48 millón de viajes metropolitanos realizados en bus urbano e interparroquial. Por otro lado, 152.400 personas provienen de la parte sur de la ciudad y 142.700 de la parte norte. Por último, 67.500 moradores de los sectores suburbanos llegan en bus cada día al espacio central. Eso significa que el 90 por ciento de los traslados desde las cuatro zonas periféricas (Pomasqui, Calderón, Tumbaco y Los Chillos) tienen como destino el espacio central.

27. Rumipamba, Iñaquito, Belisario Quevedo, Mariscal Sucre, Itchimbía, San Juan y el Centro Histórico.

28. Para mayor información, véase R. D'Ercole, P. Metzger, 2002. Capítulo 13, pp. 147-158. 


\section{Frecuentación y motivos de viaje dentro de la ciudad: situaciones muy heterogéneas}

\section{Sectores urbanos desigualmente atractivos}

En detalle, todos los sectores urbanos no registran la misma cantidad de movimientos. Ello se debe a la presencia más o menos abundante de funciones urbanas dentro de los sectores de referencia delimitados para la encuesta origen-destino, a la heterogeneidad de su tamaño y de su población. Sin sorpresa se constata una importancia de movimientos que va creciendo a medida que se acerca al centro de gravedad de la ciudad (mapa 1-14, cuadro A). En los nueve sectores que reciben más de 40.000 personas, siete se encuentran al interior del espacio central, dos en el espacio norte de la ciudad (sectores 51 y 57) y ninguno en el espacio sur. Los barrios del centro histórico y de La Mariscal en donde se censa muchas actividades y empresas, registran respectivamente una afluencia de 65.000 y 70.000 personas cada día.

\section{Contraste en la repartición horaria de los viajes}

La repartición a lo largo del día de los viajes evidencia las tendencias de movilidad características de cada sector urbano (mapa 1-14, cuadros B y C). De modo general, el espacio central recepta la mayonía de los flujos en la mañana; en la tarde, predominan las salidas. Ello confirma su frecuentación diurna muy marcada. Las salidas son mayoritarias antes del medio día en los espacios norte y sur de la ciudad, lo que confirma su carácter residencial dominante. En efecto, sus habitantes salen de su barrio para cumplir con sus obligaciones y responder a sus necesidades al inicio del día. El regreso a estos dos espacios no tiene un perfil único, a veces, de preferencia en la mañana, otras, en la tarde.

\section{Motivos variados de viaje según los sectores}

En la mañana el trabajo motiva la mayoría de los viajes sobre todo en el espacio central y en el espacio norte de la ciudad (mapa 1-14, cuadro D). El regreso al hogar ocupa la segunda posición en el espacio sur y en el extremo norte. A pesar de ser esencialmente residencial, el espacio norte de la ciudad acoge también muchos trabajadores. Los traslados de las personas que trabajan en el servicio doméstico explican parcialmente este fenómeno. En efecto, en el espacio norte vive la clase media (cerca de 110.000 viviendas con consumo medio o alto de electricidad) que suele contratar este tipo de servicio.

En la tarde, el regreso al hogar alcanza la primera posición salvo en el espacio central en donde el trabajo sigue siendo de manera general el motivo dominante (mapa 1-14, cuadro E).

Conociendo los principales rasgos de la movilidad, se analiza a continuación en qué sistema de transporte se basa esta movilidad en particular dentro de la aglomeración, cuáles son sus principios de funcionamiento $\mathrm{y}$ sus características generales. 


\section{Mapa 1-12}

Fuerte concentración de las funciones urbanas al interior del espacio central de Quito
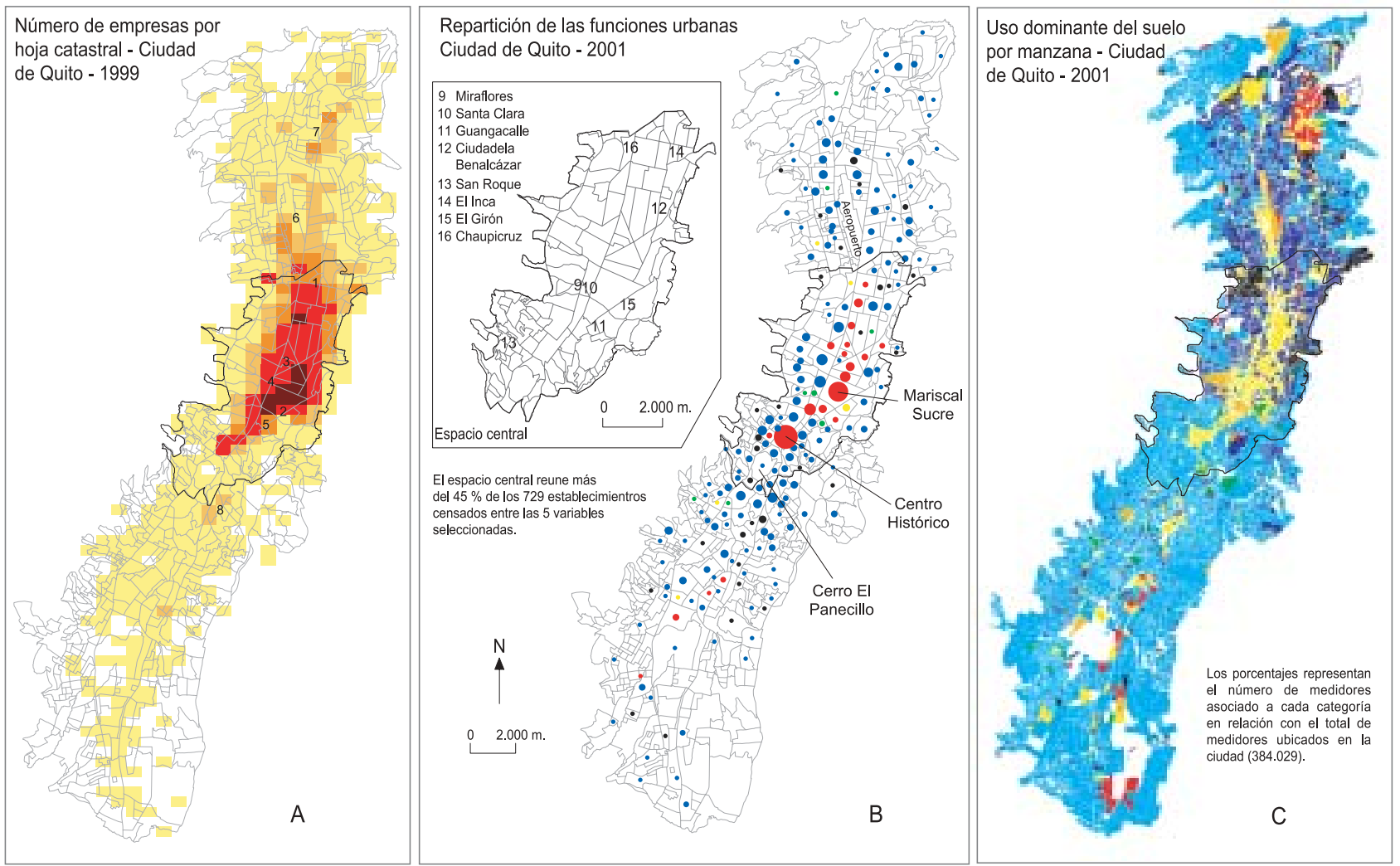

\begin{tabular}{|lll|}
$\square$ 0 & 1 Río Coca \\
$\square$ menos de 25 & 2 Mariscal \\
$\square$ de 25 a 49 & 3 La Pradera \\
$\square$ de 50 a 99 & 4 Colón \\
$\square$ de 100 a 299 & 5 El Ejido \\
$\square$ de 300 a 730 & 7 Ponceano \\
& 8 Villaflora \\
\hline
\end{tabular}

\begin{tabular}{|c|c|}
\hline $\begin{array}{l}\text { Número acumulado de establecimientos } \\
\text { cual sea su función (considera también } \\
\text { los lugares de mercado) }\end{array}$ & $\begin{array}{l}\text { Función dominante por barrio } \\
\text { administración }\end{array}$ \\
\hline & escuelas (primaria y secundaria) \\
\hline $\int^{33}$ & enseñanza superior \\
\hline 27 & - comercio (productos alimenticios) \\
\hline $\begin{array}{ccc}0 & 18 \\
0 & 9\end{array}$ & salud \\
\hline
\end{tabular}

Tipo de medidores
eléctricos dominante
Residencial (bajo
consumo) - $47,6 \%$
Residencial (consumo
medio) - $31 \%$
Comercial - $13,8 \%$

Residencial (consumo
alto) - $5,1 \%$
Industrial - $1,9 \%$
$\square$ Entidad oficial - $0,4 \%$
$\square$ Medidores sociales - $0,2 \%$
$\square$ Manzanas baldias (1.820)

(Fuentes: SRI, DTM , M EC, CONUEP, DM C, M SP, DM PT, encuestas IRD, EEQ) 


\section{Mapa 1-13}

Desplazamientos de personas realizados cada día en bus urbano e interparroquial con destino al espacio central de la ciudad de Quito

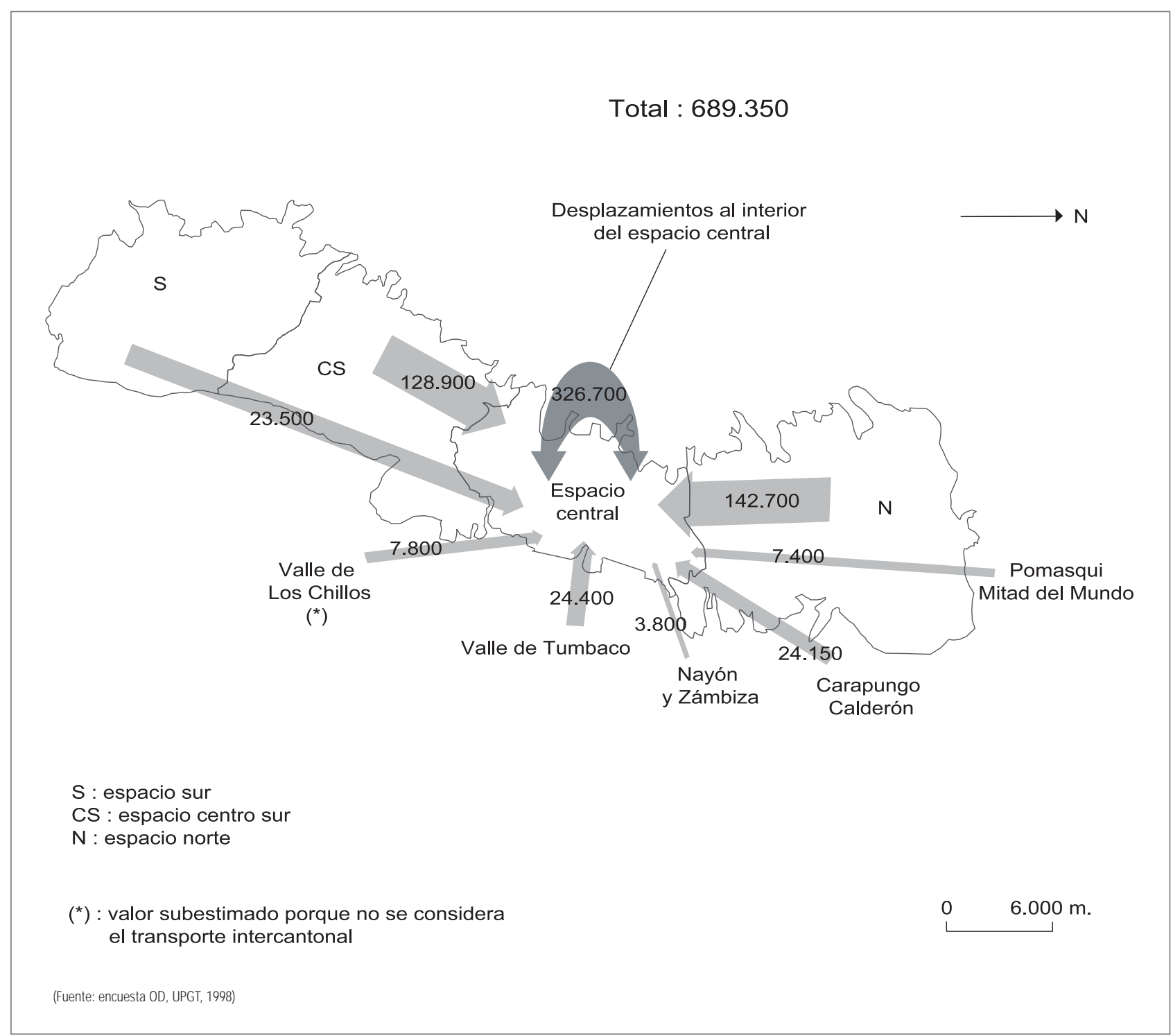




\section{Mapa 1-14}

Afluencia, salidas y motivos de los viajes de personas efectuados en bus urbano e interparroquial en la ciudad de Quito
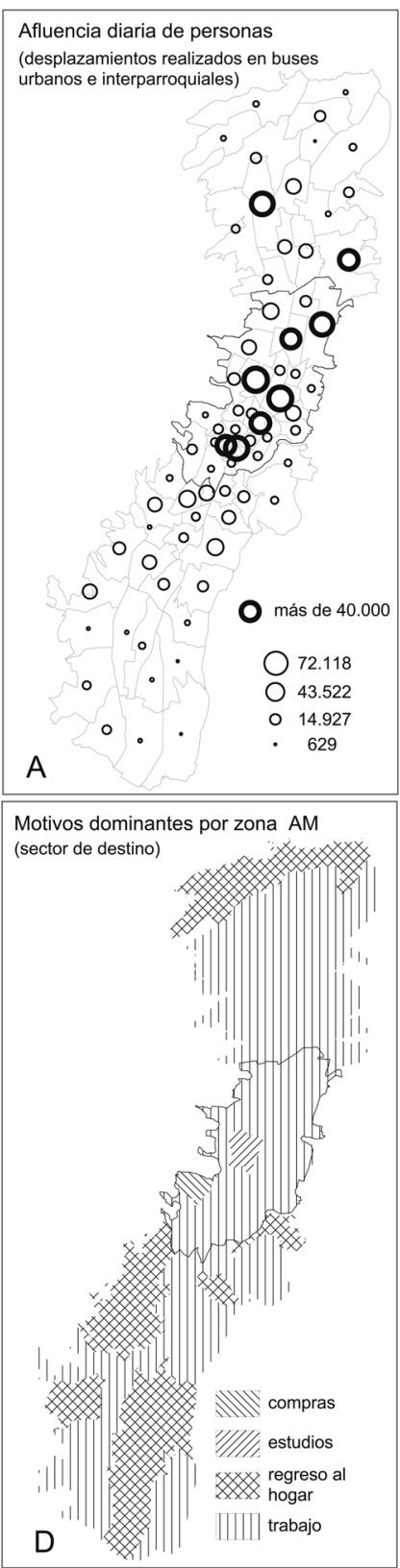

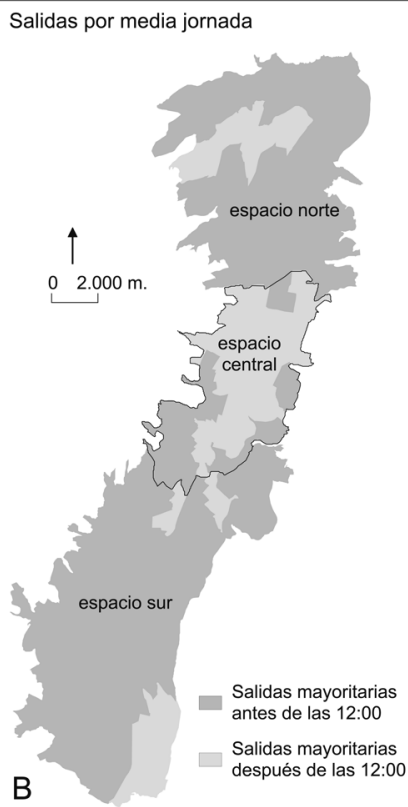

Motivos dominantes por zona PM (sector de destino)$$
\text { o) }
$$

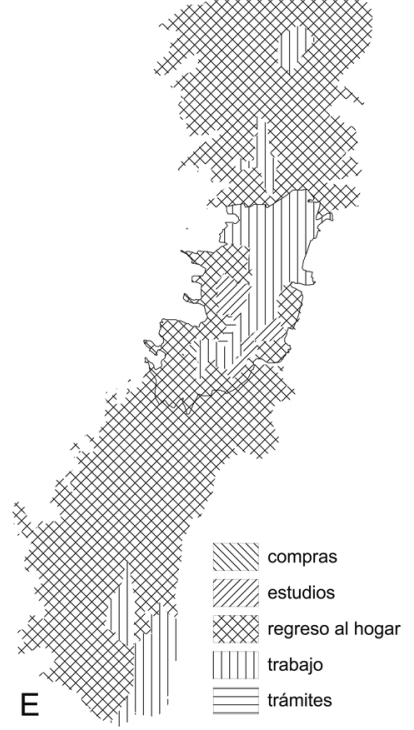

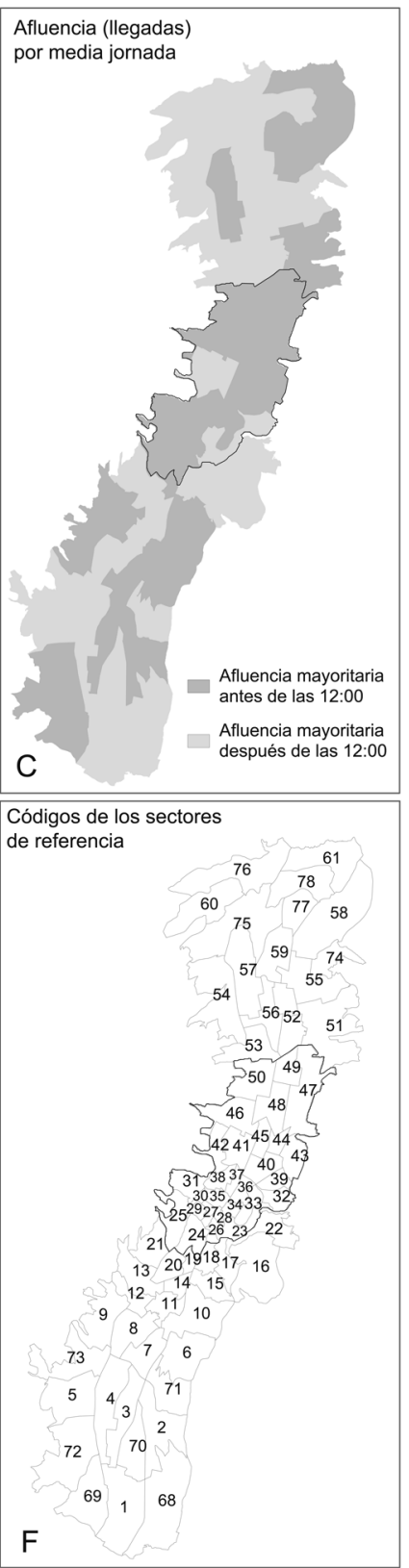




\section{2 - Estructura, organización y}

funcionamiento del sistema de transporte

En este capítulo se analizan los componentes del funcionamiento de la movilidad y su evolución a lo largo de los últimos veinte años. De hecho, durante este período ocurrió un gran número de cambios que tienen actualmente, por un lado, implicaciones positivas como la municipalización de la competencia del transporte así como la implementación de una red integrada y por otro lado, consecuencias negativas como el crecimiento exponencial del parque automotor y problemas de accesibilidad.

El sistema de transporte es el motor de la movilidad. Gracias a él la población se puede trasladar en la ciudad. Posee su estructura propia y depende de otros subsistemas, de otros factores (uso del suelo, distribución de la población, configuración del espacio urbano, contexto económico).

Se analiza entonces los tres siguientes componentes:

- El marco jurídico e institucional que define las competencias de los distintos actores.

- Las infraestructuras viales (red, obras y equipamientos) en las cuales se basa la movilidad.

- La oferta de transporte (vehículos y redes) que posibilitan los desplazamientos.

\section{El marco juńdico e institucional}

El análisis se fundamenta en la revisión de los textos de ley que definen las premogativas de cada actor en una determinada jurisdicción. A lo largo de la última década, ocurrieron cambios notables en la repartición de las atribuciones entre actores. Entre las principales modificaciones, la municipalización de la gestión del transporte es sin lugar a dudas aquella que más transformó la movilidad de los quiteños, con la instauración de un sistema de transporte integrado.

\section{Actores involucrados en la vialidad}

En el ámbito de la vialidad, varias instituciones intervienen en el DMQ, la más importante es el Municipio de Quito.

\section{Empresa Metropolitana de Obras Públicas (EM OP-Q)}

La facultad del Distrito Metropolitano en materia de vialidad se formula primero en la Ley de Régimen $\mathrm{Mu}-$ nicipal del año 1966 que rige para todos los municipios del Ecuador. Los municipios tienen como función: "construir, mantener, asear, embellecer y reglamentar el uso de los caminos, calles, plazas y demás espacios públicos". Esta facultad fue complementada en 1993 por la Ley de Régimen del Distrito Metropolitano de Quito que autoriza la constitución de empre- 
sas municipales bajo la forma de sociedad de economía mixta para la prestación y el mejoramiento de los servicios públicos. Es así como la Empresa Metropolitana de Obras Públicas ${ }^{29}$ fue creada en 1994 remplazando a la Unidad de Obras Públicas. Hoy, el papel principal de la EMOP-Q es el diseño y fiscalización de la ejecución de obras viales cuya planificación y programación son determinadas en concertación con los demás entes municipales (DMT, DMPT, EMSAT) ${ }^{30}$.

En las parroquias periféricas cercanas (Conocoto, Cumbayá, Tumbaco, Calderón, Pomasqui), la EMOP$\mathrm{Q}$ es responsable del mantenimiento y de la construcción de nuevas vías en colaboración con las administraciones zonales y la EMAAP-Q (Empresa Metropolitana de Alcantarillado y Agua Potable). El radio de acción espacial de la EMOP-Q se limita entonces esencialmente a la aglomeración metropolitana y sobre todo a la ciudad de Quito (mapa 2-1).

\section{Consejo Provincial de Pichincha (HCPP)}

En la aglomeración, la segunda institución que interviene en el ámbito de la vialidad es el Honorable Consejo Provincial de Pichincha (HCPP), creado en 1945 por la ley del Régimen Provincial. Esta institución depende del régimen descentralizado autónomo. Las atribuciones y deberes del Consejo en materia de obras viales son: "dirigir y realizar las obras viales de carácter provincial e interprovincial, promover convenios de intercambios con los municipios para llevar a cabo conjuntamente obras de interés común, tales como ejes de comunicación (...) y presentar un plan general de desarrollo provincial ${ }^{31}$ ".

En el DMQ el gobierno provincial es el encargado de una parte de la red vial que se limita a unos ejes principales y a las vías secundarias y locales en las zonas suburbanas y rurales que llegan a los sectores de producción agrícola. El HCPP administra todavía en forma directa algunos tramos viales con peajes (Intervalle, Autopista a La Mitad del Mundo) y concesiona otros a la iniciativa privada. Por ejemplo la Autopista Rumiñahui es administrada por la sociedad TribasaColisa (mapa 2-1).

\section{Ministerio de Obras Públicas (MOP)}

De su lado, el MOP interviene a otro nivel, establece las normas de ingeniería civil aplicadas a las obras viales y de construcción y mantenimiento de las vías de comunicación de interés nacional. Su intervención directa en el ámbito de la vialidad en el DMQ no es despreciable y tiende incluso a reforzarse con la recuperación de algunos tramos viales inicialmente administrados por la EMOP-Q. A nivel nacional, el MOP es actualmente responsable de un proyecto de desarrollo de concesión de las vías principales. La administración de las vías de acceso al Distrito Metropolitano de Quito (Panamericana sur y Panamericana norte) fue, por ejemplo, concesionada en el 2002 a la sociedad Panavial. Por último, la vía de circunvalación del Distrito (perimetral metropolitana) y la vía Interoceánica al este de Pifo, también le competen (mapa 2-1).

El sistema de actores que intervienen en el tema de la vialidad al interior del DMQ depende entonces de una yuxtaposición complementaria de poderes municipal, provincial y central en el que el sector privado desempeña un papel cada vez más importante. La concesión

29. La EMOP fue creada por Ordenanza Municipal №3074.

30. Véase más adelante.

31. El HCPP presentó al público en 2002 su plan para el período 2002-2022. 
Mapa 2-1

Repartición territorial de las competencias institucionales en el ámbito de la vialidad en el Distrito Metropolitano de Quito - Julio de 2003

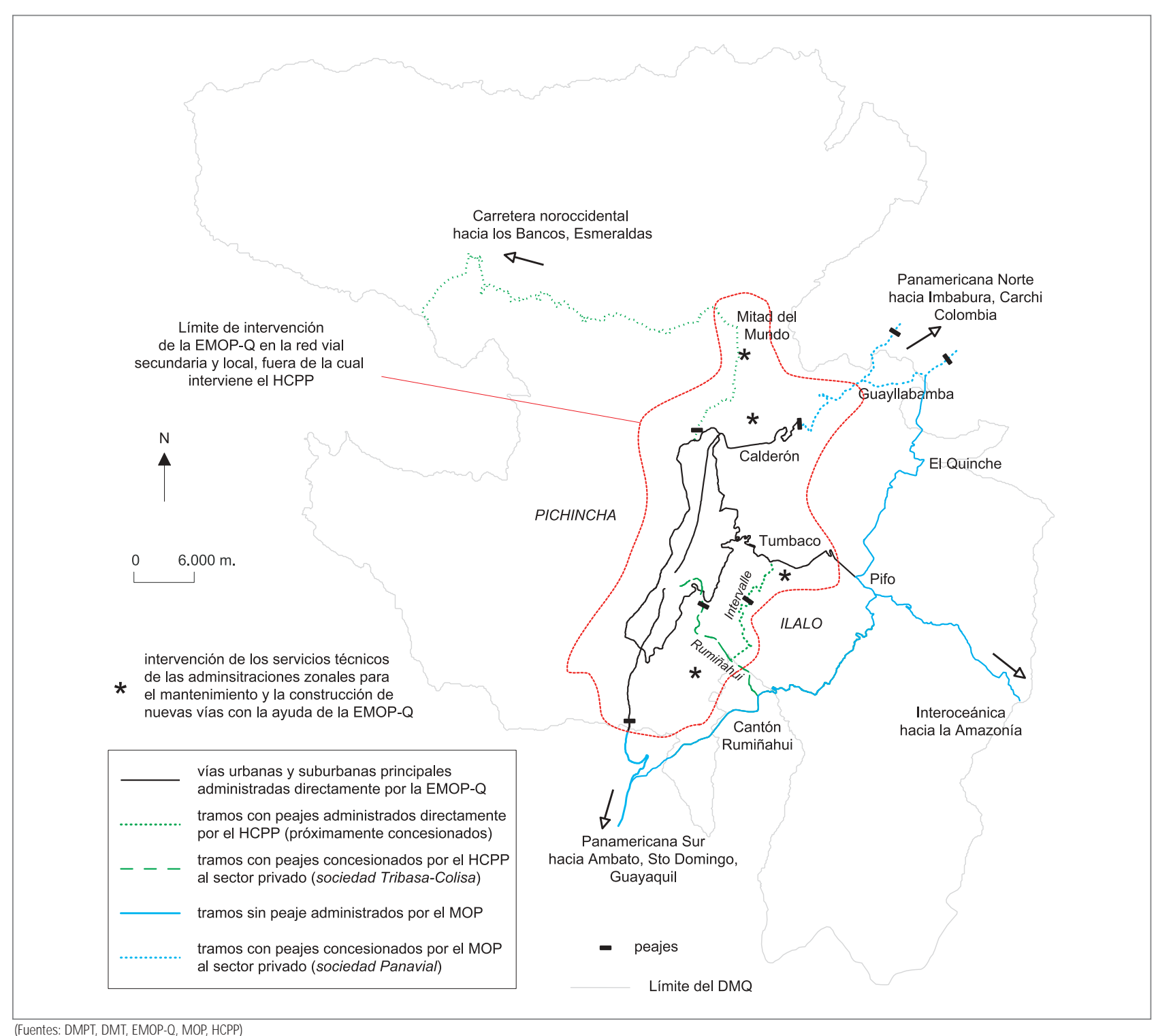


de los tramos viales y la implementación de peajes permiten mejorar la calidad y el mantenimiento de la vialidad, pero vuelve cada vez más problemático el control de las políticas tarifarias, a menudo elevadas, definidas por las empresas privadas lo que origina conflictos como en el caso de la Autopista Rumiñahui.

Aún más que el ámbito de la vialidad, el sistema de actores encargados de la organización del transporte experimentó cambios marcados durante la década de los 90. Esta evolución se debe al proceso de municipalización de la competencia del transporte colectivo en el DMQ.

Este proceso, no específico a Quito, es el resultado de la adaptación progresiva a una política cuyo objetivo era transferir la responsabilidad de algunas actividades y servicios, inicialmente en manos de las instancias centrales, a favor de las locales que tienen un mejor conocimiento de los problemas a los cuales está expuesta su jurisdicción y pueden, consecuentemente, responder mejor a las necesidades de la colectividad. Con este proceso aparecieron nuevos actores en la escena de la gestión y planificación del transporte. A continuación se analiza las competencias de los organismos que representan la autoridad (organismos concedentes, organismos de planificación, regulación y fiscalización). Los actores reflejan también las múltiples formas de la movilidad (transporte colectivo o individual, público o privado, urbano o extra urbano).

\section{Los organismos tutelares del transporte colectivo}

\section{Municipio de Quito}

El Municipio de Quito es el organismo responsable del transporte colectivo urbano e interparroquial; tiene un papel clave en el Distrito Metropolitano desde la expedición de Ley de Régimen del Distrito Metropolitano de Quito de 1993 que notifica las siguientes obligaciones: "planificar, regular y coordinar todo lo relacionado con el transporte público y privado dentro de su jurisdicción".

El sistema de gestión municipal del transporte implementado en el DMQ sirve en cierto modo como modelo al proceso de municipalización de la competencia del transporte urbano a nivel nacional. En efecto, las prerrogativas que tiene el DMQ desde 1993 en cuanto a transporte se aplican ahora en la totalidad de los municipios del país como indica la última Constitución de 1998: "el Concejo Municipal (...) podrá planificar, organizar, regular el tránsito y el transporte terrestre, en forma directa, por concesión, autorización u otras formas de contratación administrativa, de acuerdo con las necesidades de la comunidad". (Art. 234).

Dos entes municipales aseguran la gestión del transporte colectivo urbano e interparroquial en el DMQ. Se trata de la Dirección Metropolitana de Transporte y Vialidad (DMT) y de la Empresa Metropolitana de Servicios y Administración del Transporte (EMSAT). El primero, establece la política general, las estrategias y directrices mayores del transporte y vialidad ${ }^{32}$. Elabora planes, propuestas de regulación y orienta la política tarifaria y la reglamentación. El segundo ente ejecutor

32. Resolución Municipal $N^{\circ}$ 002, del 2 de enero de 2002 
desempeña un papel operativo ${ }^{33}$. Su función es en particular administrar y fiscalizar el transporte. Atribuye los permisos de operación y define los itinerarios y frecuencias de las líneas de bus urbanas e interparroquiales. La EMSAT administra también los taxis, el transporte escolar e institucional ${ }^{34}$. Los principales rasgos de la acción municipal futura en cuanto a transporte y vialidad se insertan en el marco del Plan Maestro de Transporte y Vialidad (MDMQ-DMT, 2002). Este plan resulta de un trabajo llevado a cabo por la DMT conjuntamente con la EMSAT, la EMOP-Q y la Dirección Metropolitana de Planificación Territoral (DMPT). Muestra un aspecto innovador en el sentido de que integra los múltiples componentes de la movilidad (transporte, circulación, vialidad) y toma en cuenta las directrices en términos del ordenamiento territorial y uso de suelo formuladas en el Plan General de Desarrollo Territorial (MDMQ/DMT, 2000).

\section{Consejo Nacional de Tránsito (CNT)}

El CNT es el organismo responsable del transporte colectivo interprovincial que depende del Ministerio de Gobierno. Se estipula su competencia en la Ley de Tránsito y Transporte Terrestre de 1966. El CNT define los itinerarios y frecuencias de los buses interprovinciales. También es responsable de la determinación del precio del transporte colectivo interprovincial e intercantonal. A inicios de los años 90 definía también las tarifas del transporte urbano. Esa competencia le fue retirada a favor de las municipalidades en dos etapas, primero con la Ley del Régimen del Distrito Metropolitano de Quito de 1993 y luego con la última Constitución del Ecuador de 1998.

\section{Consejo Provincial de Tránsito de Pichincha (CPTP)}

El CPTP es el organismo responsable del transporte colectivo intercantonal (intraprovincial) que depende directamente del CNT. Entidad que define los itinerarios y las frecuencias de los buses intercantonales y aplica las directrices tarifarias determinadas por el CNT.

\section{Organismos encargados del parque automovilístico y del tráfico}

\section{Jefatura Provincial de Tránsito de Pichincha}

Según la Ley de Tránsito y Transporte Terrestre, el control del parque automovilístico y la matriculación de los vehículos dentro del DMQ compete a la Jefatura Provincial de Tránsito de Pichincha que depende de la Policía Nacional. Según la misma ley, el control del tráfico dentro de la ciudad está a cargo de la Dirección Nacional de Tránsito (DNT), organismo que depende también de la Policía Nacional. La DNT es responsable de la prevención y seguridad vial. Interviene igualmente en caso de accidentes de tránsito, los cuales son registrados en una base de datos estadísticos actualizados. Estos datos fueron útiles para determinar la peligrosidad de los tramos viales (tercera parte).

\section{Centro de Control de Operación (CCO)}

El Centro de Control de Operación (CCO) que depende de la EMSAT está encargado del monitoreo de las condiciones de circulación vehicular urbana. Su papel

33. Ordenanza Municipal № 055, del 13 de junio del 2001

34. La DMT y la EMSAT reemplazaron a la UPGT (Unidad de Planificación y Gestión de Transporte) creada en 1995 y disuelta en el 2001. 
es informar acerca de los problemas de tránsito a los organismos competentes (a la Policía Nacional, en caso de accidente o de congestión; a la EMOP-Q, en caso de daños en la vía; a la EMAAP-Q, en caso de problemas ligados al agua; a los bomberos, en caso de anegamiento de los pasos a desnivel). Todas estas perturbaciones reportadas por unos observadores de campo son comunicadas a una central y registradas en una base de datos. Esta base sirve para estudios cuyo objetivo es mejorar la fluidez del tráfico mediante la ejecución de reformas geométricas en la calzada, mejoramientos en la calibración del sistema de semáforos.

El CCO desempeña un papel fundamental en las emergencias. Durante la enupción del volcán Pichincha en octubre 1999, los observadores fueron enviados a distintos lugares en la ciudad y notificaron a la central sobre la congestión y dificultades vehiculares. Esta información fue útil para determinar las diferencias en el monitoreo de la red vial que sirvieron para el análisis de la vulnerabilidad de los tramos viales (tercera parte).

Adicionalmente, la EMSAT tiene como función administrar y gestionar la semaforización y señalización. Desde 1996, la Municipalidad de Quito implementó un sistema centralizado de semaforización eléctrica única en el Ecuador. Este sistema se extendió progresivamente y contaba con 230 intersecciones a finales de 2001, es decir el 50 por ciento de los cruces semaforizados. Los demás semáforos, más antiguos, funcionan de manera independiente y están a cargo todavía, temporalmente, de la Dirección Nacional de Tránsito. Dos sistemas de semaforización coexisten en la ciudad de Quito e imposibilitan una gestión óptima de la circulación vehicular lo que evidencia también una cierta forma de vulnerabilidad (tercera parte).
Conociendo el sistema institucional de la vialidad y del transporte, se plantea a continuación cuáles son las características de la red vial en la aglomeración y cuáles los principios de funcionamiento del sistema de transporte.

\section{Las infraestructuras viales (red, obras y equipamientos)}

En esta sección se analiza en qué infraestructuras viales se funda la movilidad en el DMQ, sus principales características y cómo se estructura la red.

\section{Función y frecuentación de los ejes viales}

La red vial de la aglomeración de Quito se compone de un conjunto de vías, calles y callejones y cuenta con puentes y túneles. La red principal y las vías en la parte central de la ciudad son totalmente asfaltadas, pero en el sur de la ciudad, en los bamios periféricos urbanos y en los espacios suburbanos la red no cuenta siempre con una rodadura asfaltada.

Se diferencia de modo esquemático tres tipos de vías. Se consideró su función principal y frecuentación (desplazamientos de personas exclusivamente). Los tres tipos de vías son los siguientes: ejes estructurantes, vías principales y vías secundarias.

\section{Ejes estructurantes}

Se trata de las arterias que permiten las comunicaciones a escala del Distrito y los intercambios con el exterior. Se considera en esta categoría: a) los accesos al Distrito, b) los ejes centro-periferia, c) la vía de circunvalación de la aglomeración, d) las vías Intervalle, e) las vías de entrada central a la urbe, f) el anillo urbano. 
Cuatro accesos al Distrito: Panamericana sur, Panamericana norte, vía Interoceánica y carretera noroccidental

Los accesos al Distrito (mapa 2-2), como lo indica su nombre, permiten las conexiones con los demás cantones y provincias mediante la red nacional. Se usan estos itinerarios de gran dimensión, entre otros, para el transporte de personas de mediana y larga distancia. Cabe recordar que el eje más transitado es la Panamericana sur a nivel de Tambillo con 16.000 Vehículos Livianos Equivalentes (VLE) por día y por sentido $(\mathrm{MOP})^{35}$, lo que posiciona a este eje interprovincial como el más frecuentado del Ecuador (tabla 2-1). A la entrada sur de la ciudad, circulan por la Panamericana cerca de $9.400 \mathrm{VLE}$ cada día por sentido. La Panamericana norte, entre Guayllabamba y Calderón, es transitada cotidianamente por alrededor de 6.815 VLE por sentido. La importancia del transporte colectivo en los accesos al Distrito es muy variable. El transporte colectivo representa cerca del 47 por ciento de los vehículos transportando personas en la vía Interoceánica hacia la Amazonía ${ }^{36}$, el 27 por ciento a

Tabla 2-1

Volumen de tráfico por sentido en los accesos al Distrito (días hábiles)

Vehículo Liviano Equivalente, integra también los camiones

\begin{tabular}{|l|r|c|c|c|c|}
\hline Vías & \multicolumn{1}{|c|}{ VL } & Bus & VL + bus & $\%$ bus / VL & VLE* \\
\hline $\begin{array}{l}\text { Panamericana Sur } \\
\text { al sur de Tambillo }\end{array}$ & 7.080 & 1.630 & 8.710 & 18.7 & 15.676 \\
\hline $\begin{array}{l}\text { Panamericana Sur } \\
\text { a la salida de Quito }\end{array}$ & 3.590 & 1.350 & 4.940 & 27.3 & 9.363 \\
\hline $\begin{array}{l}\text { Panamericana Norte entre } \\
\text { Guayllabamba y Calderón }\end{array}$ & 3.490 & 680 & 4.170 & 16.3 & 6.815 \\
\hline $\begin{array}{l}\text { Interoceánica, } \\
\text { al este de de Pifo }\end{array}$ & 160 & 140 & 300 & 46.7 & 827 \\
\hline $\begin{array}{l}\text { Carretera Noroccidental } \\
\text { después de Calacalí }\end{array}$ & 650 & 20 & 670 & 3.0 & 792 \\
\hline
\end{tabular}

(Fuente: M OP - 2001) la entrada sur de la ciudad y el 3 por ciento en la caretera noroccidental.

\section{Los cuatro ejes centro-periferia}

Se trata de la prolongación de los accesos al Distrito (vía a Pomasqui, Panamericana norte desde Calderón, vía Interoceánica hacia Tumbaco) y de la autopista Rumiñahui hacia el Valle de Los Chillos (mapa 2-2). Estos ejes de gran tamaño llegan a las zonas suburbanas y son esencialmente el soporte de los movimientos pendulares. Estos cuatro ejes registran un tráfico superior a 15.000 VLE por día y por sentido (tabla 2-2). Desafortunadamente, no se pudo conseguir aforos vehiculares más detallados.

Tabla 2-2

Volumen de tráfico por sentido en los ejes centro-periferia (días hábiles).

Vehículo Liviano Equivalente, integra también los camiones

\begin{tabular}{|l|c|cccr|}
\hline Vías & VL & Bus & VL + bus & $\%$ bus / VL & VLE* \\
\hline $\begin{array}{l}\text { Vía a Pomasqui, } \\
\text { a la entrada de Quito }\end{array}$ & 10.280 & - & - & - & 15.000 \\
\hline $\begin{array}{l}\text { Panamericana Norte } \\
\text { a la entrada de Quito }\end{array}$ & - & - & - & - & 16.930 \\
\hline $\begin{array}{l}\text { Vía a Tumbaco, } \\
\text { a la entrada de Quito }\end{array}$ & 15.935 & 490 & 16.425 & 3.0 & \\
\hline $\begin{array}{l}\text { Autopista Rumiñahui, } \\
\text { a la entrada de Quito }\end{array}$ & 15.500 & - & - & - & 20.000 \\
\hline \hline
\end{tabular}

(Fuentes: EM OP-Q, HCPP, M OP, 2000 y 2001).

35. Los técnicos del Municipio de Quito consideran por ejemplo que un bus equivale a 1,83 vehículo liviano, un camión a 2,03 y un semiremolque a 2,5 vehículos livianos.

36. Este valor representa el porcentaje de buses en relación con los vehículos livianos. Permite comparar la importancia relativa del transporte colectivo respecto al transporte individual. 
Mapa 2-2

Estructura, tipología y frecuentación de la red vial de la aglomeración de Quito, 2001

Carretera Noroccidental hacia la Costa

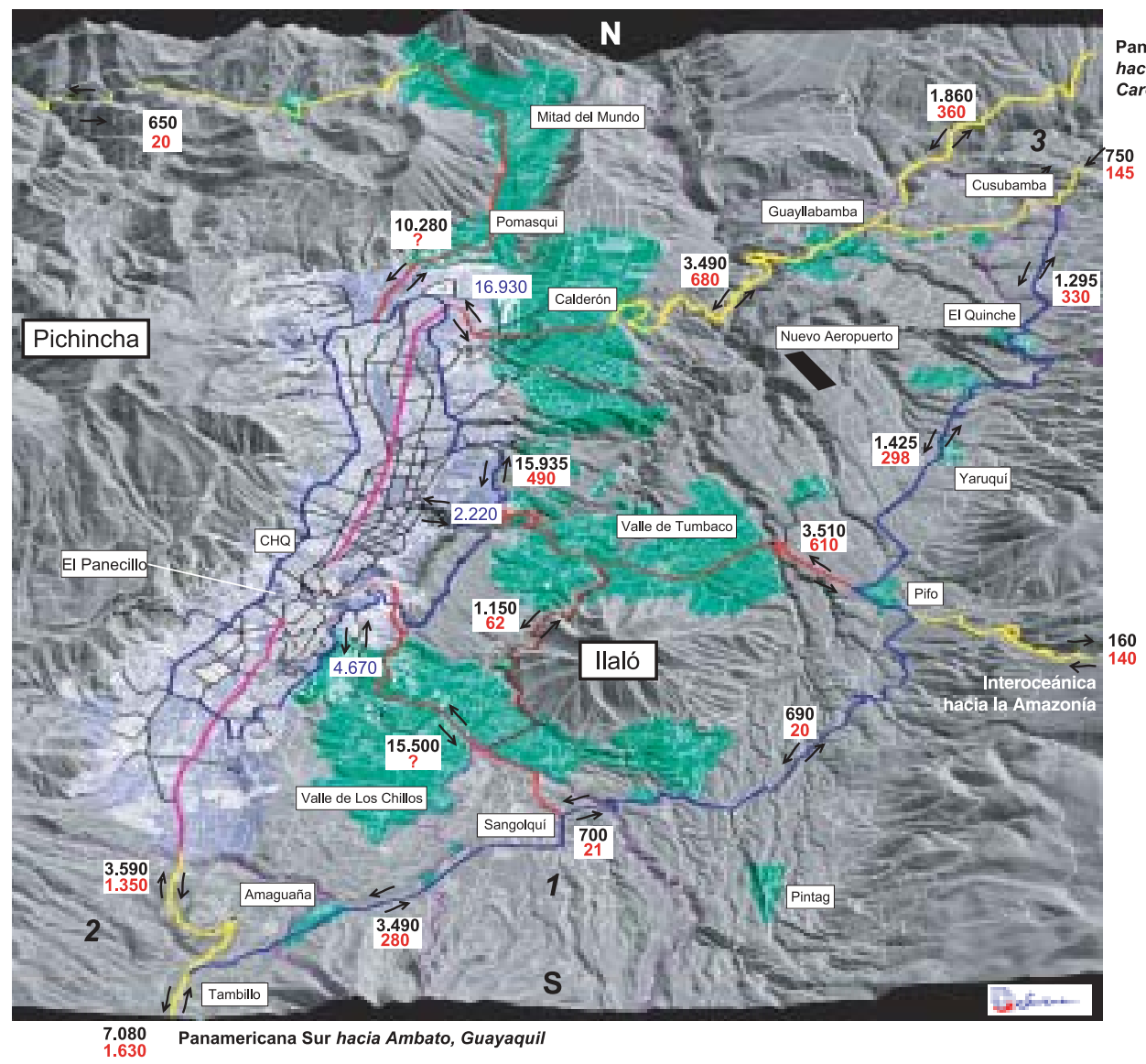

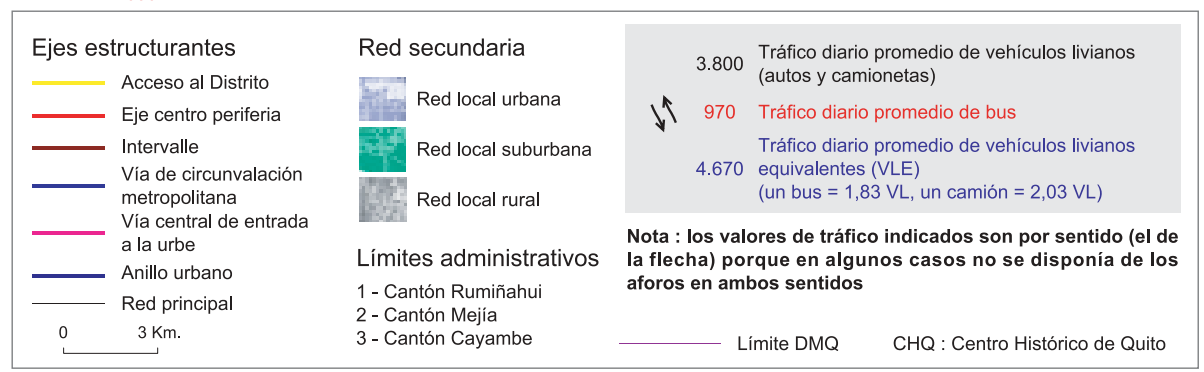


La vía de circunvalación al este de la aglomeración (perimetral metropolitana)

Se trata de una carretera que desvía el tráfico y que vincula directamente el norte con el este y el sur del país evitando así la ciudad de Quito (mapa 2-2). En detalle, esta vía sirve también para el transporte metropolitano (buses interparroquiales), en particular en el tramo El Quinche-Pifo conectado con Tumbaco. De Cusubamba a Pifo 1.450 autos y 300 buses circulan por sentido. Entre Pifo y Sangolquí, el aforo es mucho menor con 690 autos y 20 buses por día y por sentido. Entre Sangolquí y Amaguaña el tráfico es el más alto en esta vía de circunvalación con cerca de 3.500 autos y 280 buses por día y por sentido.

La vía Intervalle al este de la ciudad, al pie del cerro llaló

Se trata de una vía que vincula ambos valles (Tumbaco y Los Chillos). Cada día 1.150 autos y unos 60 buses por sentido transitan por este eje (mapa 2-2).

Las dos grandes vías de entrada central a la urbe

Estas arterias anchas (mapa 2-2) son la prolongación de los ejes suburbanos (Panamericana norte y sur). Permiten un acceso masivo a la ciudad y en especial al espacio central, sea desde el norte o el sur. En su sección central, soporta el corredor del trolebús. Al norte, la Avenida 10 de Agosto a la altura del Parque La Carolina registra alrededor de 32.000 VLE por sentido y por día. Al sur, la prolongación de la Avenida Maldonado a la altura de la planta de almacenamiento de combustible El Beaterio registra 17.000 VLE por sentido y por día.

\section{El anillo urbano}

Rodeando la ciudad, el anillo se conecta con las vías centrales de entrada a la urbe y con los ejes centro-periferia (mapa 2-2). En detalle, cada tramo asegura un papel sensiblemente diferente. La sección este, construida en la parte alta de las colinas que bordean la ciudad, es muy utilizada por el transporte interprovincial de personas con destino al sur. En este anillo se encuentran al oeste del centro histórico los túneles (mapa 2-3) atravesados diariamente por más de 35.000 VLE en cada sentido, mayor aforo vehicular registrado en el DMQ. El tramo noreste del anillo (Avenida Eloy Alfaro) es transitado por 22.000 VLE por día y por sentido. El tramo noroeste (sección norte de la Avenida Mariscal Sucre) registra cerca de 13.000 VLE (a la altura del barrio El Condado). En su parte suroeste, el anillo (sección sur de la Avenida Mariscal Sucre) es transitado por 14.500 VLE (a la altura de la Avenida Rodrigo de Chávez). En su parte central al este de la ciudad (entre la autopista Rumiñahui y la vía a Tumbaco), transitan cerca de 7.000 VLE por día y por sentido.

\section{Vías principales}

Salvo los ejes estructurantes (que conforman también la red principal pero con una función adicional) se diferencia un conjunto de vías cuyo papel es de igual manera importante pero a una escala diferente: la de la ciudad o de las parroquias suburbanas. Se considera como vía principal aquella asociada a los siguientes criterios:

- Se llaman "avenidas" y/o

- Cuentan con una rodadura asfaltada y/o

- Cuentan por lo menos con 2 x 2 vías y/o 
- Permiten el acceso principal a un barrio urbano, a una cabecera suburbana $\mathrm{y} / 0$

- Se sobreponen con un corredor de transporte colectivo.

La tabla 2-3 presenta los bulevares en los cuales se censa más de 20.000 VLE por día y por sentido (ver también el mapa 2-4). Los ejes con mayor tráfico se orientan esencialmente de norte a sur. La Avenida Patria es la única orientada de este a oeste que registra un aforo superior a 20.000 VLE por día y sentido. Ello resalta una dinámica circulatoria con una dominante longitudinal que no es sorprendente debido a la configuración alargada de la ciudad.

Tabla 2-3

Tráfico por sentido en las principales avenidas más transitadas en días hábiles

\begin{tabular}{|l|l|l|c|}
\hline Avenida Prinicipal & Orientación & Cerca de...(0 entre) & VLE diarios \\
\hline Mariscal J osé Sucre & Longitudinal & Túnel de San J uan & 35.364 \\
\hline 10 de Agosto & Longitudinal & J uan Sanz e Ignacio Santa M aría & 32.342 \\
\hline Patria & Latitudinal & Amazonas y J uan León M era & 27.584 \\
\hline Prensa & Longitudinal & La Y & 27.511 \\
\hline América & Longitudinal & San Gabriel y M ariana de J esús & 26.997 \\
\hline Eloy Alfaro & Longitudinal & Granados (Aprox. Sur) & 24.104 \\
\hline Amazonas & Longitudinal & Corea y J uan Sanz & 23.778 \\
\hline Shyris & Longitudinal & NN-UU Y Suecia & 23.269 \\
\hline
\end{tabular}

Fuentes: DM T, EM OP-Q, 2000 y 2001)

\section{Vías secundarias: urbana y suburbana}

Se trata del conjunto de vías cuya función es esencialmente el acceso local: calles, callejuelas al interior de los barrios. La velocidad es generalmente reducida y estas vías no cuentan siempre con asfalto.

\section{Las obras viales: últimas construcciones y su repartición en la ciudad}

Son un conjunto de infraestructuras destinadas a mejorar las condiciones de tráfico, reducir la congestión vehicular y salvar los obstáculos topográficos. Se trata de obras que cuentan con una sección aérea, es decir, provistas de un vano: puentes, viaductos, tramos viales aéreos de enlace. Para simplificar, se denomina "puentes" a todas estas obras. También se incluye entre las obras viales a los túneles.

De un total de 90 puentes ubicados en la aglomeración, 76 (84 por ciento) fueron construidos antes de 1990, 11 (12 por ciento) entre 1990 y 1996 y tres después de esta fecha, hasta finales de 2003. Un intercambiador cuya construcción se inició en diciembre de 2001 fue inaugurado en diciembre de 2003 en el sector de La Villa Flora. Otros ubicados en las intersecciones de las avenidas Mariana de Jesús y América y de las avenidas Naciones Unidas y América se inauguraron en el 2004². La repartición de estas obras evidencia un desequilibrio marcado a favor de la mitad norte de la ciudad de Quito que concentra 54 obras (60 por ciento del total). El espacio central reúne 41 infraestructuras (46 por ciento), las zonas suburbanas 34 (38 por ciento) y la mitad sur de Quito tiene solo dos obras viales. El espacio central es entonces mejor provisto para afrontar cada día la afluencia masiva de los vehículos (espacio a donde llega el 50 por ciento de los usuarios del transporte colectivo urbano e interparroquial). En los sectores periféricos suburbanos, las obras son en su mayoría puentes que permiten cruzar los ríos, cuyo lecho puede ser profundo (Río Chiche).

37. Estas infraestructuras no constan en este estudio ya que se realizaron luego de concluido el trabajo de campo. 







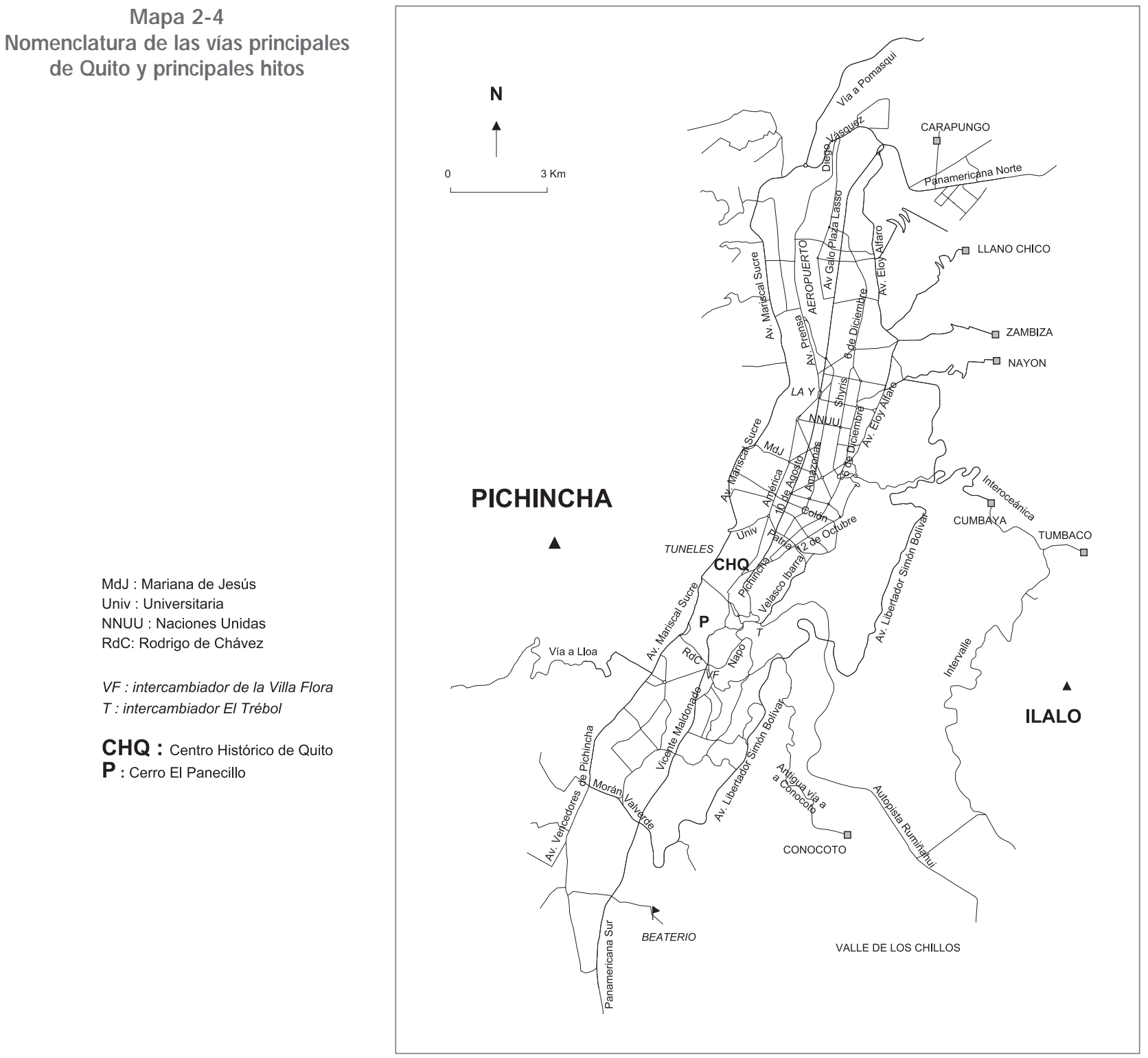

68 
Algunas intervenciones descritas a continuación hacen pensar que hoy la municipalidad parece haber superado la difícil época de la segunda mitad de los 90, en la que se había constatado un deterioro de la red vial, dada la falta de mantenimiento y el incremento de la presión circulatoria. En el 2002, el Municipio pudo beneficiarse, por ejemplo, de un crédito de 50 millones de dólares de la Corporación Andina de Fomento (CAF) para construir 17 nuevos intercambiadores (de los cuales varios ya fueron inaugurados como por ejemplo en La Y) destinados aparentemente a resolver la congestión vehicular cada vez más problemática en las horas pico. La ejecución de otros equipamientos está igualmente planificada. Dos túneles están en construcción para vincular Quito con el valle de Tumbaco por la vía Interoceánica, cerrada desde mayo 1998 luego de un deslizamiento de tierra. Estas obras son financiadas por el gobierno nacional (12 millones de dólares). De su lado, la EMOP-Q supervisa también un amplio programa de repavimentación de las calzadas y empezó la eliminación de los redondeles ${ }^{38}$ problemáticos reemplazándolos por intersecciones semaforizadas. El transporte colectivo y la vialidad fueron una de las prioridades de la administración municipal 2000-2004.

38. Avenidas Naciones Unidas y Shyris o Avenidas Eloy Alfaro y Granados.

39. Un tren sigue funcionando varias veces a la semana y transporta varios centenares de pasajeros en el mejor de los casos. Su vocación es esencialmente turística ya que permite acceder al Parque del Cotopaxi. En este sentido, no forma parte integrante del sistema de transporte cotidiano de la aglomeración.
Quito cuenta también con tres túneles situados en la parte alta del centro histórico al oeste en la Avenida Mariscal Sucre (mapa 2-3). Estos túneles inaugurados en 1978 y 1979 permiten conectar el espacio norte con el sur de la ciudad pero están, desde hace algunos años, saturados en especial en las horas pico.

Además de los ejes y obras viales, otros elementos materiales son imprescindibles para el funcionamiento de los sistemas de transporte colectivo e individual. Se trata de diferentes terminales de transporte colectivo, talleres de mantenimiento de los operadores de transporte, parqueaderos públicos, gasolineras.

\section{Otros equipamientos e instalaciones necesarios para la movilidad}

En Quito no se cuenta con transporte ferroviario ${ }^{39} \mathrm{ni}$ con transporte subterráneo (metro). Los medios de transporte funcionan gracias a un conjunto de instalaciones superficiales las cuales tampoco se reparten de manera equitativa. Se presenta a continuación las principales, que desempeñan un papel importante a diario y que pueden resultar esenciales en caso de emergencia (cuarta parte).

\section{Instalaciones específicas para el transporte colectivo}

Para el transporte colectivo interprovincial de personas existe una gran terminal terrestre (Cumandá) ubicada en el margen del centro histórico al sureste (mapa 2-5). De allí salen cada día más de cincuenta compañías de buses. Durante los feriados unas 30.000 personas convergen a la terminal para viajar.

Quito cuenta también con terminales de transporte colectivo intercantonal, interparroquial y urbano y unas estaciones de transferencias multimodales. Terminales 
y estaciones de transferencias se encuentran en casi todos los casos en el mismo lugar. El intercambiador El Trébol (mapa 2-5) era por ejemplo en el 2002, un nodo de conexión entre cuatro líneas de transporte interparroquial, seis líneas intercantonales y 43 líneas urbanas. Este nodo a partir del cual las conexiones son múltiples no cuenta con una construcción específica, los pasajeros esperan en la calle ${ }^{40}$. Una situación similar se vivía en La Marín, Plaza Argentina y Seminario Mayor pero fue superada en el 2004 con la construcción de infraestructuras especiales.

De su lado, los dos sistemas de transporte colectivo que circulan en carril exclusivo (el trole y la ecovía) cuentan con instalaciones propias, carril exclusivo y sus paradas específicas incluyen algunas grandes estaciones. Se trata de centros intermodales que conectan el trole con el bus o en el caso de la ecovía los buses articulados del tramo central con los buses integrados que atienden los barrios periféricos ${ }^{41}$.

\section{Principales equipamientos asociados}

a la circulación en general

Parqueaderos públicos con varios pisos: la disponibilidad en estacionamientos públicos en un lugar de destino condiciona profundamente el uso de transporte individual. De un total de siete parqueaderos que cuentan con varios niveles, cinco se encuentran en el centro histórico (mapa 2-5), con una capacidad total de 2.100 puestos $^{42}$. La existencia de estos parqueaderos se debe al hecho de que no hay posibilidades de estacionamiento en las callejuelas, menos aún con el hecho de que el Municipio ha favorecido los desplazamientos peatonales mediante el ensanchamiento de las veredas. En los demás sectores, en cambio, el estacionamiento a lo largo de las veredas es co- mún, no siempre legal y a menudo molestoso para el tránsito. Un proyecto de implementación de parquímetros está en estudio.

Estaciones de servicio: garantizan la distribución de combustibles para autos, camiones y también las unidades de transporte colectivo (excepto trolebús). El trole cuenta con su propio sistema de abastecimiento en diesel (para el motor auxiliar). En cambio, según las encuestas realizadas, ningún operador de transporte colectivo posee su propio reservorio de combustible. En caso de desabastecimiento temporal (como fue el caso en 1987 luego del terremoto) los buses podrían encontrarse en la imposibilidad de mantener su servicio. Ello evidencia una forma de vulnerabilidad del transporte en bus (tercera parte) en comparación con el trole que además funciona ante todo con energía eléctrica. Las gasolineras no se reparten de manera equitativa en la aglomeración. Se observa una densidad más alta al norte del cerro El Panecillo, zona de mayor consumo debido a su alta frecuentación. La mitad norte de la ciudad cuenta también con el parque automovilístico más elevado.

40. Una estación de transferencia cuya construcción está prevista en las inmediaciones de la actual parada de buses intercantonales, entre La Marín y El Trébol, permitirá resolver pronto el problema.

41. Desde diciembre del 2004 funciona también el "metrobús" sobre el corredor de las Avenidas La Prensa y América bajo el mismo principio.

42. Se trata de los siguientes parqueaderos: El Tejar ( 717 puestos), Montúfar (542), Cadisán (393), San Blas (373) y Museo de la Ciudad (44). 
Mapa 2-5

Infraestructuras viales $y$ equipamientos para el transporte, Aglomeración de Quito, 2001

Infraestructuras viales

Intercambiador

- Paso a tres niveles

$\checkmark$ Paso deprimido

- Paso aéreo de enlace

- Puentes

- Túneles

Equipamientos para el transporte

- Parqueadero público con varios pisos

P Principales gasolineras

Vías metropolitanas estructurantes y principales

Centros y terminales de transporte colectivo

Interprovincial (terminal terrestre de Cumandá)

- Trolebús

- Ecovía (Río Coca)

Interparroquial e intercantonal (El Trébol)

- Interparroquial

- Urbano y Ecovía (La Marín)

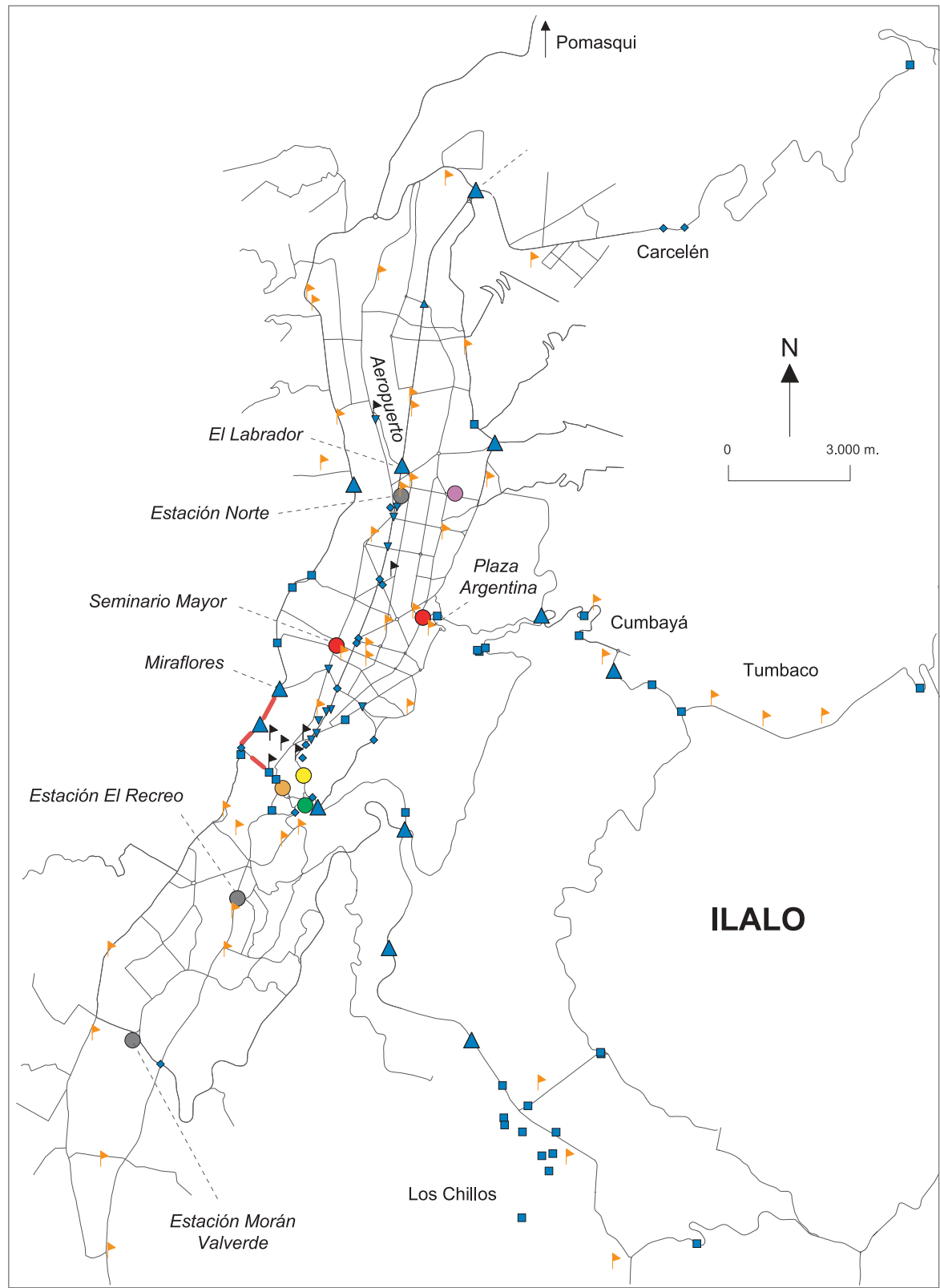




\section{El sistema de transporte: particularidades, funcionamiento, utilización y evolución}

Una vez estudiado el marco jurídico e institucional y las características de la red vial, es necesario analizar el sistema de oferta de transporte ya que posibilita los desplazamientos necesarios para el funcionamiento de la ciudad. Es importante entonces conocer los diferentes modos de transporte de las personas que viven en el DMQ, la demanda diaria, las principales diferencias de un modo a otro, la configuración de las diferentes redes de transporte colectivo, las principales evoluciones de la oferta y sus características actuales.

\section{Modos de transporte colectivo}

La oferta de transporte colectivo en el DMQ se asienta en la circulación de unos 4.350 vehículos (bus, minibus, unidades del trole) gestionados por diferentes tipos de operadores y que transportan cotidianamente cerca de 2 millones de personas ${ }^{43}$ como se indica la tabla 2-4.

La flota de buses del sector privado representa el 97,2 por ciento del total de las unidades en circulación (4.235 vehículos) y satisface al 84,3 por ciento de la demanda diaria en transporte colectivo (1'732.000 pasajeros transportados). De su lado, el trole con solamente el 1,7 por ciento del total de vehículos traslada al 11 por ciento de la demanda diaria en transporte colectivo. Ello se debe a que el trole tiene una capacidad de 180 pasajeros, mientras los buses convencionales solo tienen 50 asientos. Por el contrario, el transporte escolar e institucional (transporte exclusivo financiado por los establecimientos educativos y por las empresas u otros empleadores) con el 26 por ciento de la flota (1.124 vehículos) transporta solamente el
2,5 por ciento de la demanda diaria (48.200 pasajeros) debido al uso masivo de minibuses que no pueden llevar a más de 15 personas, en general.

\section{Un viaje en bus por día y por habitante}

Según las estimaciones de la Unidad Municipal de Estudios de Transporte, al principio de la década de los 90, los buses transportaban cerca de 1,3 millón de personas cada día mientras la población de la aglomeración era de 1'336.250 habitantes (INEC, 1990). En el 2001, la población era de 1'841.200 (INEC, 2001), lo que implica que el índice de movilidad en transporte colectivo se mantuvo sensiblemente igual a lo largo de la última década pasando de 1,03 viaje por habitante por día en 1990 a 1,07 en el 2001. En cambio, dado el espectacular crecimiento del parque automovilístico que casi se duplicó entre 1990 y 2001, pasando de


el índice de movilidad en transporte individual creció fuertemente en el mismo intervalo de tiempo. A pesar de todo, según los técnicos del Municipio, más del 80 por ciento de los desplazamientos motorizados se realizaban todavía en el 2002 en transporte colectivo, lo que resalta la innegable importancia que sigue asegurando este modo de locomoción en el funcionamiento cotidiano del DMQ.

Como se indica en la tabla 2-4, la movilidad se funda entonces en diferentes tipos de operadores. En este sentido, Quito se caracteriza al igual que muchas ciu-

43. Sin embargo, estos valores son subestimados porque no toman en cuenta el transporte intercantonal ni el informal en buses y camionetas no regularizadas por la EMSAT, esencialmente al final de los recorridos de las líneas convencionales en los barrios marginales o de difícil acceso.

44. Jefatura Provincial de Tránsito de Pichincha, 2001. 
Tabla 2-4

Características generales de la oferta de transporte colectivo y utilización de esta oferta en el DMQ en el 2001

\begin{tabular}{|c|c|c|c|c|c|c|c|}
\hline $\begin{array}{l}\text { Tipo de transporte } \\
\text { colectivo }\end{array}$ & $\begin{array}{l}\text { Número de } \\
\text { operadores }\end{array}$ & $\begin{array}{c}\text { Tipo de } \\
\text { operadores }\end{array}$ & $\begin{array}{l}\text { Número de } \\
\text { unidades en } \\
\text { circulación }\end{array}$ & $\begin{array}{l}\text { Porcentaje } \\
\text { de unidades } \\
\text { / total }\end{array}$ & $\begin{array}{c}\text { Número de pasajeros } \\
\text { transportados } \\
\text { por día }\end{array}$ & $\begin{array}{c}\text { Porcentaje de } \\
\text { pasajeros } \\
\text { transportados/total }\end{array}$ & $\begin{array}{l}\text { Número de } \\
\text { líneas }\end{array}$ \\
\hline Urbano & 55 & privados & 2.339 & 53.7 & 1'463.100 & 76.4 & 146 \\
\hline Interparroquial & 29 & privados & 675 & 15.5 & 158.000 & 8.2 & 52 \\
\hline Escolar, institucional & 47 & privados & 1.124 & 25.8 & 48.200 & 2.5 & - \\
\hline $\begin{array}{c}\text { "Urbano integrado } \\
\text { (líneas de alimentación)" }\end{array}$ & - & privados & 97 & 2.2 & 63.000 & 3.3 & 15 \\
\hline Trole & 1 & público (UOST) & 76 & 1.7 & 210.000 & 11.0 & 1 \\
\hline Ecovía & 1 & público (UOST) & 20 & 0.5 & 30.000 & 1.6 & 1 \\
\hline M unicipal & 1 & público (EM T) & 25 & 0.6 & 6.700 & 0.3 & 4 \\
\hline TOTAL & & & 4.356 & & $1^{\prime} 916.000$ & & \\
\hline
\end{tabular}

(Fuentes: DM T, EM SAT, UOST, EM T)

dades de América Latina por una atomización de la oferta de transporte colectivo en manos de operadores privados, en su gran mayonía.

\section{La oferta privada del transporte colectivo público}

El transporte colectivo público se define como un transporte realizado de manera colectiva y accesible a todos, es decir, no es exclusivo. En esta sección se analizan los actores privados que prestan un servicio de transporte colectivo público. A este sistema se le da el nombre de "sistema convencional privado de transporte colectivo" opuesto al "sistema integrado municipal" descrito posteriormente.

J. M. Cusset (1993) en una síntesis comparativa sobre los sistemas de transporte colectivo en los países del sur menciona: "si bien el concepto de servicio público no es desconocido en los países latinoamericanos, el papel del Estado y del sector público no es prepon- derante en la oferta del transporte colectivo. Históricamente, el servicio público fue concesionado a unos monopolios privados en los años veinte o treinta, época en la cual empresas de tranvías con fondos extranjeros operaban las redes en la mayonía de las capitales. Muy temprano prevaleció un servicio de transporte público multiconcesionado al sector privado...".

La evolución de la oferta de transporte colectivo en Quito no es distinta a la experimentada en Latinoamérica. De hecho, el abandono en 1948 del tranvía inaugurado en 1914 se dio debido a la competencia feroz con las cooperativas de buses recién conformadas. Éstas se adaptaron fácilmente a la expansión urbana cada vez más intensa y podían atender a los barrios periféricos lejos de la línea del tranvía. Es así como nació la organización del transporte en numerosas cooperativas pequeñas, rivales entre sí. Dadas las condiciones actuales (tamaño de la ciudad, magnitud de los flujos...) tal sistema de transporte ya no es adecuado. 
A pesar de los intentos municipales para incentivar su cambio, las cooperativas tardan en ser reemplazadas totalmente por un sistema empresarial eficiente.

\section{Cooperativas versus compañías}

Dos estatutos jurídicos diferencian los operadores de transporte en Quito. Algunos son constituidos en cooperativas, otros en compañías (empresas). Esta diferencia tiene una implicación directa en la calidad del servicio propuesto y explica la competencia muy violenta entre los múltiples operadores.

En las cooperativas de transporte los miembros no pueden tener más de un vehículo, deben ser choferes profesionales y manejar ellos mismos su vehículo. En la práctica, pocos dueños de bus conducen el suyo, entregan la conducción a choferes contratados.

De su lado, el funcionamiento de las compañías de transporte se parece más al de las empresas constituidas por accionarios. Las compañías poseen un capital y son dueñas de la flota de bus. En este sentido, los vehículos no pertenecen directamente a un socio, es la empresa que los adquiere directamente y contrata a choferes profesionales asalariados.

En el 2001, la mitad de los operadores de transporte urbano estaban organizados bajo la forma de cooperativas y gestionaban la mitad de la flota (MDMQ/DMT, 2002). La otra mitad era constituida en compañías. De su lado, las cooperativas interparroquiales seguían siendo mayoritarias en número y administraban el 73 por ciento de la flota.

La permanencia de las cooperativas tradicionales y la atomización de la oferta conllevan un conjunto de externalidades nefastas. Entre ellas, cabe destacar la competencia y las carreras violentas entre los choferes de una misma cooperativa, entre cooperativas o entre cooperativas y compañías. En efecto, en las cooperativas los choferes son pagados a destajo y entregan una cantidad fija de dinero al dueño del bus al final del día; mientras más pasajeros recogen los choferes de las cooperativas, mayores serán sus beneficios. El afán de ventaja económica lleva a la competencia entre choferes quienes son particularmente irresponsables por los cambios bruscos de carril y dirección que realizan. Además no se detienen completamente a recoger a los pasajeros, lo que implica una tremenda falta de seguridad, alto número de accidentes, problemas de contaminación atmosférica y ruido.

\section{Repartición desigual de las flotas entre operadores}

En el 2001, los operadores privados de transporte colectivo urbano e interparroquial eran 55 y 29, respectivamente. Se evidencia una repartición desigual del número de buses entre los operadores. En el caso del transporte urbano, el 20 por ciento de operadores tenía flotas inferiores a 20 unidades mientras que el 17 por ciento poseía flotas superiores a 70 unidades y concentraba el 36 por ciento de la flota total. Dos operadores (Paquisha y Catar) administraban 106 y 196 unidades, respectivamente.

El panorama era similar en cuanto al transporte interparroquial en el 2001. El 31 por ciento de los operadores tenía flotas inferiores a 12 unidades y sólo el 12 por ciento de los operadores poseía flotas superiores a 40 unidades y concentraba el 34 por ciento de la flota total.

La política de reagrupación y profesionalización de los operadores

A lo largo de los últimos nueve años, para remediar esta prestación de servicio deficiente y peligrosa, las 
instancias municipales a cargo del transporte incentivaron la conversión de las cooperativas en compañías y la reagrupación de los operadores en empresas dotadas con bases financieras sólidas, capaces de prestar un servicio en un amplio sector urbano. La Municipalidad lo logra poco a poco, no sin dificultad, a través de la concesión de la operación en algunos corredores. Por ejemplo, en el 2000, el Municipio inició un proceso innovador cuyo objetivo fue entregar la prestación de la operación de la ecovía a la empresa TRANASOC que reúne a todos los operadores que circulaban inicialmente en la Avenida 6 de Diciembre. En lo que se refiere al transporte interparroquial, la tendencia ha sido la misma. En el corredor periférico Quito-El Quinche, se observó en el año 2002 una reagrupación de cuatro cooperativas interparroquiales ${ }^{45}$ que conforman desde entonces la empresa SOTRANOR.

Esta evolución cualitativa y cuantitativa del sistema de oferta de transporte responde a una voluntad de mejorar el servicio bajo el impulso del sistema tutelar municipal; algunos indicadores hacen pensar que la situación está mejorando. Por ejemplo la proporción de compañías de transporte urbano se incrementó del 26 por ciento de los operadores en 1990 (H. Núñez, 1997) al 50 por ciento en el 2001. Por otro lado, gracias a distintas medidas como el bloqueo del crecimiento de la flota de buses y el retiro obligatorio de cerca de 550 unidades que habían cumplido más de 20 años de vida útil en 1996, la flota fue renovada; en el 2001 los vehículos tenían nueve años en promedio mientras tenían 18 años en 1991 (EMT, 1991). Ello confiere a Quito una situación intermedia a nivel de Latinoamérica ${ }^{46}$. Para el 2001 en Quito el 40 por ciento del parque automotor tenía menos de 5 años y el 11 por ciento más de 15 años.

\section{Servicios y tarifas}

Durante muchos años el CNT practicó una política muy particular que consistía en determinar a nivel nacional las tarifas de transporte colectivo urbano sin tomar en cuenta el tamaño de la ciudad y la extensión de las redes de transporte.

Hasta el 2003, dos servicios de bus coexistían: (1) el servicio "popular", el más barato (18 centavos de dólar) con buses vetustos (más de 10 años) y (2) el servicio "especial", el más caro (25 centavos) con buses más nuevos. La tarifas son ajustadas según el precio de los combustibles el cual no dejó de subir desde 1999, situación que originó varios levantamientos indígenas. Sin embargo, con la devaluación de la moneda nacional, el Sucre, reemplazado desde el 2001 por el dólar estadounidense, el costo del pasaje (calculado en dólares) bajó en una primera etapa. Luego, en el 2003 volvió a alcanzar el costo vigente en 1997 el cual era relativamente bajo a nivel latinoamericano.

\section{Escasez de paradas fijas}

De modo general, en el DMQ los buses no se detienen a tomar pasajeros en lugares fijos, sino en donde los peatones manifiestan el deseo de subir o bajar de tal forma que para llegar a su destino, la distancia que deban caminar sea mínima. Esta práctica, que es muy cómoda para el usuario, presenta múltiples inconvenientes: la seguridad de los usuarios no está garantizada, el manejo brusco provoca accidentes de tránsito, aumenta el consumo en combustibles, genera contaminación, molestias de ruido y conlleva bajas velocidades comerciales y consecuentemente los recorridos

45. Cooperativas Yaruquí, Tumbaco, Pifo y Puembo. 46. La situación más crítica parece ser en Lima 
toman mucho tiempo. Para remediar esto, la EMSAT implementó la ejecución de paradas de bus a lo lango de las avenidas principales (Amazonas, Shyris) que se extenderán progresivamente a toda la ciudad. Si bien la existencia de estos equipamientos es una condición necesaria para que los choferes y usuarios respeten las paradas de bus, no es en ningún caso una condición suficiente.

\section{Reciente renovación de la flota}

Hasta el 2002, por decreto del Consejo Nacional de Tránsito (CNT), todos los pasajeros estaban obligados a viajar sentados, excepto en los buses "populares". Desde 2002 la EMSAT adoptó la resolución de continuar aplicando esta medida en los buses "populares" y "especiales" construidos antes de 2001 con un chasis de camión, equipados con 40 a 50 asientos y que cuentan con un pasillo central estrecho. En cambio, esta medida ya no rige para los nuevos buses "ecológicos", llamados "buses tipo", especialmente diseñados para el transporte de personas con un chasis más bajo que ofrece a los usuarios un acceso más fácil y más puestos de pie. Desde el 2002, se reemplaza progresivamente los buses viejos "populares" y "especiales" por "buses tipo" uniformizados que pueden transportar a 90 personas y en los cuales la tarifa es también de 25 centavos de dólar.

La adopción progresiva de estos vehículos permite transportar un mayor número de personas utilizando un menor número de unidades lo que se traduce en beneficios para el sistema territorial metropolitano gracias a la reducción de la contaminación y congestión vehicular. De su lado, los operadores resultan favorecidos en la medida en que los costos de operación son menores (más pasajeros por unidad en circulación) y al ser uniformizados, los operadores reducen el costo de mantenimiento de sus vehículos. Esta evolución cualitativa del sistema de transporte bajo la iniciativa del Municipio, tiene tres objetivos: mejorar la calidad del servicio (confort, seguridad), limitar las emanaciones de gases tóxicos y dar mayor fluidez al tráfico (al disminuir poco a poco la flota de buses).

\section{Ordenamiento de la red de transporte colectivo}

La red de transporte colectivo oficial contaba en el 2001 con 146 líneas de buses urbanos, 52 líneas interparroquiales y una docena de líneas intercantonales; los operadores prestan servicio en varias rutas. La organización de la red urbana es esencialmente de norte a sur dada la configuración longitudinal de la ciudad (mapa 2-6).

A la red urbana, se superpone la red interparroquial que recubre parcialmente la primera en algunos corredores (Prensa, Galo Plaza Lasso, América, Patria, Gran Colombia, Eloy Alfaro) y la red intercantonal. Las líneas intercantonales procedentes de Los Chillos transitan por la autopista Rumiñahui y se detienen en el intercambiador de El Trébol. Aquellas que conectan Quito con Machachi llegan a la terminal terrestre Cumandá por la Avenida Maldonado. Aquella procedente de Cayambe entra a la ciudad por la Avenida Mariscal Sucre al norte hasta su terminal en el centronorte. En lo que se refiere a la red interparroquial no se conoce en detalle las rutas de bus, salvo en el corredor Quito-El Quinche ${ }^{47}$. Por eso solo se representó los ejes colectores hacia los cuales convergen los buses después de haber atendido a las localidades y barios alejados.

47. Cuyo trazado fue digitalizado por F. Bondoux y F. Demoraes (2002). 
La superposición de un gran número de líneas en manos de diferentes operadores permite entender de alguna manera la competencia entre choferes, previamente descrita. El hecho de que los servicios extra urbanos lleguen al interior de la ciudad contribuye a incrementar la sobrecarga de tráfico y la contaminación. Para resolver este problema, se prevé en el Plan Maestro de Transporte y Vialidad (MDMQ/DMT, 2002) implementar a corto plazo una serie de estaciones a las entradas de la ciudad para la transferencia de un sistema a otro. La red cambia frecuentemente y el diseño de las rutas que se presentan en este estudio es del año 2001.

\section{Distancia promedio de un viaje}

En promedio un usuario recorre en bus aproximadamente $10,6 \mathrm{~km}$. por viaje en la ciudad de Quito. Se evaluó a grosso modo esta distancia a partir de los desplazamientos realizados en bus únicamente urbano, sin considerar los viajes interparroquiales, escolares y en trole (por falta de datos). Se entiende como viaje un recorrido ida o regreso realizado por una persona por diferentes motivos, mediante uno o varios buses urbanos para trasladarse desde un punto A hasta un punto B. Este cálculo se funda en los datos recolectados en la encuesta origen-destino en 1998.

En el SIG Savane se calculó primero una distancia en línea recta (distancia euclidiana) entre los centroides de los sectores origen-destino registrados para cada viaje. Para simplificar se considera que el punto de partida de los viajes se ubica en el centroide de los sectores de referencia. Ello ocurre de vez en cuando pero a menudo no es el caso (los buses pasan a 200 ó 300 metros del centroide como máximo). Ello constituye un límite del método. Sin embargo, las zonas de referencia tienen una extensión limitada ${ }^{48}$ lo que no implica un error grande.

Un coeficiente multiplicador fue aplicado a esta primera distancia euclidiana para evaluar las distancias realmente recorridas por los buses. El coeficiente es de 1,7, es decir las distancias reales son superiores en un 70 por ciento a las distancias euclidianas dada la sinuosidad de los recorridos dentro de la ciudad. Se calculó este coeficiente comparando la longitud de 77 líneas urbanas con las distancias euclidianas entre los puntos de inicio y de llegada de cada una de estas líneas. Se debe considerar estos valores con precaución, por las simplificaciones y límites del método, sin embargo muestran que el uso de un modo de transporte motorizado es más que imprescindible en la ciudad de Quito para que los capitalinos puedan cumplir con sus labores y realizar sus obligaciones diarias.

$\mathrm{Si}$ bien los buses privados aseguran el 84 por ciento de la demanda diaria, la municipalidad tiene provisionalmente a cargo todavía el resto a través del sistema integrado de transporte colectivo.

\section{La oferta municipal de transporte colectivo público}

Este sistema experimentó varios cambios a lo largo de los últimos 15 años, dadas las modificaciones del contexto (en especial tarifario) que generaron crisis y al cual tuvo que adaptarse cambiando su organización para desembocar en la situación actual: un sistema integrado.

48. En promedio, el tamaño de los sectores es de 274 ha. 
Mapa 2-6 interparroquiales e intercantonales en la aglomeración de Quito, 2001

Número de líneas de bus

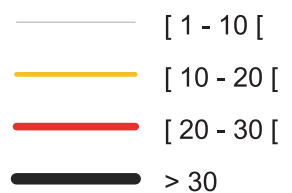

Tipo de transporte (valles)

a : interparroquial

b : intercantonal

Nota : la densidad contabiliza

la ida y el regreso de las líneas

Límites de la ciudad de Quito
Densidad de líneas de buses urbanos,

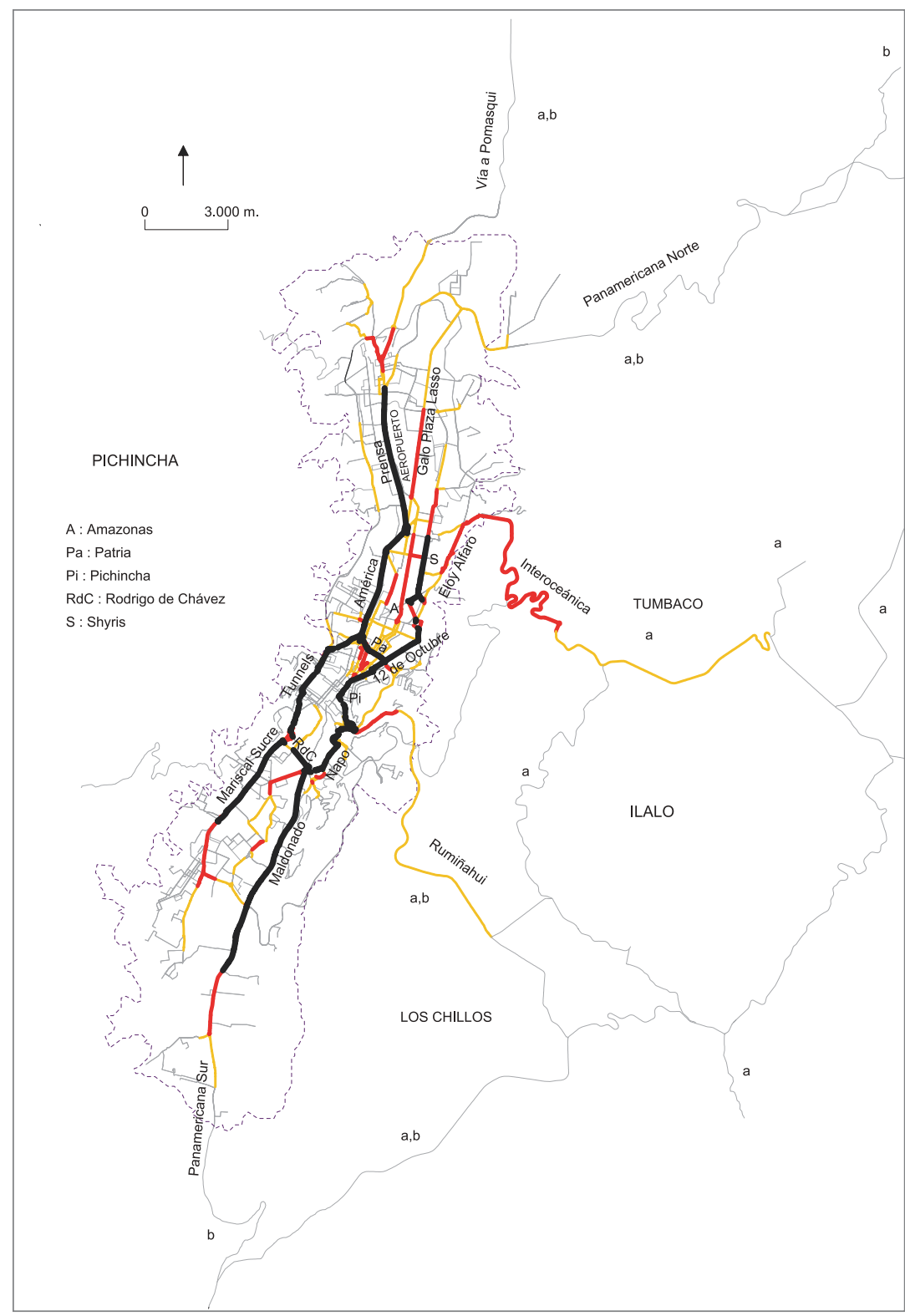

(Fuentes: EM SAT, DM T) 


\section{El Municipio de Quito como operador de transporte}

A partir de 1983, el Municipio de Quito asumió una parte de la operación del transporte colectivo urbano mediante la creación de la Empresa Municipal de Transporte (EMT). Su papel, hoy muy limitado, fue decisivo en varias ocasiones en el pasado y en particular en 1988. Por aquel entonces, el precio del pasaje definido por el Consejo Nacional de Tránsito (CNT) era de cinco centavos de dólar, tarifa muy baja que no incentivaba a los dueños de buses de las cooperativas privadas a mantenerse en esta actividad y menos aún sus vehículos (I. Thomson, 1992). Muchas cooperativas se retiraron para prestar un servicio extra urbano o transformar su bus en camión cisterna o de carga. La flota total que era de 2.110 unidades en 1985 bajó a 1.160 unidades a finales de 1988.

La reacción de las autoridades municipales fue el incremento considerable de la flota de la EMT, la cual adquirió buses británicos de dos pisos y se benefició de una donación de 100 buses articulados del gobierno de Japón. De esta manera, la EMT que sólo transportaba unos 400.000 pasajeros en el año 1988, pasó a un poco más de 20 millones de personas en 1990 con una flota de 128 buses. Este auge fue breve. En 1995 la EMT transportaba todavía 12 millones de pasajeros al año con 72 buses y en el 2002 transportaba, con 25 buses, únicamente 2,4 millones usuarios, es decir el 0,3\% de la demanda. Este ocaso se debe a varios factores. Rápidamente las unidades empezaron a padecer de deficiencias técnicas que no podían ser solucionadas de manera inmediata dados los procedimientos burocráticos que dificultaban la importación de repuestos. Por otro lado, debido a problemas de gestión interna, la EMT no pudo amortizar sus costos de operación ni mantener su flota ${ }^{49}$.
A pesar del incremento de la oferta municipal, la carencia en transporte siguió siendo severa a principios de la década de los 90, mientras seguía creciendo la demanda. En reacción, un sistema de subsidios gubernamentales a las cooperativas fue implementado para incentivar nuevamente la inversión privada. En febrero de 1993, 1.622 buses "populares" se beneficiaron de esta ayuda financiera (C. Arias, 1997). Se pudo lograr la paz civil y un nuevo crecimiento del parque resolviendo puntualmente parte del problema, no obstante, la organización y la calidad del transporte empeoraron.

\section{Reestructuración institucional:}

Municipalización del Transporte

En este contexto, la Municipalidad creó en 1990 la Unidad de Estudios de Transporte encargada de proponer un plan de racionalización del sistema que conllevaba una reestructuración institucional, una refundación de la red de transporte y sobre todo la implementación de un sistema de transporte colectivo público masivo.

Varias hipótesis fueron consideradas (metro, tren urbano, tranvía), pero muy pronto abandonadas dados los costos elevados de construcción ${ }^{50}$. Poco a poco, ma-

49. En una serie de entrevistas realizadas en abril 2001, el gerente de la EMT manifestó que se encontraba en una situación incómoda. La política actual del Municipio es retirarse de la operación. De otro lado, los funcionarios de la EMT se afiliaron a un poderoso sindicato que imposibilita cualquier tentativa de negociación de despido. En el 2001 la EMT contaba todavía con 260 personas de las cuales 80 eran choferes, mientras apenas unos 25 buses seguían circulando.

50. El metro cuesta cerca de 100 millones de dólares por kilómetro, el tren urbano 30 millones y el trole 5,5 millones. 
duró la idea de adoptar un sistema integrado superficial en carril exclusivo en su tramo central que atravesaría el centro histórico. Es así como nació el sistema trolebús inspirado del modelo de Curitiba, Brasil. En esta propuesta, el Municipio debía desempeñar un papel preponderante en la definición de la política del transporte, determinación de las tarifas y administración del sistema, marginando al Consejo Nacional de Tránsito. Este proyecto se concretó durante la administración municipal de Jamil Mahuad (1992-96) que se benefició del respaldo del gobierno nacional. Este último inició una reforma de Ley de Tránsito y Transporte Terrestre e integró las prerrogativas en cuanto a transporte en la Ley del Régimen del Distrito Metropolitano de Quito.

En 1995 se crearon la Unidad de Planificación y Gestión del Transporte ${ }^{51}$ (UPGT) y la Unidad Operadora del Sistema Trolebús (UOST), ente municipal responsable de la operación y administración del trole dependiente de la UPGT. Luego, en 1996 se conformó la Unidad Ejecutora del Proyecto Trolebús (UEPT), unidad municipal que dependía también de la UPGT, encargada de seguir con la implementación del proyecto trolebús, en especial para las extensiones norte y sur.

\section{El trolebús: revolución del transporte en Quito}

El diseño del sistema integrado del trolebús, inaugurado en diciembre de 1995, es un esquema particularmente innovador en el sistema territorial metropolitano ya que propone una integración tarifaria y de servicio. En otros términos, un usuario de este sistema puede realizar una transferencia sin pagar un pasaje adicional. En cambio, en el sistema privado convencional de transporte colectivo en bus, dada la atomización de la oferta entre múltiples operadores, un usuario debe pagar un pasaje cada vez que sube a una unidad. En el 2003 la tarifa del trole definida por el alcalde con el respaldo de la UOST, la DMT y la EMSAT equivalía a la tarifa vigente en los buses convencionales de categonía "especial", es decir 25 centavos de dólar. La determinación del precio del pasaje del trole es influenciada también por consideraciones políticas y sociales.

La integración del servicio en estaciones de transferencia también es algo nuevo. En el sistema convencional, las transferencias se realizan donde mejor conviene a los usuarios, es decir en cualquier lugar de la ciudad. De su lado, el sistema trolebús se basa en la integración de dos modos de transporte interconectados entre sí a la altura de las cuatro estaciones de transferencia (mapa 2-7): La Y, El Recreo, Morán Valverde, España (la última es de menor importancia). En el corredor central circulan los coches articulados del trole. Este eje es conectado con 15 líneas alimentadoras cuyo servicio es asegurado por un centenar de buses integrados que atienden a los barrios periféricos desfavorecidos, poco accesibles en buses convencionales sobretodo en el extremo sur de la ciudad.

La otra peculiaridad del trolebús se debe a la circulación en carril exclusivo en la mayor parte de su recorrido. Entre la estación norte y el centro histórico, su itinerario sigue la vía central de entrada a la urbe, la Avenida 10 de Agosto. A través del centro histórico el trole utiliza calles estrechas por lo que en algunos tramos, la calzada no es exclusiva para su recorrido. Las velocidades comerciales resultan, en este sector, menores. Al sur del centro histórico, circula en carril ex-

51. Resolución Municipal No. 051 del 23 de noviembre 1995. 
clusivo en la vía de entrada a la urbe, la Avenida Maldonado, hasta la estación El Recreo, y luego en la Avenida Hugo Ortiz hasta la estación Morán Valverde. En las horas pico el trole tiene una velocidad promedio de $20 \mathrm{~km} / \mathrm{h}$, mientras los buses convencionales atrapados en la congestión vehicular no exceden 12 $\mathrm{km} / \mathrm{h}$ en promedio, en la zona central. Desde el 2002 para optimizar la operación, la UOST implementó nuevos circuitos. Setenta y seis coches articulados circulan cada dos minutos y pueden transportar a unos 180 pasajeros lo que equivale a la capacidad de cuatro buses convencionales "popular" o "especial" o de dos nuevos buses "tipo". El trole opera todos los días desde las 6 h00 hasta la media noche. Su recomido se extiende de norte a sur en una distancia de 16,5 km. y cuenta con 51 paradas en ambos sentidos.

\section{El trolebús: 210.000 pasajeros diarios}

El trole, inicialmente previsto para transportar 115.000 pasajeros diarios, moviliza hoy a cerca de 210.000 personas, es decir el 11 por ciento de la demanda total en transporte colectivo, por lo que los usuarios viajan sumamente incómodos en las horas pico. Los buses alimentadores, de su lado, transportan 63.000 personas diariamente de las cuales el 90 por ciento realiza una transferencia hacia el trole. Una encuesta ascensosdescensos realizada por la UOST en el trole, en marzo de 2001, muestra que en promedio las paradas registran 8.430 entradas y salidas cotidianas, pero esta frecuentación es en realidad muy variable; algunas paradas cuentan con apenas 1.100 entradas y salidas por día $^{52}$, mientras otras registran hasta 80.000 movimientos cotidianos ${ }^{53}$ (mapa 2-7).

Las paradas de mayor afluencia son las tres principales estaciones de transferencia que registraban en el 2001 más de 29.000 movimientos diarios. Se trata de las siguientes: La Y, El Recreo, Morán Valverde a partir de las cuales las conexiones son múltiples en la red integrada. Sin embargo, se debe considerar estos valores con precaución. En algunos casos las paradas cuentan con una sola infraestructura que sirve para ambos sentidos de circulación del trole mientras que en la mayoría de los casos una parada cuenta con dos infraestructuras, una para cada sentido por lo que registran menor cantidad de usuarios. De modo general, los movimientos por parada son mucho mayores en la parte norte de la ciudad. Al sur, únicamente cuatro paradas cuentan con valores superiores a 8.000 movimientos (las dos estaciones de transferencia, y las paradas del Registro Civil y Villa Flora). Al norte, fuera de la estación "La Y", entre la parada Cumandá y la Avenida Colón se cuenta con diez paradas de igual manera muy frecuentadas por el carácter altamente atractivo de estos sectores asociada a la centralidad urbana.

Por otro lado, el sistema trolebús opera gracias a la energía eléctrica. Los capitalinos lo ven como un modo de transporte más limpio, en comparación con el sistema de transporte convencional en bus, cuyas emanaciones sumadas a las del parque automovilístico individual contribuían en 1998 a un 87 por ciento de la contaminación atmosférica de Quito ${ }^{54}$. Las unidades del trole están equipadas con motores auxiliares a diesel que les permiten funcionar desde el despacho hasta el corredor electrificado. Este motor es útil también en caso de cortes eléctricos. En el 2003 la operación del trole seguía asegurada parcialmente por la

52. Parada Machángara.

53. La estación norte La Y.

54. Según http://www.cepis.ops-oms.org/bvsci/E/fulltext/lencuent/ecupre2.pdf. 
UOST que sin embargo ya había exteriorizado la recaudación, la fiscalización de la operación y del mantenimiento de las unidades. En cuanto a los choferes, son asalariados de una empresa privada. De 1.000 personas aproximadamente que trabajan en la UOST, apenas el 5 por ciento eran empleados municipales con nombramiento. El sistema trolebús y la EMT son los únicos operadores de transporte colectivo público que poseen talleres de mantenimiento, reservorios de combustibles e instalaciones específicas para estacionar su flota. Esta organización empresarial no tiene nada que ver con el modo de funcionamiento de las cooperativas de transporte en bus, previamente descritas.

\section{La ecovía}

Considerando el éxito de la acogida del sistema trolebús por parte de los usuarios desde su inauguración en 1996, así como por la eficiencia del servicio ${ }^{55}$ no contaminante en el sitio, la municipalidad quiso seguir ampliando esta red integrada en otro corredor longitudinal, la Avenida 6 de Diciembre.

Este proyecto ya había sido diseñado en el plan municipal de racionalización de 1993 y fue confrontado con los resultados de la encuesta origen-destino de 1998 que mostraron que la demanda en este eje vial era alta ${ }^{56}$. Iniciada en la administración de Roque Sevi$\| \mathrm{a}$, alcalde de tendencia ecologista, se pretendía favorecer el transporte colectivo. La ejecución de obras y equipamientos (carril exclusivo, paradas, sistemas de semaforización y señalización) y la repavimentación completa de la calzada duró dos años y medio a pesar de que la longitud del corredor no excedía $8,6 \mathrm{~km}$. Varios factores influenciaron el retraso de las obras. En primer lugar, se menciona el contexto económico extremadamente desfavorable con la devaluación de la moneda nacional, el Sucre, luego de la quiebra de los bancos. Los años 1999 y 2000 fueron un período de cambio de administración municipal. La administración 2000-2004 tuvo que encargarse, mal que bien, de la continuación del proyecto. Dos años y medio de obras en uno de los principales bulevares que atraviesa el espacio central de norte a sur generaron disminuciones de velocidad, congestiones vehiculares y un alto número de accidentes de tránsito (208 accidentes en el 2000, un fallecido y 40 víctimas, según la DNT). Este eje vial fue en el 2000 uno de los más accidentados después de la Avenida Mariscal Sucre norte y sur (486 casos) y la Avenida Eloy Alfaro (239 casos). Los accidentes en la Avenida 6 de Diciembre se debieron a la ausencia de señalización que tardó en implementarse.

Si la construcción del soporte físico de la ecovía fue problemático, la implementación del sistema de transporte destinado a operar en este corredor también experimentó dificultades. La Municipalidad, queriendo favorecer la participación de los siete operadores que prestaban inicialmente el servicio en este corredor, estimuló la conformación de una gran empresa mediante la fusión de dichos operadores. En diciembre de 1999 fue creada la sociedad TRANASOC. Según los acuerdos entre el Municipio y TRANASOC, ésta debía adquirir 42 buses articulados "ecológicos" que debían

55. Con solamente el 1,7 por ciento de la flota de vehículos de transporte colectivo, el trole transporta el 11 por ciento de la demanda diaria en transporte colectivo.

56. A pesar de todo, la integración de otros corredores era seguramente más urgente, en especial de la Avenida La Prensa dada la amplitud de la demanda en este itinerario. La decisión dependía más de un reto político. 
Mapa 2-7

Configuración de las redes de transporte colectivo integrado y frecuentación del eje del trolebús

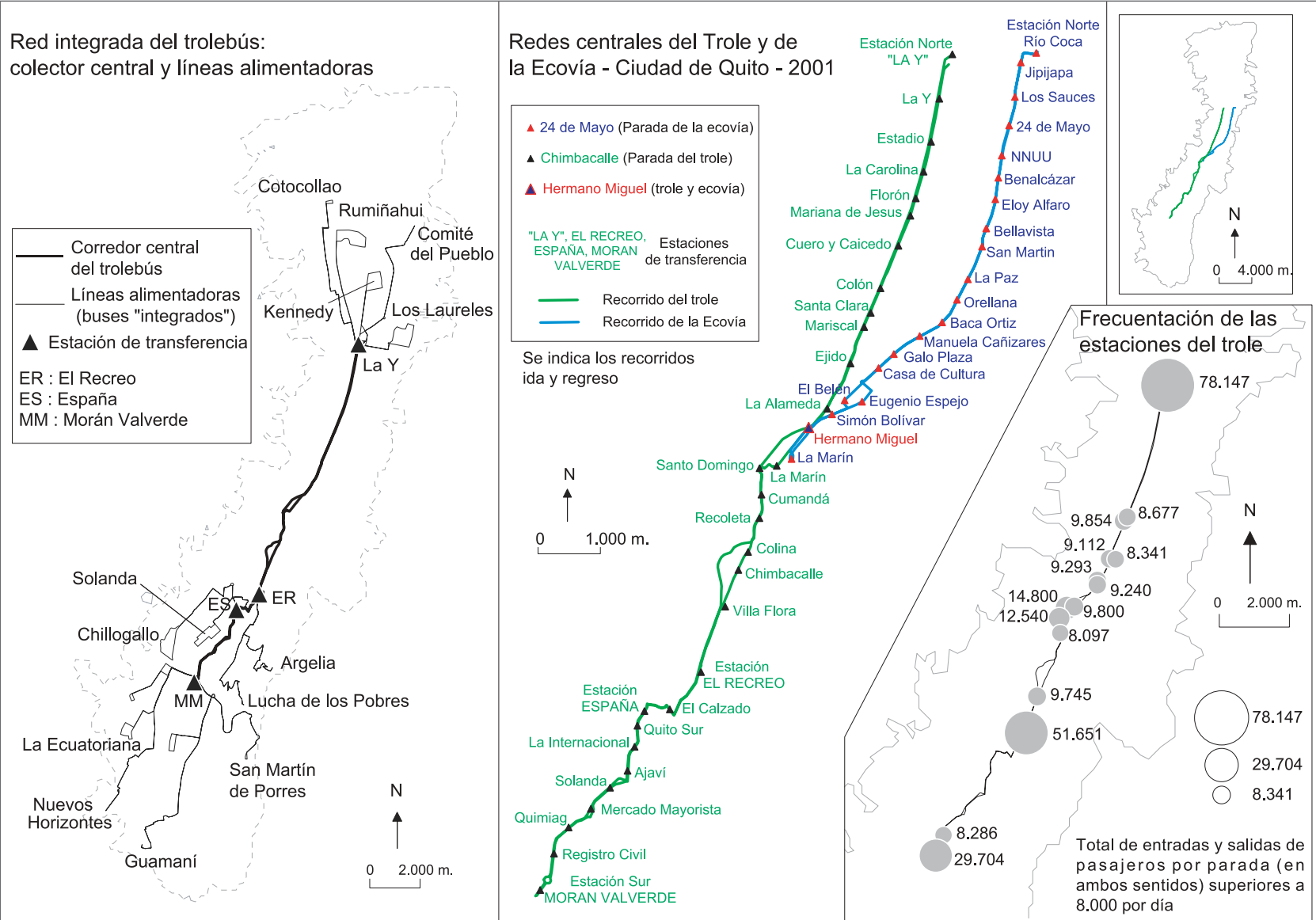


operar a partir del primer trimestre de 2001. Conformada con antiguos operadores tradicionales del transporte, TRANASOC (con limitada visión empresarial, carente de organización, con rivalidades internas y sin ninguna base financiera) no fue capaz de comprar los vehículos cuyo precio total era de seis millones de dólares. Frente a esta inercia y dadas las protestas cada vez mayores de la sociedad civil, que consideraba como inadmisible el que no se de uso a la mitad de una avenida principal, el Municipio decidió como medida emergente, comprar las 42 unidades en lugar de recumir a una licitación internacional. Debido a que la llegada de los vehículos iba a tomar varios meses, el Municipio empezó finalmente a operar, a partir de julio de 2001, de manera provisoria, con unidades del trolebús administradas directamente por la UOST, a pesar de no haber concluido la construcción de la terminal norte de la Río Coca y sur de La Marín.

En noviembre del 2001, cerca de 30.000 personas viajaban en la ecovía. Este corredor constituido por las avenidas 6 de Diciembre, Gran Colombia y Pichincha cuenta con 20 paradas de las cuales 17 sirven en ambos sentidos (mapa 2-7). La ecovía en su funcionamiento hasta 2003 era parcialmente conectada al sistema integrado del trolebús. En su esquema definitivo, se prevé una demanda diaria de 110.000 personas, también una integración tarifaria y de servicio con 21 líneas urbanas que llegarán a la terminal norte Río Coca. Estas líneas alimentadoras urbanas funcionarán con 136 buses de TRANASOC.

Por último, se preveía en esta terminal las transferencias con las líneas interparroquiales que prestan un servicio en el valle de Tumbaco-Cumbayá ${ }^{57}$. Con estas últimas, el debate de la integración tarifaria seguía abierto dada la dificultad de su implementación. En efecto, la integración tarifaria entre líneas urbanas y líneas extra urbanas implica la definición de una zonificación tarifaria que no se había definido todavía en el 2003.

A diferencia del trolebús, no se ha previsto un funcionamiento eléctrico para la ecovía, porque la inversión fue considerada demasiado alta (en especial en el contexto de la época). Desde finales de 2002, la nueva flota de 42 buses ecológicos articulados con capacidad de 180 personas reemplazó las unidades del trole. Los buses circulan a diesel a $17 \mathrm{~km} / \mathrm{h}$ en promedio y respetan normas técnicas y ambientales estrictas. La tarifa es la misma que la del trole, 25 centavos de dólar. Ahora le compete a la sociedad TRANASOC administrar la operación y la prestación del servicio, recaudar los pasajes y mantener los buses, las paradas y terminales. Según el contrato le corresponde también a TRANASOC reembolsar la deuda contraída por el Municipio para la adquisición de los buses. De su lado, el Municipio es el responsable del mantenimiento de la vía y la señalización. La EMSAT se encarga de fiscalizar el nivel de servicio y las condiciones de operación.

Continuando con la extensión del sistema integrado, un nuevo corredor longitudinal con carril exclusivo se inauguró en las avenidas América y La Prensa. En este corredor, los buses articulados prestan el servicio y los choferes detienen su vehículo en las paradas construidas con tal efecto. Ello permite mejorar las velocidades comerciales, disminuir la duración de los viajes en transporte colectivo y dar mayor fluidez al tráfico de automóviles que transitan por los carriles ubicados a cada lado de aquel usado por el trole.

57. La estación de transferencia ya está en funcionamiento. 
El sistema de transporte colectivo público privado y municipal asegura el 80 por ciento de la demanda diaria; los automóviles transportan el resto.

\section{Crecimiento del parque automovilístico en el Distrito Metropolitano de Quito}

Incremento del uso del automóvil

El parque automovilístico individual en Quito no dejó de crecer desde 1970 lo que origina los graves problemas actuales de congestión. En el DMQ el número total de vehículos (figura 2-1), se multiplicó por cinco en 26 años, pasando de 38.798 en 1975 a 196.936 en el 2001 (JPTP). En el mismo intervalo de tiempo, la población se triplicó (INEC). La tasa individual de motorización pasó de 6,5 vehículos por cada 100 habitantes en 1975 a 10,7 en el 2001. Desde 1995, el parque automovilístico registró una tasa de variación promedio de 3,1 por ciento por año. En el 2001, 23.000 vehículos adicionales se integraron a la circulación.

Concentración del parque automovilístico nacional en las calles de Quito

En el 2001 el 42 por ciento del parque automovilístico nacional ecuatoriano circulaba en el DMQ, mientras reunía apenas el 15 por ciento de la población nacional. Esta alta concentración de vehículos evidencia la magnitud del reto que afronta la Municipalidad para encontrar soluciones a la congestión vehicular. $\mathrm{Si}$ bien se explica generalmente el crecimiento del parque por el esquema clásico (esto es elevación del nivel de vida, voluntad de ascensión social), en el caso del DMQ el fuerte incremento del parque se debió sobre todo al hecho de que los ciudadanos, después de haber perdido toda confianza en el sistema bancario,
Figura 2-1

Evolución del parque automovilístico del Distrito Metropolitano de Quito, 1975-2000.

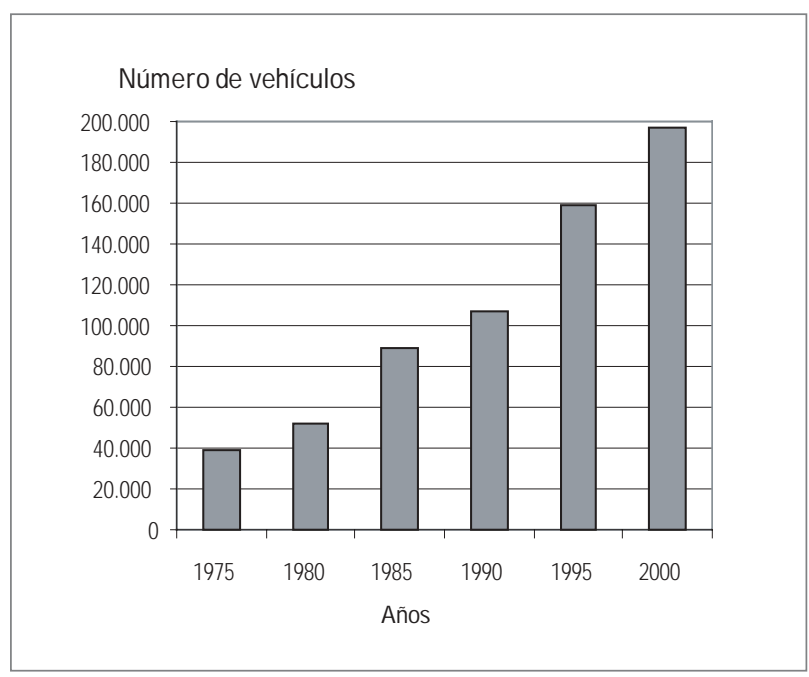

(Fuente: J PTP)

luego de la crisis de 1998, decidieron "invertir" masivamente en bienes materiales, compra de autos y construcción inmobiliaria. Este comportamiento no fue tan marcado en las demás provincias, lo cual permite pensar que la sociedad capitalina fue particularmente tocada por la crisis ya que el DMQ concentra la mayor cantidad de establecimientos bancarios a nivel nacional. Se sabe también que la riqueza de Quito, sin ser superior a la de Guayaquil, es repartida (en proporción) de manera menos desigual, lo que permite a un mayor número de gente, en especial a la clase media inicialmente conformada alrededor de la actividad petrolera, acceder a un medio de transporte individual. 
$\mathrm{Si}$ bien el uso de vehículos es desigual a nivel nacional, lo es también al interior de la aglomeración. De modo general, la sierra y la provincia del Guayas concentran el mayor número de vehículos (mapa 2-8). La provincia de Pichincha registra una tasa de motorización individual de 9,89 vehículos por cada 100 habitantes (tabla 2-5), valor más alto a nivel nacional, el promedio general es de 5,16. Al interior de la provincia de Pichincha, las diferencias entre los cantones son también muy marcadas. El cantón Rumiñahui es el que registra la mayor tasa, un auto cada cuatro habitantes. En segunda posición se encuentra el DMQ, con una tasa de 10,7.

Al interior del DMQ, el número de vehículos por hogar es extremadamente variable dada la heterogeneidad de las condiciones socio económicas de su población. Se calcula una fuerte correlación $(r=0,91)^{58}$ entre el número de hogares con un bajo consumo de

Tabla 2-5

Tasa de motorización por cantón, en el 2001, Provincia de Pichincha

\begin{tabular}{|l|c|c|c|}
\hline $\begin{array}{l}\text { Nombre de los cantones } \\
\text { (Provincia de Pichincha) }\end{array}$ & $\begin{array}{c}\text { Tasa de por } \\
\text { motorización } \\
\text { 100 habitantes }\end{array}$ & Población & $\begin{array}{c}\text { Vehículos } \\
\text { inmatriculados }\end{array}$ \\
\hline Quito & 10.7 & $1^{\prime} 839.853$ & 196.936 \\
\hline Cayambe & 5.15 & 95.394 & 4.911 \\
\hline Pedro M oncayo & 8.79 & 62.888 & 5.531 \\
\hline M ejía & 23.05 & 65.882 & 15.189 \\
\hline Rumiñahui & & & 13.789 \\
\hline Santo Domingo & 4.24 & 324.800 & \\
\hline San M iguel de los Bancos & & & \\
\hline Pedro Vicente Maldonado & Puerto Quito & & \\
\hline (Fuentes: INEC, J PTP) & & & \\
\hline
\end{tabular}

electricidad (inferior a $120 \mathrm{KW} / \mathrm{h}$ por mes) y el número de hogares sin vehículo propio. Parece lógico pensar que en los barrios desfavorecidos el número de autos sea menor. Se define esta correlación estadística utilizando los datos recolectados durante una encuesta realizada en octubre de 1998 por R. D’Ercole y P. Metzger en una muestra de nueve sectores (que suman 16 barrios) suficientemente representativos en el sentido en que corresponden a sectores ubicados tanto en el norte como en el sur de Quito, en los cuales viven moradores cuyo nivel socio económico es fuertemente contrastado ${ }^{59}$. En base a esta muestra se calcula extrapolando las tasas de motorización por hogar en todos los barrios de la aglomeración.

Este método tiene sus límites por el tamaño muy reducido de la muestra (16 barrios) en relación con el universo (668 barrios), es decir el 2,4 por ciento del total. La correlación es muy buena pero tampoco óptima. En efecto, no se puede determinar exactamente el número de vehículos simplemente considerando la riqueza de los hogares, la cual tampoco se evalúa solamente en base al consumo eléctrico.

Conscientes de estos límites, el mapa 2-8 muestra grandes disparidades dentro de la aglomeración. Resaltan tasas bajas en el sur de la ciudad y en el centro histórico, con rara vez más de un auto cada dos hogares, y más a menudo, con menos de un auto cada tres hogares. En el centro norte y norte de la ciudad, las

58. Se trata del coeficiente de correlación lineal de Bravais-Pearson. 59. Véase D'Ercole R., Metzger P., 2002. El objetivo de esta encuesta era conocer la opinión de la población en cuanto a la emergencia asociada a la reactivación del volcán Pichincha y la alerta amarilla del 1 de octubre de 1998. 
tasas son superiores a 60 vehículos cada 100 hogares y alcanzan más de 95 por ciento en algunos barrios (El Bosque, Quito Tennis, Bellavista). En los sectores suburbanos, las tasas son altas en las cabeceras de Cumbayá, Tumbaco y al norte del cantón Rumiñahui al pie del cerro Ilaló. Se nota también que, de modo general, los hogares en los valles poseen más autos que en el sur de Quito. Ello se debe al carácter residencial de los valles y a la menor densidad de la red de transporte colectivo, lo que incentiva a los habitantes adquirir un vehículo propio para acceder a las centralidades.
En esta primera parte se abordó las características generales de la movilidad de las personas en el Distrito Metropolitano de Quito y se explicitó los principios de funcionamiento del sistema de transporte en el que se fundan los desplazamientos. En base a este análisis se identifica a continuación los elementos esenciales del sistema de movilidad (flujos, red vial, transporte) cuyos disfuncionamientos trastocarían gravemente los desplazamientos cotidianos y/o causarían problemas de accesibilidad. 
Mapa 2-8

Tasa de motorización en el Ecuador, en la Provincia de Pichincha y en la aglomeración de Quito en el 2001

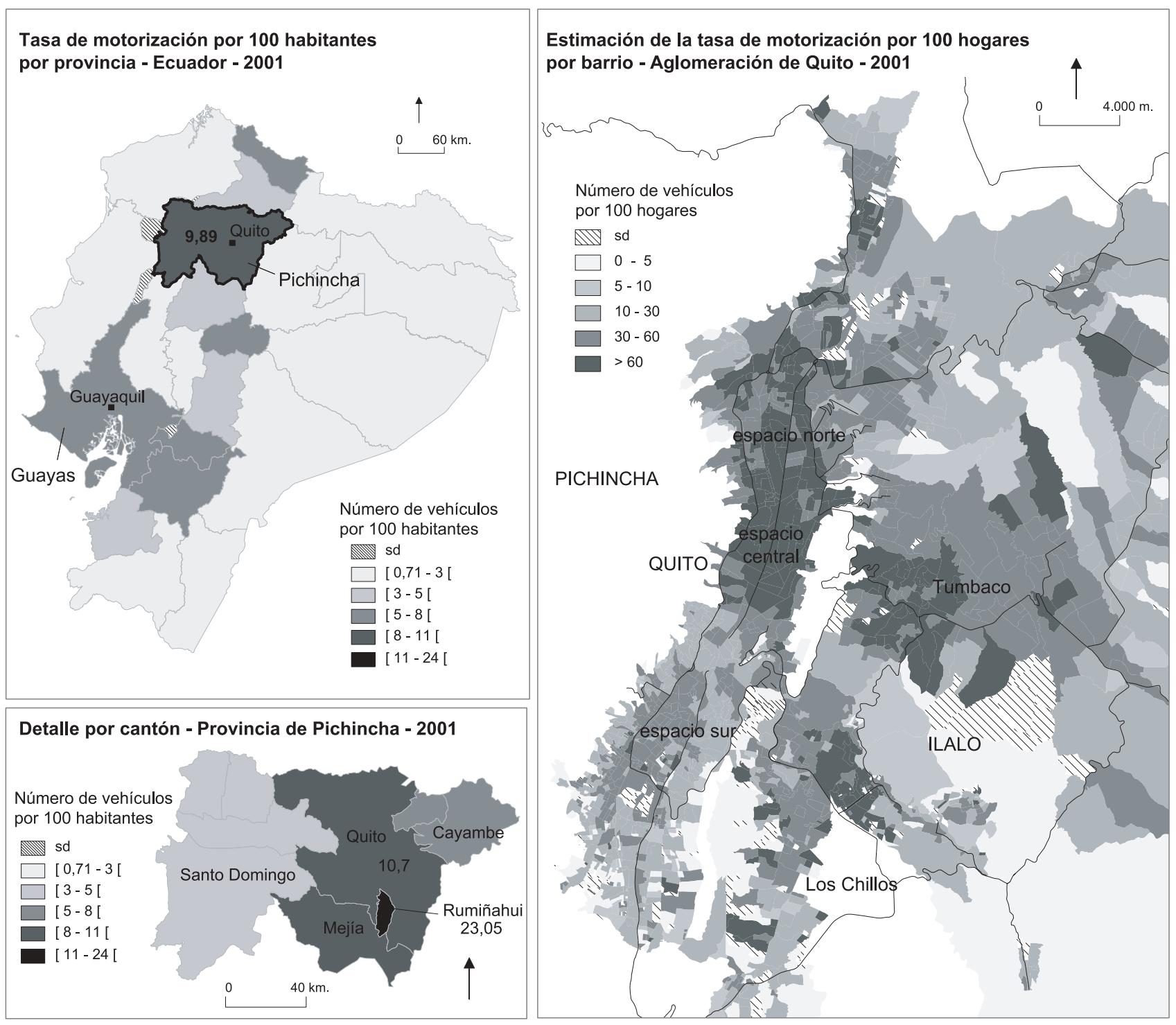

(Fuentes: DNT, J PTP, INEC, EEQ, DM TV, encuestas IRD). 


\section{ELEMENTOS ESENCIALES DEL FU NCIONAMIENTO DEL SISTEMA DE MOVILIDAD METROPOLITANA}

En esta segunda parte se define la noción de "elemento esencial" y se la aplica a un sistema de movilidad. En base a una metodología desarrollada en el marco del programa "Sistema de información y riesgos en el Distrito Metropolitano de Quito", se identifica y localiza los elementos esenciales del sistema de movilidad del territorio metropolitano. Esta metodología que se funda en la diferenciación y jerarquización de los elementos ante todo materiales, considera variables cuantitativas, cualitativas y también espaciales. 



\section{3 - El uso de la noción de "elemento esencial" en los análisis de riesgo urbano: un enfoque reciente}

Hasta hace poco satisfacía definir el riesgo a través de la relación entre las amenazas (fenómeno de origen natural capaz de afectar a los intereses humanos) y la vulnerabilidad (propensión a sufrir daños) de los elementos expuestos (personas, patrimonio, actividades, infraestructuras). Gracias a algunas investigaciones iniciadasa mediados de la década de los 9060, esta definición ha evolucionado y ya no considera únicamente la totalidad de elementos que presentan un interés humano expuestos a una amenaza, sino que se da relevancia a ciertos elementos a los cuales se debe dirigir toda atención. Para que las políticas de prevención sean eficaces y operativas se ha de focalizar los estudios en algunos espacios y elementos cuyo papel es esencial, por lo que deben ser tomados en cuenta de manera prioritaria. En efecto, su daño o pérdida constituiría un perjuicio grave para el funcionamiento y desarrollo del sistema estudiado y para el funcionamiento delos demás sistemas vinculados. El reto tiene envergadura ya que la propuesta conceptual subyacente a este enfoque posiciona la cuestión de los elementos esenciales (susceptibles de estar expu estos a amenazasy de ser vulnerables) "al centro de la definición y evaluación del riesgo ${ }^{61 " . ~}$

\section{Niza y Annecy: enfoque en los elementos esenciales en un contexto de amenaza sísmica}

La utilización de la noción de elemento esencial en los análisis de riesgo urbano fue inicialmente utilizada en trabajos llevados a cabo en las ciudades de Niza $^{62}$ y Annecy ${ }^{63}$. No obstante, se trata los elementos esenciales de modo distinto, en cada caso, debido a la información disponible (que influenció las variables consideradas para su identificación) y en función del objetivo a alcanzar. En Niza y Annecy se trató ante todo de discernir los elementos esenciales en una perspectiva de reducción del riesgo sísmico. Este enfoque condicionó directamente la escala de identificación de los elementos esenciales, la escala de la aglomeración en la medida en que los efectos de un sismo se sienten en una amplia zona que engloba toda la urbe.

60. Las primeras reflexiones metodológicas en este ámbito empezaron en 1996 en el marco de una colaboración entre la Oficina Francesa de Investigación Geológica y Minera (BRGM) y el Departamento de Geografía de la Universidad de Saboya (Francia) en la ciudad de Niza.

61. R. D'Ercole, P. Metzger, 2004.

62. Véase C. Lutoff , 2000.

63. R. D'Ercole, P. Pigeon, O. Bausart, V. Cambot, L. Gnemmi, J. Wattez, 2000. 
A continuación se presenta el interés de la noción de "elemento esencial" en el marco de una investigación de riesgo en medio urbano, la manera en la que se usó en Quito y su aplicación específica a la cuestión de la movilidad.

\section{El uso de la noción de elemento esencial en el programa "Sistema de información y nesgos en el Distrito Metropolitano de Quito"}

\section{Enfoque en los elementos esenciales, independientemente de las amenazas}

En el programa "Sistema de información y riesgos en el Distrito Metropolitano de Quito" se identifica los elementos esenciales sin considerar las amenazas. El énfasis se da a la ciudad y a los elementos esenciales de su funcionamiento antes de cualquier otra consideración. Esta orientación estuvo influenciada por el Municipio de Quito, organismo clave a cargo de la planificación y gestión urbana. En una perspectiva de optimización de la reducción de riesgo tomando en cuenta la capacidad financiera limitada del DMQ, la multiplicidad de las amenazas a las cuales está expuesto (amenazas cuya localización y extensión son difíciles de prever) y considerando que resulta sumamente difícil llevar a cabo análisis exhaustivos en ciudades grandes, pareció oportuno apuntar a los pilares del funcionamiento urbano, cuyo fallo o daño sería lo más perjudicial para el desenvolvimiento de las actividades en la aglomeración. Por tanto, son aquellos pilares los que se debe proteger, reforzar o resguardar a toda costa.

En el libro Los lugares esenciales del Distrito Metropolitano de Quito ${ }^{64}$ se presenta un balance del análi- sis de discernimiento de elementos esenciales llevado a cabo en el marco del programa de investigación. Se divide en tres secciones:

- Los elementos esenciales de los habitantes y sus necesidades

- Los elementos esenciales de la logística urbana

- Los elementos esenciales de la economía y gestión del Distrito

\section{Elementos esenciales: una noción relativa}

En la introducción del libro se reflexiona sobre la gradación creciente que existe entre lo que es importante, a diferentes escalas, sea a nivel de individuo, hogar, barrio y lo que es de mayor relevancia, es decir, lo que es esencial para la sociedad en su conjunto, para el funcionamiento de todo el sistema territorial metropolitano. "Obviamente, la noción de importancia es muy relativa. Todo lo que es importante para un individuo no necesariamente lo es para otro. El grado de importancia varía según dos grandes tipos de lógica: una lógica social y una lógica espacial o de proximidad. Por una parte, el contexto en el que viven las personas (su nivel de vida, sus ambiciones, sus prácticas sociales) influye en lo que se considera como importante. Así el transporte colectivo no es importante para quien no se desplaza sino en vehículo particular. Por otra parte, la lógica de localización o de cercanía hará que lo que importa en un lugar se revele de interés secundario en otra parte. Por ejemplo, la planta de agua que abastece a un barrio es de importancia

64. R. D'Ercole, P. Metzger P, 2002. 
mayor para los habitantes de ese barrio pero de interés secundario para quienes residen en sectores geográficos atendidos por otra planta. La escala en la que se ubica también es fundamental para determinar lo que es importante. Situarse a la escala de una aglomeración permite identificar elementos de interés común, que son importantes para todos, como el abastecimiento alimentario, el empleo o los ejes de circulación, o el acceso a un hospital o universidad. Semejante procedimiento aplicado a un barrio no dará el mismo resultado. Una asociación, una pequeña escuela, una cancha, un parque o un mercado, de poca importancia a nivel de la aglomeración, puede revelarse fundamental para la vida de ese barrio".
A continuación se presenta la aplicación específica de la noción de elemento esencial a la cuestión de la movilidad. 


\section{4 - Los elementos esenciales de la movilidad a escala del Distrito}

Algunos intercambios (movimientos pendulares, desplazamientos hacia las centralidades, comunicaciones con los demáscentros urbanosimportantes) son de primera importancia para el desenvolvimiento normal de las actividades urbanas y las prácticas sociales de los ciudadanos. Estosintercambiosimprescindibles se fundan en determinadas obras e instalaciones (un puente entre dos sectores urbanos, una vía de acceso a una centralidad, una gran estación de transferencia en una red integrada de transporte...). En estecapítulo se describe la metodología y los criterios utilizados para discernir los elementos esenciales en los diferentes sectores geográficos de la aglomeración (límites exteriores del Distrito, zonas suburbanas, sectores urbanos, espacio central) y se presentan los resultados.

\section{Los ejes viales esenciales: método de identificación y cartografía}

En esta párrafo se utiliza el análisis anterior relativo a las comunicaciones a nivel de los cuatro conjuntos geográficos: los intercambios con el exterior del Distrito, los desplazamientos entre la ciudad y el resto de la aglomeración, dentro de la ciudad y a nivel del es- pacio central (véase primera parte). El objetivo es guardar sólo los desplazamientos muy importantes y los intercambios esenciales para el funcionamiento del Distrito y extraer las vías asociadas. Se diferencia y jerarquiza en primer lugar los ejes en el siguiente orden:



En segundo lugar, se reagrupará los ejes muy importantes y de primera importancia bajo la denominación "ejes esenciales". Para implementar este trabajo se utilizó el paquete informático SIG Savane. El método, las variables consideradas y la definición de umbrales no son los mismos en función del número de elementos a jerarquizar en los diferentes conjuntos geográficos de la aglomeración.

\section{Los accesos al Distrito}

Se examinó las cuatro vías de acceso al Distrito en base a las tres variables siguientes (Véase tabla 4-1):

1. La importancia del tráfico vehicular.

2. La importancia del transporte colectivo interprovincial.

3. La importancia de las relaciones que mantiene el Distrito con las demás provincias. 
Tabla 4-1

Variables consideradas para la jerarquización de las vías de acceso al Distrito

\begin{tabular}{|c|c|c|c|c|c|c|c|c|c|c|}
\hline \multirow[b]{3}{*}{$\begin{array}{l}\text { Vía de acceso } \\
\text { al Distrito }\end{array}$} & \multicolumn{3}{|c|}{1} & \multicolumn{4}{|c|}{2} & \multicolumn{3}{|l|}{3} \\
\hline & \multicolumn{3}{|c|}{ Importancia del tráfico } & \multicolumn{4}{|c|}{$\begin{array}{l}\text { Importancia del transporte } \\
\text { colectivo interprovincial }\end{array}$} & \multicolumn{3}{|c|}{ Lazos con las demás provincias } \\
\hline & $\begin{array}{l}\text { Aforo } \\
\text { vehicular } \\
\text { diario a la } \\
\text { entrada del } \\
\text { Distrito }\end{array}$ & Comentario & $\begin{array}{l}\frac{8}{0} \\
\frac{0}{8} \\
8\end{array}$ & $\begin{array}{l}\text { Número } \\
\text { de buses } \\
\text { por día } \\
\text { (ambos } \\
\text { sentidos) }\end{array}$ & $\begin{array}{l}\text { Número de } \\
\text { compañías } \\
\text { de bus } \\
\text { interprovin- } \\
\text { ciales }\end{array}$ & 용 & $\begin{array}{l}\frac{5}{0} \\
\frac{0}{8} \\
8\end{array}$ & $\begin{array}{l}\text { Estimación de los lazos } \\
\text { con las demás provincias }\end{array}$ & $\begin{array}{l}\text { Importancia } \\
\text { de las } \\
\text { conexiones }\end{array}$ & $\begin{array}{l}\frac{5}{0} \\
\frac{0}{8} \\
8\end{array}$ \\
\hline $\begin{array}{l}\text { Carretera } \\
\text { Noroccidental }\end{array}$ & 2.053 & $\begin{array}{l}(\mathrm{VL}+\text { buses }+ \\
\text { camiones, en ambos } \\
\text { sentidos) Fuente: } \\
\text { HCCP } 2001\end{array}$ & 3 & 40 & 3 & $\begin{array}{l}\text { Fuente: } \\
\text { Terminal } \\
\text { Terrestre } \\
\text { Cumandá }\end{array}$ & 4 & $\begin{array}{l}\text { Los lazos con la Costa son intensos pero este } \\
\text { itinerario no es muy transitado por los buses } \\
\text { interprovinciales porque pocos pueblos y talleres } \\
\text { mecánicos se encuentran a lo largo de esta vía. }\end{array}$ & moderada & 3 \\
\hline $\begin{array}{l}\text { Panamericana } \\
\text { Norte }\end{array}$ & 10.387 & $\begin{array}{l}(\mathrm{VL}+\text { buses }+ \\
\text { camiones, en ambos } \\
\text { sentidos) Fuente : } \\
\text { HCCP } 2001\end{array}$ & 2 & 1.360 & 13 & $\begin{array}{l}\text { Fuente : } \\
\text { Terminal } \\
\text { Terrestre } \\
\text { Cumandá }\end{array}$ & 2 & $\begin{array}{c}\text { Presencia de ciudades intermedias dinámicas como } \\
\text { Otavalo, Cayambe, Ibarra, Tulcán en un amplio } \\
\text { corredor de comunicación hacia Colombia. El 13,2\% } \\
\text { de los migrantes instalados en Quito en los últimos } \\
5 \text { años proceden de estas provincias. }\end{array}$ & fuerte & 2 \\
\hline Interoceánica & 1.054 & $\begin{array}{l}\text { (VL + buses }+ \\
\text { camiones, en ambos } \\
\text { sentidos) Fuente: } \\
\text { M OP } 2001\end{array}$ & 4 & 280 & 7 & $\begin{array}{l}\text { Fuente : } \\
\text { Terminal } \\
\text { Terrestre } \\
\text { Cumandá }\end{array}$ & 3 & $\begin{array}{l}\text { La cuenca amazónica es poco poblada y no cuenta } \\
\text { con ningún centro urbano grande. M enos del } 6 \% \text { de } \\
\text { los migrantes instalados en Quito en los últimos } 5 \\
\text { años proceden de estas provincias orientales. }\end{array}$ & baja & 4 \\
\hline $\begin{array}{l}\text { Panamericana } \\
\text { Sur }\end{array}$ & 22.949 & $\begin{array}{l}\text { (VL + buses }+ \\
\text { camiones, en ambos } \\
\text { sentidos) Fuente: } \\
\text { M OP } 2001\end{array}$ & 1 & 3.270 & 52 & $\begin{array}{l}\text { Fuente : } \\
\text { Terminal } \\
\text { Terrestre } \\
\text { Cumandá }\end{array}$ & 1 & $\begin{array}{l}\text { Los dos tercios de los principales centros urbanos } \\
\text { se encuentran en el sur del Distrito entre los cuales } \\
\text { está la aglomeración porturaria de Guayaquil. La } \\
\text { Panamericana Sur sirve para acceder a la Sierra } \\
\text { central, a la Sierra sur y también a toda la Costa. }\end{array}$ & $\begin{array}{l}\text { muy } \\
\text { fuerte }\end{array}$ & 1 \\
\hline
\end{tabular}

\section{BALANCE}

\begin{tabular}{|l|c|c|c|}
\hline Vía de acceso al Distrito & $\begin{array}{c}\text { Suma de las } \\
\text { posiciones }\end{array}$ & Jerarquización & $\begin{array}{c}\text { Esencial para las comunicaciones } \\
\text { de personas con el exterior del Distrito }\end{array}$ \\
\hline Carretera Noroccidental & 10 & bastante importante & no \\
\hline Panamericana Norte & 6 & muy importante & si \\
\hline Interoceánica & 11 & bastante importante & si \\
\hline Panamericana Sur & 3 & de primera importancia & \\
\hline
\end{tabular}


Se clasificó los cuatro accesos dándoles una posición (de 1 a 4), considerando las tres variables. Por ejemplo, en el caso de la primera variable, la Panamericana sur soporta un tráfico de 23.000 vehículos por día en ambos sentidos (mayor aforo vehicular interprovincial de todo el país). Se le atribuye entonces el valor 1 (primera posición). La vía Interoceánica, la menos transitada, se encuentra entonces en cuarta posición. Según la misma lógica, se clasificó la importancia del transporte colectivo interprovincial. Por último, se estimó la magnitud de los lazos que mantiene el Distrito con las demás provincias. Para ello, se consideró la situación de Quito en la red urbana ecuatoriana y las características migratorias de la población que se instaló en Quito en los últimos años. Los dos tercios de los principales centros urbanos se encuentran al sur del Distrito entre los cuales está la aglomeración portuaria de Guayaquil.

Luego se sumó las posiciones. La Panamericana sur logra el mínimo valor (3). Ello confirma el carácter primordial que tiene este eje en las relaciones que el Distrito mantiene con el resto del país. Se lo considera en la categoría "eje de primera importancia". La vía Interoceánica con un total de 11 es, al contrario, la menos importante respecto a las comunicaciones con las demás provincias. Se la posiciona en la categonía "eje bastante importante" al igual que la carretera Noroccidental (10). Se considera la Panamericana norte como "eje muy importante" porque su papel, a pesar de ser inferior al de la Panamericana sur, es sin lugar a duda superior a los otros dos accesos (vía Interoceánica y carretera Noroccidental).

\section{Los ejes centro periferia}

Se examinó los cuatro ejes viales que soportan los desplazamientos pendulares en base a las seis variables siguientes (Véase tabla 4-2):

1. La importancia del tráfico vehicular.

2. La importancia del transporte colectivo interparoquial.

3. El peso demográfico de los espacios peri urbanos (estimación de la demanda).

4. Las posibilidades de seguir hacia el exterior del DMQ y la intensidad de estos desplazamientos (eje de tránsito o simple eje para llegar a un espacio).

5. La dependencia de los espacios suburbanos respecto a la ciudad de Quito.

6. La existencia de alternativas viales para conectar los espacios suburbanos con la ciudad (en el caso de que exista un solo eje, éste es particularmente vital).

Se clasificó los cuatros ejes dándoles una posición (de 1 a 4) considerando las seis variables. Por ejemplo, en el caso de la primera variable, se registra el mayor tráfico vehicular entre el valle de Los Chillos y la ciudad de Quito (38.000 vehículos de todo tipo por día en ambos sentidos). Se atribuye entonces a la autopista Rumiñahui el valor 1 (primera posición) delante de la vía que comunica Quito con Cumbayá-Tumbaco.

Se sumó las posiciones. El eje hacia Carapungo-Carcelén totaliza el mínimo valor (12). Se lo considera en la categonía "eje de primera importancia". Por otro lado, se posiciona en la categoría "eje muy importante" 
Tabla 4-2

Variables consideradas para la jerarquización de los ejes centro-periferia

\begin{tabular}{|c|c|c|c|c|c|c|c|c|c|c|c|c|c|c|c|c|c|c|c|}
\hline & \multicolumn{3}{|c|}{1} & \multicolumn{3}{|c|}{2} & \multicolumn{2}{|l|}{3} & \multicolumn{5}{|c|}{4} & \multicolumn{3}{|l|}{5} & \multicolumn{3}{|c|}{6} \\
\hline & \multicolumn{3}{|c|}{$\begin{array}{l}\text { Importancia } \\
\text { del tráfico }\end{array}$} & \multicolumn{3}{|c|}{$\begin{array}{l}\text { Importancia del } \\
\text { transporte colectivo } \\
\text { interparroquial }\end{array}$} & \multicolumn{2}{|c|}{$\begin{array}{c}\text { Peso } \\
\text { demográfico }\end{array}$} & \multicolumn{5}{|c|}{$\begin{array}{l}\text { Posibilidades de seguir hacia } \\
\text { el exterior del DM Q e intensidad } \\
\text { de los desplazamientos }\end{array}$} & \multicolumn{3}{|c|}{$\begin{array}{l}\text { Intensidad de la dependencia de los } \\
\text { espacios suburbanos } \\
\text { respecto a la ciudad }\end{array}$} & \multicolumn{3}{|c|}{$\begin{array}{l}\text { Existencia de alternativas } \\
\text { viales para conectar los } \\
\text { espacios suburbanos con la ciudad }\end{array}$} \\
\hline $\begin{array}{c}\text { Ejes viales } \\
\text { que soportan } \\
\text { los } \\
\text { movimientos } \\
\text { pendulares }\end{array}$ & $\begin{array}{c}\text { Volumen de } \\
\text { tráfico } \\
\text { cotidiano a } \\
\text { la entrada } \\
\text { de la } \\
\text { ciudad }\end{array}$ &  & $\frac{8}{8}$ & $\begin{array}{l}\text { Desplaza- } \\
\text { mientos de } \\
\text { personas } \\
\text { en TC } \\
\text { metropo- } \\
\text { litano }\end{array}$ & है & $\frac{8}{8}$ & $\begin{array}{l}\frac{5}{8} \\
\frac{\pi}{8} \\
\frac{\pi}{2}\end{array}$ & $\frac{8}{8}$ & $\begin{array}{c}\text { Conexión } \\
\text { con el } \\
\text { exterior } \\
\text { del DMQ }\end{array}$ & \begin{tabular}{|c|} 
Tránsito con el \\
exterior \\
del DMQ \\
en los \\
ejes de \\
prolongación
\end{tabular} & $\begin{array}{l}\text { Núm. de } \\
\text { Cias de } \\
\text { bus inter- } \\
\text { provin- } \\
\text { ciales }\end{array}$ & $\begin{array}{c}\text { Síntesis : } \\
\text { Importancia } \\
\text { de las } \\
\text { conexiones } \\
\text { con el } \\
\text { exterior }\end{array}$ & $\frac{8}{8}$ & $\begin{array}{l}\text { Síntesis : Importancia de las } \\
\text { conexiones con el exterior }\end{array}$ & \begin{tabular}{|c|} 
Alter- \\
nativa \\
vial \\
posible
\end{tabular} & $\frac{8}{8}$ & $\begin{array}{c}\text { Alter- } \\
\text { nativa } \\
\text { vial } \\
\text { posible }\end{array}$ & है & $\frac{8}{8}$ \\
\hline $\begin{array}{l}\text { Pomasqui - } \\
\text { Mitad } \\
\text { Mundo }\end{array}$ & 25.603 & $\begin{array}{c}\text { (VL }+ \\
\text { bus }+ \\
\text { camiones } \\
\text { en ambos } \\
\text { sentidos) } \\
\text { Fuente: } \\
\text { HCCP } \\
2001\end{array}$ & 4 & 19.612 & $\begin{array}{c}\text { (en } \\
\text { ambos } \\
\text { sentidos) } \\
\text { Encuesta } \\
\text { OD - } \\
1998 \text { UPGT }\end{array}$ & 4 & 44.000 & 4 & $\begin{array}{c}\text { hacia } \\
\text { Santo } \\
\text { Domingo y } \\
\text { la Costa }\end{array}$ & $\begin{array}{l}\text { menos de } \\
1.500 \\
\text { vehículos } \\
\text { livianos y } \\
\text { menos de } \\
40 \text { buses } \\
\text { por día (en } \\
\text { ambos } \\
\text { sentidos) }\end{array}$ & 3 & $\begin{array}{l}\text { muy } \\
\text { baja }\end{array}$ & 3 & $\begin{array}{l}\text { Sin considerar la proporción } \\
\text { relativamente alta de industrias, las } \\
\text { demás funciones locales son } \\
\text { reducidas. Ningún centro comercial } \\
\text { importante, ningún centro médico } \\
\text { con camas se encuentra en este } \\
\text { sector. El } 22,3 \% \text { de los moradores } \\
\text { de esta periferia se traslada cada } \\
\text { día a Quito. }\end{array}$ & fuerte & 2 & no & $\begin{array}{c}\text { Un camino de tierra } \\
\text { permite sin embargo } \\
\text { conectar la Mitad del } \\
\text { M undo con } \\
\text { Carapungo, pero no es } \\
\text { transitable por todo } \\
\text { tipo de vehículos. }\end{array}$ & 1 \\
\hline $\begin{array}{l}\text { Carapungo- } \\
\text { Calderón }\end{array}$ & 33.854 & $\begin{array}{c}\text { (VL + bus }+ \\
\text { camiones, } \\
\text { en ambos } \\
\text { sentidos) } \\
\text { Fuente: } \\
\text { UPGT } \\
2000\end{array}$ & 3 & 57.645 & id & 1 & 91.000 & 3 & $\begin{array}{c}\text { hacia } \\
\text { Cayambe, } \\
\text { Imbabura, } \\
\text { Carchi, } \\
\text { Colombia }\end{array}$ & $\begin{array}{c}\text { cerca de } 7.000 \\
\text { vehículos } \\
\text { livianos y } \\
1.360 \text { buses } \\
\text { por día (en } \\
\text { ambos } \\
\text { sentidos) }\end{array}$ & 13 & fuerte & 1 & $\begin{array}{l}\text { Las actividades locales son escasas } \\
\text { (algunas industrias y una } \\
\text { administración zonal). Ningún centro } \\
\text { comercial importante, ningún centro } \\
\text { médico con camas se encuentra en } \\
\text { este sector. } \\
\text { El } 30 \% \text { de los moradores de esta } \\
\text { periferia se traslada cada día a } \\
\text { Quito. }\end{array}$ & $\begin{array}{c}\text { muy } \\
\text { fuerte }\end{array}$ & 1 & si & $\begin{array}{c}\text { Por El Comité del } \\
\text { Pueblo, pero este } \\
\text { itinerario es muy } \\
\text { sinuoso, estrecho y } \\
\text { empinado. El índice de } \\
\text { sinuosidad (distancia de } \\
\text { Manhattan en relación } \\
\text { con la distancia } \\
\text { euclidiana) es la mayor } \\
(2,09) \text {. La pendiente } \\
\text { promedio es de } 5,93^{\circ} \text {. }\end{array}$ & 3 \\
\hline $\begin{array}{l}\text { Cumbayá- } \\
\text { Tumbaco }\end{array}$ & 34.159 & $\begin{array}{l}\text { (VL + bus }+ \\
\text { camiones, } \\
\text { en ambos } \\
\text { sentidos) } \\
\text { Fuente: } \\
\text { UPGT 2001 }\end{array}$ & id & 2 & id & 2 & 120.000 & 2 & $\begin{array}{c}\text { hacia la } \\
\text { Amazonía }\end{array}$ & $\begin{array}{c}\text { Cerca de } 320 \\
\text { vehículos } \\
\text { livianos y } 280 \\
\text { buses por día } \\
\text { (en ambos } \\
\text { sentidos) }\end{array}$ & 7 & $\begin{array}{c}\text { bastante } \\
\text { fuerte }\end{array}$ & 4 & $\begin{array}{c}\text { En relación con los dos sectores } \\
\text { anteriores, un mayor número de } \\
\text { senvicios y actividades en especial a } \\
\text { nivel de las dos centralidades } \\
\text { locales (Cumbayá y Tumbaco) se } \\
\text { encuentra en este valle. El } 21,5 \% \text { de } \\
\text { los moradores de esta periferia se } \\
\text { traslada cada día a Quito. }\end{array}$ & $\begin{array}{c}\text { mode- } \\
\text { rada }\end{array}$ & 3 & si & $\begin{array}{c}\text { Por Guápulo, pero este } \\
\text { itinerario es muy } \\
\text { sinuoso, estrecho y } \\
\text { empinado. El índice de } \\
\text { sinuosidad es moderado } \\
\text { (1,37). La pendiente } \\
\text { promedio es de } 9,63^{\circ} \text {. }\end{array}$ & 2 \\
\hline Los Chillos & 38.000 & $\begin{array}{c}\text { VL + bus }+ \\
\text { camiones, } \\
\text { en ambos } \\
\text { sentidos) } \\
\text { Fuente: } \\
\text { Tribasa } \\
\text { Colisa } \\
2001\end{array}$ & 1 & 19.215 & $\begin{array}{c}\text { idem pero } \\
\text { valor subes- } \\
\text { timado por- } \\
\text { que no se } \\
\text { considera } \\
\text { os desplaza- } \\
\text { mientos } \\
\text { inter- } \\
\text { cantonales }\end{array}$ & 3 & 182.000 & 1 & $\begin{array}{c}\text { hacia la } \\
\text { Panameri- } \\
\text { cana sur } \\
\text { (por } \\
\text { Amaguaña } \\
\text { y Tambillo) }\end{array}$ & $\begin{array}{c}\text { cerca de } 7.000 \\
\text { vehículos } \\
\text { livianos y } 560 \\
\text { buses por día } \\
\text { (en ambos } \\
\text { sentidos) }\end{array}$ & 4 & $\begin{array}{l}\text { muy } \\
\text { baja }\end{array}$ & 2 & $\begin{array}{l}\text { La configuración de este valle con } \\
\text { dos centralidades (Conocoto y } \\
\text { Sangolquí), a pesar de contar con } \\
\text { una población mayor, se parece a la } \\
\text { del valle de Tumbaco. }\end{array}$ & $\begin{array}{l}\text { mode } \\
\text { rada }\end{array}$ & 4 & si & $\begin{array}{l}\text { Por la antigua vía a } \\
\text { Conocoto, pero este } \\
\text { itinerario es muy } \\
\text { sinuoso, estrecho y } \\
\text { empinado. El índice } \\
\text { de sinuosidad es } \\
\text { moderado (1,51). La } \\
\text { pendiente promedio } \\
\text { es de } 4,3^{\circ}\end{array}$ & 4 \\
\hline
\end{tabular}

Balance

\begin{tabular}{|l|c|c|c|}
\hline $\begin{array}{l}\text { Ejes viales que soportan los } \\
\text { movimientos pendulares }\end{array}$ & $\begin{array}{c}\text { Suma de } \\
\text { las posiciones }\end{array}$ & J erarquización & $\begin{array}{c}\text { Eje esencial para las } \\
\text { comunicaciones centro periferia }\end{array}$ \\
\hline Mitad M undo & 18 & importante & no \\
\hline Calderón & 12 & de primera importancia & si \\
\hline Tumbaco & 15 & muy importante & si \\
\hline Los Chillos & 15 & muy importante & si \\
\hline
\end{tabular}




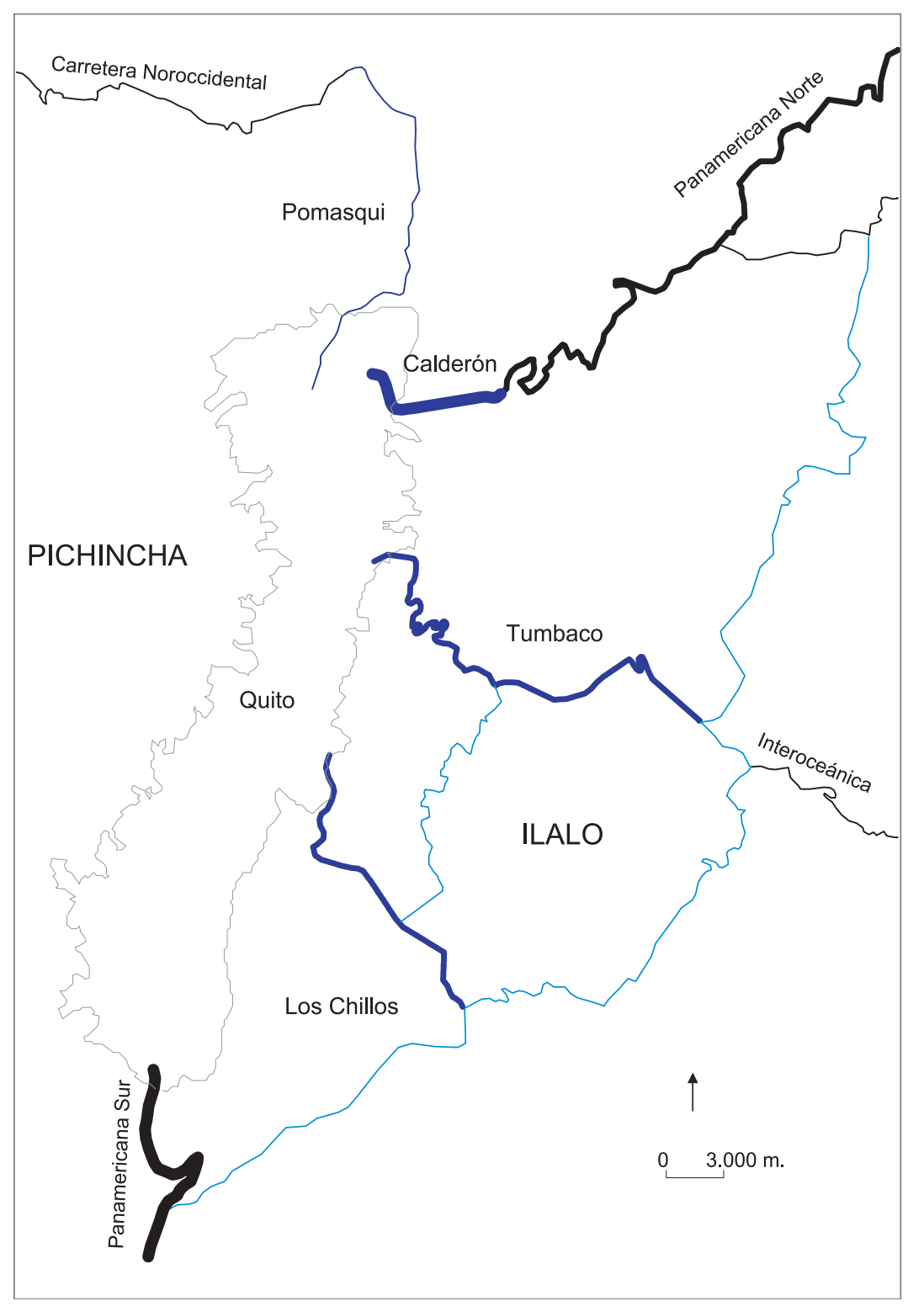

Mapa 4-1

Síntesis cartográfica de la jerarquización de los ejes suburbanos (accesos al Distrito y ejes centro-periferia)

Vías de acceso al Distrito

[ 10 - 12 [ Vías de acceso al Distrito bastante importantes

[ 6 - 10 [ Vía de acceso al Distrito muy importante

[ 3 - 6 [ Vía de acceso al Distrito de primera importancia

\section{Vías centro periferia}

[ 18 - 19 [ Ejes centro periferia importantes

[ 15 - 18 [ Ejes centro periferia muy importantes

[ 12 - 15 [ Ejes centro periferia de primera importancia

Vías suburbanas (circunvalación metropolitana e Intervalle)

Otros ejes viales estructurantes suburbanos bastante importantes o importantes 
las vías hacia Tumbaco y hacia Los Chillos, sectores peri urbanos con mayor población (120.000 y 182.000 habitantes) que mantienen, a pesar de contar con centralidades locales, lazos intensos con la ciudad como lo muestra la magnitud de los movimientos pendulares. Por último, se considera la carretera entre Quito y Pomasqui en la categońa "eje importante" por ser la periferia menos poblada (44.000 habitantes).

Se clasifica también en la categonía "eje bastante importante" los demás ejes viales estructurantes ubicados en las zonas suburbanas (mapa 4-1).

\section{Los ejes urbanos}

El método en este caso es diferente. Se selecciona entre centenares de avenidas urbanas las que son más utilizadas por los distintos medios de transporte. Se considera las cuatro variables siguientes:

1. Los ejes urbanos que cuentan con los mayores aforos vehiculares.

2. Los corredores en donde se concentra el transporte colectivo convencional.

3. El eje de circulación del trolebús.

4. Los corredores utilizados por el transporte interparroquial, intercantonal e interprovincial.

La primera variable permite medir el uso de las avenidas de Quito por la circulación en automóvil. Los ejes con mayor tránsito son altamente importantes por el hecho de que no existen muchas alternativas viales que podrían soportar estos aforos. El tráfico en Quito se organiza esencialmente según una dinámica longitudinal. La tabla 4-3 indica los aforos vehiculares censados por la DMT en las principales arterias urbanas.
El cuadro A del mapa 4-2 muestra la preponderancia de los ejes más transitados al norte de la ciudad. Una marcada concentración de la circulación vehicular se observa en el espacio central entre la avenida Patria y el sur del aeropuerto. Cuatro grandes avenidas permiten acceder al espacio central desde el norte. Se trata de las avenidas Eloy Alfaro y Mariscal José de Sucre (anillo urbano), de la avenida Galo Plaza Lasso y de la avenida Prensa. Seis ejes latitudinales resaltan: las avenidas Patria, Colón, Mariana de Jesús, República, Eloy Alfaro y Naciones Unidas.

La segunda variable (mapa 4-2, cuadro B) permite en algunos ejes medir la intensidad del transporte colectivo urbano convencional primordial para los desplazamientos de los quiteños. Se guardan las avenidas transitadas por más de 30 líneas de buses urbanos ida y vuelta. El cuadro B evidencia dos ejes longitudinales en ambos lados de la ciudad conectados por dos ejes transversales (Patria y Rodrigo de Chávez).

La tercera variable considera el colector central del trolebús (mapa 4-2, cuadro C). El sistema trolebús es un elemento fundamental para el transporte de los quiteños. En el 2002, transportaba en carril exclusivo en una red integrada cerca de 210.000 personas por día, es decir el 11 por ciento de la demanda diaria en transporte colectivo.

La cuarta variable abarca los corredores urbanos utilizados por el transporte interparroquial, intercantonal e interprovincial. Una avenida utilizada por varias redes de transporte que brindan un servicio a diferentes escalas es esencial. Se representan estos ejes viales en los cuadros D, E y F. En el primer caso, los ejes se orientan esencialmente de norte a sur en continuidad con los cuatro ejes centro-periferia. En el segundo caso, resaltan tres arterias, la una procedente del norte, 
Tabla 4-3

Aforo vehicular en los bulevares más transitados (días hábiles)

\begin{tabular}{|c|c|c|c|c|}
\hline $\begin{array}{l}\text { Localización } \\
\text { en la ciudad }\end{array}$ & Avenida principal & Orientación & Intersección & $\begin{array}{l}\text { Volumen de tráfico } \\
\text { en ambos sentidos }\end{array}$ \\
\hline $\mathrm{N}$ & M ariscal J osé de Sucre & $\mathrm{S} / \mathrm{N}$ & Túnel de San J uan & 69.897 \\
\hline $\mathrm{N}$ & 10 de Agosto & $\mathrm{S} / \mathrm{N}$ & J uan Sanz e Ignacio Santa M aria & 61.966 \\
\hline $\mathrm{N}$ & Prensa & $\mathrm{N} / \mathrm{S}$ & La Y & 46.156 \\
\hline $\mathrm{N}$ & Eloy Alfaro & $\mathrm{S} / \mathrm{N}$ & Granados (aprox. sur) & 45.403 \\
\hline $\mathrm{N}$ & Eloy Alfaro & $\mathrm{S} / \mathrm{N}$ & Granados (aprox. norte) & 45.242 \\
\hline $\mathrm{N}$ & Amazonas & $\mathrm{N} / \mathrm{S}$ & NN-UU & 44.556 \\
\hline $\mathrm{N}$ & Amazonas & $\mathrm{S} / \mathrm{N}$ & Corea y J uan Sanz & 43.636 \\
\hline $\mathrm{N}$ & G. Plaza Lasso & $\mathrm{S} / \mathrm{N}$ & J. Ramos (Carapungo) & 33.854 \\
\hline $\mathrm{N}$ & América & $\mathrm{N} / \mathrm{S}$ & M añosca y Fernández & 33.125 \\
\hline $\mathrm{N}$ & América & $\mathrm{N} / \mathrm{S}$ & M ariana de J esús y Rumipamba & 32.940 \\
\hline $\mathrm{N}$ & Shyris & $\mathrm{S} / \mathrm{N}$ & Eloy Alfaro & 31.790 \\
\hline $\mathrm{N}$ & América & $\mathrm{N} / \mathrm{S}$ & Ramírez Davalos y M archena & 31.294 \\
\hline $\mathrm{N}$ & Patria & $\mathrm{E} / 0$ & Amazonas y J uan León M era & 47.813 \\
\hline $\mathrm{N}$ & Granados & O/E & Eloy Alfaro (aprox. este) & 34.159 \\
\hline $\mathrm{N}$ & República & $\mathrm{E} / 0$ & Amazonas y Grecia & 33.991 \\
\hline $\mathrm{N}$ & NN-UU & $\mathrm{E} / 0$ & R. del Salvador y 6 de Diciembre & 29.155 \\
\hline $\mathrm{N}$ & Patria & $\mathrm{E} / 0$ & 6 de Diciembre y Reina Victoria (aprox. oeste) & 28.124 \\
\hline $\mathrm{N}$ & Patria & $\mathrm{E} / 0$ & Plaza y 6 de Diciembre & 26.863 \\
\hline $\mathrm{N}$ & Mariana de J esús & O/E & América y Fray Gaspar de Carvajal & 25.646 \\
\hline $\mathrm{N}$ & M ariscal J osé de Sucre & $\mathrm{E} / \mathrm{O}$ & Cárdenas y J ose Carrión & 25.378 \\
\hline $\mathrm{N}$ & M ariscal J osé de Sucre & O/E & Rumihurco y F. Pizarro & 24.202 \\
\hline $\mathrm{N}$ & M ariscal J osé de Sucre & O/E & Ingas y Rumihurco & 23.349 \\
\hline $\mathrm{N}$ & M ariscal J osé de Sucre & O/E & F. Pizarro y Cardenas & 22.579 \\
\hline $\mathrm{N}$ & Colón & O/E & Amazonas & 21.989 \\
\hline $\mathrm{N}$ & Colón & $\mathrm{E} / 0$ & 10 de Agosto y Versalles & 21.456 \\
\hline $\mathrm{S}$ & M ariscal J osé de Sucre & $\mathrm{N} / \mathrm{S}$ & R. Chávez y Tnte. García & 29.726 \\
\hline $\mathrm{S}$ & Napo & $\mathrm{S} / \mathrm{N}$ & Casitagua y 1ro de Mayo & 21.076 \\
\hline $\mathrm{S}$ & Panamericana Sur & $\mathrm{S} / \mathrm{N}$ & 200m. antes del peaje sur, Guamaní & 18.114 \\
\hline $\mathrm{S}$ & Maldonado & $\mathrm{N} / \mathrm{S}$ & R. Chávez y A. Angulo & 15.464 \\
\hline $\mathrm{S}$ & Peaje Sur & $\mathrm{S} / \mathrm{N}$ & & 15.282 \\
\hline $\mathrm{S}$ & Napo & O/E & Maldonado y Casitagua & 19.862 \\
\hline $\mathrm{S}$ & R. de Chávez & $\mathrm{E} / 0$ & Maldonado y M endoza & 16.868 \\
\hline S & Alonso de Angulo & O/E & Maldonado y M endoza & 15.744 \\
\hline
\end{tabular}

(Fuente: UPGT-DM T, 1999-2001) 
Mapa 4-2

Detalle del método de identificación de los ejes urbanos más relevantes según las variables consideradas




Mapa 4-3

Jerarquización de los ejes de comunicación a nivel de la ciudad de Quito

[ 1 - 3 [ ejes urbanos importantes

[ 3 - 5 [ ejes urbanos muy importantes

[ 5 - 8 [ ejes urbanos de primera importancia

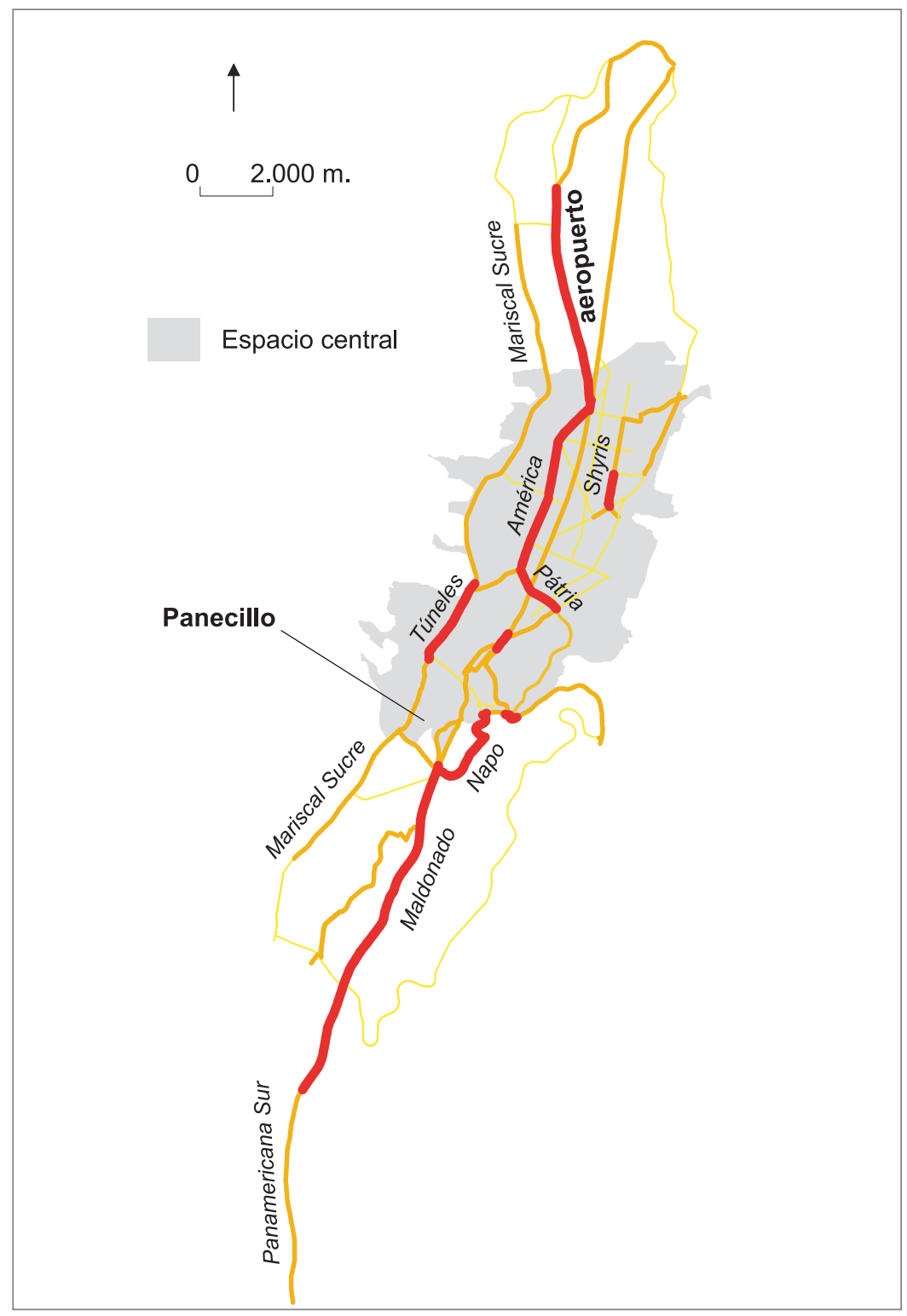


la otra procedente del valle de Los Chillos y la última prolongando la Panamericana sur. En el caso del transporte interprovincial, los tres recomidos convergen a la terminal terrestre Cumandá.

Luego de haber identificado las vías urbanas que resaltan, según las cuatro variables anteriores, se superpuso los seis cuadros en el SIG Savane. Este proceso permite singularizar los ejes que son esenciales en varios ámbitos. Esta particularidad les confiere una posición clave en el funcionamiento de la movilidad metropolitana.

Se sumó las cuatro variables por tramo vial. Por otro lado, se aplicó coeficientes de ponderación a los ejes que se considera que pueden desempeñar una función aún más esencial. Se dio una ponderación alta (3) a la vía del trolebús, dadas sus múltiples ventajas y su fuerte popularidad. Se atribuyó también a los grandes corredores de transporte colectivo en buses convencionales (transitados por más de 30 líneas ida y vuelta) un peso superior (2). Estos ejes constituyen la armazón principal de la red de transporte colectivo urbano, cuya función es fundamental para los ciudadanos. No se aplicó coeficiente a las demás variables (1). El valor sumado máximo es un total de siete para algunos tramos. Luego se agruparon estos totales en tres clases (mapa 4-3).

\section{Los ejes del espacio central}

El objetivo del análisis en esta sección es determinar los ejes de mayor importancia que permiten llegar a un sector determinado, (el espacio central) y cubrir su interior. Este trabajo es imprescindible ya que el espacio central está asociado a la centralidad metropolitana, verdadera piedra angular de la actividad del Dis- trito. Las vías de acceso al espacio central y las principales vías de circulación interna se revelan entonces, a su vez, esenciales. El método de diferenciación y jerarquización de las avenidas se fundamenta sobre todo en su papel respecto al espacio central determinado por su estructuración, importancia, tipo de intercambios que soportan y características geométricas.

\section{Los accesos al espacio central}

El acceso al espacio central por el norte es fácil. La carretera de Pomasqui y la Panamericana norte desembocan en el anillo urbano conectado con avenidas anchas que llegan en cinco puntos al interface norte del espacio central. El espacio central es accesible también, pero de manera menos fácil desde los valles de Tumbaco y de Los Chillos, por los dos grandes ejes centro periferia, previamente analizados, y desde el sur de la ciudad, por las dos avenidas Napo, al este y Mariscal Sucre, al oeste (mapa 4-4). Las pocas alternativas de acceso (desde el sur y el este) se explican por la presencia de barreras orográficas e hidrográficas (colinas orientales y El Panecillo) que deben ser circunvaladas y atravesadas. La importancia de los movimientos pendulares y los desplazamientos procedentes del sur de la ciudad y de los valles orientales, en transporte colectivo e individual, atribuibles a las interdependencias funcionales socioeconómicas previamente estudiadas, hace que estos cuatro ejes representen elementos esenciales para las comunicaciones en torno al espacio central.

\section{Las vías de circulación al interior del espacio central}

Al interior del espacio central se singulariza cinco categorías de vías en razón de su función en el sistema de circulación vehicular individual y en transporte colectivo. Se trata de las cinco categonías siguientes: ${ }^{65}$ 
1. La vía exterior occidental de desfogue y tránsito (Avenida Mariscal Sucre). Permite las llegadas y salidas masivas hacia y desde el espacio central y las conexiones entre el norte y el sur de la ciudad. Es la prolongación de las vías de acceso al espacio central.

2. Las vías exteriores orientales de desfogue. Permite las llegadas y salidas masivas hacia y desde el espacio central (por un lado, la Avenida Velasco Ibarra entre el intercambiador de El Trébol y el barrio La Vicentina y, por otro, la Avenida Eloy Alfaro desde la intersección con la vía procedente de Tumbaco y la Avenida 6 de Diciembre). Son la prolongación de las vías de acceso al espacio central.

3. La vía central de entrada y de tránsito, ubicada como lo indica su nombre, en el corazón del espacio central (Avenida 10 de Agosto). Esta arteria muy ancha permite la infiltración masiva de los flujos que se reparten al interior del espacio central gracias a una serie de intercambiadores. Se la utiliza también para el tránsito y llegada al intercambiador El Trébol pasando por La Marín (avenida Pichincha).

4. Las vías de llegada laterales hacia los diferentes centros (histórico, moderno, de negocios). Cumplen una función de conexión intermedia entre las vías exteriores de desfogue y los bulevares urbanos.

5. La armazón vial principal. Se trata de bulevares de gran o mediana anchura que permiten una circulación inter barrial. Se integra también en esta categońa las arterias que posibilitan la circulación de este a oeste, como las avenidas Colón, Orellana, Naciones Unidas y Patria.

\section{Síntesis: ejes importantes, esenciales y tramos funcionales homogéneos}

De la jerarquización de los ejes viales a la individualización de los ejes esenciales

A este nivel, se realizó un mapa sintético (mapa 4-5) que reúne de modo simplificado los ejes en los que se fundan los intercambios en los cuatro subespacios anteriores. El cuadro A muestra la jerarquización de todos los grandes ejes viales metropolitanos, según su importancia (bastante importante ${ }^{66}$, importante, muy importante, de primera importancia). En base a esta jerarquización, se pudo individualizar "los ejes esenciales" (vías muy importantes y vías de primera importancia) y "los ejes importantes" (vías bastante importantes y vías importantes) representados en el cuadro B.

\section{Determinación de tramos funcionales homogéneos: utilidad, método y cartografía}

Se identificó una primera serie de elementos esenciales para la movilidad metropolitana y el funcionamiento de la aglomeración, elementos cuya vulnerabilidad se analizará ulteriormente (tercera parte) con el fin de evaluar los riesgos a los cuales está expuesto el Distrito (cuarta parte). Sin embargo, desde una perspectiva práctica, se requiere previamente definir "tramos homogéneos" cuyas formas de vulnerabilidad pueden

65. Se desprende este párrafo en los análisis presentados en el Atlas Infográfico de Quito (M.S. Bock, H.Godard, R. de Maximy, 1992).

66. Los ejes urbanos bastante importantes son todos aquellos que no resaltaron mediante el método de jerarquización de las vías urbanas basado en las cuatro variables pero que sin embargo desempeñan un papel significativo en el acceso al espacio central o en la circulación en su interior. 
ser similares y susceptibles de dejar algunas porciones de la red vial fuera de servicio. En efecto, una avenida muy larga puede estar expuesta a los deslizamientos únicamente en un lugar preciso, ello no significa que el tráfico estará totalmente perturbado en toda la avenida; se puede desviar la circulación hacia otro tramo.

Las grandes intersecciones pueden entonces servir para delimitar los tramos homogéneos pero este criterio no es suficiente. Se debe también considerar la utilidad de las vías, es decir, su función con el fin de llegar a una tipología ${ }^{67}$. Ello permite evitar acabar en un número demasiado alto de tramos en la ciudad en donde los cruces son numerosos y en un número reducido de tramos extremadamente largos en las zonas suburbanas, en donde las intersecciones son escasas a lo largo de los ejes estructurantes (como a lo largo de la Panamericana norte, por ejemplo). Adicionalmente, permite conocer las perturbaciones posibles de la movilidad, en el caso de que un tramo resulte inoperante (por ejemplo, en caso de sismo, si un puente colapsa y este permite el acceso al Distrito, se sabrá que es la accesibilidad del Distrito la que se encontrará limitada). Se elaboró dos mapas (4-6 y 4-7), el primero indica la tipología funcional de los ejes esenciales en el DMQ; el segundo, presenta una división de estos ejes en 34 tramos homogéneos (para las nomenclaturas, véase tabla 4-4) de los que se analizará la vulnerabilidad en la tercera parte.

Si bien los elementos esenciales de la movilidad pueden ser ejes viales, también lo son algunas infraestructuras.

67. Por ejemplo, una vía central de entrada a la urbe, el corredor del trolebús, una vía de circunvalación.

\section{Las infraestructuras viales esenciales: método de identíficación y cartografía}

El objetivo es medir el grado de importancia de las distintas infraestrucutras viales (túneles, puentes, intercambiadores). El discernimiento de las infraestructuras viales esenciales está condicionado por los ejes viales esenciales. Por ejemplo, un puente ubicado en una vía de acceso al espacio central resalta también como elemento esencial del sistema de movilidad.

El paso por los tres túneles (San Juan, San Roque, San Diego) y su buen funcionamiento representan un verdadero reto para las comunicaciones entre el norte y el sur. Esto es tanto más cierto cuanto que no existen muchas alternativas ya que El Panecillo es una verdadera barrera orográfica. Los tres túneles se encuentran en un eje vial esencial (Avenida Mariscal Sucre) y son transitados por 70.000 vehículos y 56 líneas de bus urbanas por día, en ambos sentidos (túnel de San Juan).

Para seleccionar a las obras viales esenciales que cuentan con un segmento aéreo, se preseleccionó primero todos los puentes ubicados en los ejes viales esenciales. Así se guardó 67 obras de un total de 90 . Luego se enfocó en la función de las secciones aéreas respecto a la circulación vehicular en los ejes viales esenciales. Se estimó su importancia a través de las siguientes cuatro preguntas:

1. ¿El segmento aéreo sirve de soporte a un eje esencial?

2. ¿El segmento aéreo conecta dos tramos viales esenciales diferentes?

Se trata de saber si la sección aérea permite pasar de un tramo vial homogéneo a otro. Se mide así el carácter esencial del segmento aéreo en las conexiones al interior de la red. 
Mapa 4-4

Accesos al espacio central y arterias de inervación principal

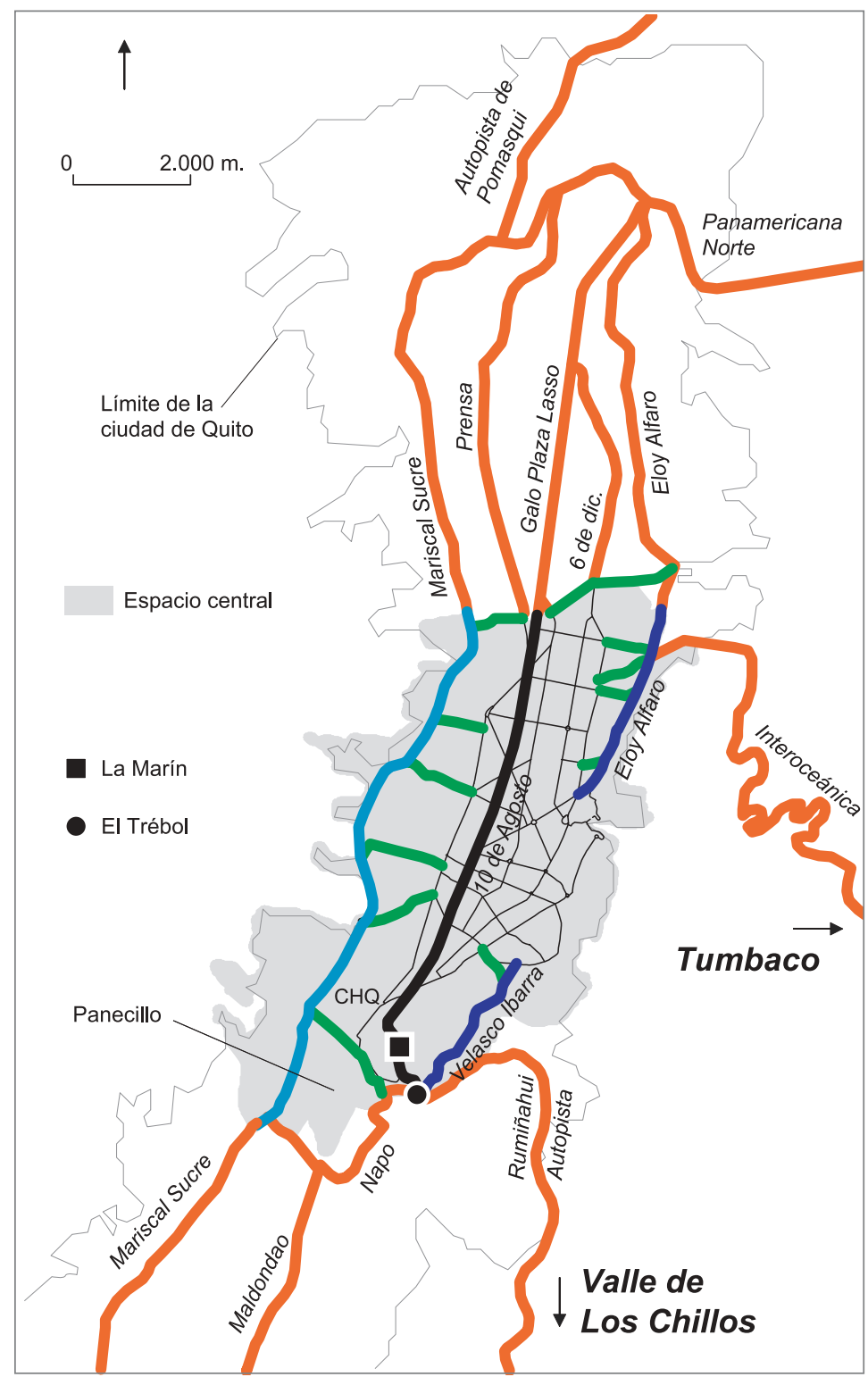

Vía de acceso al espacio central

Vía exterior occidental de desfogue y de tránsito (norte - sur)

Vía exterior oriental de desfogue

Vía central de entrada y de tránsito

Vía de llegada lateral hacia los diferentes centros (histórico, moderno, de negocios)

Armazón vial principal: bulevares de gran o mediana anchura que permiten una circulación inter barrial 
Mapa 4-5

Cuadro A: Jerarquización de los ejes metropolitanos (síntesis); Cuadro B: Ejes importantes y ejes esenciales

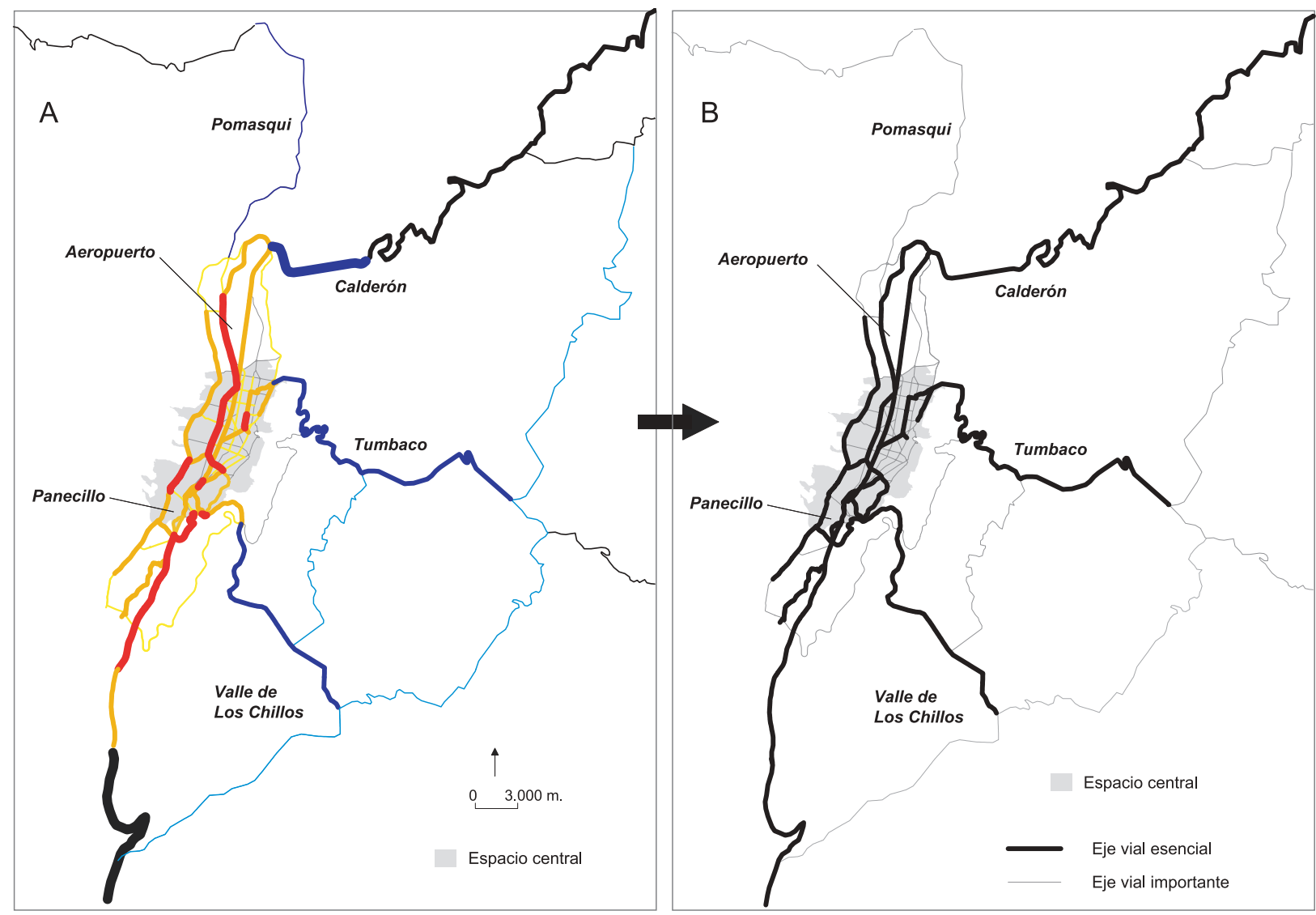

Desplazamientos urbanos Desplazamientos suburbanos

Desplazamientos con el exterior del DMQ

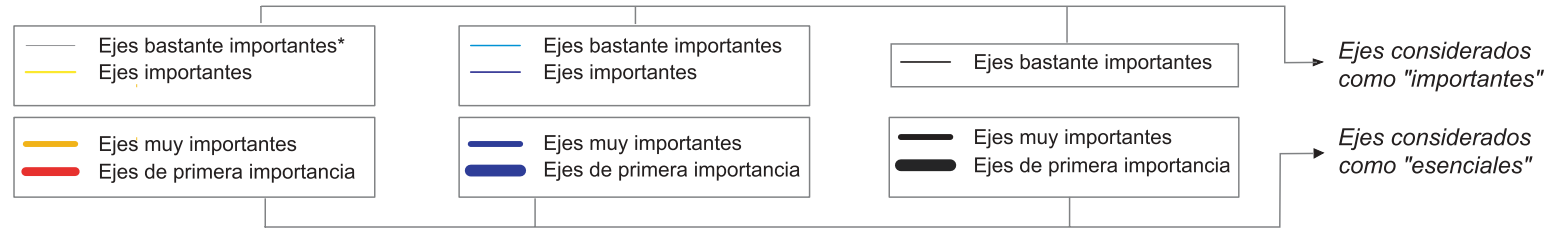

* : los ejes urbanos bastante importantes son todos los ejes que no resaltaron con el método de jerarquización de las vías urbanas basado en las cuatro variables pero que sin embargo cumplen un papel significativo en el acceso al espacio central o en la circulación en su interior (véase mapa 4-4 "Accesos al espacio central y arterias de inervación principal") 
Mapa 4-6

Tipología funcional de los ejes viales esenciales, DMQ

\section{Parte urbana (trazados continuos)}

Vía central de entrada y de tránsito que sirve también de soporte para el colector central del trolebús

Vias exteriores orientales de desfogue del espacio central

Via exterior occidental de desfogue del espacio central y de tránsito (norte-sur)

Vías de llegada laterales hacia los diferentes centros (histórico, moderno, de negocios).

Vías urbanas que atraviesan los espacios norte y sur de la ciudad y que permiten el acceso al espacio central

Vías que posibilitan los desplazamientos latitudinales al interior del espacio central (circulación inter barrial)

Vías que posibilitan los desplazamientos longitudinales al interior del espacio central (circulación inter barrial)

Extensión del trolebús que atiende el sur de Quito conectado con el espacio central

Vía que sirve de soporte para un tramo del colector central del trolebús (Villa Flora - CHQ)

\section{Parte suburbana (trazados entrecortados)}

Ejes que sirven de soporte para las comunicaciones con el exterior del Distrito (acceso a la ciudad o a la aglomeración)

Ejes que sirven de soporte para los movimientos pendulares y para las comunicaciones con el exterior del Distrito que desembocan al norte de la ciudad

Ejes que sirven de soporte para los movimientos pendulares que desembocan en el espacio central

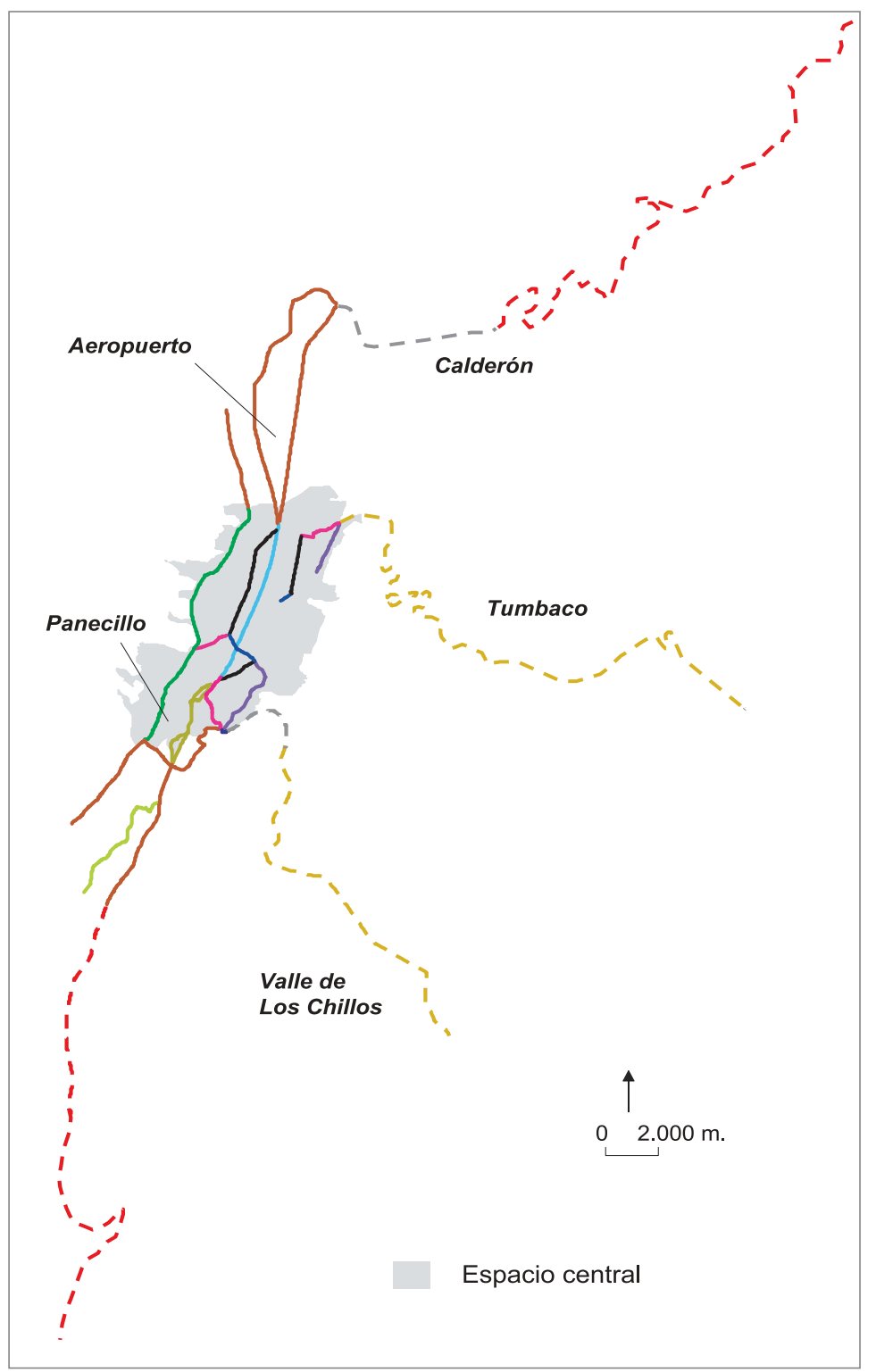




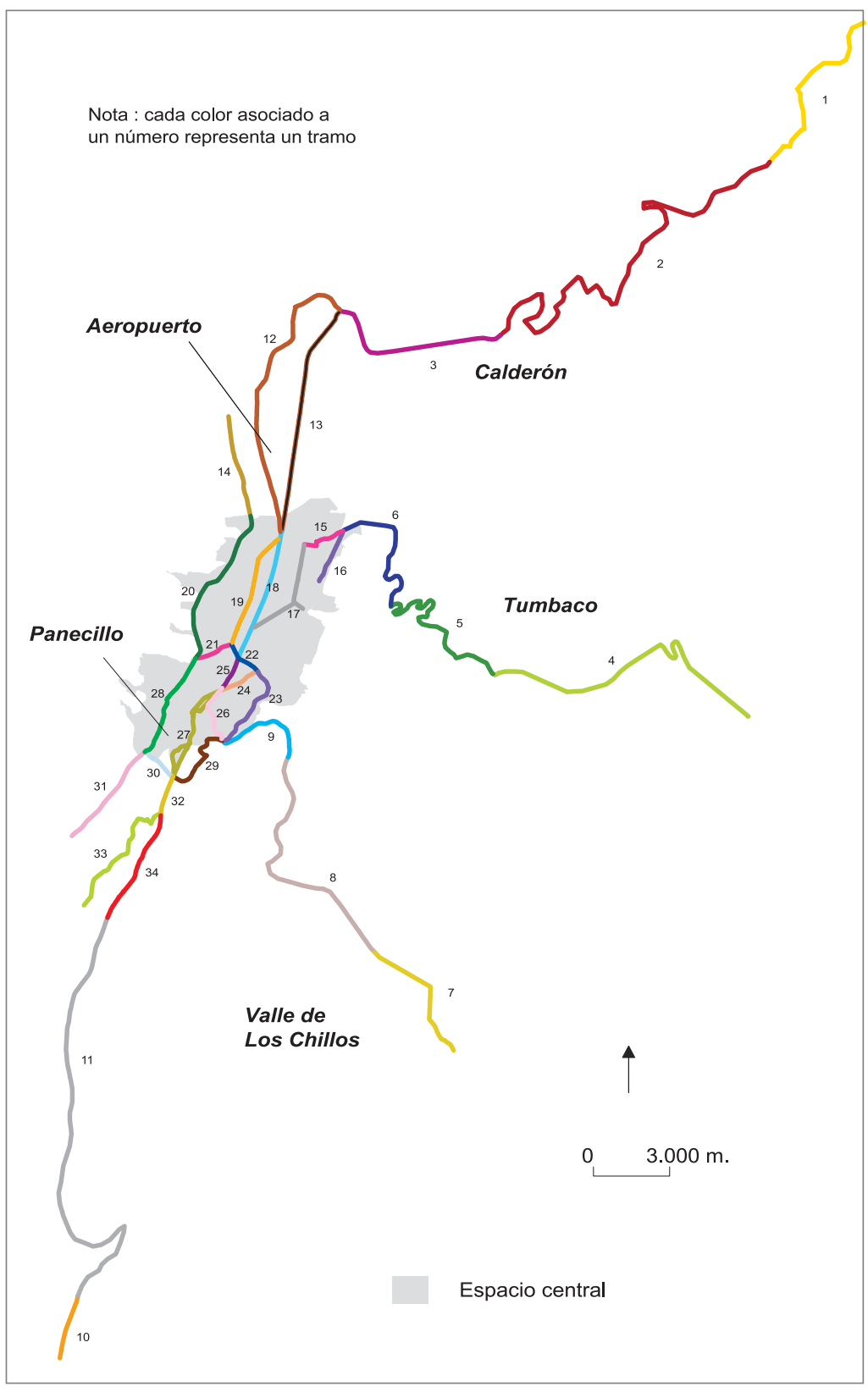

Mapa 4-7

Segmentación de los ejes esenciales respecto a su función y su posición en la red vial, DMQ 
Tabla 4-4

Denominación y localización de los tramos viales homogéneos que resultan de la segmentación de los ejes esenciales

\begin{tabular}{|c|c|c|}
\hline Clave & Denominación & Localización \\
\hline 1 & PanaNorte & salida de Guayllabamba hasta la "Y" de Tabacundo \\
\hline 2 & PanaNorte & entre Guayllabamba y Calderón \\
\hline 3 & PanaNorte & entre Calderón y la "Y" de Carcelén \\
\hline 4 & Interoceánica & entre la "Y" de Pifo y el cruce con la Intervalle (Club deportivo el Nacional) \\
\hline 5 & Interoceánica & entre el cruce de la Intervalle (Club deportivo el Nacional) y el intercambiador de Cumbayá (unión con la nueva Oriental) \\
\hline 6 & Interoceánica & entre el intercambiador de Cumbayá (unión con la nueva Oriental) y el cruce con la Eloy Alfaro \\
\hline 7 & Avenida Rumiñahui & entre el redondel El Colibrí y El Triángulo \\
\hline 8 & Avenida Rumiñahui & entre El Triángulo y el intercambiador con la Nueva Oriental (cerca del peaje) \\
\hline 9 & Avenida Rumiñahui & entre el intercambiador con la Nueva Oriental (cerca del peaje) y el intercambiador El Trébol \\
\hline 10 & PanaSur & entre Alóag y el intercambiador de Tambillo \\
\hline 11 & PanaSur & entre el intercambiador de Tambillo y el intercambiador de la Plyw ood (unión con Nueva Oriental y M orán Valverde) \\
\hline 12 & Diego Vásquez y Prensa & entre la "Y" de Carcelén y "La Y" (unión con 10 de Agosto y América) \\
\hline 13 & Galo Plaza Lasso & entre la "Y" de Carcelén y "La Y" (unión con Prensa y América) \\
\hline 14 & M ariscal Antonio J osé de Sucre & entre Doctor J osé Fernández Salvador y Coronel Edmundo Carvajal \\
\hline 15 & Granados y Gaspar de Villaroel & entre 6 de Diciembre y Shyris \\
\hline 16 & Eloy Alfaro & entre Los Granados y Portugal \\
\hline 17 & Shyris & entre Gaspar de Villaroel y Eloy Alfaro (con las dos pequeñas extensiones) \\
\hline 18 & 10 de Agosto & entre la "Y" (unión con Prensa y América) y Patria (puente del Guambra) \\
\hline 19 & América & entre la "Y" (unión con Prensa y 10 de Agosto) y el intercambiador con las avenidas Universitaria y Pérez Guerrero \\
\hline 20 & Mariscal Antonio J osé de Sucre & entre Coronel Edmundo Carvajal y Universitaria (M iraflores) \\
\hline 21 & Universitaria & entre M ariscal Antonio J osé de Sucre y América \\
\hline 22 & Patria & entre 10 de Agosto (puente del Guambra) y 12 de Octubre \\
\hline 23 & Velasco Ibarra (Oriental) & entre 12 de Octubre y el intercambiador El Trébol \\
\hline 24 & Gran Colombia & entre 10 de Agosto y Patria \\
\hline 25 & 10 de Agosto & entre Patria (puente del Guambra) y San Blas \\
\hline 26 & Pichincha & entre San Blas y el intercambiador El Trébol \\
\hline 27 & $\begin{array}{l}\text { Carlos M aría de la Torre - Pedro Vicente } \\
\text { Maldonado - Guayaquil - Flores - M ontúfar }\end{array}$ & entre San Blas y la Villa Flora \\
\hline 28 & M ariscal Antonio J osé de Sucre & entre Universitaria (M iraflores) y Rodrigo de Chávez \\
\hline 29 & Napo & entre el intercambiador El Trébol y Pedro Vicente M aldonado (Villa Flora) \\
\hline 30 & Rodrigo de Chávez & entre Pedro Vicente M aldonado (Villa Flora) y M ariscal Antonio J osé de Sucre \\
\hline 31 & Mariscal Antonio J osé de Sucre & entre Rodrigo de Chávez y Ajaví \\
\hline 32 & Pedro Vicente M aldonado & entre Rodrigo de Chávez (Villa Flora) y El Recreo \\
\hline 33 & Teniente Hugo Ortíz - Circunvalación & entre Pedro Vicente M aldonado y M orán Valverde \\
\hline 34 & Pedro Vicente M aldonado & entre El Recreo y el intercambiador de la Plyw ood (unión con Nueva Oriental y M orán Valverde) \\
\hline
\end{tabular}


3. ¿El segmento aéreo permite solamente acceder a una vía esencial o salir de ella?

Se plantea esta pregunta cuando la sección aérea cruza sobre una vía esencial. Permite evaluar su función respecto al eje vial esencial.

4. ¿El segmento aéreo permite salvar un eje vial esencial y también acceder o salir de él?

Se plantea esta pregunta también cuando la sección aérea cruza sobre una vía esencial. Permite evaluar su función respecto al eje vial esencial. En el caso de que la sección aérea permita llegar al eje esencial y al mismo tiempo cruzarlo, entonces se la considera más importante.

Se individualizó siete tipos de secciones aéreas (tabla 4-5). En función de su utilidad, se jerarquizó y determinó aquellas esenciales. Estas son asociadas a 43 obras viales representadas en el mapa 4-8.

\section{Los equipamientos de transporte esenciales: método de identificación y cartografía}

En lo que se refiere a las instalaciones para el transporte colectivo de personas, se mide su grado de importancia en función de los movimientos de pasajeros que registran y del tipo de transporte que transita por dichas instalaciones. Se consideró siete nodos de la red $^{68}$ (mapa 4-9):

- El intercambiador El Trébol, lugar de transferencia entre los buses procedentes del valle de Los Chillos y las líneas urbanas. Estas últimas atienden tanto al norte como al sur de la ciudad.

- La Plaza de Argentina, lugar de salida con dirección al valle de Tumbaco-Cumbayá ${ }^{69}$. Este nodo es conectado con el servicio de la ecovía y se encuentra a lo largo de un importante corredor de transporte colectivo urbano.

- La Marín, lugar de conexión muy frecuentado entre las líneas urbanas procedentes del norte y el sur. Este nodo es conectado también con el servicio del trolebús y con la ecovía.

- La terminal terrestre Cumandá, hacia la cual convergen más de 70 líneas interprovinciales de bus y puede acoger hasta 30.000 personas durante los feriados. Este nodo es accesible mediante el trolebús y numerosas líneas urbanas de bus.

- Las tres estaciones de transferencia del trolebús que registran más de 30.000 entradas y salidas de pasajeros por día (estación Norte, estación El Recreo, estación Morán Valverde). Se trata de tres nodos principales de la red integrada de transporte colectivo (integración tarifaria y de servicio entre el trole y los alimentadores). Además, la estación Norte es la sede de la central de semaforización de la ciudad de Quito y la estación El Recreo cuenta con la dirección del sistema trolebús y los talleres de mantenimiento de los vehículos.

Después de haber identificado las vías, infraestructuras viales y equipamientos de transporte colectivo que ocupan un papel esencial en el funcionamiento de la movilidad del sistema teritorial metropolitano, se realizó un mapa sintético del conjunto de elementos

68. Se recuerda que este análisis corresponde a la situación de finales de 2002

69. Se registró más de 10.000 personas por día, según un estudio realizado en julio de 2002 por $F$. Bondoux y F. Demoraes. 
Tabla 4-5

Diferenciación y jerarquización de las obras viales

\begin{tabular}{|l|l|c|}
\hline & Descripción de la utilidad del segmento aéreo & Grado de importancia \\
\hline 1 & Sirve de soporte a una vía esencial y conecta dos tramos homogéneos & obra de primera importancia \\
\hline 2 & Sirve de soporte a una vía esencial y permite llegar o salir a / de esta vía & obra esencial \\
\hline 3 & $\begin{array}{l}\text { Sirve de soporte a una vía esencial, permite llegar o salir a / de esta vía y } \\
\text { conecta dos tramos homogéneos }\end{array}$ & obra de primera importancia esencial \\
\hline 4 & Sirve simplemente de soporte a una vía esencial & obra muy importante \\
\hline 5 & No sirve de soporte a una vía esencial pero permite llegar o salir a / de una vía esencial & obra bastante importante \\
\hline 6 & $\begin{array}{l}\text { No sirve de soporte a una vía esencial pero permite salvar una vía esencial y llegar o salir } \\
\text { a / de esta vía }\end{array}$ & obra importante bastante importante \\
\hline 7 & No sirve de soporte a una vía esencial y tampoco permite llegar o salir a / de una vía esencial & obra importante \\
\hline
\end{tabular}

esenciales (mapa 4-10). Se constata una fuerte concentración de elementos esenciales en el espacio central y en particular en la periferia del centro histórico hasta la avenida Patria, al norte.

En esta segunda parte se identificó los elementos materiales esenciales de la movilidad mediante variables cuantitativas, cualitativas y espaciales y se los cartografió. Se consideró como elementos esenciales ciertas obras viales (accesos al Distrito, ejes centro-periferia, vías urbanas) y algunos equipamientos de transporte (estaciones de transferencia, Terminal Terrestre Cumandá) en loscuales se basan los principales desplazamientos de personas e intercambios de primera importancia. Es en esta selección de elementos esenciales que se lleva a cabo a continuación el análisis de vulnerabilidad. 


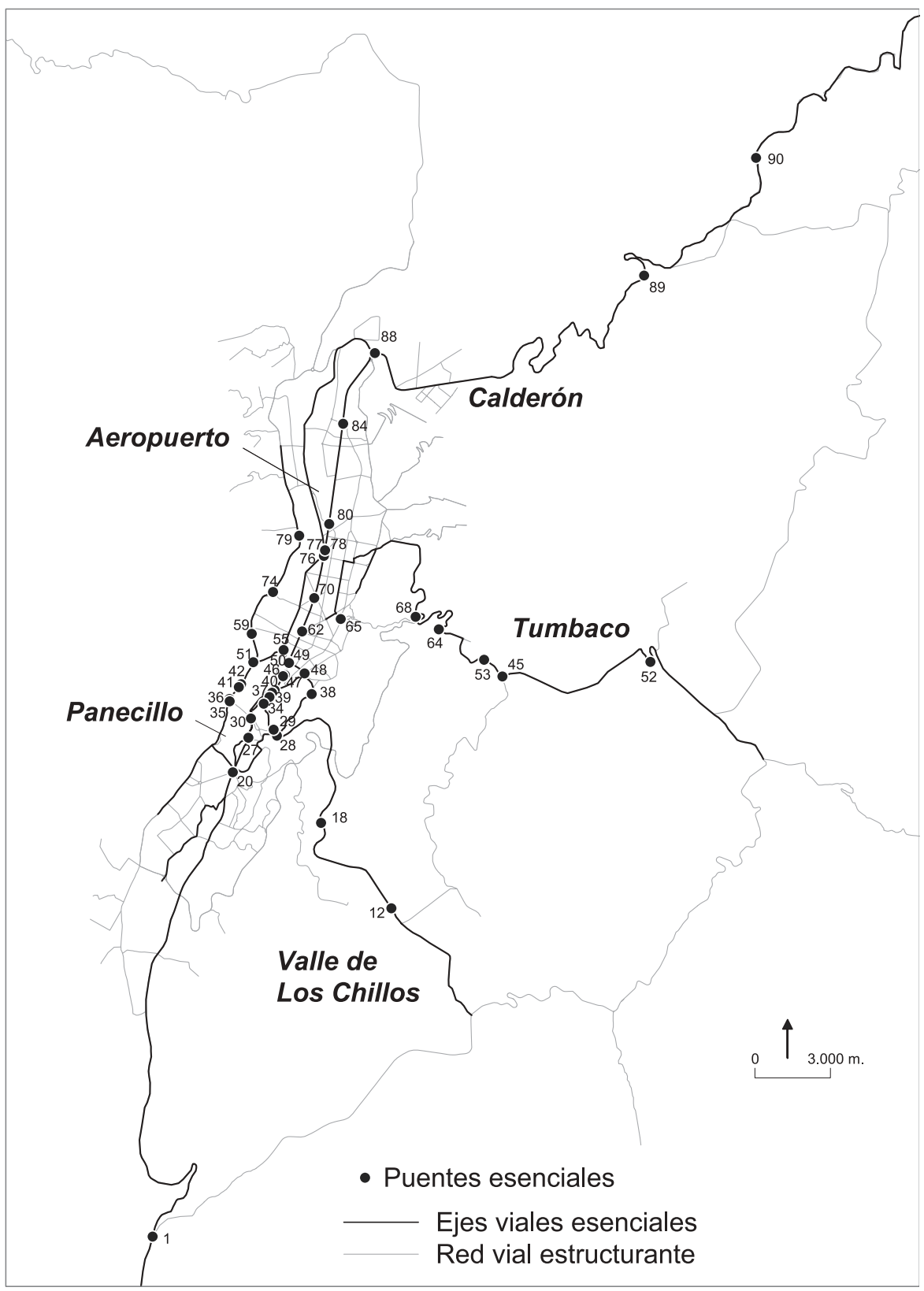

Mapa 4-8

Localización de los puentes viales esenciales, DMQ 




Mapa 4-9

Localización de los nodos esenciales de las redes de transporte colectivo

\section{Terminales y estaciones}

trolebús

$\Delta$ transporte interparroquial

- transporte urbano y interparroquial

$\checkmark$ transporte interprovincial

$\nabla$ transporte urbano, intercantonal e interparroquial 


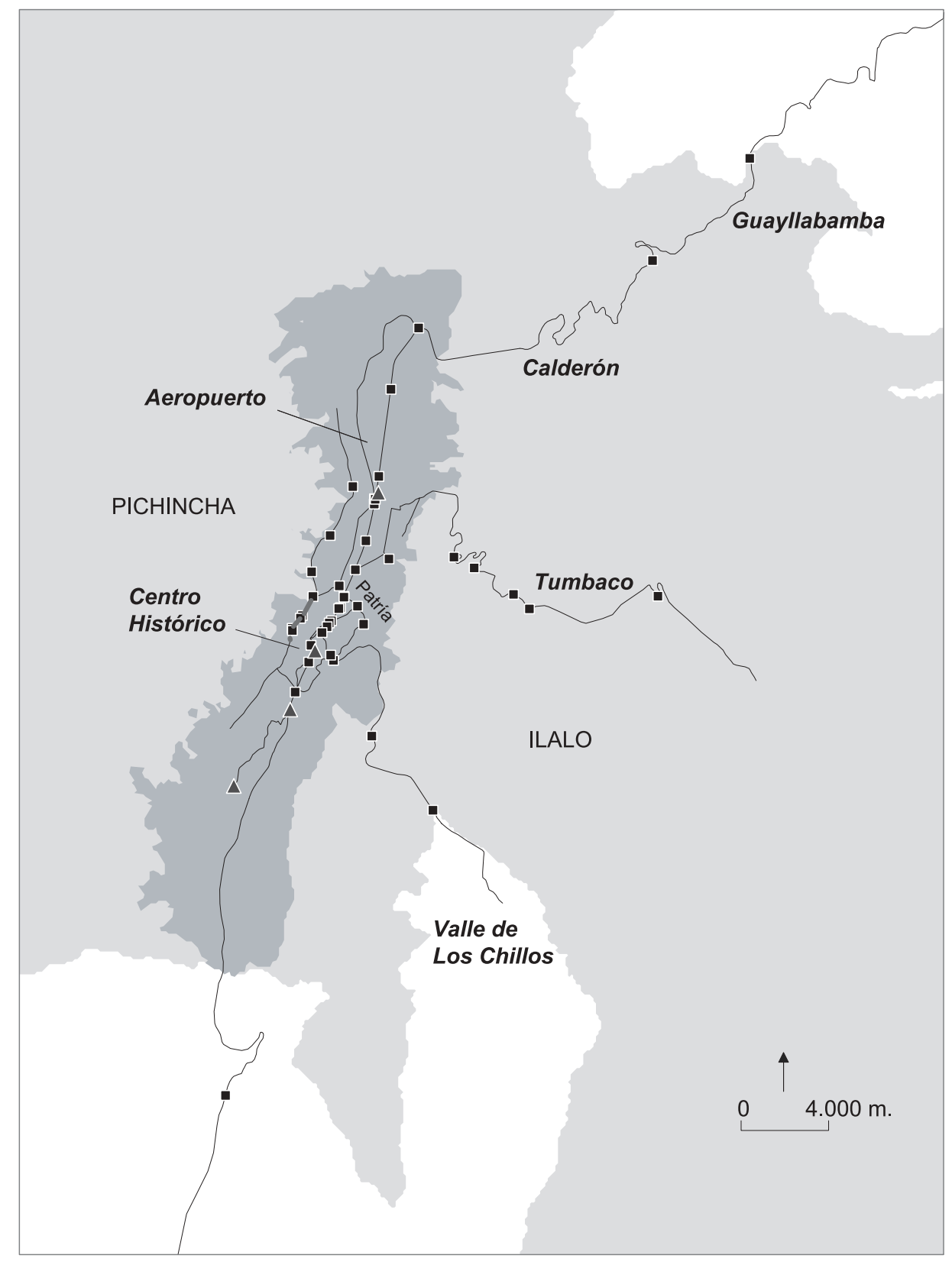

Mapa 4-10

Síntesis de los elementos esenciales de la movilidad, DMQ, 2003

Elementos esenciales

_ Ejes viales

- Túneles

- Centros de transporte

- Obras viales

Ciudad de Quito DMQ 


\section{LA VULNERABILIDAD DEL SISTEMA DE MOVILIDAD METROPOLITANA}

Una vez identificados los elementos esenciales de la movilidad, se plantea el análisis de su vulnerabilidad la cual podría predisponerlos a fallos o daños. La pérdida de operatividad de estos elementos esenciales conllevaría una reducción notoria de algunas accesibilidades y perturbaciones substanciales de la circulación vehicular. Para conocer estos fallos y daños potenciales, el análisisa continuación se enfoca en la comprensión de su vulnerabilidad a través de una metodología peculiar que considera tanto las debilidades como las fortalezas de los el ementos. Este estudio sirve como punto de partida para una reflexión ulterior sobre los riesgos a los cuales está expuesto el sistema ter ritorial en su conjunto (cuarta parte). 
I8 


\section{5 - La vulnerabilidad de los elementos esenciales de la movilidad y factores de compensación: presentación y aplicación}

El objetivo de este capítulo es describir la metodología de análisis de la vulnerabilidad de los elementos esenciales diseñada en el marco del programa de investigación. Esta metodología considera tanto la vulnerabilidad como las fortalezas de los elementos. Se detalla su aplicación específica al sistema de movilidad y se cartografían los resultados.

\section{El riesgo, un juego entre factores de vulnerabilidad y fortalezas}

Se usa el concepto de vulnerabilidad en los estudios de riesgo desde hace treinta años. Este concepto ha evolucionado en el transcurso de la última década integrando progresivamente más acepciones. A diferencia del riesgo, la vulnerabilidad no es una potencialidad, es tangible y se la puede medir de manera relativamente satisfactoria. R. D’Ercole (1998) considera la vulnerabilidad como "una expresión sintética de un determinado contexto, de un determinado número de condiciones propicias que son susceptibles de ocasionar daños o disfuncionamientos mayores en caso de concretización de una amenaza". La amenaza es un fenómeno de origen natural o antrópico cuyo advenimiento es incierto.
Generalmente, los estudios ponen énfasis en "las debilidades" pero se integra también cada vez más la otra dimensión del riesgo, es decir "las fortalezas" que permiten contrarrestar las primeras. Se menciona a menudo los conceptos de "resiliencia", "resistencia", aunque sus acepciones son múltiples. El término "resiliencia", inicialmente utilizado por los físicos anglosajones, caracteriza la resistencia de los cuerpos al choque. Desde entonces, su uso se fue ampliando. En su libro, A. Dauphiné (2001) indica que estos dos conceptos son "a menudo asociados a las capacidades de un sistema en restablecerse después de una catástrofe". C. Lutoff (2000), en la misma óptica, considera un amplio abanico de parámetros susceptibles en caso de sismo, de imposibilitar el mantenimiento de las funciones vitales (abastecimiento en agua, energía, comunicación) y considera por otro lado los elementos positivos que permiten mitigar los disfuncionamientos (construcciones parasísmicas, acciones de protección y prevención existentes). Adicionalmente, en algunos estudios se considera la noción de "capacidad de respuesta" entre las "fortalezas" que contribuyen a disminuir las vulnerabilidades (R. D’Ercole, F. Demoraes, 2003): "el niesgo es la resultante espacial de dinámicas negativas y también de dinámicas positivas cuyo papel es reducir el riesgo". Cual sea la terminología utilizada, el riesgo es entonces una interacción de vulnerabilidad contra- 
balanceada por factores de compensación característicos de los elementos esenciales (figura 5-1).

El riesgo inducido por el fallo, el daño o la pérdida de un elemento esencial es tanto mayor cuanto que el elemento esencial acumula muchos factores de vulnerabilidad y pocas fortalezas para compensarlos.

\section{Análisis de la vulnerabilidad en el marco del programa "Sistema de información y riesgos en el DMQ"}

\section{Las seis formas de vulnerabilidad consideradas}

En el marco del programa se identificó seis grandes formas de vulnerabilidad que parecieron pertinentes para intentar abarcar un amplio espectro de debilidades y fortalezas características de los elementos esenciales, cualquiera sea el tema considerado (economía, población, red eléctrica, red de agua potable, movilidad). Las seis formas consideradas son:

- La vulnerabilidad intrínseca: corresponde a las debilidades internas, a las propias fragilidades, a las debilidades estructurales del elemento estudiado.

- La dependencia: considera las relaciones de dependencia del elemento frente a otros sistemas, relaciones necesarias para su funcionamiento.

- La exposición a los peligros y la susceptibilidad de daño: abarca los diferentes tipos de amenazas de origen natural y antrópico a las cuales están expuestos los elementos y permite evaluar si estos últimos son susceptibles de experimentar disfuncionamientos o daños.
Figura 5-1

E riesgo, un juego de vulnerabilidad de los elementos esenciales contrabalanceada por factores de compensación

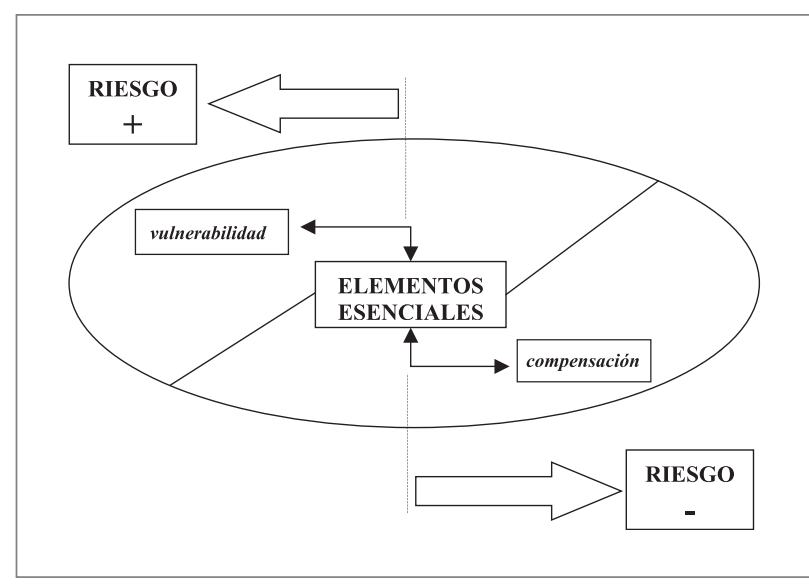

- La capacidad de control: se entiende la posibilidad de controlar el elemento. En otros términos, se analizó si es fácil o no intervenir a nivel del elemento, directamente o a distancia, en caso de problema.

- Las alternativas: consideran las posibilidades de reemplazo, de sustitución de un elemento con el fin de asegurar su función, en caso de fallo.

- La preparación a las crisis: corresponde a las medidas preventivas, diversas formas de preparación, existencia de planes previstos por los gestores para afrontar las crisis.

De modo general, se asocia las tres primeras formas a una serie de debilidades características de los elementos esenciales que tienden a aumentar el riesgo, mientras que se asocia más las tres últimas formas al con- 
junto de acciones o situaciones que tienden a contrarrestar las debilidades de los elementos esenciales y consecuentemente a reducir el riesgo. Sin embargo, esta visión es subjetiva porque al interior de cada una de las seis formas, no es siempre fácil clasificar los indicadores.

Generalmente, en los estudios clásicos de riesgo, se suele analizar las amenazas en primera instancia. Para esta investigación no se siguió igual procedimiento, sino que se empezó por identificar los elementos esenciales del funcionamiento de la movilidad. Después de haberlos identificado se analizó su vulnerabilidad y no se inició deliberadamente por la vulnerabilidad respecto a las amenazas en la medida en que "al considerar desde el principio el elemento esencial, se pueden identificar formas de vulnerabilidad independientes de su exposición. En efecto, el hecho de que un elemento de un territorio no esté expuesto a amenazas no significa que no haya vulnerabilidad: algunos elementos esenciales, a pesar de no estar en zonas de peligro, pueden depender para funcionar de uno o varios elementos vulnerables que pueden estar expuestos $^{\prime \prime 70}$. Se considera que existen factores que agravan seguramente aún más el funcionamiento cotidiano del sistema urbano sin que se concretice una amenaza. Es por eso que se analiza primero la vulnerabilidad intrínseca y la vulnerabilidad derivada de la dependencia, ámbitos en los cuales se puede desde ahora intervenir para reducir la vulnerabilidad.

Otra singularidad del procedimiento aplicado, en comparación con los estudios convencionales de riesgo, es considerar todos los peligros susceptibles de afectar a los asentamientos humanos en el Distrito. "Ello brinda la posibilidad de evidenciar mecanismos de encadenamientos cindinógenos de amenazas" ${ }^{\prime \prime 1}$.
Por ejemplo, las dos últimas enupciones volcánicas (1999 y 2002) ocasionaron caídas de ceniza afortunadamente limitadas (de 2 a $8 \mathrm{~mm}$ ). A pesar de lo cual, las perturbaciones y disfuncionamientos fueron relativamente numerosos ${ }^{72}$ y el depósito de materiales volcánicos dejó presentir la aparición de una segunda amenaza, la de las inundaciones que trastornan de manera no despreciable la movilidad. Los sedimentos volcánicos podían, con el escurrimiento de las aguas lluvias, ingresar al sistema de alcantarillado y tapar las redes ya insuficientes en época normal. Esta amenaza incentivó a los gestores municipales a implementar amplios programas de limpieza de las calzadas, como se lo detalla ulteriormente. Este ejemplo, entre otros, evidencia claramente el juego de interacciones que puede acontecer entre distintos peligros y justifica el hecho de privilegiar un enfoque multifenómeno.

\section{La exposición a las amenazas como una de las formas de vulnerabilidad}

“QQué posición ocupa la amenaza en el procedimiento propuesto? Para la evaluación y la reducción de los riesgos en un territorio, lo útil no es tanto la amenaza como tal sino la manera como ésta atañe a lo esencial para su funcionamiento. Lo que interesa es entonces la exposición a las amenazas de los elementos esenciales del Distrito en la medida en la que constituye un factor de vulnerabilidad. En efecto, si se entiende la vulnerabilidad como un conjunto de puntos débiles

\footnotetext{
70. Según una comunicación de R. D'Ercole presentada en febrero de 2004 al equipo III del laboratorio EDYTEM (Universidad de Saboya).

71. Idem.

72. Véase R. D'Ercole, P. Merzger, 2000
} 
o como la posibilidad de experimentar consecuencias más o menos graves con la ocurrencia de un fenómeno destructor, el hecho de estar expuesto a una amenaza es una forma de vulnerabilidad. Uno puede colocarse en situación de exposición con conocimiento de causa (se acepta entonces de buena gana ubicarse en situación de debilidad con algunas ganancias más o menos sustanciales en compensación) o inconscientemente, lo que también traduce debilidades en la medida en que no se ha sabido o podido identificar los peligros. La exposición a las amenazas va pues mucho más allá de un simple cruce espacial entre elementos esenciales y amenazas como se considera generalmente" $^{\prime \prime 3}$

Después de haber explicado los rasgos principales del enfoque utilizado en el marco del programa para analizar la vulnerabilidad, se presenta a continuación el método con el cual se evalúa la vulnerabilidad de los elementos esenciales del sistema de movilidad del Distrito y cuáles son los principales resultados.

\section{Análisis de la vulnerabilidad de los elementos esenciales del sistema de movilidad: procedi- miento e implementación}

\section{Un estudio en base a un amplio abanico de infor- maciones primarias}

Analizar la vulnerabilidad de un sistema de movilidad es una tarea compleja que requiere considerar un amplio abanico de datos. Este estudio se basa en diferentes fuentes con el fin de examinar el mayor número de formas de vulnerabilidad posibles entre las seis consideradas (intrínseca, dependencia, exposición a las amenazas, capacidad de control, alternativa, prepa- ración). Se consideraron las formas más visibles de vulnerabilidad del sistema, las más características, más perjudiciales, es decir, aquellas comúnmente identificadas por los gestores, ciudadanos e investigadores. No se puede analizar, sin embargo, la vulnerabilidad de los diferentes elementos esenciales en base a los mismos criterios y tampoco se puede utilizar los mismos documentos o interrogar a los mismos interlocutores sobre las seis formas de vulnerabilidad relativa a los diferentes elementos esenciales. Por eso se singularizó, entre los elementos esenciales, cuatro grandes tipos en función de sus propiedades, características y papel. Los cuatro tipos son:

\section{- Los tramos viales.}

- Los puentes (conjunto de obras viales que cuentan con una sección aérea).

\section{- Los túneles.}

- Los centros de transporte (la terminal terrestre y las estaciones de transferencia del trolebús).

La evaluación de la vulnerabilidad de los cuatro tipos de elementos esenciales se fundamenta en tres categonías de información primaria. Esta recolección inicial de información fue la primera etapa del análisis. Las tres categonías de información primaria son:

- consulta de reportes técnicos y de la prensa escrita.

- creación de datos específicos.

- entrevistas a los gestores.

73. R. D’Ercole, P. Metzger, 2004, p.6 


\section{Consulta de reportes y de la prensa}

Para entender las debilidades en tiempo normal, se revisó primero documentos, estudios, reportes realizados por los diferentes organismos a cargo del funcionamiento de la movilidad. Se utilizó el Plan Maestro de Transporte y Vialidad preparado por la Dirección Metropolitana de Transporte y Vialidad (MDMQ/DMT, 2002). Este documento menciona los múltiples problemas a los cuales están expuestos cada día el transporte y la movilidad de las personas en Quito. Las estadísticas de la Dirección Nacional de Tránsito fueron útiles para determinar los lugares conflictivos con el mayor número de accidentes. Otros reportes redactados por el equipo, en particular el de J. Estacio (2001), sobre el almacenamiento y transporte de combustibles, permitieron evaluar los ejes viales y lugares expuestos a los peligros de explosión e incendios. También se recopilaron fuentes de la prensa escrita de los diarios El Comercio y El Hoy de abril del 2000 a diciembre del 2002. A pesar de ciertas interrupciones, brinda una visión complementaria y resalta las relaciones y rivalidades entre actores.

Para discernir la fragilidad en las emengencias, el registro de prensa también fue instructivo porque permitió identificar los lugares sensibles en caso de manifestaciones, huelgas, es decir, los ejes frecuentemente propensos a perturbaciones. Se consultó, adicionalmente, los planes de contingencia ${ }^{74}$ elaborados en 1998 por el Municipio de Quito para afrontar una probable erupción del volcán Pichincha. Por último, algunas síntesis ponen énfasis en los disfuncionamientos ocurridos en el transcurso de las crisis pasadas, tales como las redactadas por R. D'Ercole y P. Metzger (2000) para la enupción del Pichincha y por J. Estacio y R. D’Encole (2003) para la erupción del Reventador.

\section{Creación de datos específicos}

En algunos ámbitos se generaron datos. Es el caso referido a la vulnerabilidad de los puentes esenciales del Distrito cuyo colapso conllevaría reducciones y rupturas de accesibilidades (Véase cuarta parte).

El estudio llevado a cabo por G. Atiaga y F. Demoraes (2002 y 2003), en colaboración con la Facultad de Ingeniería Civil de la Escuela Politécnica Nacional en la totalidad de las infraestructuras viales que cuentan con una sección aérea (90 obras), permitieron esbozar un panorama sobre su estado actual, también conocer aquellas susceptibles de experimentar graves daños en caso de sismo, tomando en cuenta sus características estructurales (material de construcción, alineación, número de vanos, longitud), su localización (suelos subyacentes) y la aceleración máxima esperada a nivel del suelo $\left(\mathrm{PGA}^{75}\right)$ asociada a los temblores. Este diagnóstico se fundamenta en una metodología de evaluación del riesgo sísmico adaptada del método HAZUS®99 implementado en los Estados Unidos por la Federal Emergency Management Agency (FEMA) en colaboración con el National Institute of Building Sciences (NIBS). Con este método se distinguen cinco niveles de daño: sin daño, ligeros, moderados, extensos, completos. Es también gracias a la colaboración de la Facultad de Ingeniería Civil que se pudo estimar la vulnerabilidad intrínseca de los túneles y centros de transporte ${ }^{76}$.

74. MDMQ, 1998, Plan de Contingencia.

75. Peak Ground Acceleration.

76. El Dr. Fabricio Yépez, profesor posgrado de la Facultad de Ingeniería Civil de la Escuela Politécnica del Ecuador, colaboró en este aspecto 


\section{Entrevistas a gestores}

A más de intercambios de opinión con funcionarios del Municipio, se realizó una serie de entrevistas ${ }^{77}$ con los gestores y técnicos a cargo de la administración de los diferentes elementos esenciales de la movilidad metropolitana. Estos interlocutores están al tanto de los principales problemas que afectan el funcionamiento de los elementos esenciales en tiempo normal o en caso de emergencia. Estas entrevistas permitieron confirmar o invalidar algunas formas de vulnerabilidad previamente reveladas y también discernir nuevas formas. En lo que se refiere a los elementos esenciales de la vialidad, se consultó a la EMOP-Q ${ }^{78}$ y la $\mathrm{DMT}^{79}$. En cuanto a las cuestiones relativas al transporte se consultó a la DMT, la EMSAT, la EMT ${ }^{80}$ y la $\mathrm{UOST}^{81}$. En lo que atañe a la gestión del tráfico, se hizo una entrevista a la central de semaforización municipal $^{82}$. Se contactó también algunos organismos que desempeñan un papel en las emergencias, como el Cuerpo de Bomberos (en especial para las intervenciones al interior de los túneles y su radio de acción).

Adicionalmente se hicieron recorridos de campo y se compartió diaria y directamente con el usuario cotidiano y ocasional del transporte colectivo algunos problemas relativos al traslado en bus y trole (baja frecuencia operativa horaria de algunas líneas, fallos técnicos de las unidades, prestación de servicio de transporte deficiente en algunas ocasiones). También, hubo una experiencia de conductor y se observaron los lugares de mayor congestión vehicular en las horas pico, los ejes saturados en los feriados, la baja conexidad de la red vial en algunos sectores). A más de estas informaciones primarias, se explotó un conjunto de datos ya integrados en la base del SIG Savane; es el caso de los mapas de amenaza que se describen posteriormente. Gracias a consultas y tratamientos en el SIG se pudo identificar otros factores de vulnerabilidad (pendientes, sinuosidad, ubicación de rellenos, alejamiento de los lugares esenciales de la movilidad respecto a la zona de intervención rápida de los bomberos).

En la siguiente sección se presenta el método de procesamiento que permitió evaluar la vulnerabilidad de los cuatro tipos de elementos esenciales (tramos viales, túneles, puentes, centros de transporte).

\section{Procedimiento y criterios de evaluación de la vulnerabilidad}

La vulnerabilidad asociada

a diferentes escalas sistémicas

Se buscó para las tres primeras formas de vulnerabilidad (intrínseca, dependencia, exposición a amenazas) los factores susceptibles de trastornar la movilidad cotidiana, dificultar las comunicaciones o conllevar problemas de accesibilidad. Para determinar estos factores se consideraron los parámetros previamente presentados. En este estudio, los criterios hacen referencia a varias escalas sistémicas. Los criterios pueden estar asociados a la vulnerabilidad relativa a la globalidad del sistema en el que se funda la movilidad (sis-

77. Las entrevistas fueron llevadas a cabo por Iván Parreño, pasante del IRD.

78. Ing. Masapanta. Departamento de Fiscalización de la EMOP-Q (en lo que atañe a los túneles).

79. Arq. Marroquín, Arq. Julio Arteaga, Arq. Gerardo Viteri, Dirección Metropolitana de Transporte y Vialidad.

80. Ing. Carlos Nielsen, Subgerente administrativo financiero de la terminal terrestre.

81. Ing. Carlos Poveda, Departamento de Operación del trolebús. 82. Ing. Roberto Cóndor, Central de Semaforización 
tema institucional, sistema vial, sistema de oferta de transporte, analizados en la primera parte). Por otro lado, pueden estar asociados a sistemas conexos (sistema eléctrico, sistema de abastecimiento de combustible) y también a la vulnerabilidad de los propios elementos materiales esenciales de la movilidad. Por ejemplo, la vulnerabilidad del trolebús remite al mismo tiempo (i) a la vulnerabilidad derivada del funcionamiento y de la gestión del servicio (desajuste de las cadencias, falta de sincronización con las líneas alimentadoras.), (ii) a la vulnerabilidad asociada a las relaciones entre sistemas (abastecimiento eléctrico) y (iii) a la vulnerabilidad de los propios vehículos (motores insuficientemente potentes o fácilmente deteriorados al contacto con el agua).

Adicionalmente, se consideró la vulnerabilidad institucional que agrava la movilidad diaria u ocasional. Afecta amplios sectores urbanos o solamente determinados elementos locales. Por ejemplo, la permanencia de un doble sistema de semaforización (el del Municipio y de la Policía) atribuible a la transferencia de competencia institucional iniciada en 1993 (Véase primera parte), imposibilita la gestión óptima del tránsito en la ciudad. La vulnerabilidad institucional se evidencia también a través de la rivalidad entre actores y puede tener repercusiones únicamente en ciertos elementos. Este es el caso del litigio entre el Consejo Provincial de Pichincha (organismo a cargo de parte de la red vial metropolitana) y Tribasa Colisa (empresa concesionaria) en cuanto a la autopista Rumiñahui. Este conflicto origina perturbaciones ocasionales de la circulación en este eje (cierre de la vía por protestas de los usuarios).

En cuanto a las otras tres formas de vulnerabilidad (capacidad de control, alternativas, preparación a las cri- sis) se buscó factores que tienden a contrarrestar las tres primeras formas. Por ejemplo el sistema institucional cuyo funcionamiento revela ciertas formas de vulnerabilidad, puede presentar por otro lado fortalezas al haber preparado planes de contingencia. En la misma óptica, el sistema de oferta de transporte puede tener dificultades para funcionar cada día, pero puede organizarse para afrontar una emergencia, por ejemplo si posee almacenamiento de combustibles, si prevé itinerarios de desvío en caso de cierre de los recomidos habituales. En el caso del sistema vial, una obra puede encontrarse sobre un relleno pero puede ser construida según las normas parasísmicas, lo que limita su susceptibilidad de daño en caso de terremoto.

Se consideró estas diferentes formas de vulnerabilidad para los cuatro tipos de elementos esenciales. El objetivo era cartografiar la vulnerabilidad con el fin de tener una visión general y proponer a los gestores documentos fácilmente comprensibles. Obviamente, el desentrañamiento de la vulnerabilidad está condicionado por el contexto local. En el caso de Quito es una particularidad la yuxtaposición de ambos sistemas de semaforización. En cambio otras formas de vulnerabilidad observadas en otras ciudades no se encuentran necesariamente en Quito (por ejemplo, la gran dificultad en Cuba para importar repuestos para autos, no es tan grave en el Ecuador). A pesar de todo, en una perspectiva de reproducción del método, se trató de considerar el mayor espectro posible de factores de vulnerabilidad.

\section{Los criterios de evaluación de la vulnerabilidad}

Las tablas 5-1 y 5-2 indican los criterios considerados para analizar los factores de vulnerabilidad y fortalezas de los elementos esenciales del sistema de movilidad de Quito. 
Movilidad, elementos esenciales y riesgos en el Distrito Metropolitano de Quito

Tabla 5-1

Matriz sinóptica de las variables analizadas para evaluar las tres primeras formas de vulnerabilidad de los elementos esenciales del transporte

\begin{tabular}{|c|c|c|c|c|c|c|c|c|}
\hline & \multicolumn{8}{|c|}{ FORMAS DE VULNERABILIDAD } \\
\hline & \multicolumn{4}{|c|}{ 1- INTRINSECA } & \multicolumn{2}{|l|}{ 2- DEPENDENCIA } & \multicolumn{2}{|c|}{ 3- EXPOSICION A AMENAZAS Y SUSCEPTIBILIDAD DE DAÑO } \\
\hline & $\begin{array}{l}\text { Variables analizadas } \\
\text { (vialidad) }\end{array}$ & Amplitud & $\begin{array}{l}\text { Variables analizadas } \\
\text { (transporte) }\end{array}$ & Amplitud & Variables analizadas & Amplitud & Amenazas analizadas & Amplitud \\
\hline \multirow{8}{*}{ 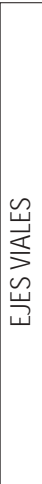 } & Estado de la rodadura & $0-2$ & Propenso a la congestión vehicular diaria & $0-4$ & Electricidad (semáforos + catenario) & $0-4$ & Aluviones & $0-4$ \\
\hline & Operatividad & $0-4$ & $\begin{array}{l}\text { Grado de contaminación derivado } \\
\text { de la emanación de los buses }\end{array}$ & $0-4$ & Asfalto (mantenimiento) & $0-2$ & Inundaciones & $0-4$ \\
\hline & $\begin{array}{l}\text { Número de sistemas } \\
\text { de semaforización }\end{array}$ & $0-2$ & Accidentalidad & $0-4$ & Medio de comunicación (radio) & $0-4$ & Inestabilidad de los suelos (deslizamiento, derrumbe, hundimiento) & $0-4$ \\
\hline & Pendiente máxima & $0-2$ & $\begin{array}{l}\text { Propenso a perturbaciones ocasionales } \\
\text { (manifestación, saturación en } \\
\text { los feriados, mantenimiento vial) }\end{array}$ & $0-2$ & & & Sismos (amplificación de las ondas vibratorias y liquefacción) & $0-4$ \\
\hline & Sinuosidad & $0-2$ & $\begin{array}{l}\text { Sirve de soporte a un servicio de } \\
\text { TC frágil }\end{array}$ & $0-2$ & & & Caída de ceniza volcánica & $0-2$ \\
\hline & Número de rellenos & $0-2$ & $\begin{array}{l}\text { ¿Recorrido principal del transporte } \\
\text { de combustible? }\end{array}$ & $0-2$ & & & Lahares, flujos piroclásticos, gases, lava & $0-4$ \\
\hline & $\begin{array}{l}\text { Número de secciones aéreas } \\
\text { (puentes, pasos elevados) }\end{array}$ & $0-2$ & & & & & Explosiones de productos peligrosos & $0-4$ \\
\hline & $\begin{array}{l}\text { Número de secciones } \\
\text { subterráneas (túneles) }\end{array}$ & $0-2$ & & & & & & \\
\hline
\end{tabular}

\begin{tabular}{|l|l|c|l|l|l|}
\hline \multirow{5}{*}{} & Daños y deterioro aparentes de la estructura & $0-4$ & Ninguna dependencia & $0-4$ & Aluviones \\
\cline { 2 - 6 } & Material de construcción & $0-4$ & & $0-4$ \\
\cline { 2 - 6 } & Construcción para sísmica & $0-4$ & & Inundaciones \\
\cline { 2 - 6 } & Suelos subyacentes (suelos inclinados o relleno) & $0-2$ & & Inestabilidad de los suelos (deslizamiento, derrumbe, hundimiento) & $0-4$ \\
\cline { 2 - 6 } & & & & Sismos (amplificación de las ondas vibratorias y licuefacción) & $0-4$ \\
\hline & & & & Caída de ceniza volcánica \\
\hline
\end{tabular}

\begin{tabular}{|c|c|c|c|c|c|c|}
\hline \multirow{7}{*}{$\begin{array}{l}\text { 过 } \\
\text { 号 } \\
\text { 글 }\end{array}$} & Longitud & $0-4$ & Electricidad (ventiladores y alumbrado) & $0-4$ & Aluviones & $0-4$ \\
\hline & Estado de rodadura en los tubos & $0-2$ & & & Inundaciones & $0-4$ \\
\hline & Debilidades en la construcción de los tubos & $0-4$ & & & Inestabilidad de los suelos (deslizamiento, derrumbe, hundimiento) & $0-4$ \\
\hline & Alumbrado (deficiencia) & $0-2$ & & & Sismos (amplificación de las ondas vibratorias y liquefacción) & $0-4$ \\
\hline & Ventilación (deficiencia) & $0-2$ & & & Caída de cenizas volcánicas & $0-2$ \\
\hline & Limpieza necesaria & $0-2$ & & & Lahares, flujos piroclásticos, gases, lava & $0-4$ \\
\hline & & & & & Explosiones de productos peligrosos & $0-4$ \\
\hline
\end{tabular}

\begin{tabular}{|c|c|c|c|c|c|c|}
\hline \multirow{7}{*}{ 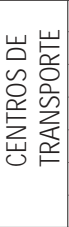 } & Daños y deterioro aparentes de la estructura & $0-4$ & Electricidad & $0-4$ & Aluviones & $0-4$ \\
\hline & Inflamabilidad & $0-4$ & Personal & $0-4$ & Inundaciones & $0-4$ \\
\hline & Construcción para sísmica & $0-4$ & & & Inestabilidad de los suelos (deslizamiento, derrumbe, hundimiento) & $0-4$ \\
\hline & Presencia de rellenos subyacentes & $0-4$ & & & Sismos (amplificación de las ondas vibratorias y licuefacción) & $0-4$ \\
\hline & Otras & $0-4$ & & & Caída de ceniza volcánica & $0-2$ \\
\hline & & & & & Lahares, flujos piroclásticos, gases, lava & $0-4$ \\
\hline & & & & & Explosiones de productos peligrosos & $0-4$ \\
\hline
\end{tabular}


Tabla 5-2

Matriz sinóptica de las variables analizadas para evaluar las tres últimas formas de vulnerabilidad de los elementos esenciales del transporte

\begin{tabular}{|c|c|c|c|c|c|c|}
\hline & \multicolumn{6}{|c|}{ FORMAS DE VULNERABILIDAD } \\
\hline & \multicolumn{2}{|c|}{ 4- CAPACIDAD DE CONTROL } & \multicolumn{2}{|l|}{5 - ALTERNATIVAS } & \multicolumn{2}{|l|}{6 - PREPARACION A LAS CRISIS } \\
\hline & Variables analizadas & Amplitud & Variables analizadas & Amplitud & Variables analizadas & Amplitud \\
\hline \multirow{8}{*}{ 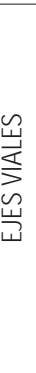 } & $\begin{array}{l}\text { Personal asignado para la gestión } \\
\text { del tráfico y/o del transporte colectivo }\end{array}$ & $0-4$ & $\begin{array}{l}\text { Desvío necesario para conectar ambos } \\
\text { extremos de un tramo por otro itinerario }\end{array}$ & $0-4$ & ¿Vehículos asignados? & $0-4$ \\
\hline & Medio de comunicación & $0-4$ & $\begin{array}{l}\text { Aptitud a la circulación en los } \\
\text { itinerarios de descongestión }\end{array}$ & $0-2$ & ¿Zona de intervención rápida de los bomberos? & $0-4$ \\
\hline & Telecontrol de la semaforización & $0-4$ & Adaptabilidad de los servicios de transporte & $0-4$ & ¿Proximidad del SIAT? & $0-4$ \\
\hline & Control por cámara video autonomía & $0-2$ & Alternativa energética & $0-4$ & ¿Los modos de transporte colectivo tienen una energética superior a 72 horas? & $0-4$ \\
\hline & Concesión vial & $0-2$ & & & ¿Existencia de un plan de descongestión señalado en caso de cierre de un eje? & $0-2$ \\
\hline & Accesibilidad & $0-4$ & & & $\begin{array}{l}\text { ¿Plan previsto de limpieza de las calzadas en caso de erupción del volcán } \\
\text { Pichincha (Octubre 1999)? }\end{array}$ & $0-2$ \\
\hline & & & & & ¿M onitoreo reforzado por el CCO en la crisis del Pichincha (Octubre 1999)? & $0-2$ \\
\hline & & & & & $\begin{array}{l}\text { ¿Limpieza de las calzadas después de la erupción del volcán Reventador } \\
\text { (Noviembre 2002)? }\end{array}$ & \\
\hline
\end{tabular}

\begin{tabular}{|l|l|l|l|l|l|}
\hline \multirow{2}{*}{$\begin{array}{l}\text { Personal asignado para la gestión del } \\
\text { tráfico y/0 del transporte colectivo }\end{array}$} & $0-4$ & $\begin{array}{l}\text { Grado de complicación de la circulación en } \\
\text { el eje vial esencial en caso de desplome } \\
\text { de la sección aérea de las obras }\end{array}$ & 0-4 & ¿Vehículos asignados? \\
\cline { 2 - 6 } & Control por cámara video & $0-4$ & & & ¿-4ona de intervención rápida de los bomberos? \\
\cline { 2 - 6 } & Accesibilidad & $0-4$ & & ¿Existencia de planes de gestión de crisis frente a todos tipos de fenómenos? & ¿Equipo de intervención especial? \\
\cline { 2 - 6 } & & & & $\begin{array}{l}\text { ¿Plan previsto de limpieza de las calzadas en caso de erupción del volcán } \\
\text { Pichincha (Octubre 1999)? }\end{array}$ \\
\cline { 2 - 6 } & & & & ¿M onitoreo resforzado por el CCO en la crisis del Pichincha (Octubre 1999)? & $0-4$ \\
\hline
\end{tabular}

\begin{tabular}{|l|l|c|l|l|l|}
\hline \multirow{5}{*}{} & $\begin{array}{l}\text { Presencia de policías a las entradas de } \\
\text { los túneles }\end{array}$ & $0-4$ & $\begin{array}{l}\text { Grado de complicación de la circulación en el eje } \\
\text { vial esencial en caso de cierre de los túneles }\end{array}$ & $0-4$ & ¿Vehículos asignados? \\
\cline { 2 - 6 } & Control por cámara video & $0-2$ & & & ¿Zona de intervención rápida de los bomberos? \\
\cline { 2 - 6 } & $\begin{array}{l}\text { Presencia de hidrantes al interior } \\
\text { de los tubos }\end{array}$ & $0-4$ & & & ¿Proximidad del SIAT? \\
\cline { 2 - 6 } & Comunicación entre tubos & $0-4$ & & & ¿Existencia de planes? \\
\cline { 2 - 6 } & Vía reservada a los socorristas & $0-4$ & & ¿Equipo de intervención especial? \\
\cline { 2 - 6 } & Accesibilidad & $0-4$ & & ¿Organización de simulaciones? \\
\cline { 2 - 6 } & & & ¿M onitoreo reforzado por el CCO en la crisis del Pichincha (Octubre 1999)? & $0-4$ \\
\hline
\end{tabular}

\begin{tabular}{|c|c|c|c|c|c|c|}
\hline \multirow{6}{*}{ 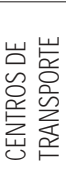 } & Grado de presencia del personal en el sitio & $0-4$ & ¿Posibilidad de transferencia? & $0-4$ & ¿Propia capacidad para apagar incendios? & $0-4$ \\
\hline & Control por cámara video & $0-2$ & Alternativa energética & $0-4$ & ¿Zona de intervención rápida de los bomberos? & $0-4$ \\
\hline & Altoparlante & $0-2$ & & & ¿Existencia de planes? & $0-4$ \\
\hline & Accesibilidad & $0-4$ & & & ¿Preparación del personal? & $0-4$ \\
\hline & & & & & ¿Organización de simulaciones? & $0-4$ \\
\hline & & & & & ¿Posibilidad de comunicar con el exterior? & $0-4$ \\
\hline
\end{tabular}


Para completar el análisis de vulnerabilidad se utilizó, además de la información primaria, las capacidades de procesamiento de un SIG.

\section{El uso de un SIG para analizar ciertas formas de vulnerabilidad}

Un SIG revela ciertas formas de vulnerabilidad mediante tratamientos específicos que recurren a la dimensión espacial de los fenómenos. En la investigación se utilizó una serie de consultas geomáticas que sirvieron para:

- medir las características de los objetos (pendiente, longitud, sinuosidad).

- medir las distancias (alejamiento respecto a los perímetros de intervención de los bomberos, evaluación de los desvíos necesarios en caso de fallo de un elemento).

- determinar la accesibilidad de los elementos esenciales (inventariando el número de entradas y salidas a/de zonas).

- superponer la localización de los elementos esenciales y otros fenómenos (congestión vehicular, itinerario de circulación de los productos peligrosos, rellenos, exposición a amenazas).

Se presenta a continuación algunos ejemplos de análisis realizados en el SIG "Savane".

\section{El cálculo de las pendientes de los tramos viales}

La pendiente es un factor pertinente en un análisis de vulnerabilidad de la movilidad porque influencia su peligrosidad en tiempo normal. Mientras más empinado, mayor es la velocidad de los vehículos y mayores son los accidentes (tanto más, si la vía es sinuosa). La pendiente también es un factor limitante, por ejemplo, en cuanto al acceso de ciertos vehículos (bomberos, ambulancias) a algunos sectores muy empinados. En Quito, por el hecho de que los desniveles son considerables y la topografía irregular, los tramos cuya pendiente excede el 10 por ciento, no son escasos.

El SIG "Savane" brinda la opción de calcular el promedio de la pendiente de cualquier objeto lineal o zonal integrado en la base a partir de un Modelo Numérico de Terreno (MNT). Se considera que la pendiente de un tramo vial es alta cuando más de un cuarto de su longitud excede una pendiente del 10 por ciento. Se considera que la pendiente es media cuando más de un cuarto de su longitud tiene una pendiente entre el 5 y 10 por ciento. Se considera que la pendiente de un tramo es débil cuando ninguna sección excede una pendiente del 5 por ciento (mapa 5-1).

Alejamiento de los elementos esenciales de la movilidad respecto a la localización de las compañías de bomberos

Para analizar los factores de compensación se localizó los diferentes elementos esenciales de la movilidad respecto al radio de intervención de los bomberos. El Cuerpo de Bomberos de Quito depende del Municipio e interviene principalmente en casos de incendio (de edificios o de tránsito) y de inundaciones (de los sótanos de los edificios y de los pasos deprimidos). El hecho de que los bomberos estén presentes rápidamente en lugares determinados es una ventaja para estos lugares. Cabe destacar que en Quito otros actores intervienen en caso de accidentes de tránsito como el SIAT, DNT, 911, pero no se pudo colectar información suficiente de estos últimos organismos. Por 
Mapa 5-1

Pendiente de los ejes viales esenciales por tramo

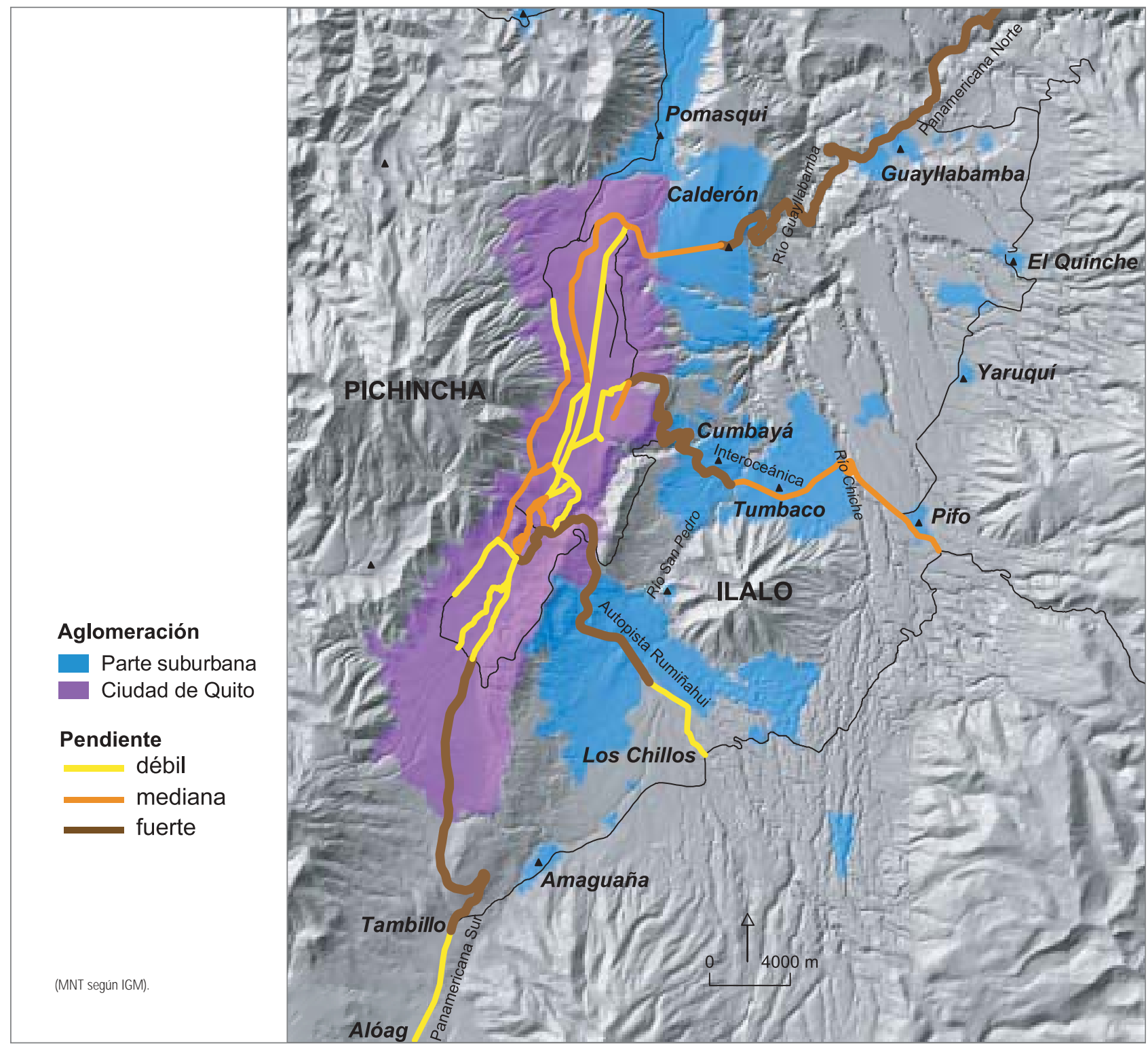


tanto, el estudio se restringe únicamente a las intervenciones de los bomberos, que se cartografió en base al registro de 500 salidas de emergencia realizadas en un período de cuatro meses (de septiembre a diciembre de 2000), de las siete compañías ubicadas en la urbe. Se determinó perímetros de intervención preferenciales por compañía, es decir las zonas urbanas en las que una compañía atiende al menos al 80 por ciento de las llamadas de emergencia. Cada intervención es cronometrada; el registro contiene la duración requerida por los equipos de socorro para llegar al lugar siniestrado. Se determinó zonas isócronas de intervención asociadas a cada una de las siete compañías, luego se las fusionó para conseguir una cobertura promedio de los bomberos en la ciudad (mapa 5-2). Se consideró el límite de 10 minutos, más allá del cual la eficacia de la acción de los bomberos ya es muy reducida (por ejemplo, en caso de accidente de tránsito o de incendio).

En la ciudad se analizó si cada elemento se encuentra dentro de la zona de intervención rápida (menos de 10 minutos). En las partes suburbanas se midió el alejamiento de los elementos esenciales respecto a las compañías de Checa y Sangolquí. No se indica el radio de acción de estas dos compañías porque se inauguró la de Checa en el 2002, luego de terminado el estudio. En cuanto a la de Sangolquí, se ubica fuera del DMQ y depende del cantón Rumiñahui. Se evidencia una relativa buena cobertura de la ciudad por los bomberos. De su lado, las zonas suburbanas (Calderón, Guayllabamba, Pomasqui) se encuentran en una situación mucho menos favorable.
Las amenazas: una multitud de fenómenos presentes

El DMQ está expuesto a varios peligros, algunos tienen una extensión nacional, incluso supranacional y otros más locales. De modo general, Ecuador es altamente expuesto a las amenazas de origen natural por sus características físicas y geográficas:

- Precipitaciones abundantes y/o con altas intensidades.

- Sucesión de estaciones secas con estaciones lluviosas.

- Desniveles importantes (más de 5.000 metros, en algunos casos en cortas distancias).

- Laderas abruptas y extensas.

- Formaciones geológicas sensibles a la erosión.

- Situación ecuatorial en la orilla del Océano Pacífico (eje del ENOS ${ }^{83}$ ).

- Amplias llanuras fluviales costeras con pendientes débiles (cuenca del Guayas).

- Zona de subducción de la placa Nazca con la de Sudamérica (de las más activas del mundo, etc).

El DMQ está expuesto a todos los tipos de amenazas de origen natural observadas a nivel nacional excepto inundaciones fluviales y tsunamis. En el transcurso de los últimos dos siglos, el evento volcánico que provocó mayores destrucciones en la red vial en el Distrito fue la erupción del Cotopaxi en 1877. De su lado, las últimas dos erupciones volcánicas (la del Guagua Pichincha en 1999 y del Reventador en el 2002) no generaron lahares. Sin embargo las débiles caídas de cenizas (algunos milímetros como máximo) ocasionaron

83. El Niño Oscilación del Sur. 
Mapa 5-2

Radio de acción del Cuerpo de Bomberos del DMQ, Ciudad de Quito, 2000

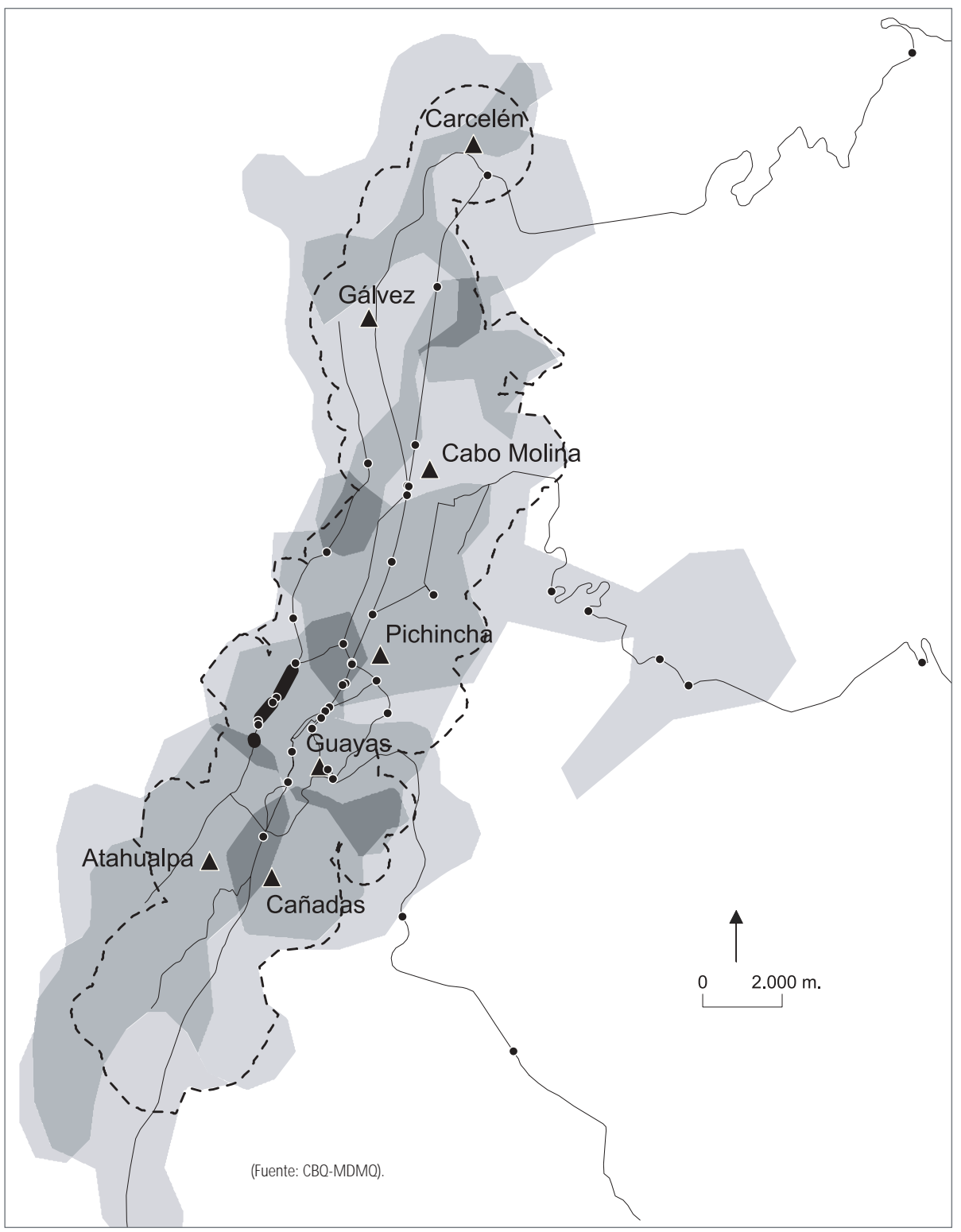

Elementos esenciales

- Puente

$\bigoplus$ Túne

Eje vial

Zona cubierta en menos de 10 minutos

Compañías

de bomberos

Zonas cubiertas por:

una sola compañía

dos compañías

tres compañías

zona en la que los bom-

beros no intervienen o en muy escasa ocasión 
consecuencias no despreciables (perturbaciones del tráfico, cierre de vías y reducción de la accesibilidad aérea).

Por otro lado, a causa del gran sismo de 1987 (cuya intensidad en Quito fue de VI en la escala de Mercalli modificada) los daños en las construcciones fueron signiticativos y los desplazamientos de personas trastornados, debido a múltiples deslizamientos de tierra asociados al temblor en algunos ejes viales mayores.

Con excepción de sismos y enupciones volcánicas, otros fenómenos físicos menores mucho más locales suelen ocurrir regularmente. Se trata, en particular, de las inundaciones, deslizamientos, hundimientos, aluviones que pueden deteriorar la red vial y obstaculizar la circulación vehicular. Se califica generalmente las amenazas geofísicas como "naturales" pero los procesos que conllevan al daño remiten más bien a las modalidades de urbanización que condicionan la susceptibilidad de daño. En Quito se generan inundaciones, deslizamientos, aluviones luego de fuertes precipitaciones en las cuales el hombre no interviene. Pero la casi totalidad de estos fenómenos ocurren o son acentuados por el hecho de las modificaciones de la red hidrográfica original y los cortes operados en los taludes para construir vías.

Adicionalmente, otros peligros coexisten. Se trata de las amenazas inducidas por el transporte de productos peligrosos o por algunas instalaciones de almacenamiento de productos inflamables (El Beaterio).

Las zonas expuestas a los diferentes fenómenos perjudiciales previamente mencionados fueron cartografiadas. En base a estos mapas integrados en el SIG, se pudo evaluar la exposición de los elementos esenciales del sistema de movilidad.
Las amenazas: cartografía de los fenómenos y medición de la exposición

Varios organismos se encargan de generar mapas de amenazas en Quito. La tabla 5-3 indica los que se utilizó en este estudio.

Se consideró los cinco tipos de peligros siguientes:

- Aluviones, flujos de lodo.

- Inestabilidad de los suelos (deslizamientos, hundimientos, derrumbes).

- Inundaciones.

- Sismos (suelos propensos a la licuefacción, suelos que acentúan las ondas vibratorias).

- Erupciones volcánicas (lahares, flujos piroclásticos, gases, lava y caída de ceniza).

Para algunos fenómenos se dispone de un solo mapa. Para otros, varios documentos cartográficos existen. En este caso, se realizó tratamientos geomáticos en el SIG, con el fin de identificar los lugares reconocidos por los diferentes autores como expuestos (tabla 5-3). Se realizó dos operaciones: las intersecciones y las uniones (o fusiones). Las primeras permiten guardar únicamente los sectores que son comúnmente identificados como expuestos. En otros términos, el resultado es una restricción de zonas entre las más susceptibles de estar amenazadas. Se asoció esta restricción de modo esquemático a un nivel mayor de peligro. El segundo tipo de operación (las uniones) guarda todos los espacios percibidos como expuestos por las diferentes fuentes, pero que no logran la unanimidad. Se asocia los resultados de las uniones a un nivel moderado de amenaza. No se descarta el hecho de que ciertas obras (retención de sedimentos en las quebradas 
Tabla 5-3

Descripción de los mapas de amenazas consideradas y tratamientos realizados para llegar a grados sintéticos de peligro.

\begin{tabular}{|c|c|c|c|c|}
\hline \multirow[t]{2}{*}{ Peligro } & \multirow[t]{2}{*}{ Referencias cartográficas } & \multirow{2}{*}{$\begin{array}{l}\text { Escala de } \\
\text { digitalización }\end{array}$} & \multicolumn{2}{|c|}{ Metodología de determinación de los niveles de amenaza } \\
\hline & & & Alto peligro & Peligro moderado \\
\hline $\begin{array}{l}\text { Aluviones/ } \\
\text { Flujo de lodo }\end{array}$ & $\begin{array}{l}\text { Mapa 1: Resultados de las investigaciones de Pierre Peltre } \\
\text { (IRD) en la frecuencia de los aluviones en Quito (período 1900- } \\
\text { 1988) y localización de los sectores afectados. }\end{array}$ & $1 / 20.000$ & $\begin{array}{l}\text { Sectores afectados más de una } \\
\text { vez }\end{array}$ & $\begin{array}{l}\text { Todos los sectores que ya fue- } \\
\text { ron siniestrados en el pasado }\end{array}$ \\
\hline \multirow{3}{*}{$\begin{array}{l}\text { Inestabilidad } \\
\text { de suelos }\end{array}$} & $\begin{array}{l}\text { Mapa 2: Susceptibilidad de deslizamientos en la ciudad de } \\
\text { Quito (EPN) - } 1993\end{array}$ & $1 / 50.000$ & \multirow{3}{*}{$\begin{array}{l}\text { Intersección de los sectores los } \\
\text { más expuestos, representados } \\
\text { en los mapas } 2 \text { y } 3 \text {, y unión con } \\
\text { los sectores afectados más de } \\
\text { una vez, localizados en el } \\
\text { mapa } 4\end{array}$} & \multirow{3}{*}{$\begin{array}{l}\text { Intersección de los sectores re- } \\
\text { presentados como al menos } \\
\text { moderamente expuestos en los } \\
\text { mapas } 2 \text { y } 3 \text {, y unión con los } \\
\text { sectores afectados una sola } \\
\text { vez en el pasado, localizado en } \\
\text { el mapa } 4\end{array}$} \\
\hline & $\begin{array}{l}\text { Mapa 3: Estabilidad geomorfológica de la aglomeración de } \\
\text { Quito (Atlas Infográfico de Quito, 1992) }\end{array}$ & $1 / 50.000$ & & \\
\hline & $\begin{array}{l}\text { Mapa 4: Resultados de las investigaciones de Pierre Peltre } \\
\text { (IRD) en la frecuencia de los deslizamientos, derrumbes y hun- } \\
\text { dimientos en Quito (periodo 1900-1988) y localización de los } \\
\text { sectores afectados }\end{array}$ & $1 / 20.000$ & & \\
\hline \multirow{3}{*}{ Inundaciones } & $\begin{array}{l}\text { Mapa 5: Inundaciones en Quito debidas a la insuficencia de } \\
\text { los colectores de alcantarilldo (EM AAP, 2000) }\end{array}$ & $1 / 20.000$ & \multirow{3}{*}{$\begin{array}{l}\text { Intersección de las zonas ex- } \\
\text { puestas a inundaciones en los } \\
\text { mapas } 5,6 \text { y } 7 \text { (zonas comunes } \\
\text { expuestas en los tres mapas) }\end{array}$} & \multirow{3}{*}{$\begin{array}{l}\text { Unión de las zonas expuestas a } \\
\text { inundaciones en los mapas } 5,6 \\
\text { y } 7 \text { (fusión de las zonas expues- } \\
\text { tas en los tres mapas) }\end{array}$} \\
\hline & $\begin{array}{l}\text { Mapa 6: Zonas inundables en Quito (Atlas Infográfico de Qui- } \\
\text { to, 1992) }\end{array}$ & $1 / 50.000$ & & \\
\hline & $\begin{array}{l}\text { Mapa 7: Resultados de las investigaciones de Pierre Peltre } \\
\text { (IRD) sobre la frecuencia de las inundaciones en Quito (período } \\
\text { 1900-1988) y localización de los sectores siniestrados }\end{array}$ & $1 / 20.000$ & & \\
\hline \multirow[t]{2}{*}{ Sismos } & $\begin{array}{l}\text { Mapa 8: M icrozonificación sísmica de los suelos del Distrito } \\
\text { M etropolitano de Quito (EPN) - Convenio Escuela Politécnica } \\
\text { Nacional y M unicipio de Quito - Abril } 2001 .\end{array}$ & $1 / 175.000$ & \multirow{2}{*}{$\begin{array}{l}\text { Zonas altamente expuestas del } \\
\text { mapa } 8 \text { y unión con las zonas } \\
\text { expuestas del mapa } 9\end{array}$} & \multirow{2}{*}{$\begin{array}{l}\text { Zonas moderada y altamente } \\
\text { expuestas del mapa } 8 \text { y unión } \\
\text { con las zonas expuestas del } \\
\text { mapa } 9\end{array}$} \\
\hline & $\begin{array}{l}\text { Mapa 9: Sectores propensos a la licuefacción (Atlas Infográfi- } \\
\text { co de Quito, 1992) }\end{array}$ & $1 / 50.000$ & & \\
\hline $\begin{array}{l}\text { Erupciones } \\
\text { volcánicas }\end{array}$ & $\begin{array}{l}\text { Mapa 10: Amenazas asociadas a los volcanes Guagua Pichin- } \\
\text { cha, Cotopaxi, Pululahua y Ninahuilca (EPN) }\end{array}$ & $1 / 50.000$ & $\begin{array}{l}\text { Los sectores más altamente ex- } \\
\text { puestos del mapa } 10 \text { (a nivel } \\
\text { del Distrito) y unión con los } \\
\text { sectores de Quito moderamen- } \\
\text { te expuestos (porque cuentan } \\
\text { con un mayor número de ele- } \\
\text { mentos esenciales) }\end{array}$ & $\begin{array}{l}\text { Todos los sectores expuestos a } \\
\text { una amenaza volcánica cual } \\
\text { sea su grado }\end{array}$ \\
\hline
\end{tabular}


Mapa 5-3

Exposición de los elementos esenciales de la movilidad a los aluviones
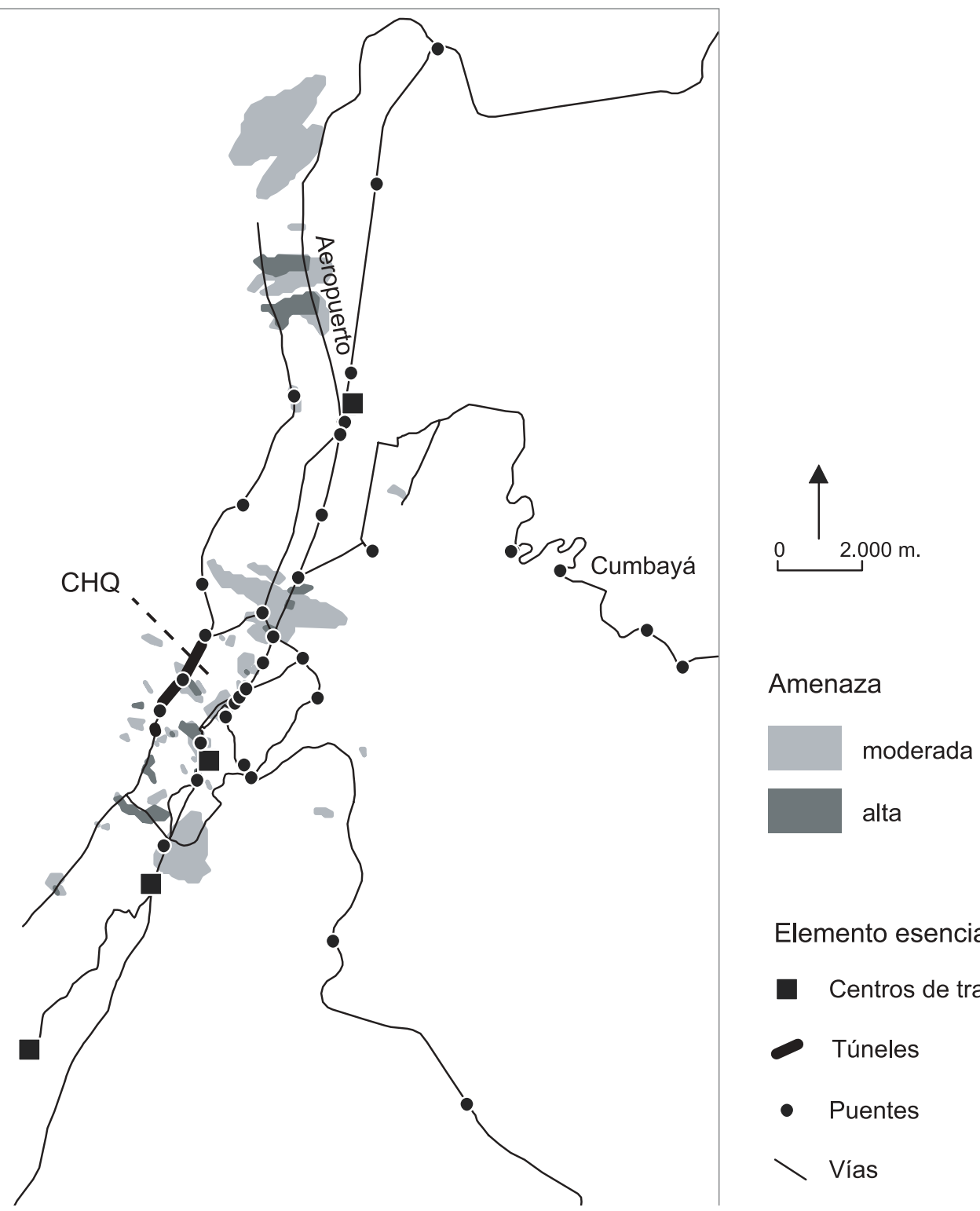

\section{Elemento esencial}

- Centros de transporte

Túneles

- Puentes

$\backslash$ Vías 
Mapa 5-4

Exposición de los elementos esenciales de la movilidad respecto a la inestabilidad de los suelos
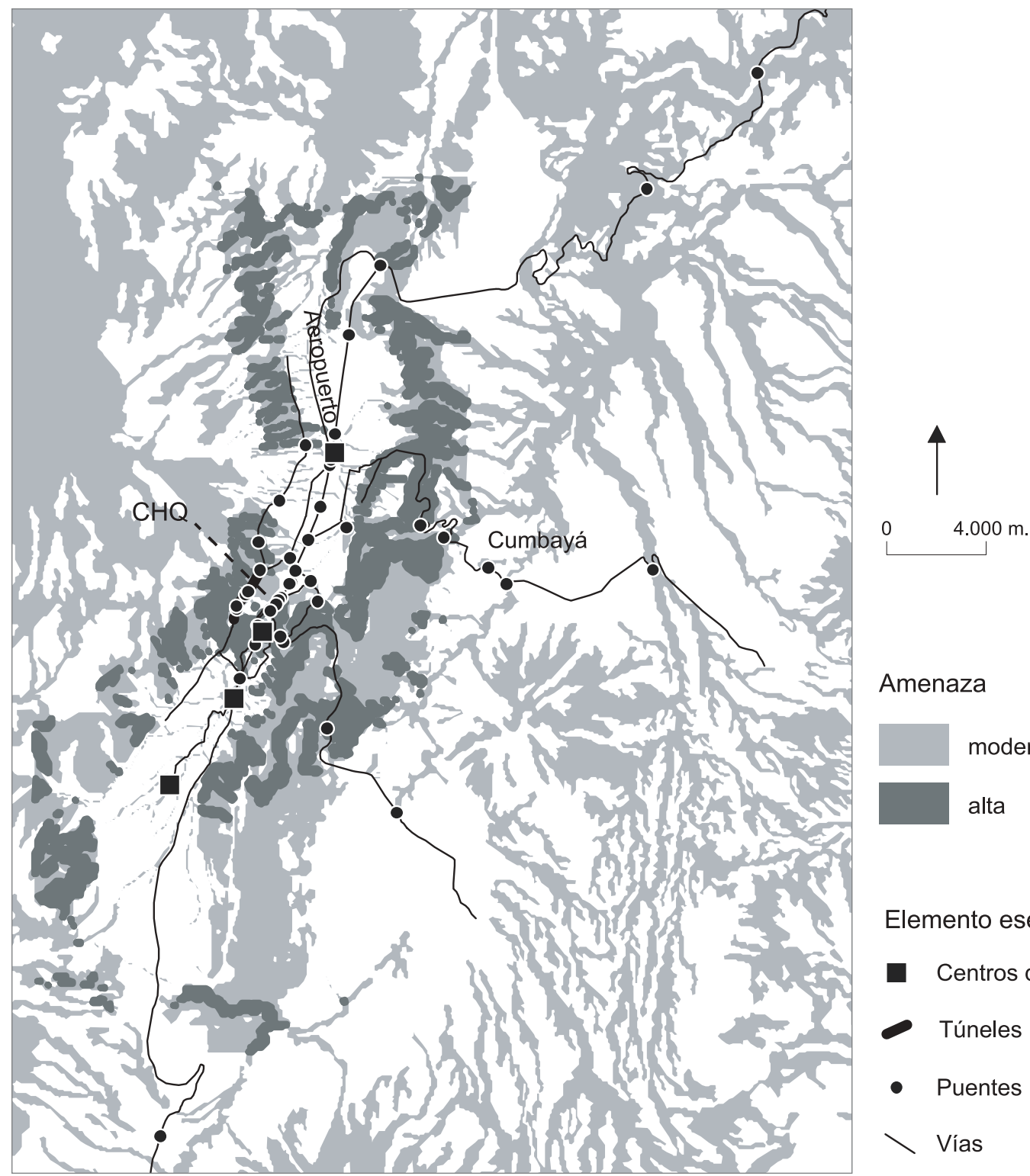

Amenaza

moderada

alta

\section{Elemento esencial}

- Centros de transporte

Túneles

- Puentes

$\backslash$ Vías 
Mapa 5-5

Exposición de los elementos esenciales de la movilidad a las inundaciones

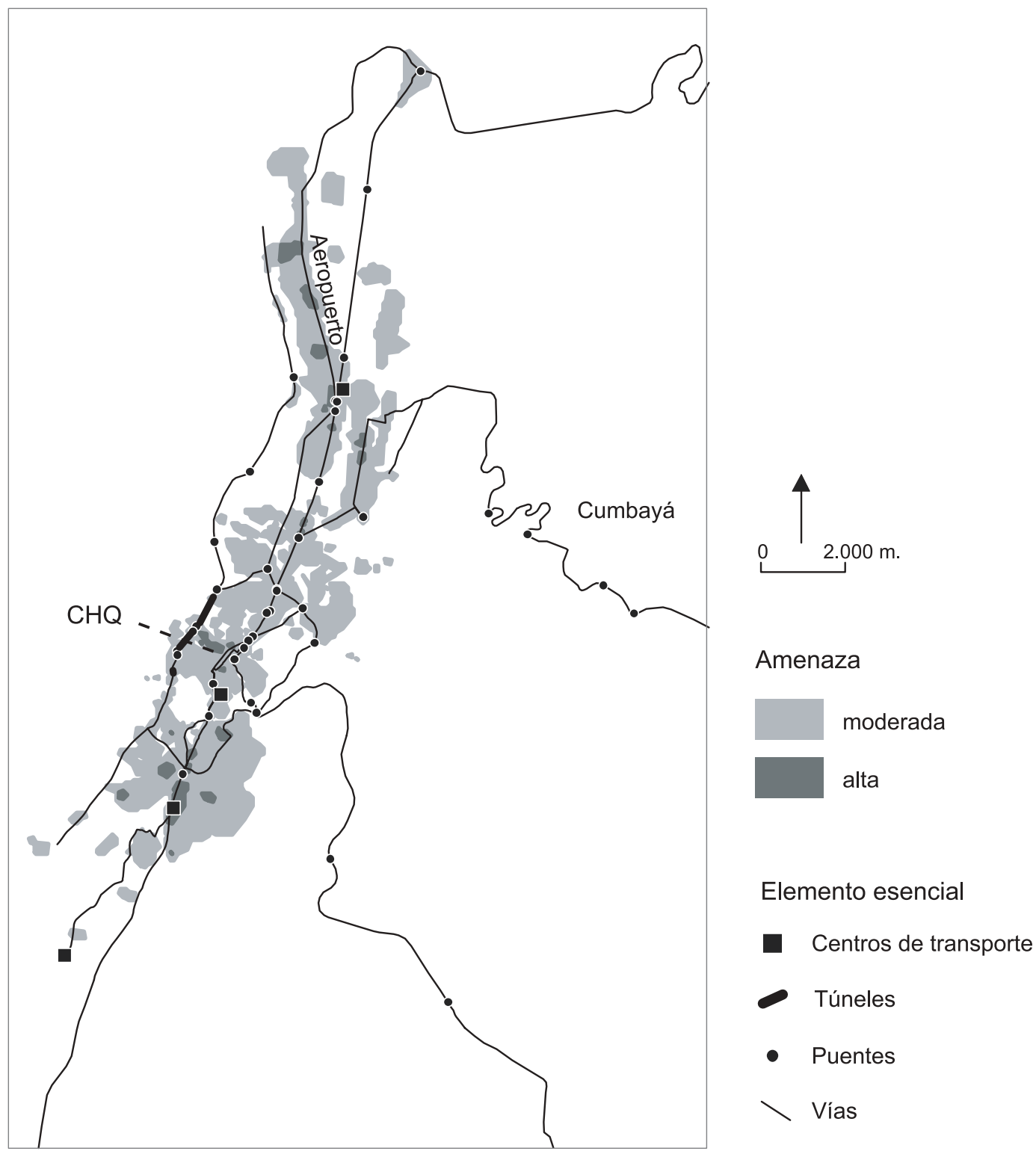


Mapa 5-6

Exposición de los elementos esenciales de la movilidad a la licuefacción de los suelos y a la amplificación de las ondas en caso de sismo
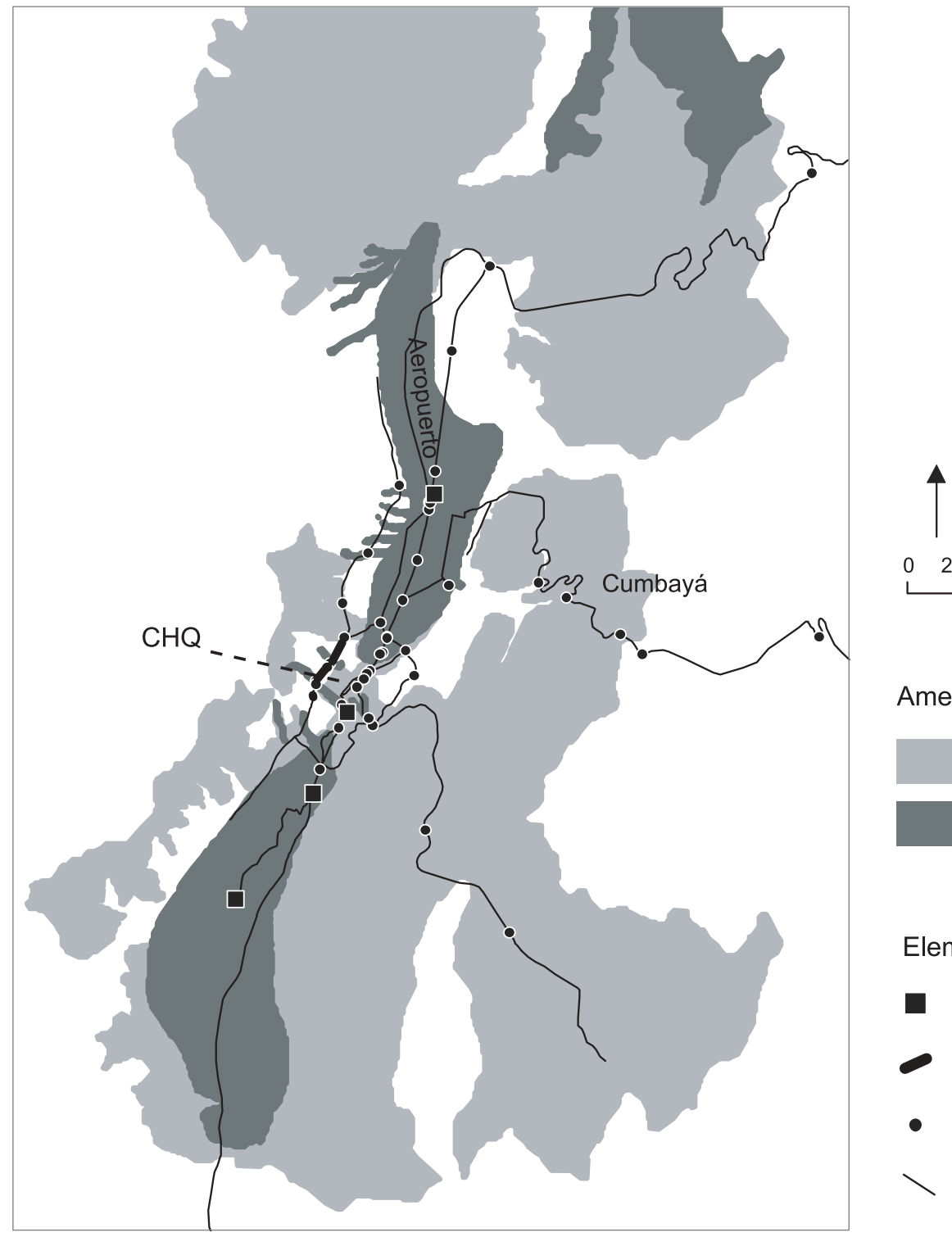

$0 \quad 2.000 \mathrm{~m}$.

Amenaza

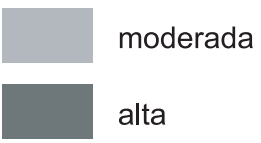

Elemento esencial

- Centros de transporte

Túneles

- Puentes

$\searrow$ Vías 
Mapa 5-7

Exposición de los elementos esenciales de la movilidad a las amenazas volcánicas (lahares, flujos piroclásticos)
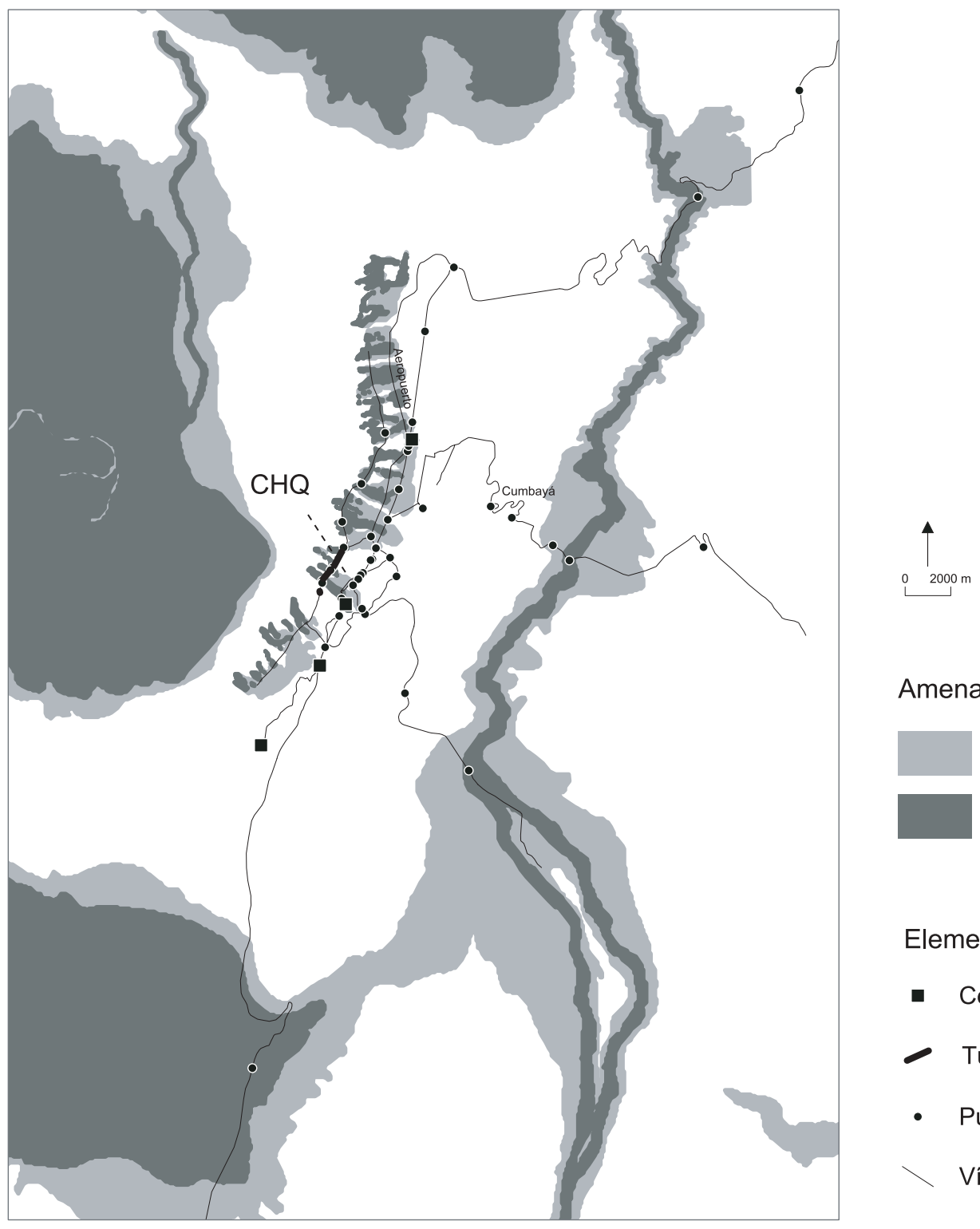

Amenaza

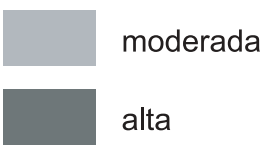

\section{Elemento esencial}

- Centros de transporte

Túneles

- Puentes

Vías 
Mapa 5-8

Exposición a los peligros relacionados con productos inflamables (almacenamiento y transporte)

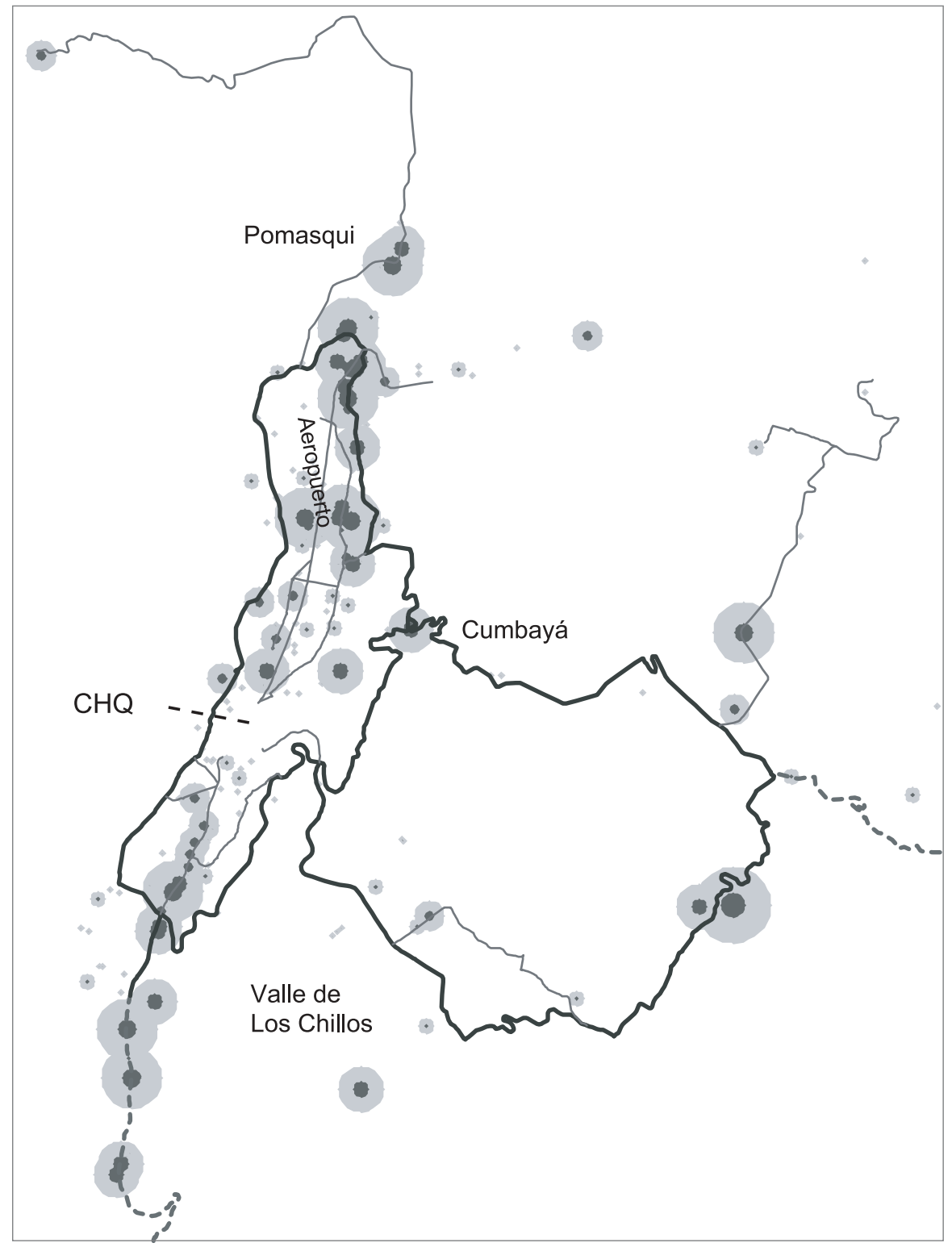

Transporte de combustibles

Vía de abasteci-

- - miento de la planta de El Beaterio

Vías de distribución del combustible

Vías principales

Vías secundarias

Almacenamiento de productos peligrosos

Peligro de explosión muy elevado

Peligro de explosión moderado o elevado 
del Pichincha, ensanchamiento de los colectores de alcantarillado) llevadas a cabo en el transcurso de estas últimas décadas, hayan podido limitar la exposición de ciertos lugares. Este método, que tiene sus límites, presenta la ventaja de informar a los gestores sobre los fenómenos susceptibles de dañar los elementos esenciales, lo que podnía justificar estudios locales más detallados.

Se examinó también la exposición de los elementos esenciales al peligro de explosión de productos inflamables. Estos datos fueron colectados, analizados y cartografiados por J. Estacio (2001) y R. D'Ercole (2004). El mapa 5-8 muestra los lugares de almacenamiento de productos químicos, gases y combustibles líquidos (gasolina). El perímetro alrededor de los depósitos no es más que una aproximación, pero este mapa presenta la ventaja de ser el primero realizado en Quito. En lo que se refiere a los combustibles, las vías que se utilizan para el abastecimiento y distribución resultan peligrosas debido a los fuertes declives, al tipo de transporte utilizado (camiones cisternas no adaptados y vetustos) y al hecho de que los camiones circulan a cualquier hora del día (J. Estacio, 2001).

Gracias al SIG se pudo medir las características geométricas de los elementos esenciales de la movilidad (pendientes, longitud, sinuosidad), distancias (alejamiento respecto a las compañías de bomberos) y también la exposición de los elementos esenciales a las amenazas de origen natural y antrópico.

Ahora se plantea el método a usar para medir el grado de vulnerabilidad de cada elemento esencial considerando los factores previamente presentados en las seis formas de vulnerabilidad.

\section{Método de ponderación y valoración de las formas de vulnerabilidad: enfoque cualitativo y cuantitativo}

Factores de vulnerabilidad más

o menos perjudiciales

La información anterior fue convertida en niveles de vulnerabilidad asociados a valores. Mientras mayor es la vulnerabilidad, mayor el valor asignado al elemento esencial. Cuando no se detecta vulnerabilidad, se da el valor cero. No obstante, no todos los factores agravan la movilidad, de la misma manera cada día, y tampoco conllevan perturbaciones de la misma magnitud en las emergencias. Para ilustrar esta consideración se muestran dos ejemplos, el primero se refiere a la fragilidad intrínseca de los elementos esenciales (vulnerabilidad) y el segundo, a la preparación para afrontar crisis (compensación).

Ejemplos de la vulnerabilidad intrínseca de los ejes viales: estado del revestimiento y operatividad de las vías.

El estado de rodadura de un eje esencial puede reducir la velocidad del tránsito, incrementar los accidentes pero no llega a un paro total de la circulación ${ }^{84}$. En este sentido, este factor es sin duda agravante, aunque otros factores lo son aún más. Por ejemplo, considerar la operatividad de una vía permite evaluar su aptitud para el tránsito. Un eje puede ser totalmente operativo cuando la circulación vehicular tiene una fluidez normal; puede ser parcialmente operativo cuando se ejecutan obras (repavimentación, ensanchamiento, construcción de pasos elevados o deprimidos, implementación de un carril exclusivo). En Quito, las obras en las vías pueden en algunos casos demorar varios

84. El estado de las calzadas analizado en esta sección es de diciembre de 2003. 
meses e incluso varios años (caso de la ecovía) lo que genera a menudo congestión. Esto es tanto más cierto cuanto que la ejecución de obras se realiza en ejes esenciales muy transitados. En efecto, en la ciudad de Quito, tomando en cuenta su configuración muy alargada, existen pocas alternativas para la descongestión. Por último, un eje puede tener una operatividad altamente reducida e incluso nula cuando está cerrado (luego de un deslizamiento, hundimiento). Este es el caso de la vía Interoceánica entre el espacio central de Quito y el valle de Tumbaco, Cumbayá. Esta vía está cerrada al tráfico desde mayo de 2000 después de un derrumbe.

Ejemplos de compensación:

planes de desvíos y autonomía energética

La ausencia de planes para orientar los desvíos, en caso de cierre de una vía, puede ocasionar congestión vehicular, pero en Quito no conlleva a un bloqueo total ni de larga duración del tráfico. En efecto, los automovilistas y choferes de buses se han acostumbrado a no tener alternativas de circulación cuando la Policía cierra una vía en caso de ejecución de obras, de marchas, de derrumbe. En cambio, la falta de reserva energética entre los operadores de transporte colectivo, de los cuales depende el 80 por ciento de la población para trasladarse, puede ocasionar, en caso de desabastecimiento de combustible, una limitación de la movilidad mucho más importante (como ocurrió en 1987 con la ruptura del oleoducto).

En comparación, el hecho de que los operadores no tengan depósitos de gasolina puede ser más desventajoso que la ausencia de planes para orientar los desvíos. Las entrevistas realizadas a los operadores de transporte colectivo indican que en muy raros casos cuentan con reservas energéticas. La mayoría se abastece cada día en las estaciones de servicio de la ciudad. De su lado, la Unidad de Operación del Sistema Trolebús posee su propio depósito de diesel que le permitiría funcionar durante, al menos 72 horas, en caso de apagón eléctrico. Estas formas de vulnerabilidad del sistema institucional (gestión del tránsito) y del sistema de oferta de transporte (los operadores) se refieren a variables dinámicas (la circulación y el transporte). En la investigación, se asignó estas formas de vulnerabilidad a objetos estáticos, las líneas materiales inmóviles (vías). En efecto, se considera que los desplazamientos en un eje son vulnerables cuando los modos de transporte o de gestión de la circulación vehicular, en los cuales se fundan, son vulnerables.

Estos ejemplos muestran el hecho de que algunos factores considerados implican una simple reducción de la fluidez del tránsito, otros pueden llegar al bloqueo total de la circulación, a una limitación significativa de la movilidad, por lo que dos amplitudes fueron consideradas.

- de 0 a 2 para los factores moderadamente perjudiciales.

- de 0 a 4 para los factores altamente perjudiciales.

Se asocia el valor cero a la mejor situación (cuando no hay vulnerabilidad) y 2 ó 4 a las peores situaciones (vulnerabilidad máxima). Se presenta la amplitud de cada factor de vulnerabilidad en las tablas 5-1 y 5-2. Cabe anotar que para algunos elementos esenciales, la situación vulnerabilidad nula o vulnerabilidad máxima no existe. Luego se evalúa el nivel de vulnerabilidad de cada elemento esencial en función de los datos conseguidos gracias al análisis y cálculos anteniores. Un valor fue asignado a cada elemento esen- 
cial. Los ejemplos siguientes evidencian las equivalencias establecidas entre los datos y los valores asignados (nivel de vulnerabilidad).

\section{Método de valoración de la vulnerabilidad}

El ejemplo de la vulnerabilidad de

los túneles asociada a su dependencia de energía.

La dependencia se refiere a la necesidad que tiene un elemento de otro para garantizar su funcionamiento correcto. En el caso de los túneles, para lograr las mejores condiciones para la circulación vehicular se requiere que los sistemas de alumbrado y ventilación funcionen. Un alumbrado deficiente puede ocasionar un alto número de accidentes y la falta de evacuación

\section{Tabla 5-4}

Método de valoración de la vulnerabilidad de los túneles derivada de su dependencia del sistema eléctrico

\begin{tabular}{|c|c|}
\hline \multicolumn{2}{|c|}{ DEPENDENCIA RESPECTO A LA ELECTRICIDAD } \\
\hline Explicación & $\begin{array}{l}\text { Los sistemas de ventiladores y de alumbrado necesitan } \\
\text { electricidad para funcionar. En Quito, consideramos que los } \\
\text { túneles que cuentan con ambos sistemas tienen una } \\
\text { "dependencia mediana" respecto a la energía eléctrica, y el } \\
\text { túnel de San Diego, que cuenta solo con alumbrado, tiene } \\
\text { una "dependencia débil". En Quito, tomando en cuenta la } \\
\text { relativa baja longitud de los túneles, no se censa } \\
\text { dependencia alta o muy alta para los túneles. }\end{array}$ \\
\hline Valoración & $\begin{array}{l}\text { dependencia nula }-->0 \\
\text { dependencia débil }-->1 \\
\text { dependencia mediana }-->2 \\
\text { dependencia alta }-->3 \\
\text { dependencia muy alta }-->4\end{array}$ \\
\hline Nombre & Electricidad \\
\hline San J uan & dependencia mediana \\
\hline San Roque & dependencia mediana \\
\hline San Diego & dependencia débil \\
\hline
\end{tabular}

de los gases de escape conlleva una fuerte opacidad del aire, lo que lleva a una reducción peligrosa de la visibilidad. Para que los sistemas de alumbrado y ventilación funcionen, se requiere energía que en este sentido es una forma de dependencia que tienen los túneles.

En este ejemplo, la amplitud se extiende de 0 a 4 . En Quito, la vulnerabilidad de los túneles en cuanto a su dependencia de la energía eléctrica es débil o mediana. Las mejores y peores situaciones hipotéticas no existen. Se podría considerar que un túnel que excede tres kilómetros de longitud tiene una dependencia alta y que un túnel cuya longitud es superior a seis kilómetros tiene una dependencia muy alta, porque no sería factible transitar por éste en caso de fallo del sistema eléctrico. Al contrario, la circulación podría darse sin peligro en un túnel cuya longitud es menor a cincuenta metros y que no cuenta con alumbrado o ventilación ya que no serían imprescindibles. En este ejemplo, se considera un solo factor para evaluar la dependencia de los túneles (el único que parece existir para este tipo de infraestructuras).

El ejemplo de la vulnerabilidad de los centros de transporte por su exposición a las amenazas y sus susceptibilidades de daño y perturbación.

Para cada elemento, el análisis de la forma de vulnerabilidad exposición y susceptibilidades de daño y perturbación se funda en cuatro etapas:

Primera etapa: evaluación de la exposición de los centros de transporte: para cada centro se observó gracias al SIG su localización respecto a los sectores susceptibles de ser afectados por las amenazas (aluviones, inundaciones, inestabilidad de suelo, sismo, caída de cenizas, lahares y peligro de explosión de productos peligrosos). Cuando un centro y sus acce- 
Tabla 5-5

Exposición de los centros de transporte y de sus accesos inmediatos respecto a las amenazas de origen natural y a los peligros de explosión de productos peligrosos

\begin{tabular}{|c|c|c|c|c|c|c|c|c|c|c|c|c|c|c|c|}
\hline \multirow[b]{2}{*}{ Nombre del centro } & \multicolumn{12}{|c|}{ Amenazas de origen natural } & \multicolumn{2}{|c|}{ Amenaza antrópica } & \multirow[b]{2}{*}{ Total } \\
\hline & Aluviones & Valor & Inundaciones & Valor & $\begin{array}{c}\text { Inestabilidad } \\
\text { de los suelos } \\
\text { (deslizamiento, } \\
\text { hundimiento) }\end{array}$ & Valor & \begin{tabular}{|c|} 
Sismos \\
(amplificación de las \\
ondas vibratorias y \\
licuefacción)
\end{tabular} & Valor & $\begin{array}{l}\text { Caída de } \\
\text { ceniza } \\
\text { volcánica }\end{array}$ & Valor & $\begin{array}{c}\text { Lahares, flujos } \\
\text { piroclásticos } \\
\text { gas, lava }\end{array}$ & Valor & $\begin{array}{l}\text { Explosión } \\
\text { de productos } \\
\text { peligrosos }\end{array}$ & Valor & \\
\hline Estación Norte & $\begin{array}{c}\text { no } \\
\text { expuesta }\end{array}$ & 0 & $\begin{array}{c}\text { edificio y } \\
\text { accesos } \\
\text { expuestos } \\
\text { (amenaza alta) }\end{array}$ & 3 & $\begin{array}{c}\text { no } \\
\text { expuesta }\end{array}$ & 0 & $\begin{array}{c}\text { edificio y } \\
\text { accesos } \\
\text { expuestos } \\
\text { (amenaza alta) }\end{array}$ & 3 & $\begin{array}{l}\text { edificio y accesos } \\
\text { expuestos } \\
\text { como el resto } \\
\text { de la ciudad }\end{array}$ & 2 & $\begin{array}{l}\text { accesos } \\
\text { expuestos } \\
\text { (amenaza } \\
\text { moderada) }\end{array}$ & 1 & $\begin{array}{l}\text { accesos } \\
\text { expuestos } \\
\text { (amenaza } \\
\text { moderada) }\end{array}$ & 1 & 10 \\
\hline Estación El Recreo & $\begin{array}{c}\text { accesos } \\
\text { expuestos } \\
\text { (amenaza } \\
\text { moderada) }\end{array}$ & 1 & \begin{tabular}{|c|} 
edificio accesos \\
expuestos \\
(amenaza \\
modearada) \\
\end{tabular} & 2 & $\begin{array}{c}\text { no } \\
\text { expuesta }\end{array}$ & 0 & $\begin{array}{c}\text { edificioy } \\
\text { accesos } \\
\text { expuestos } \\
\text { (amenaza alta) }\end{array}$ & 3 & $\begin{array}{l}\text { edificio y accesos } \\
\text { expuestos } \\
\text { como el resto } \\
\text { de la ciudad }\end{array}$ & 2 & $\begin{array}{c}\text { no } \\
\text { expuesta }\end{array}$ & 0 & $\begin{array}{c}\text { no } \\
\text { expuesta }\end{array}$ & 0 & 8 \\
\hline Estación M orán Valverde & $\begin{array}{c}\text { no } \\
\text { expuesta }\end{array}$ & 0 & \begin{tabular}{|c|} 
edificio accesos \\
expuestos \\
(amenaza \\
modearada)
\end{tabular} & 1 & $\begin{array}{c}\text { edificio accesos } \\
\text { expuestos } \\
\text { (amenaza } \\
\text { modearada) } \\
\end{array}$ & 1 & $\begin{array}{c}\text { edificioy } \\
\text { accesos } \\
\text { expuestos } \\
\text { (amenaza alta) }\end{array}$ & 3 & $\begin{array}{l}\text { edificio y accesos } \\
\text { expuestos } \\
\text { como el resto } \\
\text { de la ciudad }\end{array}$ & 2 & $\begin{array}{c}\text { no } \\
\text { expuesta }\end{array}$ & 0 & $\begin{array}{l}\text { accesos } \\
\text { expuestos } \\
\text { (amenaza } \\
\text { moderada) }\end{array}$ & 1 & 8 \\
\hline Terminal Terrestre de Cumandá & $\begin{array}{c}\text { edificio y } \\
\text { accesos } \\
\text { expuestos } \\
\text { (amenaza alta) }\end{array}$ & 3 & \begin{tabular}{|c|} 
edificio accesos \\
expuestos \\
(amenaza \\
modearada)
\end{tabular} & 2 & $\begin{array}{c}\text { edificio accesos } \\
\text { expuestos } \\
\text { (amenaza } \\
\text { modearada) }\end{array}$ & 3 & $\begin{array}{c}\text { edificioy } \\
\text { accesos } \\
\text { expuestos } \\
\text { (amenaza alta) }\end{array}$ & 3 & $\begin{array}{c}\text { edificio y accesos } \\
\text { expuestos } \\
\text { como el resto } \\
\text { de la ciudad }\end{array}$ & 2 & $\begin{array}{c}\text { edificioy } \\
\text { accesos } \\
\text { expuestos } \\
\text { (amenaza alta) }\end{array}$ & 3 & $\begin{array}{c}\text { no } \\
\text { expuesta }\end{array}$ & 0 & 16 \\
\hline
\end{tabular}

sos inmediatos se encuentran fuera de los sectores expuestos, se considera que no hay exposición (exposición nula $=0$ ). Cuando un centro o uno de sus accesos inmediatos se encuentran en una zona en donde la amenaza es moderada, se considera que la exposición es débil $(=1)$. Cuando el centro y uno de sus accesos inmediatos se encuentran en una zona en donde la amenaza es moderada, se considera que la exposición es bastante alta $(=2)$. En cuanto a la caída de ceniza, se considera que la exposición de los centros es también bastante alta $(=2)$. Por último, cuando el centro y/o uno de sus accesos se encuentran en una zona en donde la amenaza es alta, se considera que la exposición es alta $(=3)$. Estos valores fueron luego sumados (tabla 5-5) para lograr un valor sintético de exposición. La terminal terrestre Cumandá es el cen- tro de transporte que cuenta con la exposición másalta $(=16)$ y la estación El Recreo con la exposición en comparación más débil $(=8)$.

Segunda eta pa: análisis de la susceptibilidad de daño de las infraestructuras: una inundación puede volver a un edificio parcialmente disfuncional (perturbación de los servicios de transporte) sin necesariamente ocasionar daño. Por ello, se diferenció la susceptibilidad de daño de las infraestructuras y la susceptibilidad de perturbación del transporte. Se evalúa entonces a priori la susceptibilidad de daño de los edificios y sus vías de acceso, en caso de concretización de cada amenaza. Se considera la susceptibilidad más previsible tomando en cuenta las características de las amenazas en Quito. Por ejemplo, la ceniza volcánica no deteriora para nada los edificios o sus accesos (sal- 
Tabla 5-6

Susceptibilidad de daño de los centros de transporte y de sus vías de acceso

\begin{tabular}{|c|c|c|c|c|c|c|c|c|c|c|c|c|c|c|c|}
\hline \multirow[b]{2}{*}{ Nombre del centro } & \multicolumn{12}{|c|}{ Amenazas de origen natural } & \multicolumn{2}{|c|}{ Amenaza antrópica } & \multirow[b]{2}{*}{ Total } \\
\hline & Aluviones & Valor & Inundaciones & Valor & \begin{tabular}{|l|} 
Inestabilidad \\
de los suelos \\
(deslizamiento, \\
hundimiento) \\
\end{tabular} & Valor & \begin{tabular}{|c|} 
Sismos \\
(amplificación de las \\
ondas vibratorias y \\
licuefacción)
\end{tabular} & Valor & \begin{tabular}{|c|} 
Caída de \\
ceniza \\
volcánica \\
\end{tabular} & Valor & \begin{tabular}{|c|} 
Lahares, flujos \\
piroclásticos \\
gas, lava
\end{tabular} & Valor & $\begin{array}{l}\text { Explosión } \\
\text { de productos } \\
\text { peligrosos }\end{array}$ & Valor & \\
\hline Estación Norte & débil & 1 & nula & 0 & alta & 3 & débil & 1 & nula & 0 & alta & 3 & alta & 3 & 11 \\
\hline Estación El Recreo & débil & 1 & nula & 0 & alta & 3 & débil & 1 & nula & 0 & alta & 3 & alta & 3 & 11 \\
\hline Estación M orán Valverde & débil & 1 & nula & 0 & alta & 3 & débil & 1 & nula & 0 & alta & 3 & alta & 3 & 11 \\
\hline Terminal Terrestre de Cumandá & débil & 1 & nula & 0 & alta & 3 & alta & 3 & nula & 0 & alta & 3 & alta & 3 & 13 \\
\hline
\end{tabular}

vo en el caso de que el espesor de material sea mayor a cincuenta centímetros, lo que podría ocasionar el desplome del techo por ejemplo; en Quito esta situación es poco probable). En el peor de los casos, la ceniza podría afectar el sistema de aeración (pero no generaría graves repercusiones). Para simplificar se individualiza tres clases: susceptibilidad de daño nula, susceptibilidad débil y susceptibilidad alta. En lo referente a la susceptibilidad de daño de los centros de transporte en caso de sismo, se consultó un ingeniero civil (Dr. F. Yépez) especializado en riesgo sísmico (tabla 5-6).

Tercera etapa: análisis de la susceptibilidad de per- turbación de los servicios de transporte: se evalúa a priori la susceptibilidad de perturbación del transporte colectivo (trole y transporte interprovincial) en caso de concretización de cada amenaza. Se considera la susceptibilidad más realista en base a las perturbaciones pasadas (el trole por ejemplo es más sensible a la caída de ceniza y a las inundaciones que los demás servicios de transporte). En Quito, cada amenaza podría perturbar al menos ligeramente el tráfico. Se individualiza dos clases "susceptibilidad débil" y "alta susceptibilidad" y se podría considerar también la clase "ninguna susceptibilidad". Por ejemplo, un demumbe que acontece en una vía no afecta el funcio-

Tabla 5-7

Susceptibilidad de perturbación del servicio del trole y del transporte interparroquial asociada a fallos en las estaciones

\begin{tabular}{|c|c|c|c|c|c|c|c|c|c|c|c|c|c|c|c|}
\hline \multirow[b]{2}{*}{ Nombre del centro } & \multicolumn{12}{|c|}{ Amenazas de origen natural } & \multicolumn{2}{|c|}{ Amenaza antrópica } & \multirow[b]{2}{*}{ Total } \\
\hline & Aluviones & Valor & Inundaciones & Valor & \begin{tabular}{|c|} 
Inestabilidad \\
de los suelos \\
(deslizamiento, \\
hundimiento) \\
\end{tabular} & Valor & \begin{tabular}{|c|} 
Sismos \\
(amplificación de las \\
ondas vibratorias y \\
licuefacción)
\end{tabular} & Valor & $\begin{array}{c}\text { Caída de } \\
\text { ceniza } \\
\text { volcánica }\end{array}$ & Valor & $\begin{array}{c}\text { Lahares, flujos } \\
\text { piroclásticos } \\
\text { gas, lava }\end{array}$ & Valor & $\begin{array}{l}\text { Explosión } \\
\text { de productos } \\
\text { peligrosos }\end{array}$ & Valor & \\
\hline Estación Norte & alta & 3 & alta & 3 & alta & 3 & alta & 3 & alta & 3 & alta & 3 & alta & 3 & 21 \\
\hline Estación El Recreo & alta & 3 & alta & 3 & alta & 3 & alta & 3 & alta & 3 & alta & 3 & alta & 3 & 21 \\
\hline Estación M orán Valverde & alta & 3 & alta & 3 & alta & 3 & alta & 3 & alta & 3 & alta & 3 & alta & 3 & 21 \\
\hline Terminal Terrestre de Cumandá & alta & 3 & débil & 1 & alta & 3 & alta & 3 & débil & 1 & alta & 3 & alta & 3 & 17 \\
\hline
\end{tabular}


Tabla 5-8

Balance: Exposición de los centros de transporte a las amenazas, susceptibilidad de daño y de perturbación

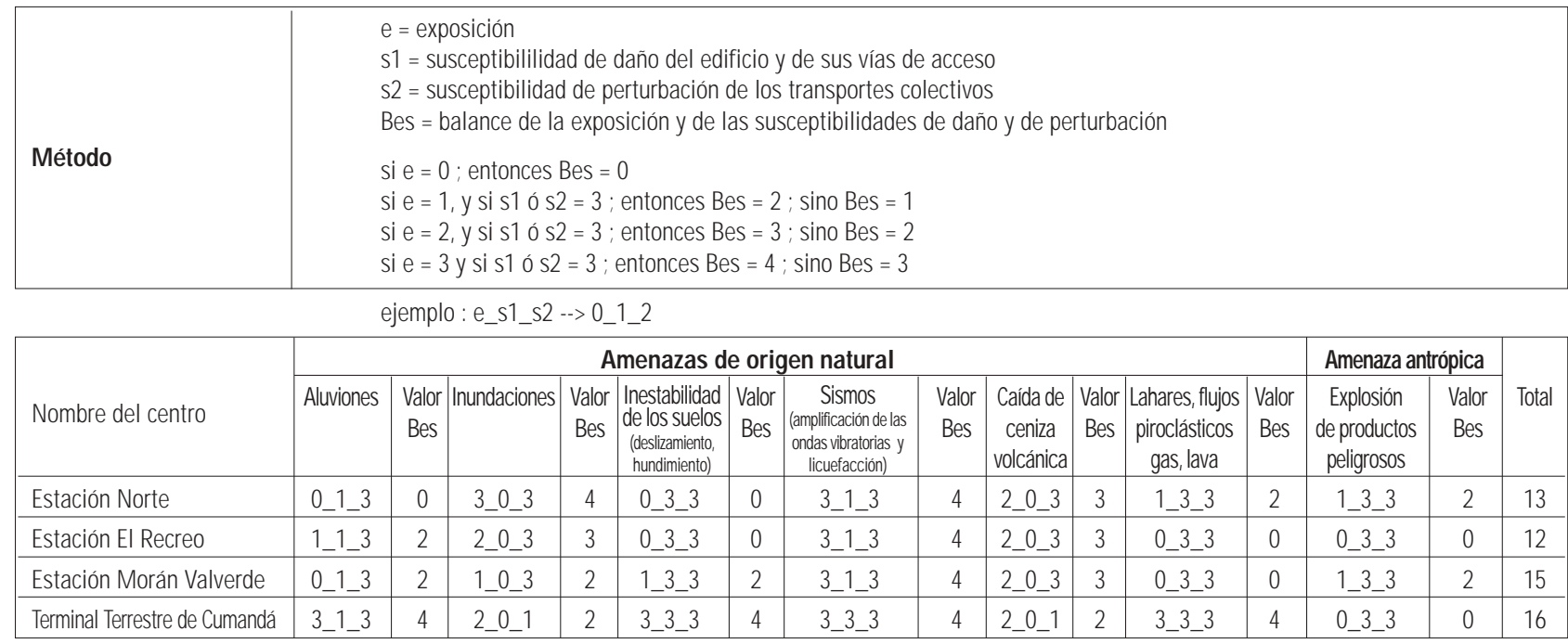

namiento del metro, pero este caso no se encuentra en Quito. Las estaciones del trole y el funcionamiento del trole son altamente susceptibles de experimentar perturbaciones cualquiera fuera la amenaza debido a la fragilidad de los vehículos. Para el transporte colectivo interprovincial, se considera que existe una "susceptibilidad débil de perturbación" cuando se observa alrededor de la terminal terrestre una reducción de la velocidad del servicio (circulación posible de las unidades pero que puede ser peligrosa y que requiere que los choferes tengan una gran precaución). Este es el caso de las inundaciones por sus características en Quito (algunos decímetros como máximo). Se considera que existe una "alta susceptibilidad de perturbación" cuando existe la posibilidad de que los buses interprovinciales queden totalmente bloqueados (paso imposible en el sector de la terminal terrestre Cumanda). Este es el caso cuando suelen ocurrir aluviones, derrumbes, sismos (tabla 5-7).

Cuarta etapa: Balance: exposición a amenazas, susceptibilidades de daño y perturbación: se considera los valores asignados a los elementos esenciales en cada una de las tres etapas previas (tabla 5-8). En base a estas combinaciones se determina niveles (de 0 a 4) que posteriormente se adiciona. Se llega así a un valor sintético de vulnerabilidad frente a amenazas. Se evidencia así que la terminal terrestre Cumandá es la más vulnerable $(=16)$ y que la estación El Recreo es, en comparación, menos vulnerable (=12). 
Luego se sumó las valoraciones de los elementos esenciales en función de los factores de vulnerabilidad analizados en las seis formas y se clasificó esta suma. El método de clasificación consiste en posicionar los elementos esenciales respecto a dos situaciones extremas: una vulnerabilidad nula $(=0)$ y una vulnerabilidad hipotética máxima. La primera se evidencia cuando la suma de las valoraciones es igual a cero (lo que no se observa en Quito, excepto en el caso de la dependencia de los puentes). La segunda se evidencia cuando todas las valoraciones son máximas (caso que tampoco se observa en Quito). Por ejemplo, en la forma "vulnerabilidad intrínseca" de los puentes (tabla 59), se consideró seis variables. La suma de su amplitud es de 16.

En el caso de que un túnel acumule las peores situaciones para cada uno de los seis factores, entonces totalizanía el valor máximo hipotético, es decir 16. Como el objetivo es lograr cinco grados sintéticos de vulnerabilidad (tabla 5-10), se dividió este valor máximo hipotético para cinco en base a lo cual se determinó los umbrales de las clases (de igual amplitud). El intervalo de clase en el ejemplo seleccionado es de 3,2 (16/5). Se presenta a continuación el método de clasificación de la suma de las valoraciones para las seis formas de vulnerabilidad de los túneles (tabla 5-11), método que rige también para los demás tipos de elementos esenciales.

Este trabajó permitió comparar la vulnerabilidad de los diferentes elementos esenciales y resaltar los que son más vulnerables en cada forma. También logró posicionar la vulnerabilidad de los elementos esenciales de la movilidad del Distrito en relación con una vulnerabilidad que puede existir en otras ciudades. En efecto, las peores o mejores situaciones no se encuen-
Tabla 5-9

Ejemplo de cálculo del valor máximo de vulnerabilidad que puede alcanzar un elemento esencial.

(en base a la amplitud de las variables analizadas, caso de la vulnerabilidad intrínseca de los túneles)

\begin{tabular}{|l|l|c|}
\hline \multirow{4}{*}{ TUNELES } & \multicolumn{2}{|c|}{ INTRINSECA } \\
\cline { 2 - 3 } & Variables analizadas & Amplitud \\
\cline { 2 - 3 } & 1 - longitud & $0-4$ \\
\cline { 2 - 3 } & 2 - estado de rodadura & $0-2$ \\
\cline { 2 - 3 } & 3 - fragilidad en la construcción & $0-4$ \\
\cline { 2 - 3 } & 4 - alumbrado (deficiencia) & $0-2$ \\
\cline { 2 - 3 } & 5 - ventilación (deficiencia) & $0-2$ \\
\cline { 2 - 3 } & 6 - limpieza necesaria & $0-2$ \\
\cline { 2 - 3 } & \multicolumn{2}{|c|}{ Total } \\
\hline
\end{tabular}

tran todas en Quito. Los grados sintéticos de vulnerabilidad fueron luego cartografiados con el objetivo de mostrar una visión sinóptica fácilmente entendible.

Tabla 5-10

Cinco grados sintéticos de vulnerabilidad (calculados en base a las sumas de las valoraciones)

\begin{tabular}{|c|l|}
\hline 1 & una vulnerabilidad nula o muy débil \\
\hline 2 & una vulnerabilidad bastante débil \\
\hline 3 & una vulnerabilidad bastante alta \\
\hline 4 & una vulnerabilidad alta \\
\hline 5 & una vulnerabilidad muy alta \\
\hline
\end{tabular}


Tábla 5-11

Suma de las valoraciones de las seis formas de vulnerabilidad y determinación de los grados sintéticos de vulnerabilidad. (el caso de los túneles)

\begin{tabular}{|c|c|c|}
\hline \multicolumn{3}{|c|}{ Formas de vulnerabilidad } \\
\hline Vulnerabilidad intrínseca & Dependencia & $\begin{array}{c}\text { Exposición a amenazas y } \\
\text { susceptibilidad de daño y } \\
\text { perturbación }\end{array}$ \\
\hline $\begin{array}{l}\text { Amplitud máx posible }=16 \\
16 / 5=3,2\end{array}$ & $\begin{array}{l}\text { Valor máx observado }=4 \\
\text { en este caso de } 1 \text { en } 1\end{array}$ & $\begin{array}{l}\text { Amplitud máx posible }=26 \\
26 / 5=5,2\end{array}$ \\
\hline$[0-3,2[\quad->1$ & $0-->1$ & {$[0-5,2[-->1$} \\
\hline$[3,2-6,4[-->2$ & $1->2$ & {$[5,2-10,4[-->2$} \\
\hline$[6,4-9,6[-->3$ & $2->3$ & {$[10,4-15,6[-->3$} \\
\hline$[9,6-12,8[-->4$ & $3->4$ & {$[15,6-20,8[-->4$} \\
\hline$[12,8-16]-->5$ & $4->5$ & {$[20,8-26] \rightarrow>5$} \\
\hline
\end{tabular}

\begin{tabular}{|c|c|c|c|c|c|c|}
\hline \multirow[b]{2}{*}{$\begin{array}{l}\text { Nombre de } \\
\text { los túneles }\end{array}$} & \multicolumn{2}{|c|}{ Vulnerabilidad intrínseca } & \multicolumn{2}{|c|}{ Dependencia } & \multicolumn{2}{|c|}{$\begin{array}{l}\text { Exposición a amenazas y } \\
\text { susceptibilidad de daño y } \\
\text { perturbación }\end{array}$} \\
\hline & $\begin{array}{c}\text { suma de las } \\
\text { valoraciones }\end{array}$ & $\begin{array}{c}\text { grado de } \\
\text { vulnerabilidad }\end{array}$ & $\begin{array}{c}\text { suma de las } \\
\text { valoraciones }\end{array}$ & $\begin{array}{c}\text { grado de } \\
\text { vulnerabilidad }\end{array}$ & $\begin{array}{c}\text { suma de las } \\
\text { valoraciones }\end{array}$ & $\begin{array}{c}\text { grado de } \\
\text { vulnerabilidad }\end{array}$ \\
\hline San Juan & 9 & 3 & 2 & 3 & 15 & 3 \\
\hline San Roque & 9 & 3 & 2 & 3 & 15 & 3 \\
\hline San Diego & 6 & 2 & 1 & 2 & 4 & 1 \\
\hline
\end{tabular}

\begin{tabular}{|c|c|c|}
\hline \multicolumn{3}{|c|}{ Formas de compensación } \\
\hline capacidad de control & alternativas & preparación a las crisis \\
\hline $\begin{array}{l}\text { Amplitud máx posible }=22 \\
22 / 5=4,4\end{array}$ & $\begin{array}{l}\text { Valor máx observado }=4 \\
\text { en este caso de } 1 \text { en } 1\end{array}$ & $\begin{array}{l}\text { Amplitud máx posible }=24 \\
24 / 5=4,8\end{array}$ \\
\hline$[0-4,4[->1$ & $0-->1$ & {$[0-4,8[->1$} \\
\hline$[4,4-8,8[-->2$ & $1-->2$ & {$[4,8-9,6[-->2$} \\
\hline$[8,8-13,2[-->3$ & $2-->3$ & {$[9,6-14,4[-->3$} \\
\hline$[13,2-17,6[-\rightarrow 4$ & $3->4$ & {$[14,4-19,2[->4$} \\
\hline$[17,6-22]-\rightarrow 5$ & $4->5$ & {$[19,2-24]->5$} \\
\hline
\end{tabular}

\begin{tabular}{|c|c|c|c|c|c|c|}
\hline $\begin{array}{c}\text { nombre de } \\
\text { los túneles }\end{array}$ & $\begin{array}{c}\text { sumas de las } \\
\text { valoraciones }\end{array}$ & $\begin{array}{c}\text { grado de } \\
\text { vulnerabilidad }\end{array}$ & $\begin{array}{c}\text { sumas de las } \\
\text { valoraciones }\end{array}$ & $\begin{array}{c}\text { grado de } \\
\text { vulnerabilidad }\end{array}$ & $\begin{array}{c}\text { sumas de las } \\
\text { valoraciones }\end{array}$ & $\begin{array}{c}\text { grado de } \\
\text { vulnerabilidad }\end{array}$ \\
\hline San Juan & 6 & 2 & 4 & 5 & 19 & 4 \\
\hline San Roque & 6 & 2 & 4 & 5 & 19 & 4 \\
\hline San Diego & 10 & 3 & 4 & 5 & 20 & 5 \\
\hline
\end{tabular}


48 


\section{6 - Análisis de vulnerabilidad de los elementos esenciales del sistema de movilidad: resultados cartográficos}

Considerando que el mapa presenta interés cuando es sintético y rápidamente enten di do por los gestores, se intentó elaborar documentos cartográficos que permitan resaltar los elementos esenciales más vulnerables, en los cuales las acciones deberán priorizarse. También se presenta en este capítulo un mapa sintético tentativo de vulnerabilidad.

\section{Representación cartográfica de la vulnerabili- dad de los elementos esenciales}

\section{Los ejes viales: vulnerabilidad heterogénea}

Los ejes viales esenciales tienen una vulnerabilidad muy variable según la forma considerada (mapas 6-1 y 6-2). El grado máximo (5) se lo observa en cuatro formas (dependencia, exposición, capacidad de control, preparación a las crisis). En lo que se refiere a la dependencia, el eje del trole resalta como el más vulnerable. Depende fuertemente de la electricidad para funcionar; en efecto, sus motores son eléctricos y el carril exclusivo por el cual transita cuenta con muchos semáforos imprescindibles para la regulación del servicio respecto a la circulación automóvil. Por otro lado, requiere necesariamente de un sistema de comu- nicación por radio para funcionar. Debido a la alta frecuencia de las unidades, el trole no podría funcionar sin este medio de comunicación, porque apenas ocume un contratiempo (lo que pasa a menudo) se debe avisar a todas las unidades. El carril exclusivo por el que transita depende más de la calidad de asfalto que las otras vías. Ya se ha perdido la cuenta del número de veces que han repavimentado el carril exclusivo, cuya implementación es reciente (1996); ello se debe a la mala calidad del asfalto y a la alta frecuencia de las unidades que circulan atiborradas.

En cuanto a la exposición a las amenazas, susceptibilidades de daño y de perturbación, numerosos son los tramos con alta vulnerabilidad, en especial en la ciudad. Ello se debe a la multiplicidad de peligros de origen natural y antrópico que existen. En lo atinente a la capacidad de control, se evidencia debilidades en los accesos a la ciudad (Panamericanas sur y norte, autopista Rumiñahui). En efecto, en estos ejes la presencia de autoridades de Policía es escasa. Estas vías tampoco cuentan con sistema de monitoreo a distancia y los accesos hacia ellas son limitados. Eso significa que en caso de accidente o interrupción de tráfico la ayuda tardanía en llegar y las perturbaciones de tránsito seńan significativas. Por otro lado, se nota que la capacidad de intervención y los planes para afrontar 
las crisis son restringidos para estos ejes. Esta lectura cruzada entre las diferentes formas de vulnerabilidad resalta los elementos esenciales vulnerables en varios ámbitos, y evidencia también que la vulnerabilidad es compensada por determinadas fortalezas. Es el caso del trole que tiene alta dependencia pero cuya capacidad de control es buena. Además, existe alternativas de funcionamiento, el motor funciona también con diesel.

Si bien ciertos tipos de vulnerabilidad son difíciles de resolver (¿cómo mejorar la accesibilidad de un eje vial estructurante en sectores rurales o suburbanos en donde la red es poco densa?), se podría ya empezar a reducir otros. Por ejemplo, la instalación de una docena de cámaras video o la creación de unos puntos de observación adicional (Central de Control de Operación, CCO) en las lomas entre la ciudad y los valles, permitiría monitorear a distancia las condiciones de tráfico en los ejes periféricos mayores, bastante vulnerables y avisar rápidamente a los equipos de intervención adecuados, en caso de problema. Eso permitińa un ahorro de tiempo para enviar ayuda. Por otro lado, la implementación de itinerarios señalizados de descongestión, en caso de cierre de un eje esencial, permitiría mejorar las condiciones de tráfico. Se podría incluso determinar alternativas viales en caso de cierre de cada uno de los tramos de las vías esenciales. Del mismo modo, algunos factores que provocan accidentes, en especial el transporte de productos inflamables, podrían ser más reglamentados. Una ordenanza municipal podría, por ejemplo, prohibir la entrega de combustibles durante el día o las horas pico.

\section{Los puentes: entre una vulnerabilidad nula y una máxima}

Al igual que los ejes, la vulnerabilidad de los "puentes" (obra vial que cuenta con una sección aérea) es muy heterogénea según la forma considerada (mapas 6-3 y 6-4). La vulnerabilidad es nula en cuanto a dependencia, porque se puede estimar que los puentes en Quito no dependen de nada en especial. Sin embargo, se puede imaginar formas de dependencia. Por ejemplo, los puentes podrían depender de un tipo de energía, si se levantaran sobre una vía navegable. También un sistema de regulación (semáforos, barreras automáticas) sería necesario para los puentes de un solo carril. Este tipo de puentes no existen en Quito, por lo tanto, no existe vulnerabilidad de esta forma.

En el ámbito de la vulnerabilidad intrínseca, la mayoría de las obras se caracterizan por grados bastante altos. Se asocia esta forma de vulnerabilidad a los daños y desgastes visibles en la estructura, a los materiales de construcción, a la sismoresistencia de las obras y a los suelos en los cuales se encuentran. El 42 por ciento de los puentes cuenta con grietas que pueden deberse a la calidad de los materiales de construcción y los suelos en los cuales se ubican (suelos que pueden hundirse). Únicamente seis obras viales esenciales, de un total de 43, fueron construidas con hormigón presforzado. Apenas dos obras cumplen las normas actuales de sismoresistencia (intercambiadores de la Villa Flora y de la Universidad Central) y 14 se ubican sobre rellenos cuyo hundimiento y comportamiento en caso de sismo (amplificación de las ondas) podrían ocasionar daños severos.

Frente a las amenazas la vulnerabilidad de los puentes es muy débil o bastante débil, en todo caso muy 


\section{Mapa 6-1}

Grados sintéticos de las tres primeras formas de vulnerabilidad de los ejes viales esenciales

Vulnerabilidad intrínseca de la red vial, de los flujos y del transporte

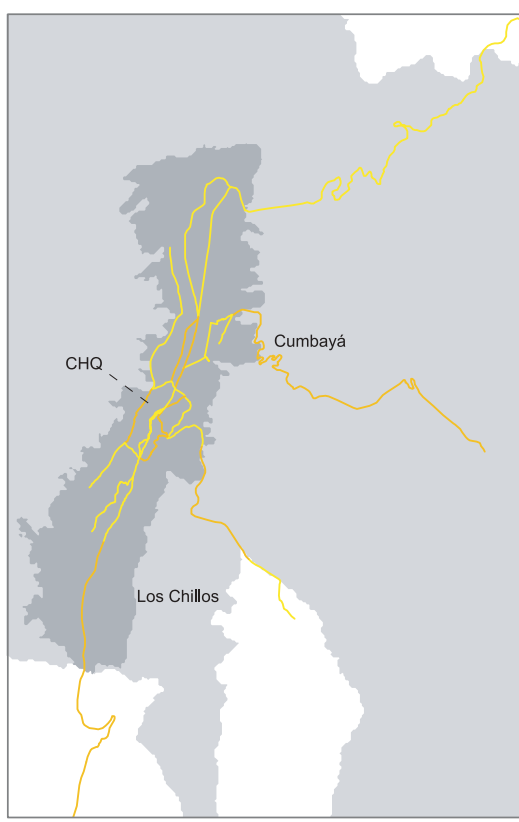

Variables consideradas:

Estado de rodadura, operatividad, número de sistemas de semaforización, pendiente máxima, sinuosidad, relleno, presencia de pasos elevados, puentes, túneles, congestión vehicular, contaminación por el TC, frecuencia de los accidentes, perturbación esporádica, debilidades del TC, peligro derivado del transporte de combustibles.

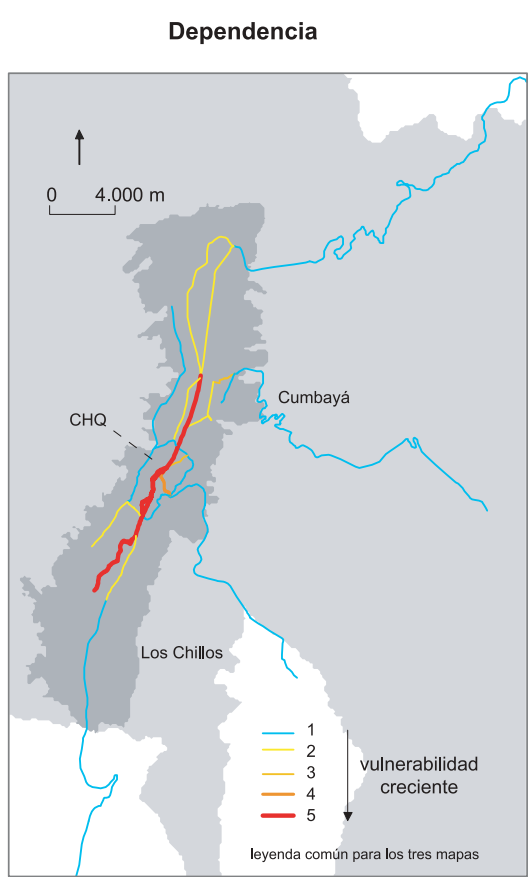

\section{Variables consideradas}

Electricidad (semaforización + catenarios), asfalto (mantenimiento), medio de comunicación (radio)
Exposición a amenazas, susceptibilidad de daño y de perturbación

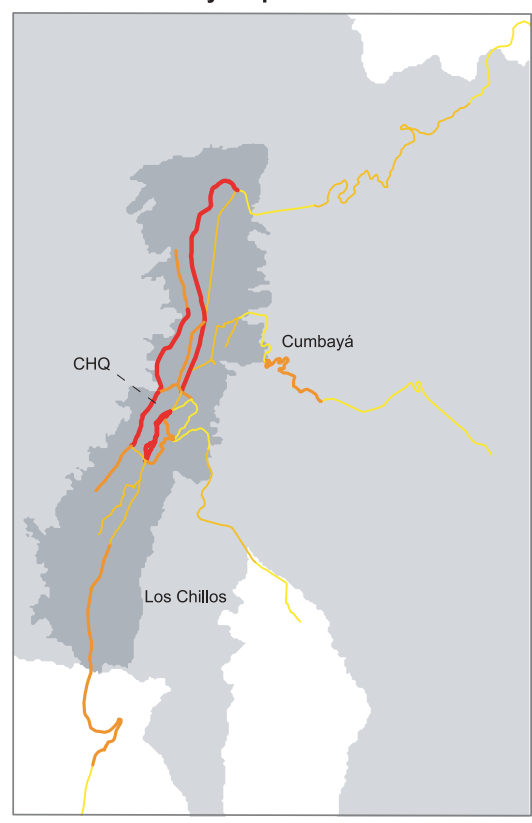

Variables consideradas

Aluviones, inundaciones, inestabilidad de suelo, licuefacción y amplificación de ondas sísmicas, caída de ceniza volcánica, lahares, flujos piroclásticos explosiones de productos inflamables. 


\section{Mapa 6-2}

Grados sintéticos de las tres formas de compensación de la vulnerabilidad de los ejes viales esenciales

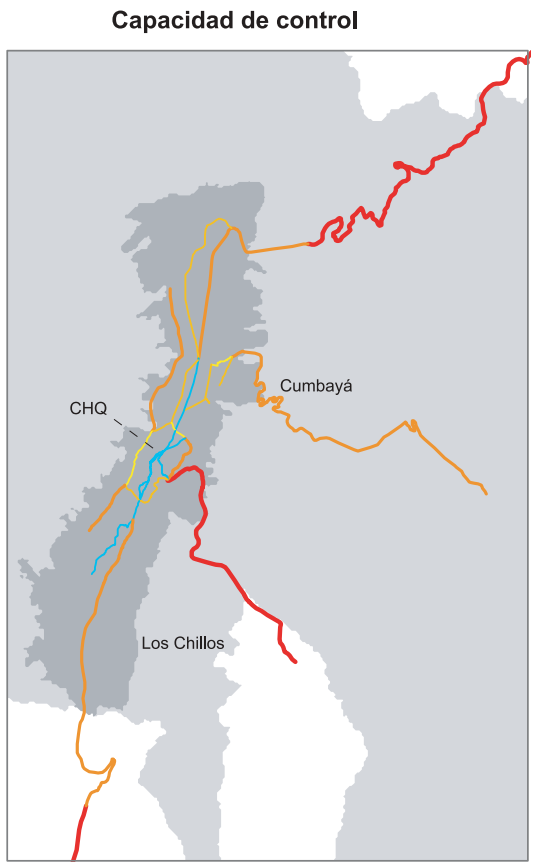

Variables consideradas

Personal asignado a la gestión del tráfico y/o del TC, medio de comunicación, control a distancia de la semaforización, control por cámara video, concesión vial, facilidad de acceso.
Alternativas de funcionamiento

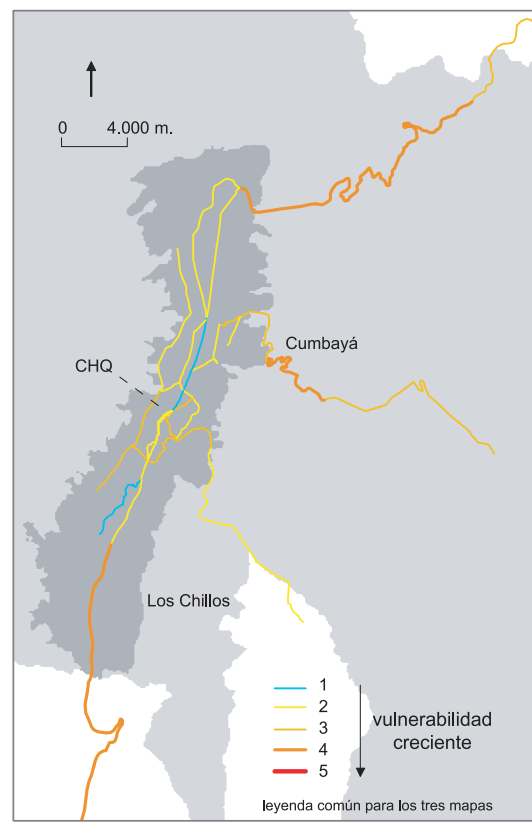

Variables consideradas

Alternativas viales, adaptabilidad de los servicos de transporte, alternativa energética.

\section{Preparación a las situaciones de crisis}

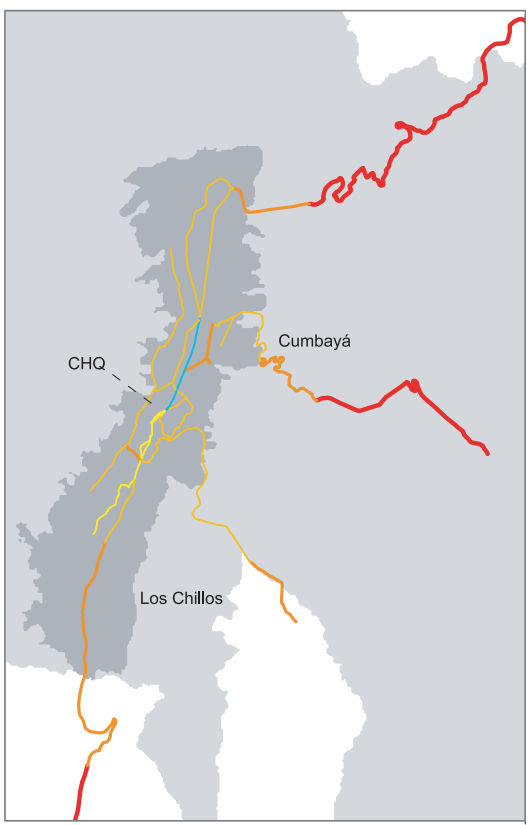

Variables consideradas

Capacidad de intervención en tiempo normal preparación a las crisis en general, preparación para afrontar fenómenos particulares. 
inferior a la de los ejes viales. Ello se debe a que los puentes tienen una extensión espacial más reducida en comparación con los tramos viales, que son consecuentemente más susceptibles de ser afectados por una amenaza. Debido a la vulnerabilidad intrínseca bastante alta de los puentes, la concretización de una amenaza aunque fuese moderada, podnía ocasionar daños importantes. Esto es muy preocupante porque las alternativas viales en caso de destrucción de un puente son globalmente limitadas (grados bastante altos 0 altos de vulnerabilidad). Por otro lado, la capacidad de control de las obras es también reducida fuera del espacio central y ningún plan de preparación a las crisis existe específicamente para los puentes. Eso es problemático porque se sabe que el colapso de un puente podría limitar o incluso interrumpir la accesibilidad de ciertos sectores (Véase cuarta parte).

Se podría pensar en la posibilidad de remediar diferentes formas de vulnerabilidad. Por ejemplo, a pesar de que el costo de un puente de hormigón presforzado sea superior al de un puente de hormigón armado, la resistencia del primero es mucho mejor frente a los sismos. Se podría plantear un cambio en la manera de otorgar los contratos de ejecución de obras viales, esto es, contratar únicamente a las empresas que utilicen la tecnología del hormigón presforzado y que construyan bajo las normas de sismoresistencia. Adicionalmente, un mantenimiento regular poco costoso de las obras permitiría aumentar su resiliencia frente a las amenazas. El reforzamiento de las infraestructuras cuya vulnerabilidad intrínseca es alta, en especial las que se ubican en las vías de acceso al Distrito, es también una tarea a corto plazo. Por último, se podría plantear la constitución de un equipo especial para intervenir rápidamente en caso de daño de las infraestructuras, al organizar las potencialidades actuales (inventarian- do por ejemplo la maquinaria que poseen algunas constructoras) y realizar simulacros.

\section{Los centros de transporte y los túneles: un balance moderado}

En ninguna de las formas consideradas los centros de transporte cuentan con una vulnerabilidad máxima (grado 5, véase mapas 6-5 y 6-6). En los temas de dependencia y de exposición a amenazas, la vulnerabilidad alcanza los niveles más altos (grado 4). En efecto, los centros dependen mucho del sistema eléctrico pero, por otro lado, todos los centros poseen generadores propios. En este sentido, no corren teóricamente el riesgo de experimentar graves problemas. En cambio, los centros son bastante expuestos o muy expuestos a las amenazas y susceptibles de experimentar daños.

La terminal terrestre está expuesta a todo tipo de amenazas, excepto a la explosión de productos peligrosos. Las estaciones de transferencia del trole son vulnerables a las inundaciones, la caída de ceniza, a la licuefacción de los suelos subyacentes en caso de sismo, y de modo menos marcado a la explosión de productos peligrosos. Por otro lado, la preparación a las emergencias no es óptima (grado 3). La lectura simultánea de estas dos formas, dependencia y exposición a amenazas, indica que los servicios de transporte colectivo son particularmente vulnerables. Para remediar esta situación, varias acciones son posibles entre las cuales llevar a cabo estudios de amenazas más precisos a la escala de estos centros. Por otro lado, simulacros, planes de acción frente a los distintos tipos de fenómenos podrían contribuir a superar eficazmente las emergencias y mantener el servicio de transporte colectivo que es esencial en Quito. 
Mapa 6-3

Grados sintéticos de las tres primeras formas de vulnerabilidad de los puentes esenciales

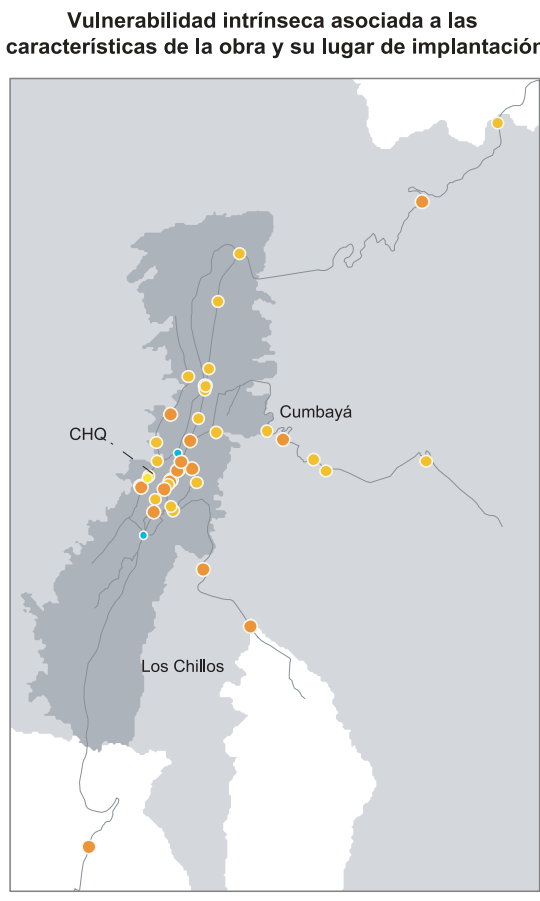

Variables consideradas

Daño y desgaste visible en la estructura, material de construcción, sismo resistencia, suelos subyacentes.

\section{Dependencia}

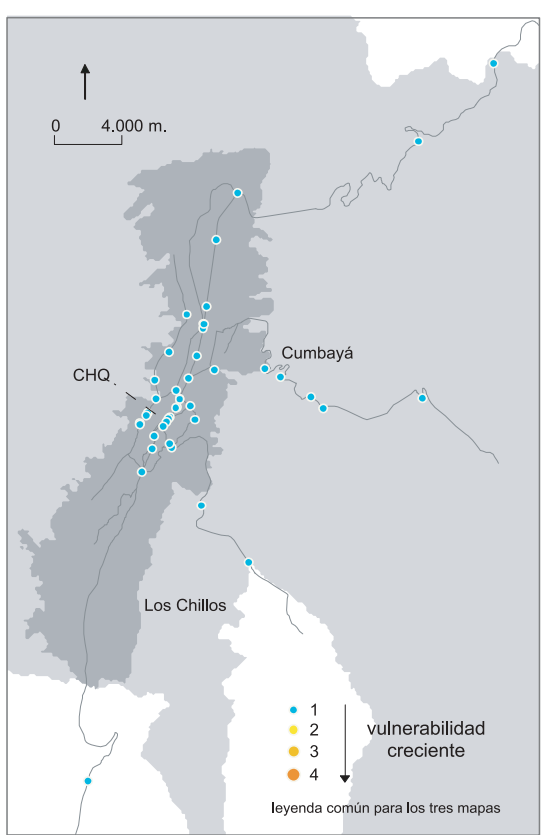

Variables consideradas

En Quito, los puentes no dependen de nada en particular.

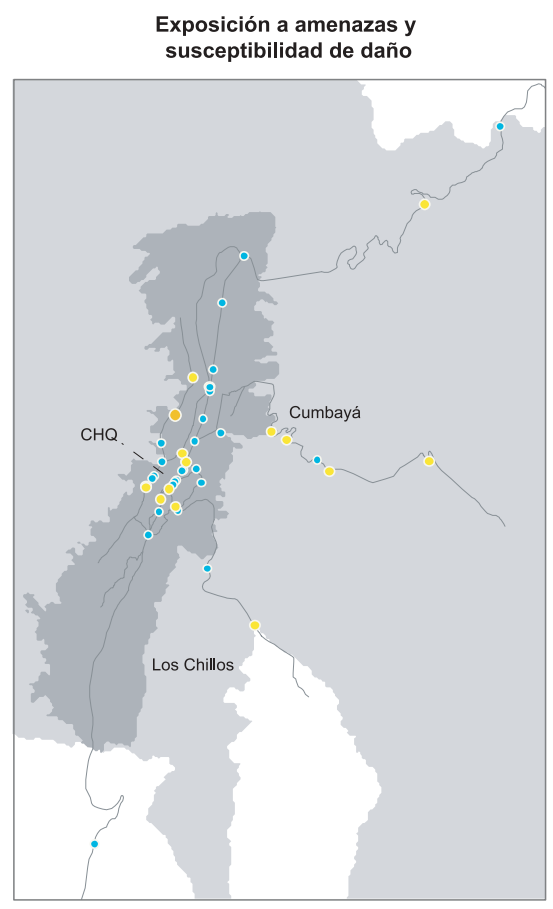

Variables consideradas

Aluviones, inundaciones, inestabilidad de suelo, licuefacción y amplificación de ondas sísmicas, caída de ceniza volcánica, lahares, flujos piroclásticos, explosiones de productos inflamables. 


\section{Mapa 6-4}

Grados sintéticos de las tres formas de compensación de la vulnerabilidad de los puentes esenciales

Capacidad de control

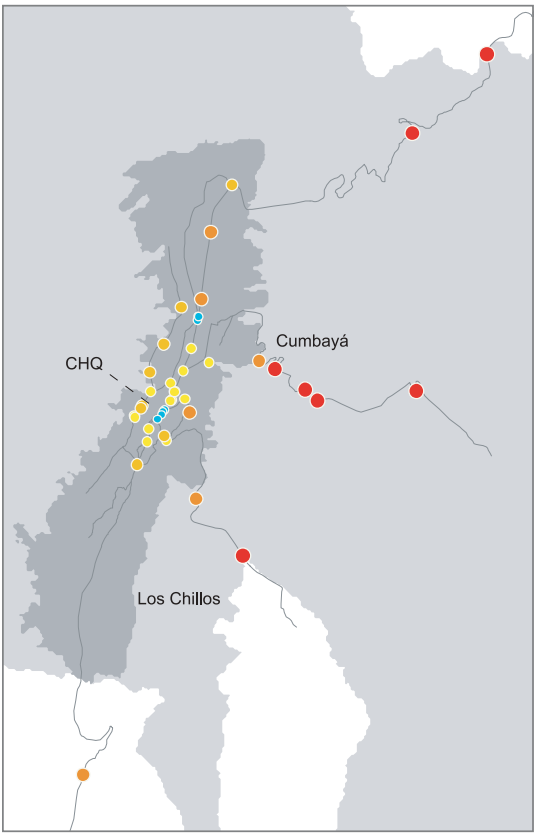

Variables consideradas

Personal asignado a la gestión del trafico y/o del TC, control por cámara video, facilidad de acceso.
Alternativas de funcionamiento

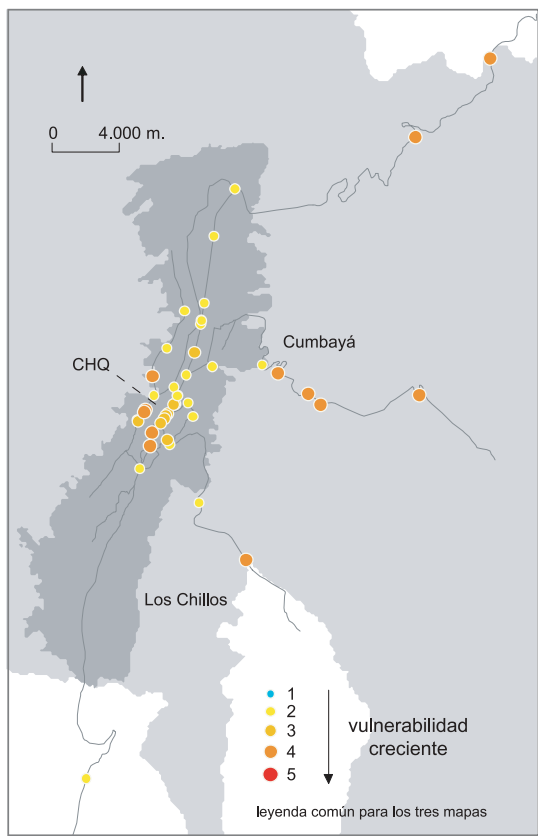

Variables consideradas

Existencia de alternativas de circunvalación cercana.
Preparación a las situaciones de crisis

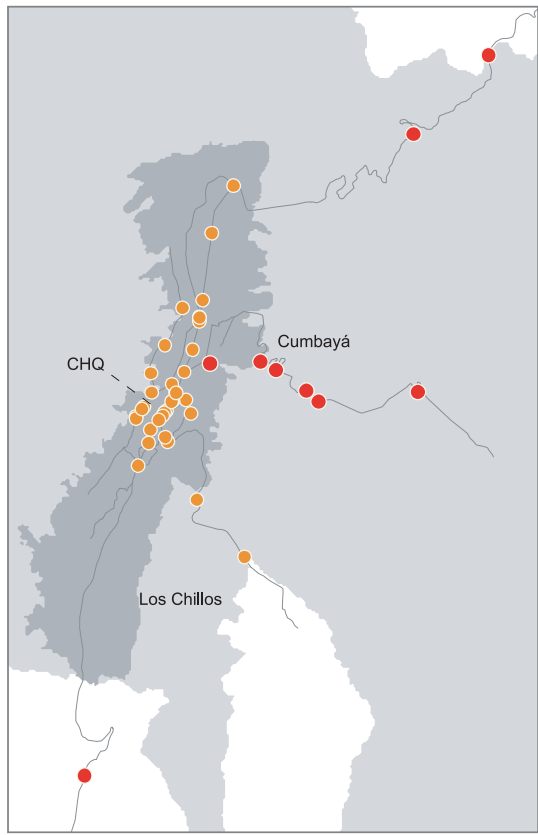

Variables consideradas

Capacidad de intervención en tiempo normal, preparación a las crisis en general, preparación para afrontar fenómenos particulares. 
En cuanto a los túneles (mapas 6-5 y 6-6) se revela una vulnerabilidad media en las tres primeras formas (intrínseca, dependencia, exposición a amenazas). La longitud de los túneles no excede de 700 metros, que no es muy largo en comparación con túneles de otras ciudades. La longitud influye sobre la peligrosidad de la circulación y la capacidad de intervención al interior, en caso de problema. Mientras más largo es el túnel, más difíciles son las intervenciones. En Quito, el estado de la rodadura al interior (San Juan y San Roque) es de modo general satisfactorio pero existen problemas de infiltración de agua.

De su lado, la calzada construida en forma deprimida en el túnel de San Diego conlleva problemas de evacuación del agua lluvia. En los tres túneles el alumbrado es adecuado pero la ventilación es deficiente. En cuanto a la capacidad de intervención es globalmente correcta (grado 2). En efecto, la avenida Mariscal Sucre es la vía más transitada de la ciudad, por lo que muchos policías dirigen el tráfico cerca de los túneles (sobre todo a las entradas de los túneles de San Juan y San Roque). Hidrantes y pasos peatonales entre los tubos se encuentran en los dos túneles más largos (San Juan y San Roque). Los pasos podrían ser útiles para el acceso de los organismos de socorro porque en ningún túnel existe un carril exclusivo para el paso de vehículos o personal de atención de emergencias. En cambio, en el ámbito de las alternativas de funcionamiento y de preparación a las crisis, la vulnerabilidad es una de las más altas (grados 4 y 5). No existe realmente una alternativa vial cercana satisfactoria para reemplazar la travesía de los túneles. Los otros dos ejes viales mayores que conectan el norte con el sur de la ciudad se encuentran del otro lado de la ciudad (Avenidas Pichincha, La Marín y Queseras del Medio, Velasco Ibarra) y ya están saturados habitualmente en las horas pico. Por último, no existe preparación tanto del Municipio como del lado de la Policía o Bomberos para casos de emergencia.

Adicionalmente, si bien en el plan de contingencia de la erupción del volcán Pichincha se había pensado, por precaución, en la posibilidad del cierre de los túneles no se proponía ningún otro itinerario de descongestión. Tomando en cuenta las observaciones previas, se podría plantear la implementación de alternativas viales para mitigar los problemas de tránsito. Se podrían definir itinerarios señalizados, por ejemplo, desde las entradas de la ciudad o en intersecciones estratégicas mucho antes de desembocar en los túneles. Se podrían organizar simulacros con el fin de probar la eficiencia de las vías de descongestión. Por otro lado, la existencia de este tipo de itinerario permitiría a los automovilistas y choferes de bus a evitar el desasosiego de la travesía. Los bomberos podrían aprovechar el cierre, a causa de las labores de limpieza, para practicar ejercicios de entrenamiento. Por último, la adquisición de unos trajes especiales y de máscaras de oxígeno mejoraría claramente su seguridad y eficacia en caso de incendio al interior.

La representación cartográfica previa, que permitió presentar consecutivamente las seis formas de vulnerabilidad de cada elemento esencial de la movilidad, es útil porque permite una lectura detallada de la vulnerabilidad y propone a los responsables de la toma de decisiones algunas orientaciones de prevención. La lectura cruzada de las diferentes formas de vulnerabilidad permitió también poner énfasis en los elementos que son particularmente vulnerables. Es el caso de un elemento cuya vulnerabilidad es alta y poco compensada. Para profundizar este tema, el objeto de la si- 


\section{Mapa 6-5}

Grados sintéticos de las tres primeras formas de vulnerabilidad de los túneles y centros de transporte esenciales

Vulnerabilidad intrínseca asociada a las

características de la obra, su lugar de

implantación y sus equipamientos

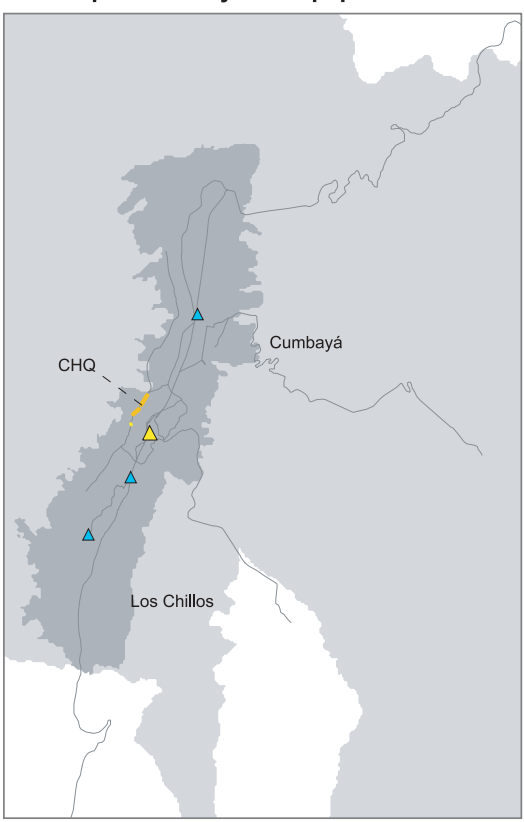

Variables consideradas:

Túneles: longitud, estado de rodadura, debilidades en la construcción, alumbrado, ventilación, atención requerida.

Centros de transporte: daño y desgastes visibles, suelos subyacentes (relleno).

\section{Dependencia}

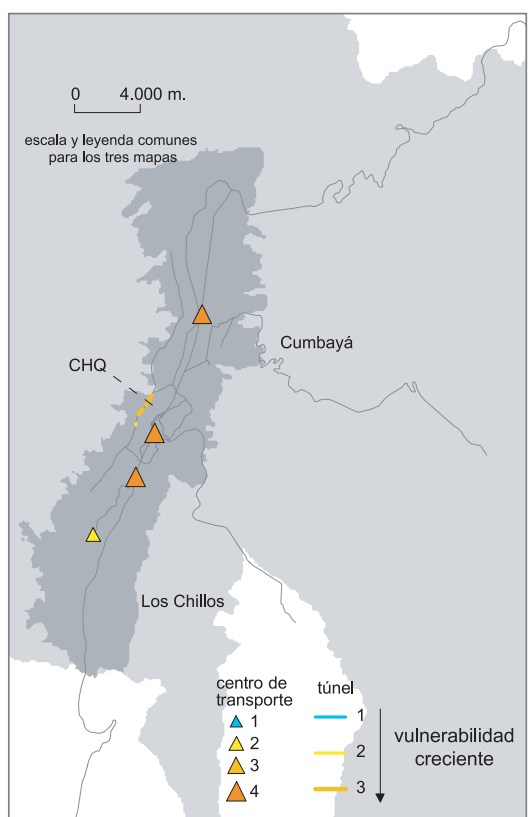

Variables consideradas:

Túneles: electricidad.

Centros de transporte: electricidad, personal.
Exposición a amenazas, susceptibilidad de daño y perturbación

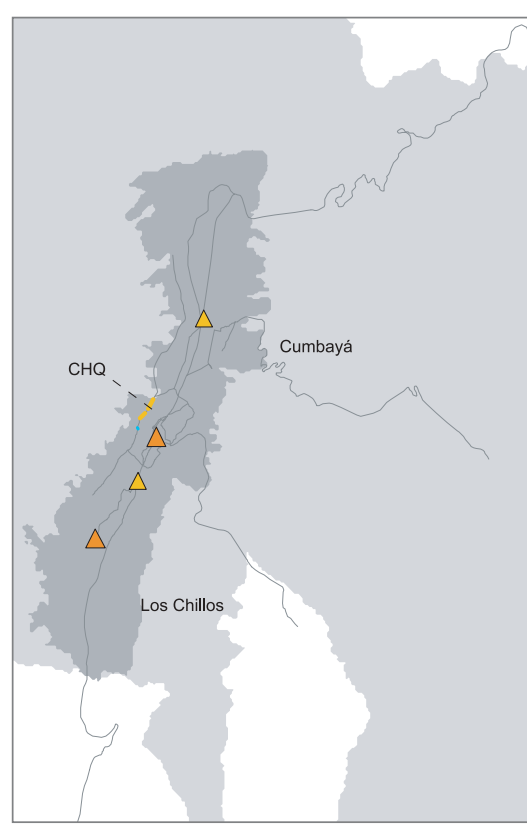

Variables consideradas:

Aluviones, inundaciones, inestabilidad de suelo, licuefacción y amplificación de ondas sísmicas, caída de ceniza volcánica, lahares, flujos piroclásticos, explosiones de productos inflamables. 


\author{
Mapa 6-6
}

Grados sintéticos de las tres formas de compensación de la vulnerabilidad de los túneles y centros de transporte esenciales

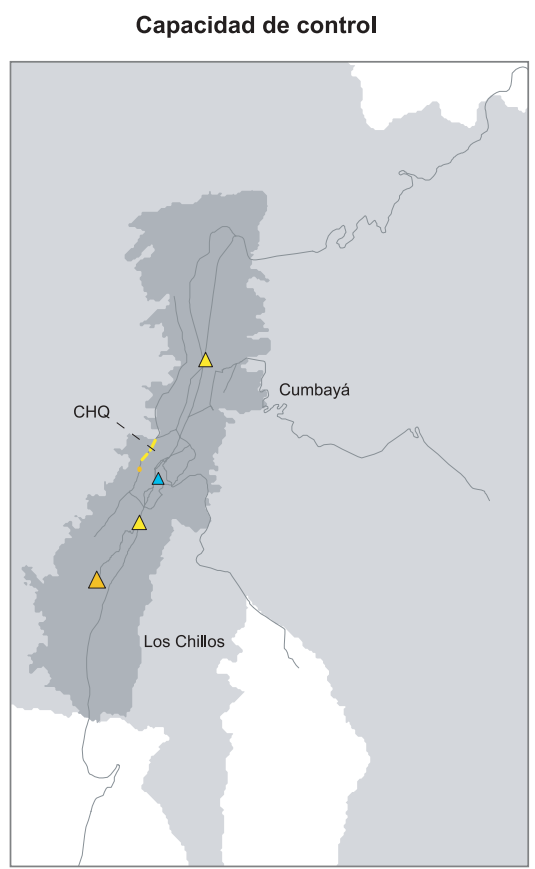

\section{Variables consideradas}

Túneles: presencia de policías a las entradas, control por cámara video, presencia de hidrantes al interior de los tubos, comunicación entre tubos, existencia de una vía reservada para los socorristas, facilidad de acceso.

Centros de transporte: grado de presencia de personal en el lugar, control por cámara video,

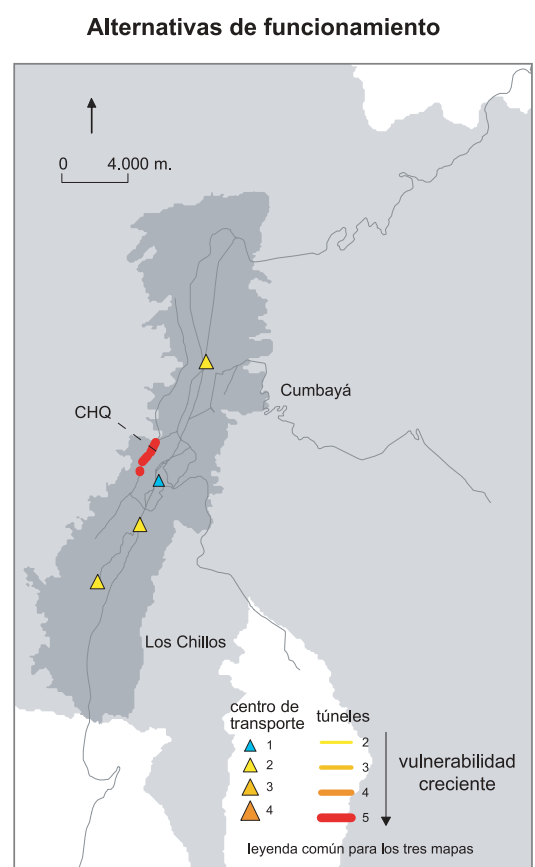

Variables consideradas

Túneles: alternativas viales

Centros de transporte: transferabilidad, alternativas energéticas
Preparación a las situaciones de crisis

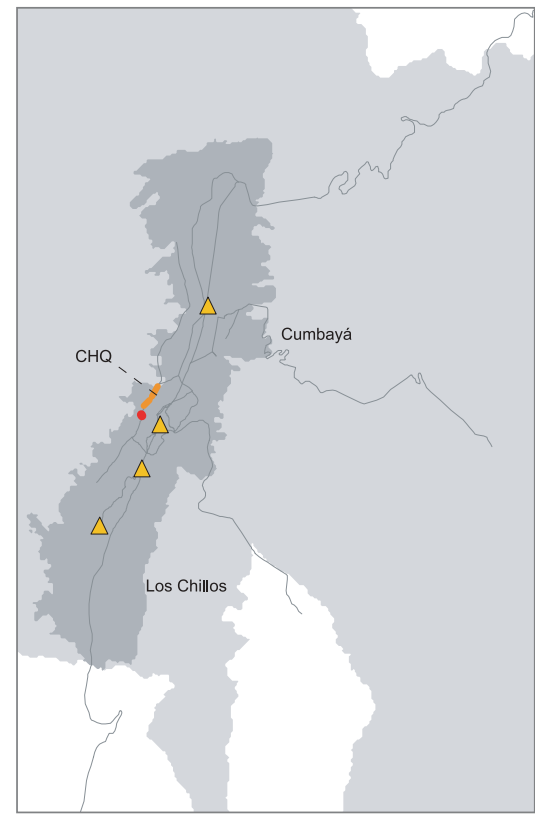

\section{Variables consideradas}

Túneles y centros de transporte: capacidad de intervención en tiempo normal que puede servir en caso de emergencia, preparación para afrontar crisis en general. 
guiente sección es acumular las seis formas con el fin de identificar los elementos esenciales más vulnerables que podrían limitar la accesibilidad de los lugares esenciales.

\section{Síntesis: los accesos a la ciudad y las comunicaciones intra urbanas norte-sur altamente vulnerables}

\section{La noción de vulnerabilidad acumulada}

La idea es acumular de manera tentativa las diferentes formas de vulnerabilidad para resaltar los elementos que cuentan con la vulnerabilidad más alta, es decir aquellos elementos que tienen la mayor susceptibilidad de ya no cumplir con su papel y consecuentemente perturbar de manera considerable la movilidad. La identificación de una concentración de vulnerabilidad en un elemento esencial representa un segundo indicativo para orientar las acciones prioritarias. Se adicionó entonces la vulnerabilidad parcial con el fin de llegar a un grado de vulnerabilidad acumulada.

\section{El cálculo de la vulnerabilidad acumulada}

Este cálculo se funda en tres etapas: 1) una ponderación de los grados sintéticos previamente cartografiados, 2) su suma y 3) una clasificación de los totales para determinar grados de vulnerabilidad acumulada.

\section{Primera etapa: Ponderación de los grados sintéticos}

Se considera que mientras más alta es la vulnerabilidad de un elemento, mayor es la susceptibilidad de perturbación de la movilidad. Por eso, se atribuyó un peso superior a los grados sintéticos más altos. Se uti- lizó un método de ponderación de los grados sintéticos por progresión geométrica. Este método presenta el interés de acentuar los contrastes entre los elementos siempre en la perspectiva de identificar los de mayor vulnerabilidad. La tabla 6-1 presenta la ponderación utilizada.

Tabla 6-1

Ponderación de los grados sintéticos de vulnerabilidad (progresión geométrica)

\begin{tabular}{|c|c|}
\hline grados sintéticos iniciales & grados sintéticos ponderados \\
\hline 1 & 1 \\
\hline 2 & 4 \\
\hline 3 & 9 \\
\hline 4 & 16 \\
\hline 5 & 25 \\
\hline
\end{tabular}

Segunda y tercera etapas:

Suma de los grados ponderados y nueva clasificación

Se adicionó los grados sintéticos ponderados. Luego se clasificó los totales y se consiguió grados de vulnerabilidad acumulada. Para determinar las clases, se consideró los valores observados en Quito y no los máximos hipotéticos. En efecto se puede observar una vulnerabilidad acumulada muy alta, sin tener necesariamente las seis formas asociadas a grados máximos de vulnerabilidad. En algunos casos, es suficiente tener uno o dos casos de vulnerabilidad muy alta para que el elemento sea globalmente muy vulnerable. Por ejemplo, saber que un puente tiene una alta vulnerabilidad intrínseca y que es al mismo tiempo susceptible de experimentar daños, es suficiente para entender que esta infraestructura es altamente vulnerable.

Se consideró límites comunes para los cuatro tipos de elementos esenciales con el fin de posicionar los ele- 
Tabla 6-2:

Determinación de la vulnerabilidad acumulada de los ejes viales esenciales. (síntesis levantada en base a las seis formas de vulnerabilidad analizadas)

\begin{tabular}{|c|c|c|c|c|c|c|c|c|c|c|c|c|c|c|c|}
\hline \multirow[b]{2}{*}{$\sum_{\frac{\pi}{0}}$} & \multirow[b]{2}{*}{ Denominación } & \multicolumn{6}{|c|}{$\begin{array}{l}\text { Recapitulación de los } \\
\text { grados sintéticos de las } 6 \\
\text { formas de vulnerabilidad }\end{array}$} & \multicolumn{6}{|c|}{$\begin{array}{l}\text { Ponderacion de los grados } \\
\text { por progresión geométrica }\end{array}$} & \multirow[b]{2}{*}{ 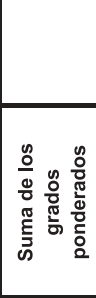 } & \multirow[b]{2}{*}{ 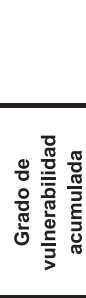 } \\
\hline & & 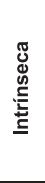 & $\begin{array}{l}\frac{\pi}{0} \\
\frac{c}{0} \\
\frac{0}{0} \\
\frac{c}{0} \\
\frac{0}{0} \\
0\end{array}$ & $\begin{array}{l}: \frac{0}{u} \\
\frac{0}{y} \\
: \\
\frac{0}{x} \\
\text { w }\end{array}$ & 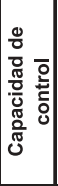 & 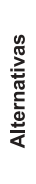 & 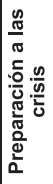 & 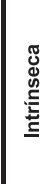 & $\begin{array}{l}\frac{\pi}{0} \\
\frac{c}{0} \\
\frac{\pi}{0} \\
\frac{c}{0} \\
\frac{0}{0} \\
0\end{array}$ & $\begin{array}{l}\frac{c}{u} \\
\frac{0}{0} \\
\frac{0}{x} \\
\frac{0}{x}\end{array}$ & 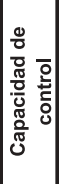 & 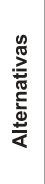 & 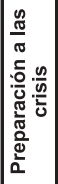 & & \\
\hline 2 & Panamericana Norte & 2 & 1 & 3 & 5 & 4 & 5 & 4 & 1 & 9 & 25 & 16 & 25 & 80 & 5 \\
\hline 10 & Panamericana Sur & 3 & 1 & 2 & 5 & 4 & 5 & 9 & 1 & 4 & 25 & 16 & 25 & 80 & 5 \\
\hline 5 & Interoceánica & 3 & 1 & 4 & 4 & 4 & 4 & 9 & 1 & 16 & 16 & 16 & 16 & 74 & 5 \\
\hline 11 & Panamericana Sur & 3 & 1 & 4 & 4 & 4 & 4 & 9 & 1 & 16 & 16 & 16 & 16 & 74 & 5 \\
\hline 1 & Panamericana Norte & 2 & 1 & 2 & 5 & 3 & 5 & 4 & 1 & 4 & 25 & 9 & 25 & 68 & 4 \\
\hline 4 & Interoceánica & 3 & 1 & 2 & 4 & 3 & 5 & 9 & 1 & 4 & 16 & 9 & 25 & 64 & 4 \\
\hline 27 & Carlos María de la Torre - Montúfar & 2 & 5 & 5 & 1 & 2 & 2 & 4 & 25 & 25 & 1 & 4 & 4 & 63 & 4 \\
\hline 18 & 10 de Agosto & 3 & 5 & 5 & 1 & 1 & 1 & 9 & 25 & 25 & 1 & 1 & 1 & 62 & 4 \\
\hline 26 & Pichincha & 3 & 4 & 4 & 1 & 3 & 3 & 9 & 16 & 16 & 1 & 9 & 9 & 60 & 4 \\
\hline 20 & Mariscal Antonio José de Sucre & 2 & 1 & 5 & 4 & 2 & 3 & 4 & 1 & 25 & 16 & 4 & 9 & 59 & 4 \\
\hline 31 & Mariscal Antonio José de Sucre & 2 & 2 & 4 & 4 & 3 & 3 & 4 & 4 & 16 & 16 & 9 & 9 & 58 & 4 \\
\hline 3 & Panamericana Norte & 2 & 1 & 2 & 4 & 4 & 4 & 4 & 1 & 4 & 16 & 16 & 16 & 57 & 4 \\
\hline 8 & Autopista Rumiñahui & 3 & 1 & 3 & 5 & 2 & 3 & 9 & 1 & 9 & 25 & 4 & 9 & 57 & 4 \\
\hline 28 & Mariscal Antonio José de Sucre & 3 & 1 & 5 & 2 & 3 & 3 & 9 & 1 & 25 & 4 & 9 & 9 & 57 & 4 \\
\hline 12 & Diego de Vásquez y Prensa & 2 & 2 & 5 & 3 & 2 & 3 & 4 & 4 & 25 & 9 & 4 & 9 & 55 & 4 \\
\hline 7 & Avenida Rumiñahui & 2 & 1 & 2 & 5 & 2 & 4 & 4 & 1 & 4 & 25 & 4 & 16 & 54 & 4 \\
\hline 29 & Napo & 3 & 1 & 4 & 3 & 3 & 3 & 9 & 1 & 16 & 9 & 9 & 9 & 53 & 4 \\
\hline 9 & Autopista Rumiñahui & 2 & 1 & 2 & 5 & 3 & 3 & 4 & 1 & 4 & 25 & 9 & 9 & 52 & 4 \\
\hline 19 & América & 3 & 2 & 4 & 3 & 2 & 3 & 9 & 4 & 16 & 9 & 4 & 9 & 51 & 4 \\
\hline 30 & Rodrigo de Chávez & 2 & 2 & 3 & 3 & 3 & 4 & 4 & 4 & 9 & 9 & 9 & 16 & 51 & 4 \\
\hline 14 & Mariscal Antonio José de Sucre & 2 & 1 & 4 & 4 & 2 & 3 & 4 & 1 & 16 & 16 & 4 & 9 & 50 & 4 \\
\hline 6 & Interoceánica & 3 & 1 & 2 & 4 & 3 & 3 & 9 & 1 & 4 & 16 & 9 & 9 & 48 & 3 \\
\hline 32 & Pedro Vicente Maldonado & 2 & 5 & 3 & 1 & 2 & 2 & 4 & 25 & 9 & 1 & 4 & 4 & 47 & 3 \\
\hline 13 & Galo Plaza Lasso & 2 & 2 & 3 & 4 & 2 & 3 & 4 & 4 & 9 & 16 & 4 & 9 & 46 & 3 \\
\hline 17 & Shyris & 2 & 2 & 3 & 3 & 2 & 4 & 4 & 4 & 9 & 9 & 4 & 16 & 46 & 3 \\
\hline 34 & Pedro Vicente Maldonado & 2 & 2 & 3 & 4 & 2 & 3 & 4 & 4 & 9 & 16 & 4 & 9 & 46 & 3 \\
\hline 15 & Los Granados y Gaspar de Villaroel & 2 & 3 & 3 & 2 & 3 & 3 & 4 & 9 & 9 & 4 & 9 & 9 & 44 & 2 \\
\hline 33 & Teniente Hugo Ortiz - Circunvalación & 2 & 5 & 3 & 1 & 1 & 2 & 4 & 25 & 9 & 1 & 1 & 4 & 44 & 2 \\
\hline 21 & Universitaria & 2 & 1 & 4 & 3 & 2 & 3 & 4 & 1 & 16 & 9 & 4 & 9 & 43 & 2 \\
\hline 24 & Gran Colombia & 3 & 3 & 2 & 1 & 3 & 3 & 9 & 9 & 4 & 1 & 9 & 9 & 41 & 2 \\
\hline 25 & 10 de Agosto & 2 & 5 & 3 & 1 & 1 & 1 & 4 & 25 & 9 & 1 & 1 & 1 & 41 & 2 \\
\hline 22 & Patria & 2 & 1 & 4 & 2 & 2 & 3 & 4 & 1 & 16 & 4 & 4 & 9 & 38 & 1 \\
\hline 23 & Velasco Ibarra (Oriental) & 2 & 1 & 2 & 4 & 2 & 3 & 4 & 1 & 4 & 16 & 4 & 9 & 38 & 1 \\
\hline 16 & Eloy Alfaro & 2 & 1 & 3 & 3 & 2 & 3 & 4 & 1 & 9 & 9 & 4 & 9 & 36 & 1 \\
\hline
\end{tabular}


mentos en niveles de vulnerabilidad comparables entre sí. Se individualizó cinco grados de vulnerabilidad acumulada que se extienden de 1 (vulnerabilidad acumulada nula o débil) a 5 (vulnerabilidad acumulada muy alta). La tabla 6-2 indica el detalle de los cálculos y los resultados para los ejes viales.

La tabla 6-3 indica las equivalencias entre la suma de los grados ponderados y los grados de vulnerabilidad acumulada:

\section{Tabla 6-3}

Equivalencia entre la suma de los grados ponderados y los niveles de vulnerabilidad acumulada

\begin{tabular}{|c|c|}
\hline $\begin{array}{c}\text { Suma de los } \\
\text { grados } \\
\text { ponderados }\end{array}$ & $\begin{array}{c}\text { Grado de vulnerabilidad } \\
\text { acumulada }\end{array}$ \\
\hline$[30 ; 41[$ & 1 \\
\hline$[41 ; 46[$ & 2 \\
\hline$[46 ; 49[$ & 3 \\
\hline$[49 ; 70[$ & 4 \\
\hline$[70 ; 97]$ & 5 \\
\hline
\end{tabular}

Se hizo luego una representación cartográfica de esta vulnerabilidad acumulada.

\section{Vulnerabilidad acumulada de los elementos esenciales de la movilidad: ensayo cartográfico}

En comparación con los demás elementos esenciales, los centros de transporte resaltan como menos vulnerables ya que no logran una vulnerabilidad acumulada alta o muy alta (Véase mapa 6-7). Ello se debe a que en tres formas (intrínseca, capacidad de control y alternativas) los centros se posicionan en una situación favorable. Por otro lado, en las tres otras formas tampoco tienen casos de vulnerabilidad máximas. En cambio, algunos elementos del sistema vial (ejes, puentes, túneles) alcanzan los niveles de alta y muy alta vulnerabilidad acumulada. Ello se debe a que los grados sintéticos máximos de vulnerabilidad son alcanzados en dos formas, en el caso de los túneles y puentes esenciales y, en cuatro formas, en el caso de los ejes viales esenciales. La vulnerabilidad acumulada máxima de los ejes (grado 5) se encuentra a nivel de los accesos a la ciudad (Panamericana norte, vía Interoceánica, Panamericana sur). De su lado, la autopista Rumiñahui logra una vulnerabilidad acumulada alta (grado 4). Esta vulnerabilidad alta refleja el cúmulo en estos ejes de una exposición a amenazas que puede ser alta, de una capacidad de control débil, de alternativas viales a menudo limitadas y de la falta de preparación a las crisis.

En lo que se refiere a los puentes, los que logran la mayor vulnerabilidad acumulada se ubican también en los sectores suburbanos a lo largo de la Panamericana norte, de la vía Interoceánica y de la autopista Rumiñahui. Estos puentes asocian una vulnerabilidad intrínseca bastante alta o alta y una capacidad de control muy reducida. Adicionalmente, son de modo general "inevitables", es decir, que las alternativas viales son muy limitadas. Para la mayoría de los puentes del Distrito no existe ningún tipo de preparación para afrontar las crisis.

En lo que se refiere a los túneles, los dos de mayor longitud (San Juan y San Roque) tienen una vulnerabilidad muy alta (grado 5) y el más corto (San Diego) tiene una vulnerabilidad alta (grado 4). Los túneles muestran una vulnerabilidad muy alta o alta tanto para lo que atañe a las alternativas de funcionamiento como para la preparación a las crisis, las cuales son casi inexistentes. La tabla 6-4 indica los elementos 
esenciales que logran una vulnerabilidad acumulada muy alta (grado 5).

El previo análisis permitió identificar los elementos esenciales de la movilidad que cuentan con formas de vulnerabilidad parcial alta y los que logran niveles de vulnerabilidad acumulada entre los más altos. Esta selección de elementos esenciales altamente vulnerables puede servir para priorizar las acciones con el fin de mejorar las condiciones de tráfico diario y sobre todo para evitar graves perturbaciones de accesibilidad en caso de concretización de amenazas.

El mapa 6-7 muestra que los accesos a la ciudad y las comunicaciones norte-sur (debido a la alta vulnerabilidad de los túneles) resaltan finalmente entre los más vulnerables.

En esta tercera parte se abordó las distintas formas de vulnerabilidad del sistema de movilidad del DMQ. Se identifió los elementos esenciales que cuentan con la mayor vulnerabilidad, es decir los que podrían experimentar graves disfuncionamientos. Es en estos elementos en los que la acción debería ser prioritaria. A continuación se reflexiona sobre las implicaciones previsibles de estos disfuncionamientos en el desenvolvimiento de las actividades metropolitanas. Para evaluar las implicaciones posibles se considera la cuestión de la accesibilidad.
Tabla 6-4

Elementos esenciales entre los más vulnerables (vulnerabilidad acumulada)

\begin{tabular}{|l|l|c|c|}
\hline Clave & $\begin{array}{l}\text { Denominación, } \\
\text { localización }\end{array}$ & $\begin{array}{r}\text { Tipo de } \\
\text { elemento }\end{array}$ & $\begin{array}{c}\text { Vulnerabilidad } \\
\text { acumulada }\end{array}$ \\
\hline 2 & Panamericana Norte & tramo vial & 5 \\
\hline 10 & Panamericana Sur & tramo vial & 5 \\
\hline 5 & Interoceánica & tramo vial & 5 \\
\hline 11 & Panamericana Sur & tramo vial & 5 \\
\hline 64 & Interoceánica - Río M achángara & puente & 5 \\
\hline 89 & Panamericana Norte - Río Guayllabamba & puente & 5 \\
\hline 45 & $\begin{array}{l}\text { Interoceánica - Río San Pedro } \\
\text { (cerca del Club El Nacional) }\end{array}$ & puente & 5 \\
\hline 52 & Interoceánica - Río Chiche & puente & 5 \\
\hline 12 & $\begin{array}{l}\text { Autopista Rumiñahui - Río San Pedro } \\
\text { (San Rafael) }\end{array}$ & puente & 5 \\
\hline 53 & $\begin{array}{l}\text { Interoceánica - Quebrada Auqui Chico } \\
\text { (antes de la Primavera) }\end{array}$ & puente & 5 \\
\hline 90 & Vía a Tabacundo - Río Pisque & puente & 5 \\
\hline 1 & San J uan & tunel & 5 \\
\hline 2 & San Roque & tunel & 5 \\
\hline
\end{tabular}




\section{Mapa 6-7}

Síntesis: Vulnerabilidad acumulada de los elementos esenciales de la movilidad

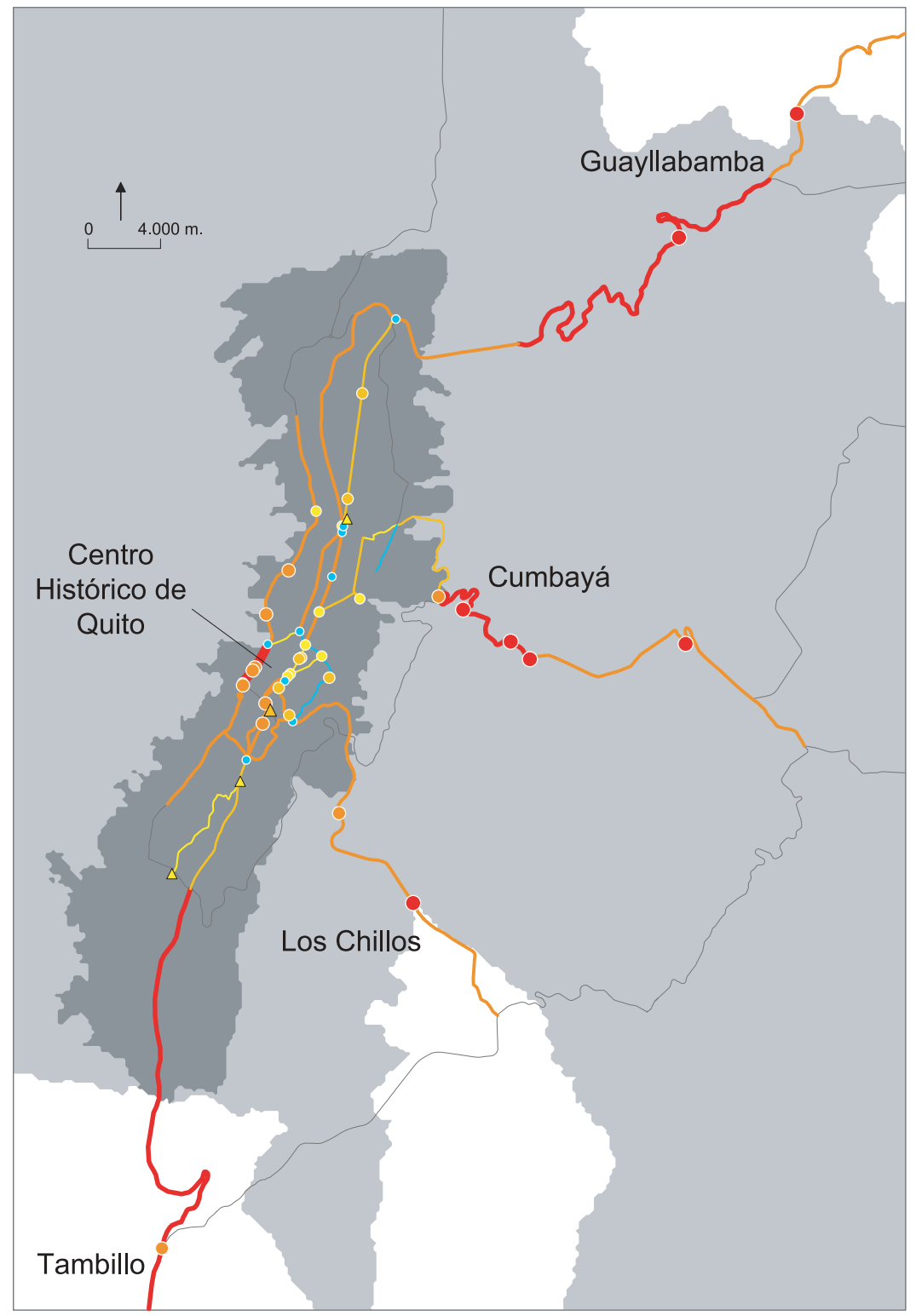

Ciudad de Quito DMQ

Ejes viales estructurantes (no considerados como elemento esencial)

Tramos viales

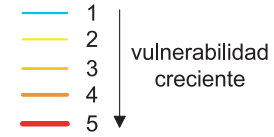

\section{Túneles}

- 4 vulnerabilidad

5 creciente

\section{Puentes}

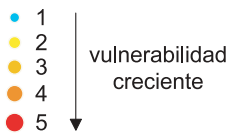

Centros de transporte
$\triangle 2$ vulnerabilidad
$\triangle 3 \checkmark$ creciente 
54 


\section{DE LA VULNERABILIDAD DE LOS ELEMENTOS ESENCIALES DE LA MOVILIDAD HACIA LOS RIESGOS POSIBLES PARA EL DMQ}

En esta cuarta parte se propone algunas reflexiones sobre los riesgos a los cuales está expuesto el sistema territorial metropolitano de Quito considerando los problemas de accesibilidad que podrían resultar del cierre de las vías esenciales debido a su alta vulnerabilidad. Se plantea de manera tentativa las posibles incidencias espaciales de los problemas de accesibilidad (desvíos, aislamientos) sobre el funcionamiento general del Distrito. 
166 


\section{7 - Interés del uso de la noción de accesibilidad para la comprensión de los riesgos}

Una circulación fluida y el fácil acceso a los diferentes espacios de una aglomeración urbana son imprescindibles para el desenvolvimiento de sus actividades. Es lógico pensar que problemas de acceso perturbarían el funcionamiento habitual de la urbe por lo que parece pertinente considerar la accesibilidad para evaluar los riesgos.

\section{Accesibilidad de los "lugares esenciales" y riesgos}

\section{La accesibilidad de los lugares esenciales...}

La movilidad y los intercambios son el motor de la ciudad. Las comunicaciones sustentan la organización de la sociedad urbana y participan en las relaciones sociales y en el desenvolvimiento de las actividades. Estas consideraciones son innegables pero es ante todo la accesibilidad de los lugares esenciales (espacios que cuentan con funciones urbanas de mayor relevancia) lo que se revela primordial para el funcionamiento y desarrollo de la ciudad.

El funcionamiento de un sistema territorial urbano se fundamenta en un conjunto de elementos urbanos de primera importancia y de diferente índole. Se trata de ciertos hospitales, algunos servicios, determinadas empresas o establecimientos educativos. Para funcionar, estos elementos urbanos esenciales requieren ser accesibles. Los lugares esenciales pueden corresponder a centralidades que cuentan con funciones urbanas de mayor interés. En la periferia de la ciudad, otros sectores en los que se encuentran las grandes instalaciones de la logística urbana (planta eléctrica, planta de almacenamiento de combustible, antenas de telecomunicación) pueden también ser asociados a lugares esenciales. La limitación o la pérdida de los accesos a los lugares esenciales permite intuir riesgos que se evalúa mediante un análisis espacial. En el caso del DMQ las funciones urbanas de mayor relevancia para su funcionamiento fueron identificadas, localizadas y presentadas en el libro "Los lugares esenciales del Distrito Metropolitano de Quito" (R. D’Ercole, P. Metzger, 2002).

\section{...accesibilidad cuya reducción conllevaría riesgos}

La limitación de las posibilidades de acceso a los lugares esenciales implica riesgos; puede contrarrestar la marcha de las funciones urbanas estratégicas y afectar el sistema territorial en su globalidad. Por ejemplo, una empresa grande experimentará dificultades si de repente quedara aislada. Las empresas que le abaste- 
cen en productos y las que dependen de ella también experimentarán disfuncionamientos. Además, sus empleados corren el riesgo de perder sus empleos y la economía de la ciudad podría quedar afectada. Ello evidencia las repercusiones en cadena a la escala de un sistema. En la misma lógica, la imposibilidad de alcanzar un centro hospitalario grande podría limitar su eficacia y perjudicar a las víctimas.

En esta sección, se considera los riesgos como consecuencias negativas posibles en caso de problema de acceso a los lugares esenciales. Estas consecuencias (víctimas, daños, disfuncionamientos, escasez de alimentos, pérdidas económicas) no son más que planteamientos de lo que podńa ocurrir. "A diferencia de una catástrofe -concretización de un fenómeno dañino- (...) el riesgo constituye una potencialidad: la posibilidad de advenimiento de un evento con consecuencias. En algunos casos, se puede asociar esta posibilidad o potencialidad a probabilidades. El riesgo reúne entonces dos a cepciones: una probabilidad y unas con secuencias" ${ }^{\prime \prime 5}$.

$\mathrm{Si}$ bien un sector puede ser habitualmente muy accesible, puede experimentar una fuerte disminución de su accesibilidad en caso de emergencia, por ejemplo si se dañan sus vías de acceso (destrucción de un puente, derrumbe de talud). La reducción del acceso a un sector es grave y lo es más aún si este sector reúne numerosas funciones urbanas estratégicas. Sin embargo, ya en época normal, se observan problemas de comunicación que pueden dificultar el funcionamiento del sistema territorial. A continuación, se mide las dificultades ordinarias de circulación en el seno de la aglomeración de Quito.

\section{Las comunicaciones en tiempo habitual al interior de la aglomeración}

Se entiende por "condiciones habituales" los períodos "normales" de funcionamiento del sistema territorial (que pueden integrar algunas breves perturbaciones). Esta situación cotidiana ordinaria se opone al período de crisis asociado a una emergencia ocasional de mayor gravedad o de mayor extensión generada por la concretización de un evento perjudicial. En esta situación el sistema territorial entra en un modo de funcionamiento inhabitual.

\section{Un sitio particularmente desfavorable a la circulación}

El DMQ cuenta con características particularmente desfavorables para la circulación: fuertes desniveles, fisonomía longitudinal (la ciudad), fragmentación topográfica asociada a algunos obstáculos orográficos (El Panecillo) e hidrográficos (nío Machángara) a los que se suman algunas barreras antrópicas (aeropuerto, parque La Carolina, centro histórico). Esta configuración de la red hace que su conexidad sea reducida; su conectividad, limitada y las distancias recorridas, largas. El mapa 7-1 indica que la aglomeración capitalina es delimitada al este y al oeste por dos cordilleras cuya altura excede los 3.000 metros sobre el nivel del mar. Al oeste, los cerros Casitagua, Pichincha y Atacazo constituyen una verdadera barrera de 55 kms. de largo. Al este, la cordillera oriental está atravesada únicamente por la carretera hacia la Amazonía que pasa por un collado a más de 4.000 metros de al-

85. Según R. D'Ercole, contribución a la definición de los conceptos del medio ambiente urbano, IRD, 2003. 
tura. El acceso al Distrito parece más fácil desde el noreste (provincias de Imbabura y Carchi) y por el sur, gracias a la Panamericana que pasa por el valle interandino. Sin embargo, las vías de acceso al Distrito y a la ciudad deben cruzar fuertes desniveles.

\section{Difícil acceso a la ciudad}

Los cuatro perfiles topográficos siguientes (figura 7-1), cuyos extremos están indicados en el mapa 7-1, muestran las dificultades para acceder al espacio central. Las pendientes de estos ejes son relativamente fuertes en algunos tramos, hasta un 11 por ciento en la autopista Rumiñahui y en la Panamericana sur, 12 por ciento en la vía Interoceánica desde Tumbaco y 13 por ciento en la Panamericana sur. Estas vías son globalmente anchas y en buen estado por lo que los automovilistas tienden a manejar a alta velocidad. No es casualidad que estas vías concentren el mayor número de accidentes que provoca consecuentemente el mayor número de muertes. En el 2000, la Dirección Nacional de Tránsito registró 186 accidentes que dejaron 25 fallecidos y 146 heridos, en la Panamericana sur entre Aloag y Quito; 199 accidentes, con 17 muertos y 103 heridos, en la vía Interoceánica entre Pifo y Quito. Si se compara el Distrito con otras ciudades ecuatorianas, se nota que el DMQ tenía la segunda tasa más alta de fallecidos por accidentes de tránsito (25,1 para 100.000 habitantes), luego de Cuenca $(32,6)$. Estos valores están por encima del promedio nacional urbano $(16,5)$ y muy superior al de Guayaquil $(11,6)$ (F. Carrión et al., 2001). Sin considerar los muertos por vejez, los accidentes de tránsito son la primera causa de mortalidad en el Distrito, le siguen las muertes por homicidios (18 por 100.000 habitantes). Las razones que permiten entender la alta tasa de Quito son múltiples. Cabe recordar que el DMQ po- see el mayor parque automovilístico por cantón de todo Ecuador (cerca de 200.000 vehículos, véase capítulo 2, sección 3.4).

\section{Trabas en la circulación vehicular}

En la ciudad, el cerro El Panecillo y el cañón del nío Machángara son las dos principales barreras naturales que dificultan las comunicaciones intra urbanas (Véase mapa 7-1). La primera, vuelve problemático los intercambios entre el norte y el sur de la ciudad, intercambios que son esenciales (acceso de las poblaciones del sur al espacio central, entre otros). La segunda, aumenta esta dificultad debido a la posición del nío, al pie de El Panecillo. No obstante, otras barreras para el tránsito están asociadas a las construcciones y equipamientos urbanos. El aeropuerto Mariscal Sucre, inicialmente ubicado en una zona rural cuando la ciudad no se extendía más allá de la Avenida Colón, hoy en día está englobada por la mancha urbana. Esta situación se observa en otras metrópolis, en particular en La Paz (Bolivia), aglomeración en la que el aeropuerto está rodeado por la urbanización de El Alto. En Quito, la pista de aterrizaje mide 3,8 kms. de largo lo que imposibilita las comunicaciones transversales ${ }^{86}$.

Otros equipamientos urbanos limitan los intercambios

86. La presencia de este aeropuerto en el seno de la ciudad conlleva también otros problemas. La longitud de la pista es inferior a la norma internacional para las naves grandes, que sin embargo aterrizan en Quito. Además a 2.800 metros de altura las condiciones aerológicas pueden ser muy turbulentas. Estas peculiaridades explican en parte la peligrosidad del aeropuerto de Quito. El accidente del Tupolev, de la empresa Cubana de Aviación, ocurrido en 1998, causó la destrucción de las urbanizaciones ubicadas al norte y la muerte de varios centenares de personas. 
Mapa 7-1

Principales barreras físicas, aglomeración de Quito

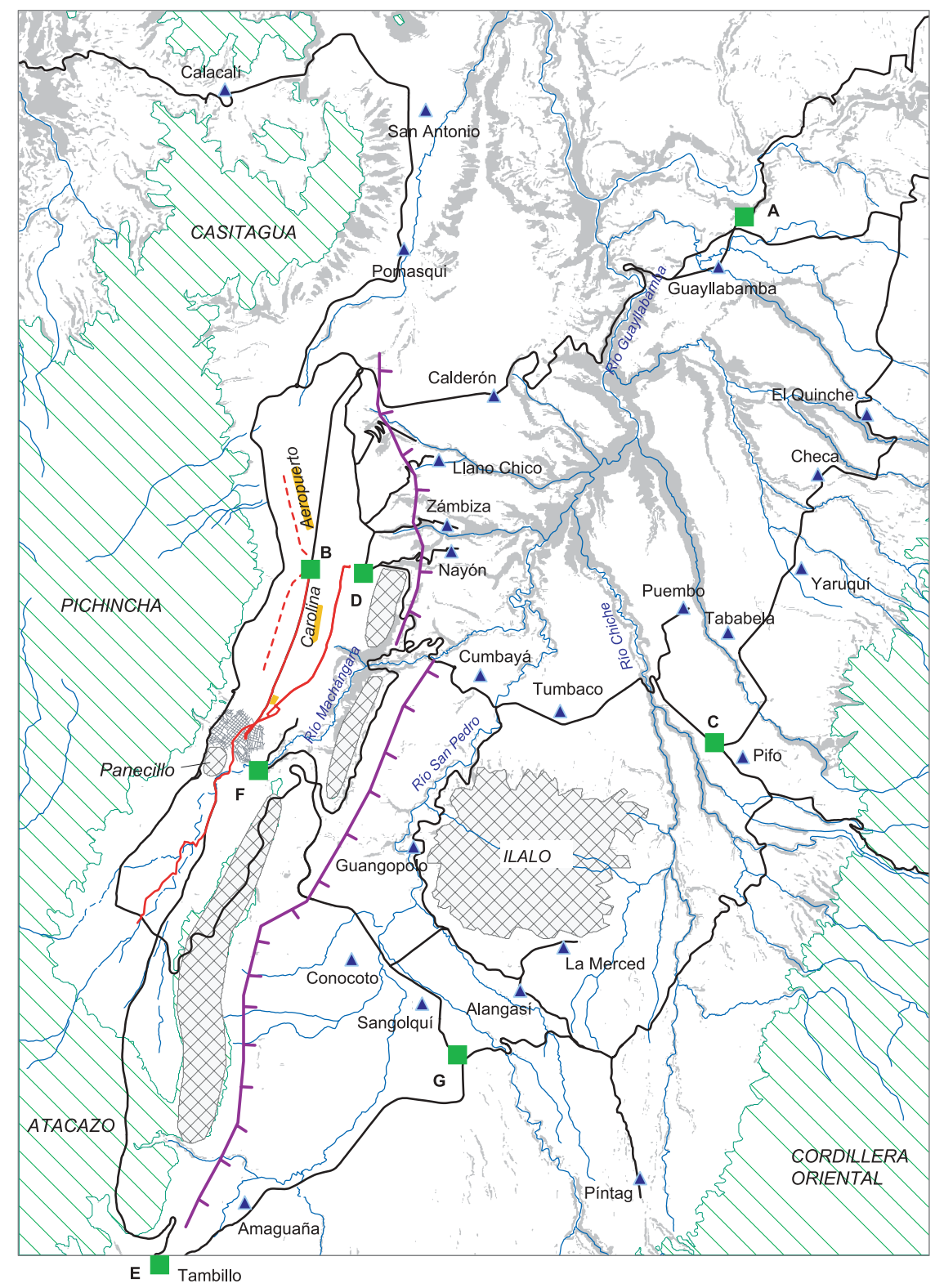

\section{Barreras topográficas}

Pendientes superiores a $30^{\circ}$

Zona de declive importante

T asociada a las fallas geológicas

Ríos principales

Límite de los 3000 metros de altura

Obstáculos orográficos por circunvalar (desvíos)

\section{Barreras antrópicas}

Ejes con carril exclusivo que limitan los desplazamientos transversales

Carril exclusivo en construcción (Avenidas América y Prensa)

Zona en la cual la capacidad vial es reducidad (CHQ)

\section{Parques y aeropuerto}

Cabeceras parroquiales

- suburbanas

Principales ejes viales

Extremos de los perfiles topográficos 
Figura 7-1

Perfiles topográficos de los accesos a la ciudad

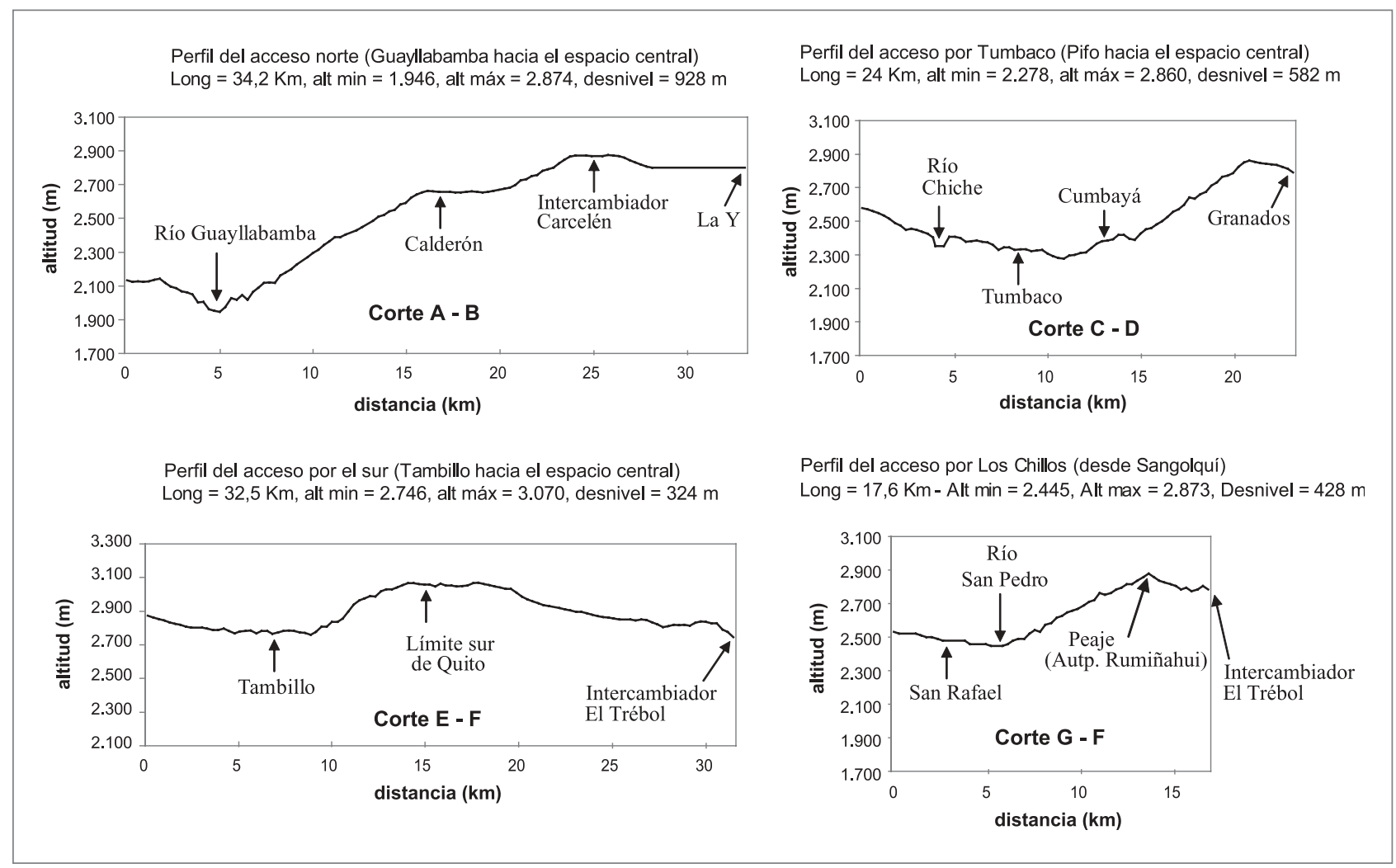


latitudinales. Por ejemplo, el parque La Carolina, implementado en el marco del Plan Odriozola de 1942, con 1,6 Km. de largo constituye una barrera en el seno del espacio central ${ }^{87}$. Del mismo modo, la construcción de carriles exclusivos al centro de algunas avenidas (trole, ecovía y ahora las avenidas América y Prensa), constituyen largas barreras, difíciles de cruzar. Adicionalmente, la gestión del tráfico en estos ejes prohíbe la posibilidad de girar a la izquierda. Esta canalización del tráfico contribuye a alargar las distancias recorridas por los automovilistas, en especial en el espacio central. Sin embargo, cabe resaltar que estos corredores de transporte colectivo en carril exclusivo son producto de una decisión política acertada que brinda a la mayoría de los capitalinos condiciones satisfatorias de desplazamiento.

El análisis resalta las numerosas dificultades de comunicación al interior de la aglomeración (por la existencia de múltiples barreras) y una primera serie de riesgos a los que está expuesto el Distrito en especial en términos de seguridad (accidentes de tránsito, accidentes aéreos). Las numerosas trabas físicas para la movilidad y los desniveles conllevan una alta contaminación atmosférica, reducen la velocidad de los intercambios y generan desgastes energéticos. En un marco de alta competitividad con Guayaquil, se podría decir que el DMQ se encuentra en una situación menos favorable en cuanto a comunicaciones terrestres.

Si este primer enfoque proporciona algunas ideas sobre los riesgos a los cuales está expuesto el Distrito, debe ser complementado para ser más preciso, por un

87. Sin embargo, este parque es vital para los capitalinos y debe ser resguardado a toda costa. segundo enfoque que considera las diferencias de accesibilidad que pueden ser muy variables al interior de la aglomeración y conllevar otras dificultades.

\section{Definición y método de evaluación de la accesibilidad de los lugares}

La accesibilidad de un lugar corresponde "al grado de facilidad con el cual se puede alcanzar un lugar" $(\mathrm{H}$. Beguin, 1995). Generalmente, la accesibilidad se define por nodos en un grafo valorado que representa esquemáticamente una red vial o de transporte. La accesibilidad puede también aplicarse a zonas. Para determinar la accesibilidad de los lugares fue necesario realizar una subdivisión del Distrito en sectores, según una lógica peculiar.

Para medir la accesibilidad de las diferentes zonas del Distrito en tiempo habitual y reflexionar sobre las rupturas de accesibilidad posibles, en caso de fallo de un tramo de la red vial, se consideró la estructuración de la red vial para entender como se enlazan los diferentes subespacios entre sí, es decir entender como se articulan las comunicaciones. El fallo de un elemento (un puente, una vía de conexión) entre dos zonas pueden limitar el acceso a una de las dos zonas o a ambas. Se realizó la división en dos etapas. Primero, se dividió el Distrito en 14 "macrozonas" que fueron a su vez subdivididas en 44 "microzonas". Las 14 macrozonas fueron delimitadas en base a la estructura de la red vial principal, estructura que depende de la topografía y de la hidrografía. Se consideró entonces las discontinuidades y las barreras del espacio metropolitano. También se consideró el principio de dependencia de los sectores en torno a ejes centrales colectores (lógica gravitacional).

El mapa 7-2 representa la división del Distrito en 14 
Mapa 7-2

Red vial, puntos de entrada y división del Distrito en 14 macrozonas

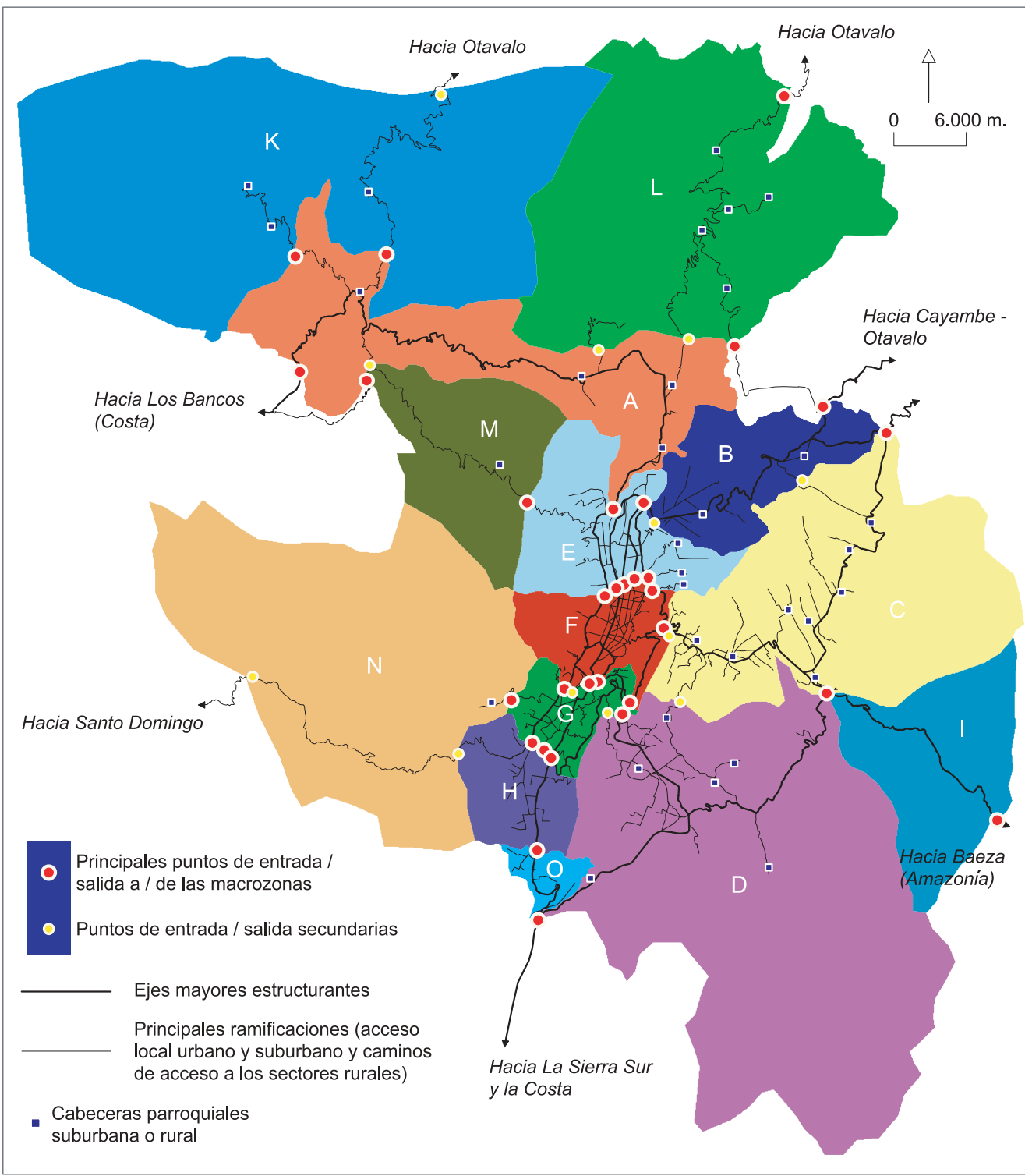

Acceso nororiental -

A Nanegalito - Calacalí -

San Antonio - Pomasqu

B Acceso Panamericana

Calderón - Carapungo

Cumbayá - Tumbaco -

C Pifo - Yaruquí -

El Quinche

Los Chillos - Guango-

polo - La Merced -

Píntag - Amaguaña

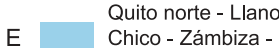

Chico -

F Quito espacio centra

y Nueva Oriental

G Quito - centro sur

H Quito sur

Acceso desde la

I Amazonia

K Pacto - Gualea

Nanegal

San José de Minas -

L Chávezpamba

M Nono

N Lloa

Acceso Panamericana Sur - Tambillo 


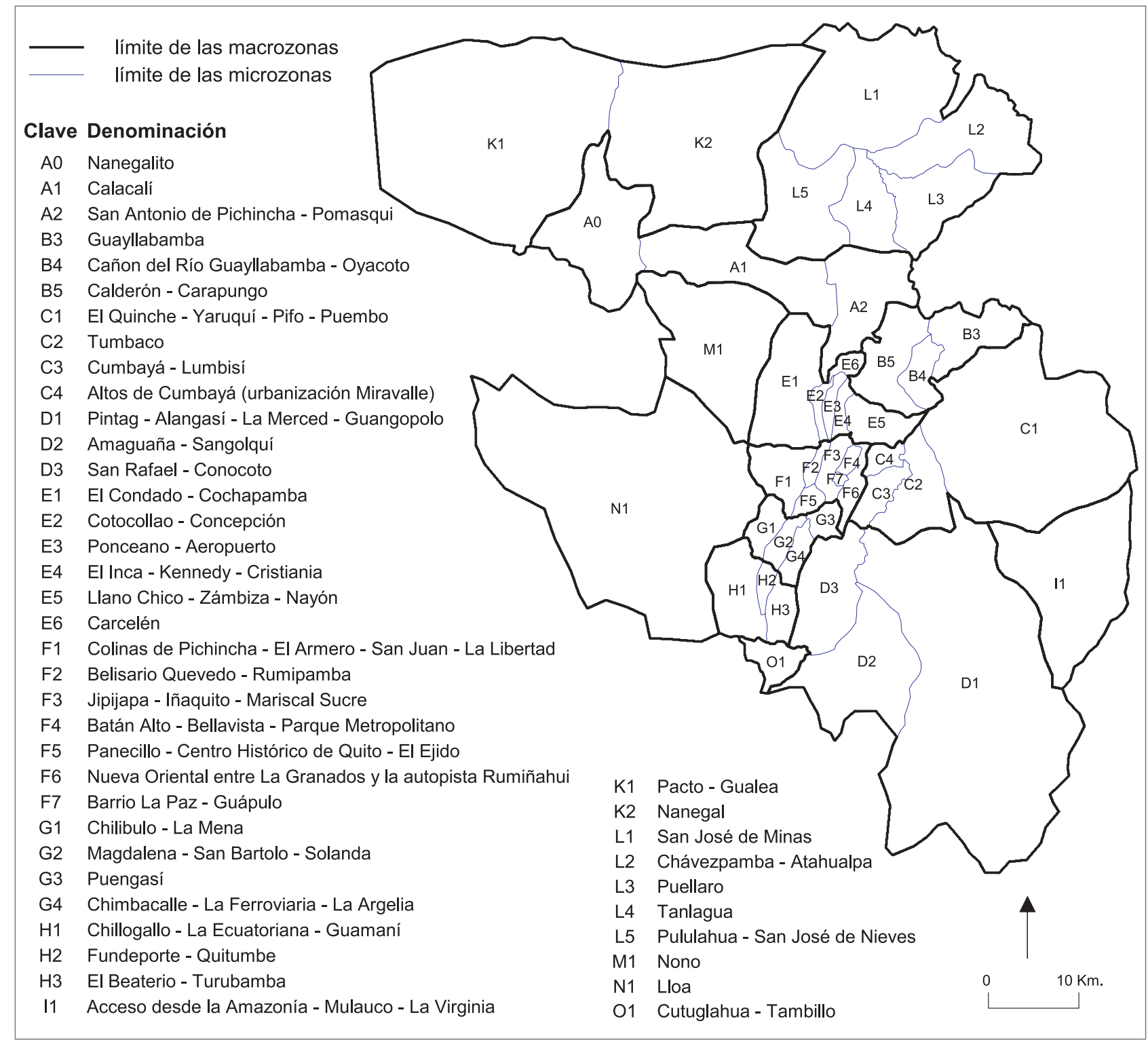


Mapa 7-3b

Microzonas y red vial en el Distrito

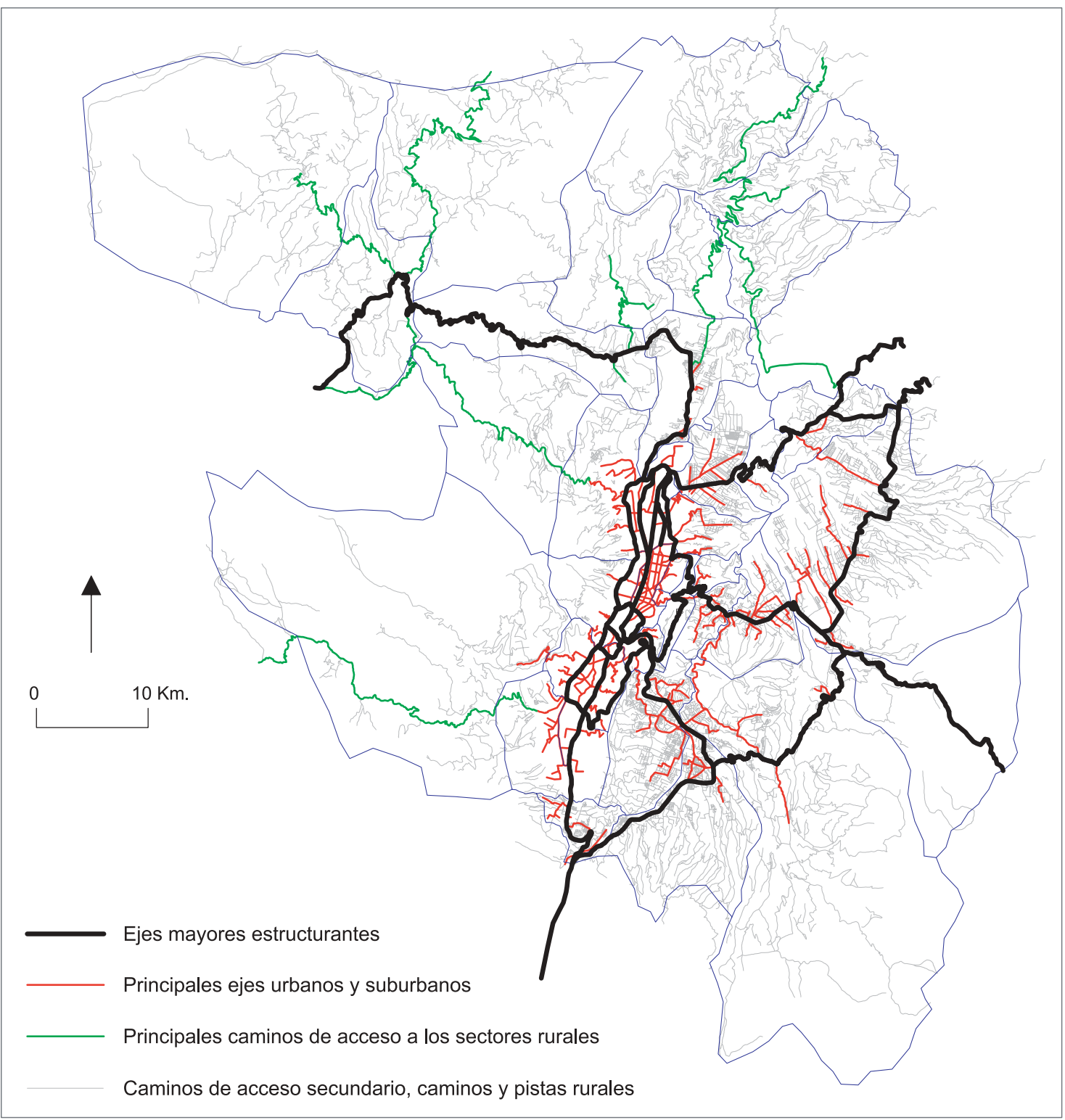


macrozonas y sus puntos de entrada y salida. En base a esta primera delimitación se hizo una subdivisión más detallada, y se determinó 44 microzonas (mapa 73 a y b) con el fin de mejorar la precisión en lo que se refiere a la evaluación de los riesgos (véase más adelante). El método de delimitación es el mismo. En la ciudad, sin embargo, se utilizó además las principales avenidas como límites interzonales, en la medida en que, como se vio antes, estas últimas pueden representar verdaderas barreras, sobre todo si cuentan con un carril exclusivo para el transporte colectivo. 


\section{Evaluación de la accesibilidad de los diferentes subespacios geográficos del Distrito: procedimiento y cartografía}

A partir de la zonificación realizada, basada en la estructuración de la red vial, es posible evaluar la accesibilidad de los subespacios del Distrito. El objetivo es resaltar los sectores que se encuentran en una situación particularmente desfavorable en tiempo habitual y los que son susceptibles de experimentar una fuerte disminución de su accesibilidad en caso de crisis debido al daño o pérdida de operatividad de ciertos tramos de la red vial. En base a este diagnóstico se podrá posteriormente apreciar los riesgos a los cuales está expuesto el Distrito.

\section{La accesibilidad en tiempo habitual}

Para determinar la accesibilidad de las zonas en condiciones habituales se consideró los criterios de la red vial y el medio físico. Se utilizó ocho variables tanto cuantitativas (número de entradas/salidas, porcentaje de superficie a más de $1 \mathrm{~km}$. de un eje colector principal, pendiente, índice de conexidad) como cualitativas (tipo de rodadura); se valoró estas ocho variables tomando en cuenta una amplitud que se extiende de 0, para la mejor situación, a 4, para la peor.

Se planteó varias escalas, tomando en consideración primero la accesibilidad de las macrozonas en las cua- les se encuentran las microzonas. En efecto, el acceso a las macrozonas condiciona a un nivel inferior el acceso a las microzonas. La accesibilidad de las macrozonas fue evaluada en base a un criterio simple: el número de entradas/salidas principales y secundarias ${ }^{88}$. Se sumó estos datos después de haber ponderado por dos el número de vías principales (que son más importantes). A partir de estos totales, se determinó un nivel de accesibilidad de las macrozonas (Véase tabla 8-1) que se aplicó luego a las microzonas (Véase más adelante).

Luego, se analizó los accesos inmediatos a las microzonas observando el tipo de rodadura y la existencia 0 ausencia de vías de entrada centrales, que permiten llegar rápidamente al interior de la microzona. Además de estas tres primeras variables (niveles de accesibilidad de la macrozonas aplicados a las microzonas, tipo de rodadura de los accesos inmediatos y existencia de vías de entrada centrales), se evaluó al interior de las microzonas la facilidad de circular en vehículos sobre la red vial local. Se consideró cinco variables que fueron calculadas en el SIG Savane:

88. Un punto de acceso puede ser principal para una zona, pero secundario para otra. Un mismo puente puede ser contabilizado tanto en la categoría "entrada principal" como en la categoría "entrada secundaria", en función de la macrozona considerada. 
1. Proporción de la superficie de la microzona ubicada a más de un kilómetro de un eje vial mayor. Este indicador da información en cuanto al aislamiento de las microzonas.

2. Pendiente promedio de la microzona. Mientras mayor es la pendiente de la zona, más empinadas y sinuosas son las vías, más difícil es la circulación.

3. Densidad de la red de inervación (número de kilómetros de vías por unidad de superficie). Mientras menos densa es la red vial local, más reducida es la cobertura local, más difícil es el acceso a los bamios.

4. Sinuosidad de la red de inervación (relación entre la longitud de un eje y la distancia en línea recta entre sus dos extremos). Se calculó el promedio de estos valores.

5. Conexidad de la red de inervación (cantidad de lazos directos existentes entre los nodos de la red vial local en relación con el número total máximo de lazos en la hipótesis de una conexidad óptima). Se calculó simplemente el número de vías sin salida en cada microzona.

Las valoraciones asignadas a cada una de las ocho variables fueron posteriormente adicionadas para determinar un nivel de accesibilidad sintética, al que se cartografió (mapa 8-1).

La accesibilidad de los diferentes sectores del Distrito es variable en periodo normal. Es globalmente mejor en la mitad oriental del Distrito y en la ciudad, en los sectores planos. Una cantidad bastante elevada de vías anchas asfaltadas llegan a estos sectores, los cuales
Tabla 8-1

Variables consideradas para medir la accesibilidad de las macrozonas

\begin{tabular}{|c|c|c|c|c|c}
\hline $\begin{array}{c}\text { Macro- } \\
\text { zonas }\end{array}$ & $\begin{array}{c}\text { Número } \\
\text { de entradas/salidas } \\
\text { principales } \\
\text { (Coeficiente 2) }\end{array}$ & $\begin{array}{c}\text { Número } \\
\text { de entradas/salidas } \\
\text { secundarias } \\
\text { (Coeficiente 1) }\end{array}$ & Suma & Valoración & $\begin{array}{c}\text { Accesibilidad } \\
\text { (síntesis) }\end{array}$ \\
\hline F & 11 & 3 & 25 & 0 & buena \\
\hline G & 8 & 4 & 20 & 0 & buena \\
\hline E & 8 & 2 & 18 & 1 & bastante buena \\
\hline A & 2 & 5 & 9 & 2 & mediana \\
\hline C & 3 & 3 & 9 & 2 & mediana \\
\hline H & 4 & 1 & 9 & 2 & mediana \\
\hline D & 3 & 2 & 8 & 3 & bastante débil \\
\hline B & 3 & 2 & 8 & 3 & bastante débil \\
\hline L & 2 & 2 & 6 & 3 & bastante débil \\
\hline I & 2 & 0 & 4 & 4 & débil \\
\hline O & 2 & 0 & 4 & 4 & débil \\
\hline N & 1 & 2 & 4 & 4 & débil \\
\hline K & 2 & 1 & 5 & 4 & débil \\
\hline M & 2 & 1 & 5 & 4 & débil \\
\hline
\end{tabular}

cuentan también con una red local bastante desarrollada. En cambio, la accesibilidad de los sectores al oeste y al norte de la aglomeración y de las laderas occidentales de la ciudad es menor. Estos sectores cuentan con una topografía accidentada y un número limitado de accesos generalmente sinuosos que no son siempre asfaltados. Entre la ciudad y los valles orientales un sector resalta como poco accesible, se trata de la zona E5 (Llano Chico, Zámbiza, Nayón) que cuenta con tres accesos asfaltados pero sin salida, entre los cuales no existe conexión por la presencia de quebradas profundas. 


\section{Mapa 8-1}

Accesibilidad de las microzonas en período habitual

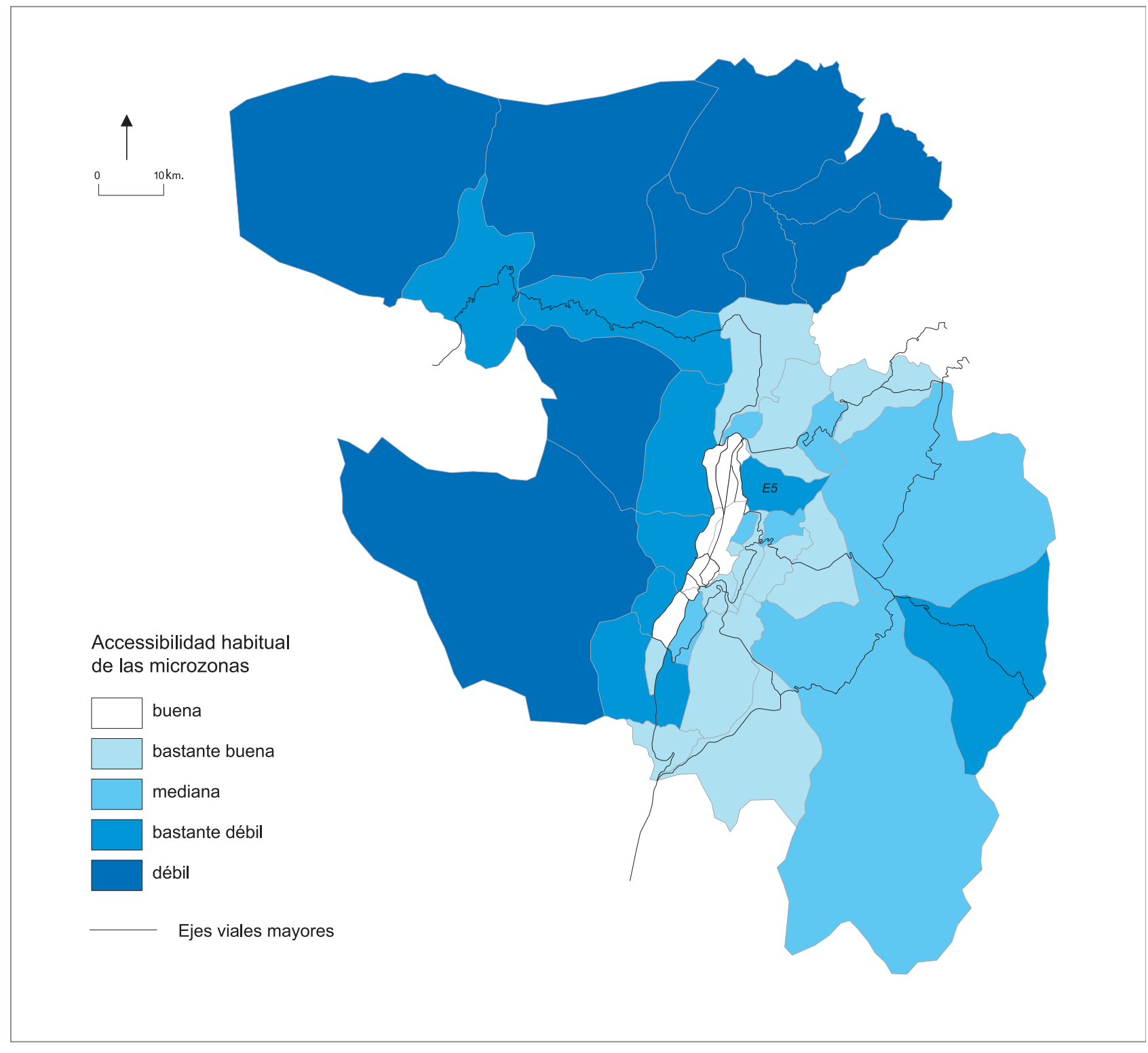




\section{Accesibilidad de las zonas, en caso de fallo en los elementos esenciales de la movilidad más vulnerables}

\section{Análisis de reducción de la accesibilidad}

El objetivo de esta sección es entender en qué medida la accesibilidad de los diferentes espacios del Distrito puede ser reducida por pérdida de operatividad de ciertos elementos del sistema vial. La primera tarea fue identificar los elementos de la red vial que tienen la mayor susceptibilidad de experimentar un fallo. Para conocer estos elementos se utilizó el análisis previo de vulnerabilidad de los elementos esenciales de la movilidad (tercera parte).

Primeramente, se extrajo los elementos de la movilidad (vías, puentes, túneles) caracterizados por los grados más altos de vulnerabilidad acumulada (grados 4 y 5). Luego se localizó las porciones de la red vial en donde la alta vulnerabilidad acumulada de diferentes elementos esenciales se concentra. Es decir, se consideró los tramos viales esenciales con alta 0 muy alta vulnerabilidad que cuentan por lo menos con otro tipo de elemento esencial (puente, túnel) también con alta o muy alta vulnerabilidad. Se consideró esta asociación de vulnerabilidad en el sentido de que se trataba de identificar las porciones de la red vial que tienen la mayor susceptibilidad de quedar inoperantes (porciones en las cuales el tráfico corre el peligro de ser bloqueado) y por tanto limitar la accesibilidad de las zonas.

Se identificó cinco porciones de la red vial con mayor vulnerabilidad. Se trata de los ejes siguientes:

- Panamericana norte (acceso nororiental).
- vía Interoceánica (acceso oriental).

- Autopista Rumiñahui (acceso suroriental).

- Panamericana sur (acceso sur).

- Eje de los túneles.

Sobre esta base se evaluó las posibilidades de reducción de la accesibilidad de las zonas, según dos lógicas:

Una lógica endótropa de proximidad

En otros términos, se evalúa la reducción de la accesibilidad de una zona considerando la vulnerabilidad de los accesos inmediatos a la zona (desde el exterior cercano). Esta lógica permite resaltar las posibilidades de aislamiento al menos parcial de algunos sectores respecto a los sectores limítrofes.

\section{Una lógica "orientada" desde el exterior del Distrito}

Debido a que las porciones de la red vial de mayor vulnerabilidad comesponden a los accesos a la ciudad y al eje de los túneles (Avenida Mariscal Sucre), se evaluó los desvíos necesarios para llegar a las diferentes partes urbanas (lugares de concentración de la mayoría de las funciones esenciales para el funcionamiento del DMQ) desde el exterior de la ciudad, según una lógica centrípeta.

\section{Reducción de la accesibilidad según la lógica endótropa de proximidad}

La destrucción o el daño de los accesos viales pueden tener múltiples causas: un sismo, lahar, un aluvión, crecida de un nóo o derrumbe (Véase tercera parte). Para evaluar las posibilidades de reducción de la accesibilidad de las zonas según la lógica endótropa de proximidad se consideran los dos siguientes criterios: 
- El número de accesos principales susceptibles de ser intransitables en relación con el número total de accesos principales.

- El número de accesos secundarios susceptibles de no experimentar problemas.

Las posibilidades de reducción de la accesibilidad de las zonas son tanto más altas cuanto que el número de accesos es limitado y los accesos vulnerables. Se individualizó seis niveles de incidencia posibles sobre la accesibilidad de las zonas: una incidencia nula (1), débil (2), bastante débil (3), moderada (4), alta (5) y muy alta (6), como se indica en el mapa 8-2.

La pérdida de operatividad de las secciones más vulnerables de la red vial no afecta de manera homogénea al Distrito. Los sectores que no poseen elementos esenciales de la movilidad lógicamente no son afectados. Estos sectores corresponden a zonas rurales ubicadas al oeste y al norte del Distrito (19 zonas). En cambio, en las zonas urbanas y suburbanas orientales, la incidencia del fallo de un elemento esencial de la movilidad no es despreciable. De un total de 25 zonas, 14 son susceptibles de experimentar una reducción por lo menos moderada de su accesibilidad. Algunas podrían incluso quedar en una situación cercana al aislamiento total (zona B4, C3, C4 y F1).

Este primer enfoque considera para cada zona del Distrito las posibilidades de que su accesibilidad disminuya debido a la vulnerabilidad de sus accesos inmediatos. Se puede completar este enfoque con un segundo análisis que abarca la accesibilidad de las zonas desde un lugar de procedencia dado.

\section{Reducción de la accesibilidad según la lógica centrípeta}

\section{Principio y método de cálculo}

El objetivo de esta sección es medir la incidencia sobre las zonas del cierre de los cinco ejes más vulnerables previamente identificados. Para ello, se evaluó el desvío necesario para acceder a cada zona en caso de fallo de uno o varios ejes. Se consideró seis lugares de procedencia:

\section{- Desde Otavalo-Cayambe (NE).}

- Desde la Amazonía por Baeza (E).

- Desde el valle de Los Chillos (SE).

- Desde el sur del Distrito por Aloag (S).

- Desde el sur de la ciudad (sur de El Panecillo)

- Desde el norte de la ciudad (norte de El PaneciIlo)

Los lugares de destino corresponden a un punto central en cada zona. Para comparar las distancias en situación normal y en situación perturbada, se las calculó entre un mismo punto de salida (intersección, inicio del desvío) y un mismo punto de llegada. La magnitud del desvío fue evaluada en base al criterio de la "distancia kilométrica"89. La importancia de los desvíos fue determinada en función del incremento de la distancia habitual, como lo indica la tabla 8-2.

89. Se hubiese podido considerar también otros criterios tales como la duración o el costo. 
Mapa 8-2

Reducción posible de la accesibilidad de las zonas en caso de fallo de los elementos esenciales más vulnerables de la red vial (lógica endótropa de proximidad)

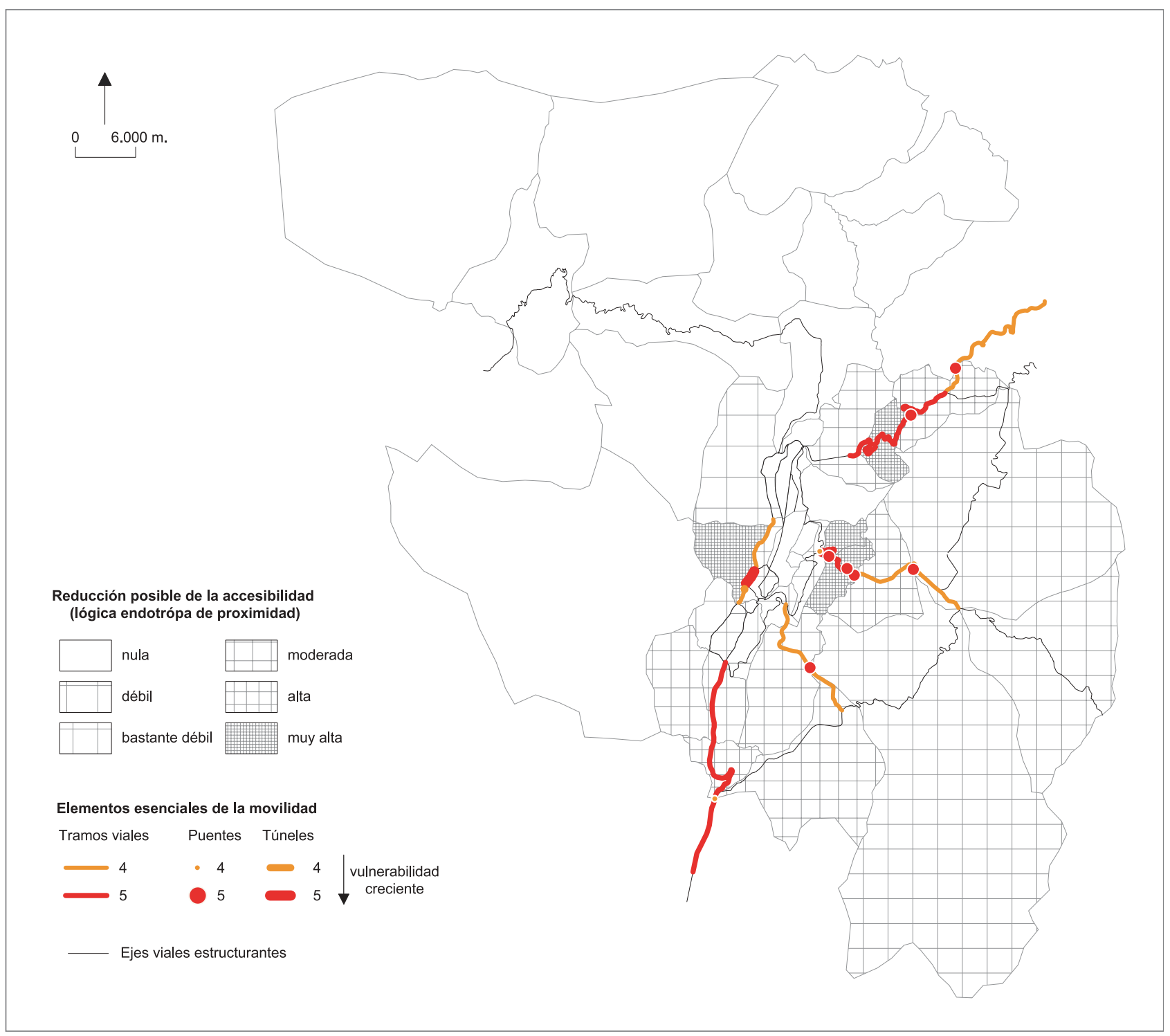


Tabla 8-2

Importancia de los desvíos en función del incremento de la distancia habitual y valoración

\begin{tabular}{|c|l|c|}
\hline $\begin{array}{l}\text { Multiplicación de la } \\
\text { distancia habitual por }\end{array}$ & Incremento de la distancia & $\begin{array}{c}\text { Valor } \\
\text { asociado }\end{array}$ \\
\hline 1 & $\begin{array}{l}\text { Ningún incremento, incremento } \\
\text { insignificante o zona no afectada }\end{array}$ & 0 \\
\hline$[1,1-1,5]$ & Incremento bastante reducido & 1 \\
\hline$[1,5-2]$ & Incremento moderado & 2 \\
\hline$[2-3]$ & Incremento elevado & 3 \\
\hline$>3$ & Incremento muy elevado & 4 \\
\hline
\end{tabular}

Dos casos fueron planteados: el cierre de un solo eje y el cierre simultáneo de todos los ejes más vulnerables. El primer caso se observa ocasionalmente durante la ejecución de obras viales o de mantenimiento, durante el bloqueo de una vía en caso de levantamiento indígena o con la concretización de amenazas localizadas (derrumbe). El segundo caso corresponde a una situación excepcional que hasta ahora, afortunadamente, no se ha observado; sin embargo, no es completamente imposible en la medida en que varios fenómenos susceptibles de ocasionar extensos daños que amenazan el área metropolitana. Por ejemplo, la erupción del volcán Cotopaxi y los lahares asociados neutralizarían tres de los cinco principales accesos a la ciudad al destruir los puentes de la Panamericana norte, de la vía Interoceánica y de la autopista Rumiñahui. Únicamente la Panamericana sur y la carretera nororiental (La Independencia-Calacalí) se mantendrían transitables (F. Demoraes, 2002). De su lado, un fuerte temblor podría conllevar el cierre de los accesos principales debido al colapso de los puentes. En efecto, en caso de sismo muy severo (PGA $=0.40 \mathrm{~g}$ ), una tercera parte de las 90 infraestructuras censadas en el Distrito tienen más de un 50 por ciento de probabilidad de experimentar daños moderados, extensos o completos (G. Atiaga, F. Demoraes, 2002). Los cuatro accesos por la Panamericana norte, la vía Interoceánica, la autopista Rumiñahui y la Panamericana sur quedanían, en consecuencia, probablemente fuera de servicio. El acceso sería probablemente mantenido por la carretera nororiental y la antigua vía a Conocoto (desde el valle de Los Chillos). Se presenta a continuación únicamente el segundo caso (cierre simultáneo de los cinco ejes más vulnerables).

\section{Incidencia del cierre simultáneo de los cinco ejes}

Las conexiones desde cada uno de los seis lugares de procedencia en dirección a las 44 zonas fueron analizadas. Para algunas conexiones el cierre simultáneo de los cinco ejes esenciales más vulnerables no tiene ninguna incidencia porque su acceso se hace mediante otros itinerarios independientes de los cinco ejes. Es el caso, en particular, de los sectores L1, L2, L3 y L4 al norte de la aglomeración que son más fácilmente accesibles desde Otavalo o Cayambe. En cambio, para llegar a la mayoría de los sectores del Distrito, el he-

\section{Tabla 8-3}

Determinación de los niveles de vulnerabilidad de las zonas asociada al incremento de la distancia

\begin{tabular}{|c|c|}
$\begin{array}{c}\text { Suma de los valores } \\
\text { asociados al incremento de } \\
\text { las distancias (desde los seis } \\
\text { lugares de procedencia) }\end{array}$ & $\begin{array}{c}\text { Vulnerabilidad de las zonas por los desvíos } \\
\text { necesarios que limitarían su accesibilidad } \\
\text { en caso de cierre simultáneo de los } \\
\text { cinco ejes esenciales más vulnerables }\end{array}$ \\
\hline$[0-1]$ & nula \\
\hline$[1-5]$ & bastante débil \\
\hline$[5-7]$ & bastante alta \\
\hline $7-9]$ & alta \\
\hline$>9$ & muy alta \\
\hline
\end{tabular}


cho de que los cinco ejes estén cerrados al mismo tiempo, incrementa a menudo considerablemente las distancias recorridas en comparación con la situación normal. Ese sería el caso en cuanto a las conexiones entre Cayambe y los espacios centrales y norte de la ciudad de Quito en caso del cierre de la Panamericana norte, la vía Interoceánica y la autopista Rumiñahui. Para cada lugar de origen, el incremento de las distancias fue calculado y valorado según el mismo método utilizado en la etapa anterior.

El mapa 8-3 presenta un ejemplo de reducción de la accesibilidad que considera dos lugares de procedencia (por la Panamericana norte y la Panamericana sur).

En base a este análisis, se realizó una síntesis. Las valoraciones definidas para los seis casos (seis orígenes) fueron luego adicionadas por zona. A partir de ello, se determinó la vulnerabilidad de las zonas tomando en cuenta la ruptura simultánea de los cinco ejes esenciales más vulnerables (tabla 8-3 y mapa 8-4).

Debido a los lugares de procedencia considerados (lógica centrípeta desde el noreste, este, sureste y sur) son lógicamente los sectores de la mitad oeste del Distrito los que resaltan particularmente vulnerables respecto a los desvíos necesarios que se deberían hacer, en caso de cieme simultáneo de los cinco ejes esenciales más vulnerables (mapa 8-4). En detalle, la ciudad en su mitad norte, las partes suburbanas norte (Pomasqui) y noreste (Calderón) así como la zona de Cumbayá son los sectores que aparecen en posición más desfavorable. La parte sur de la ciudad resalta ligeramente menos vulnerable gracias a la existencia de una vía secundaria que la conecta con el valle de Los Chillos, vía que no existe para llegar a la parte norte de la ciudad desde el valle de Tumbaco (solo existe un eje, la vía Interoceánica). El sector de Cumbayá, de su lado, es principalmente accesible por dos puentes muy vulnerables, lo que permite imaginar la magnitud de los desvíos a recorrer para llegar a esta zona, en caso de ruptura de estos dos puntos de entrada principales.

La accesibilidad del Distrito fue analizada tanto en período normal como en situaciones particulares asociadas a la pérdida de operatividad de una parte de la red vial. La vulnerabilidad de los elementos esenciales de la movilidad proporciona entonces información sobre la vulnerabilidad de la accesibilidad y finalmente sobre una forma de vulnerabilidad de las zonas. En base a esta vulnerabilidad espacial se puede proponer algunas reflexiones sobre los riesgos a los cuales está expuesto el Distrito, considerando la localización de las funciones e instalaciones urbanas esenciales del sistema territorial (hospitales, empresas, antenas de telecomunicación, plantas eléctricas...). 
Mapa 8-3

Ejemplo de reducción de la accesibilidad debido al cierre simultáneo de los ejes esenciales más vulnerables (procedencia desde el norte y el sur)
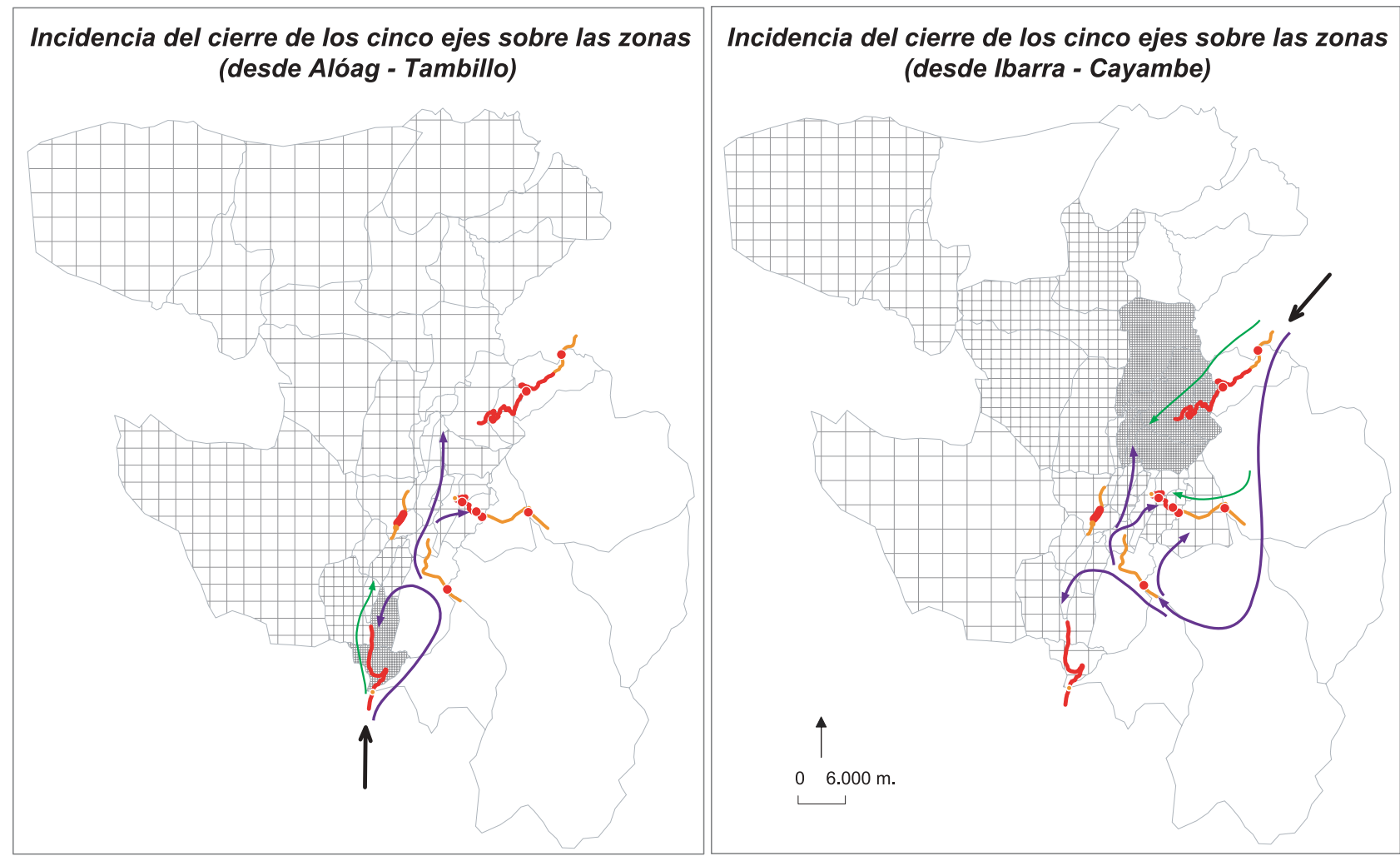

Desvío necesario en caso de cierre simultáneo de los cinco ejes esenciales más vulnerables

$\begin{aligned} & \text { ninguno (sin incremento de las distancias } \\
& \text { o con un incremento insignificante o zona no afectada) }\end{aligned}$
\begin{tabular}{|l|l|}
\hline$\square$ & bastante reducido \\
\hline$\square$ & elevado
\end{tabular} muy elevado

Elementos esenciales de la movilidad

\begin{tabular}{|c|c|c|c|}
\hline Tramos viales & Puentes & Túneles & \\
\hline 4 & - 4 & & $\begin{array}{l}\text { Vulnerabilidad } \\
\text { creciente }\end{array}$ \\
\hline 5 & - 5 & -5 & $\nabla$ \\
\hline
\end{tabular}

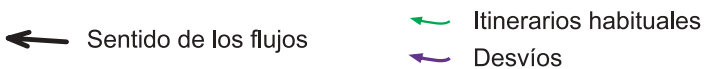


Mapa 8-4

Vulnerabilidad de las zonas asociada a los desvíos que limitarían su accesibilidad en caso de cierre simultáneo de los cinco ejes esenciales más vulnerables (síntesis de los seis lugares de procedencia)

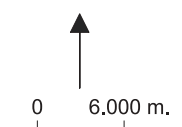

o $\quad 6.000$
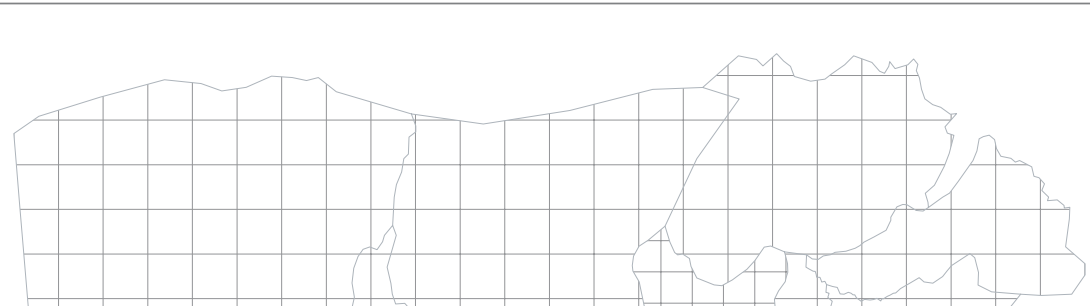

Vulnerabilidad de las zonas

$\square$ nula

$\square$ bastante débil

$\square$ bastante alta

1 alta

muy alta

\section{Elementos esenciales de la movilidad}

Tramos viales

Puentes Túneles

\begin{tabular}{lll|l}
4 & -4 & 4 & $\begin{array}{c}\text { vulnerabilidad } \\
\text { creciente }\end{array}$ \\
5 & -5 & 5 & $\nabla$
\end{tabular}




\section{Vulnerabilidad de la accesibilidad, funciones urbanas esenciales y riesgos}

El objetivo de este capítulo es evaluar de manera tentativa los riesgos a los cuales está expuesto el Distrito tomando en cuenta los problemas habituales de accesibilidad y las posibles alteraciones de la accesibilidad en caso de crisis. Estos problemaspodrían perjudicar a la población, perturbar ciertas funciones urbanas esenciales y consecuentemente contrarrestar el funcionamiento del Distrito y/o dificultar la gestión de las emergencias.

\section{Principio y método de evaluación de los riesgos}

\section{Actividades e instalaciones urbanas esenciales de funcionamiento, crisis y recuperación}

Generalmente, de modo esquemático, los análisis de riesgo se dividen en tres fases: funcionamiento habitual, gestión de la crisis y período de recuperación. Para cada fase corresponden determinadas actividades e instalaciones urbanas esenciales. Estas funciones urbanas esenciales coexisten al interior del sistema territorial y pueden ser específicas de una fase. Por ejemplo, un centro de gestión de emergencias es esencial para afrontar una situación de crisis pero no es esencial para el funcionamiento habitual de la ciudad. Sin embargo, algunas actividades e instalaciones urbanas pueden ser esenciales en varias fases. Esto es el caso, en particular, de los hospitales. En efecto, son primordiales para la atención y los tratamientos de los enfermos en tiempo normal y también en situación de emergencia para acoger a los heridos. De modo gene$\mathrm{ral}$, la asociación de las actividades e instalaciones urbanas esenciales con las distintas fases no es tan fácil. En el programa "Sistema de información y riesgos en el Distrito Metropolitano de Quito" se identificó las actividades e instalaciones urbanas esenciales del funcionamiento habitual del Distrito. Se reparten en tres categonías:

1. Actividades e instalaciones esenciales para los habitantes y sus necesidades.

2. Equipamientos esenciales de la logística urbana.

3. Elementos esenciales de la economía y gestión de crisis.

Entre estas funciones urbanas esenciales para el desenvolvimiento normal de las actividades en el Distrito, se identificó las que pueden ser también esenciales en caso de crisis, en especial los equipamientos esenciales de la logística urbana (alimentos, telecomunicación, energía). Además de estas funciones, se añadió algunos elementos específicos de la 
gestión de las emengencias. Se trata de una de las funciones imprescindibles para la atención a damnificados. Debido a que el programa de investigación no se había terminado cuando se redactó este estudio, no se han podido considerar las funciones esenciales de la recuperación. Adicionalmente, algunas funciones e instalaciones, que no son consideradas estratégicas para el conjunto del Distrito, pueden ser esenciales a un nivel más local, por ejemplo para afrontar una situación de emergencia en un barrio. Un pequeño centro de salud es primordial para la localidad por la atención de primeros auxilios, en caso de problema; su papel es más importante si la accesibilidad de la zona es mala o experimentó una fuerte disminución debido al daño de uno o varios de sus accesos. Es por eso que se identificó también las funciones vitales de proximidad.

\section{Localización de los elementos esenciales y accesibilidad}

Se superpuso la localización de los diferentes tipos de funciones e instalaciones esenciales con los mapas de accesibilidad habitual y alterada. Para evaluar los riesgos que tienen la mayor probabilidad de concretarse, se enfocó en las zonas que tienen la mayor vulnerabilidad. Estas zonas son aquellas cuya accesibilidad puede resultar la más comprometida debido a la vulnerabilidad de las infraestructuras viales esenciales, previamente analizadas. Estas zonas más vulnerables pueden adicionalmente ser poco accesibles en tiempo habitual. En base a esto, se trató de identificar las situaciones que son susceptibles de ocasionar disfuncionamientos importantes.

Para evaluar los riesgos a los cuales está expuesto el Distrito se consideró tres casos que toman en cuenta:
- La vulnerabilidad de la población, derivada de la insuficiencia de funciones vitales de proximidad en las zonas susceptibles de experimentar una alta disminución de su accesibilidad.

- La localización de actividades e instalaciones urbanas esenciales para el funcionamiento del DMQ en las zonas susceptibles de experimentar una alta disminución de su accesibilidad.

- La localización de funciones e instalaciones urbanas esenciales, particularmente dependientes de los intercambios procedentes del exterior del DMQ 0 de los valles orientales, que se localizan en las zonas susceptibles de quedar accesibles únicamente mediante considerables desvíos.

\section{Aislamiento, funciones vitales de proximidad y riesgos para el DMQ}

\section{Principio y criterios considerados}

En caso de concretización de un fenómeno (sismo, lahar) que puede ocasionar víctimas, daños a las infraestructuras viales, a edificios y disfuncionamientos en las redes urbanas (como la del agua), algunos sectores se encontrarían en situación desfavorecida o muy desfavorecida debido a que su accesibilidad podría ser reducida y debido a que cuentan con pocas funciones vitales de proximidad. Se determinó así la existencia de funciones vitales de proximidad en las zonas que son susceptibles de experimentar una reducción de su accesibilidad $^{90}$ (lógica endótropa de proximidad). La débil presencia de estas funciones vitales de proximi-

90. Se trata de las zonas B4, C4, F1, B3, C2 et C3., véase mapa 7-3a. 
dad proporciona información en cuanto a la vulnerabilidad de los moradores de estas zonas y brinda pistas para la comprensión de los riesgos asociados previsibles.

Se consideró ocho funciones vitales de proximidad, clasificadas en cuatro grupos:

1. Disponibilidad de agua:

- capacidad de los reservorios de agua (en m3).

- existencia de pozos (litro/segundo).

2. Disponibilidad de alimentos:

- número de lugares de venta de alimentos.

- número de lugares de almacenamiento de alimentos.

3. Presencia de centros médicos

- número de centros médicos.

- número de camas de hospitalización.

4. Posibilidad de atención de heridos

- número de ambulancias.

- número de albergues.

\section{Método de análisis y cartografía}

Para evaluar el nivel de representación de las funciones vitales de proximidad en cada zona fue necesario determinar un valor de referencia. Se calculó entonces el número de funciones vitales de proximidad disponibles relacionado con el número de hogares en la totalidad de la aglomeración urbana. Luego, para cada zona, se calculó el número de funciones vitales de proximidad relacionada con el número de moradores.
Se comparó después los valores de las zonas con el promedio a nivel de la aglomeración. En base a estos datos, se realizó un mapa de vulnerabilidad de las poblaciones en las zonas susceptibles de quedar aisladas (mapa 9-1).

La vulnerabilidad de la población debido a la falta de funciones vitales de proximidad es desigual entre los seis sectores susceptibles de experimentar una fuerte disminución de su accesibilidad. Los sectores de Tumbaco y Cumbayá están mejor equipados para afrontar un aislamiento. En efecto, estas dos centralidades suburbanas tienen recursos hídricos abundantes y disponen de numerosos lugares de venta de alimentos, también una clínica se encuentra en Cumbayá. Al contrario, Miravalle, Oyacoto y San Juan se encuentran desprovistos de capacidades locales para afrontar la crisis. ¿Qué enseñanzas, en cuanto a riesgos, brindan estas observaciones?

\section{Reflexiones sobre los riesgos asociados}

Cerca de un 6 por ciento de los 397.000 hogares censados en la aglomeración urbana se encuentran en los seis sectores susceptibles de quedarse aislados (al menos, parcialmente). Más del 70 por ciento de estos 25.000 hogares son altamente vulnerables debido a la insuficiencia en su zona de residencia de funciones vitales de proximidad. Los riesgos previsibles para estas poblaciones son de diferente índole. El aislamiento puede conllevar escasez de agua y dificultar la atención médica. Las zonas de Oyacoto y Miravalle no disponen de centros médicos ni ambulancias y la disponibilidad de agua en el primer sector particularmente árido (la precipitación anual es menor a $450 \mathrm{~mm}$ ) es muy reducida. En caso de fallo en el sistema de abastecimiento de agua, se podría al inicio utilizar el 


\section{Mapa 9-1}

Vulnerabilidad de la población debido a la insuficiencia de funciones vitales de proximidad (agua, alimentos, atención médica) en zonas susceptibles de quedar aisladas (al menos parcialmente)

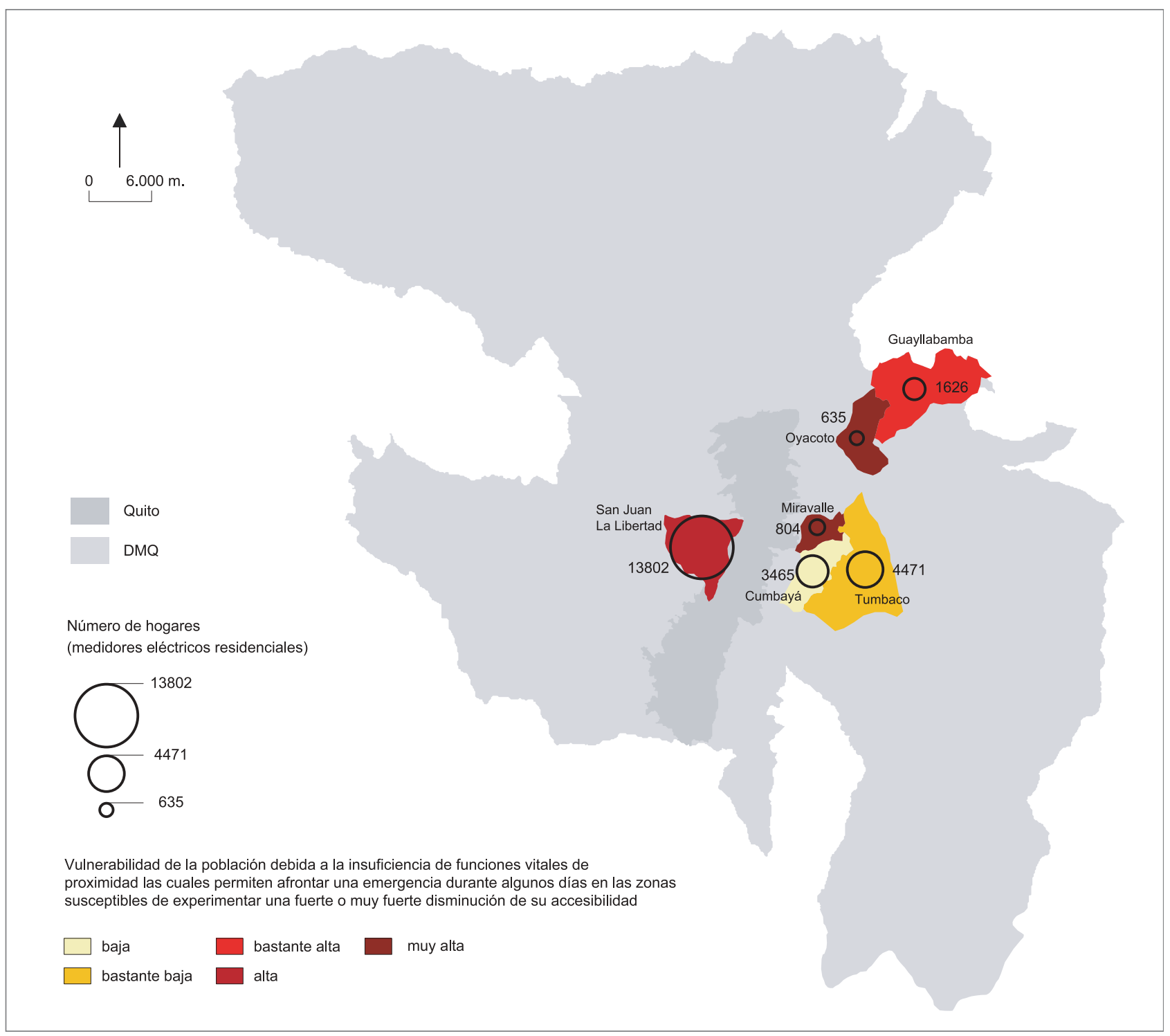


agua almacenada en los reservorios cuya capacidad total para las 6 zonas es de cerca de $20.000 \mathrm{~m} 3$. Oyacoto y Guayllabamba, con menos de $100 \mathrm{~m} 3$ cada una están en una situación menos favorable, ya que no cuentan con pozos.

Por otro lado, de un total de 80 ambulancias en la aglomeración (lo que es muy poco), las seis zonas estudiadas poseen solamente una de éstas, ubicada en Tumbaco. De un total de nueve compañías de bomberos registradas en el Distrito, ninguna se encuentra en las seis zonas. Ello deja entrever riesgos relacionados con la atención a los heridos. Esto es aún más preocupante cuanto que la tasa de motorización de los hogares es particularmente baja en la mayoría de estos sectores. En Guayllabamba, Oyacoto y San Juan se estima que más del 66 por ciento de los hogares no tienen vehículo propio (Véase capítulo 2, sección 3.4). Las dos últimas zonas son además, habitualmente, de difícil acceso debido a su topografía empinada y debido al hecho de que cuentan con escasos accesos. El traslado de heridos hacia centros médicos y la llegada de personal de atención de emergencias puede ser aún más problemático y por lo tanto incrementar el número de fallecidos.

A más de estas consecuencias directas previsibles en caso de crisis, existen también otras a mediano plazo. En efecto, la concretización de las rupturas de accesibilidad puede tener impactos sobre el precio del suelo en las zonas en cuestión. El hecho de ya no poder acceder fácilmente a un sector contribuye a deteriorar su imagen, el negocio inmobiliario y su dinamismo. Este riesgo no es despreciable, en especial en los valles de Tumbaco y Cumbayá, que cuentan con sectores económicos en crecimiento.
La pérdida o la fuerte disminución de la accesibilidad de un lugar conlleva riesgos para la población local, debido a la incapacidad de afrontar una crisis por la insuficiencia de funciones vitales de proximidad, y permite intuir riesgos a mediano plazo. Esta pérdida de accesibilidad puede adicionalmente afectar algunas actividades y equipamientos esenciales para el funcionamiento general del Distrito.

\section{Aislamiento, instalaciones esenciales para el funcionamiento del DMQ y riesgos asociados}

\section{Principio, método de análisis y cartografía}

En esta sección se analizan los riesgos previsibles tomando en cuenta la localización de algunas actividades e instalaciones esenciales para el funcionamiento general del Distrito en sectores que podrían experimentar una fuerte limitación de su accesibilidad. Se identificó las actividades e instalaciones esenciales para el funcionamiento del DMQ (en base al libro Loslugares esenciales del Distrito Metropolitano de Quito) que se encuentran en las seis zonas susceptibles de quedar poco accesibles. La falla de una instalación básica (planta de producción o de transformación eléctrica, antena de telecomunicación) localizada en uno de estos sectores puede ser problemática porque la instalación será difícilmente accesible y como consecuencia, difícilmente reparable. Adicionalmente, la imposibilidad de acceder a ciertas instalaciones primordiales puede perturbar a un sector de actividades (comercial, abastecimiento en productos alimenticios) 0 afectar a ciertos ámbitos como la educación. La mayonía de las instalaciones, consideradas en esta sección, son elementos urbanos fundamentales para el funcio- 
namiento del DMQ y también para la gestión de las crisis. Se consideró siete tipos de instalaciones esenciales en los siguientes ámbitos:

1. Educación.

2. Salud.

3. Abastecimiento y distribución de alimentos.

4. Abastecimiento y distribución de electricidad.

5. Telecomunicaciones.

6. Economía.

7. Administración municipal.

El mapa 9-2 representa las instalaciones esenciales en las seis zonas susceptibles de experimentar una muy fuerte limitación de su accesibilidad (lógica endótropa de proximidad).

\section{Reflexiones sobre los riesgos asociados}

Pérdida o fuerte limitación de accesibilidad de los elementos esenciales

La gran dificultad para acceder a una instalación esencial puede conllevar disfuncionamientos significativos. Por ejemplo, la imposibilidad de llegar a la Universidad San Francisco, que reúne a más de 3.000 estudiantes ( 5 por ciento del total de estudiantes universitarios) y centenares de trabajadores (docentes, personal administrativo y técnico), ocasionaría secuelas en las carreras educativas, puesto que algunas disciplinas solo se las imparten en este establecimiento ${ }^{91}$. En la misma lógica, una ruptura parcial o integral de la accesibilidad de ciertos sectores podría afectar gravemente la economía del Distrito debido a los proble- mas a los cuales estarían expuestas las empresas, en especial las grandes ubicadas en dichos sectores. Se considera como grandes empresas las que contratan a más de 20 personas y cuyo sector de actividad corresponde a los sectores de vanguardia o sectores más representados en el Distrito, que contribuyen al desarrollo del sistema territorial metropolitano (comercio, construcción, servicios a empresas, floricultura, industrias). De modo general, la reducción de accesibilidad suele perjudicar a las empresas; sus asalariados podrían tener dificultades en llegar al trabajo, las materias primas que requieren podrían no ser receptadas, y los productos no ser repartidos. Los riesgos inducidos serían pérdida de empleos, pérdidas financieras, reducción de competitividad.

Se identificaron en las seis zonas más vulnerables tres grandes empresas que concentran cerca de $500 \mathrm{em}$ pleados. La lógica es la misma para los grandes lugares de venta de alimentos organizados en flujos constantes, en especial en cuanto a productos perecibles. Una limitación de la accesibilidad generanía desabastecimiento y globalmente una reducción de la afluencia de los clientes. Cinco centros principales de distribución, entre los cuales está el mercado de San Roque de interés metropolitano, se encuentran entre los seis sectores más vulnerables.

Fallos en las instalaciones urbanas esenciales, accesibilidad y riesgos asociados

En función del escenario considerado (sismo, caída de ceniza, lahares), no es solamente la accesibilidad de las instalaciones esenciales la que podría resultar afec-

91. Instrumentación biomédica, microbiología, psicología transpersonal por ejemplo. 
Mapa 9-2

Localización de las instalaciones esenciales para el funcionamiento del DMQ en las zonas susceptibles de experimentar una fuerte o muy fuerte reducción de su accesibilidad

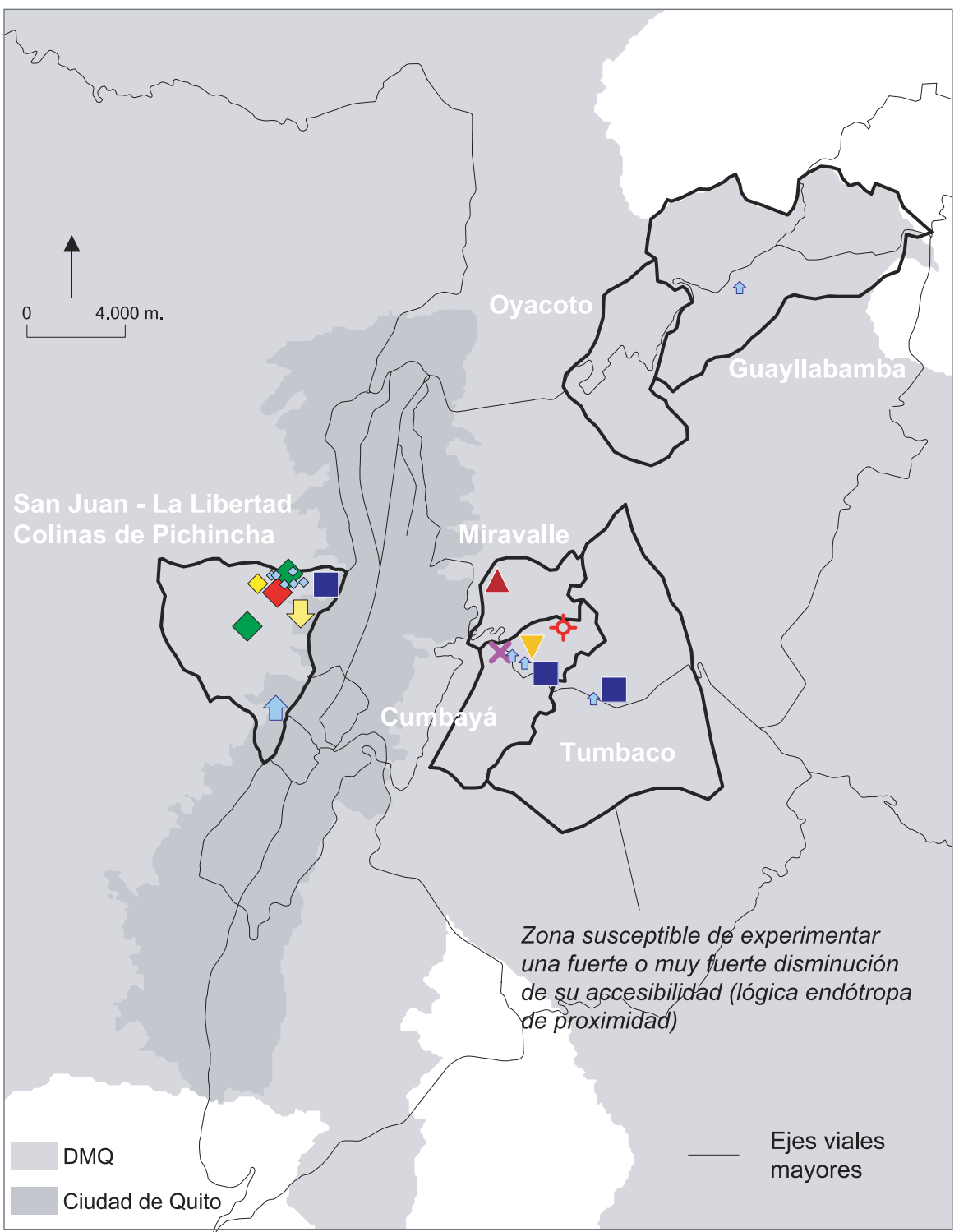

\section{Educación}

Universidad

San Fransisco

Salud

- Clínica

La Primavera

Abastecimiento y distribución de alimentos

Mercado de interés

metropolitano

(San Roque)

Supermercados

o mercados

\section{Abastecimiento y} distribución de electricidad

- Planta de producción hidroeléctrica de Cumbayá

Subestación Selva Alegre

\section{Telecomunicaciones} (antenas)

911 y servicio del trolebús (antena común)

Bomberos

E.E.Q (Empresa

Eléctrica de Quito)

Antena radio o de televisión

\section{Economía}

Grandes empresas de vanguardia

\section{Administración municipal}

$\times$ Administración zonal de Tumbaco 
tada. Algunos fenómenos podrían ocasionar daños a las instalaciones. En este caso, el acceso a las instalaciones esenciales sería crucial porque habría que repararlas de inmediato para mantener los servicios. Los seis sectores considerados reúnen dos infraestructuras esenciales del sistema eléctrico metropolitano y una gran cantidad de antenas de telecomunicación. De las 59 antenas vitales con que cuenta el Distrito, 14 se ubican en los altos de la ciudad, en el sector F1 (zona de Cruz Loma), zona habitualmente poco accesible y susceptible de quedar parcialmente aislada. Esta situación es preocupante porque varias antenas pertenecen a gestores de crisis (911, Bomberos) y algunos organismos claves como la Empresa Eléctrica de Quito (EEQ) y la Unidad Operativa del Sistema Trolebús. Un fallo en las antenas de radio y televisión dificultanía la difusión de la información sobre las medidas y comportamientos que deberían adoptarse, en caso de emergencia.

En lo referente a las dos infraestructuras esenciales del sistema eléctrico metropolitano, unos cortes eléctricos resultarían probablemente de su fallo. Para evaluar su riesgo se utilizó un estudio realizado por R. D'Ercole y P. Metzger en el 2004 en el marco del programa de investigación. En una escala que se extiende desde 1 (vulnerabilidad nula o muy débil) a 5 (vulnerabilidad máxima), la subestación Selva Alegre ubicada en la zona F1 tiene una vulnerabilidad acumulada bastante débil (2). En cambio, la planta de producción hidroeléctrica de Cumbayá tiene una vulnerabilidad acumulada alta (4). Los riesgos de fallo y de cortes eléctricos inducidos son, en comparación, más probables en el segundo caso.
Pérdida o fuerte disminución de la accesibilidad y escala de riesgo

La posible reducción de la accesibilidad de las instalaciones esenciales para el funcionamiento del Distrito puede tener incidencias más o menos extensas. Pueden extenderse en un área limitada, una parroquia, una aglomeración o el país entero. En el ejemplo que se presenta, se consideró dos escalas de repercusiones, asociadas a cada instalación esencial (mapa 9-3). Se definió las incidencias a través de la función que ocupa cada instalación esencial, en base a su perímetro de acción, cobertura o influencia, en tiempo habitual. El disfuncionamiento o imposibilidad de acceder a las instalaciones censadas en las seis zonas más vulnerables tendría, en más del 66 por ciento de los casos, una incidencia espacial en la totalidad del Distrito y ello es aún más marcado en la zona F1. En fin, este análisis permite observar que el aislamiento, al menos parcial de una pequeña cantidad de zonas (6 en 44, es decir menos del 5 por ciento de la superficie del Distrito) podría conllevar riesgos que afectarían la totalidad del Distrito, en varios ámbitos.

El aislamiento es sin duda lo que desemboca en mayores riesgos tanto para la población como para el funcionamiento del Distrito debido a la localización de sus equipamientos e instalaciones esenciales. Sin embargo, los desvíos ocasionados por el cierre de algunos accesos a la ciudad, sin impedir totalmente su acceso global, generaría otras consecuencias negativas. 
Mapa 9-3: Escala de riesgos.

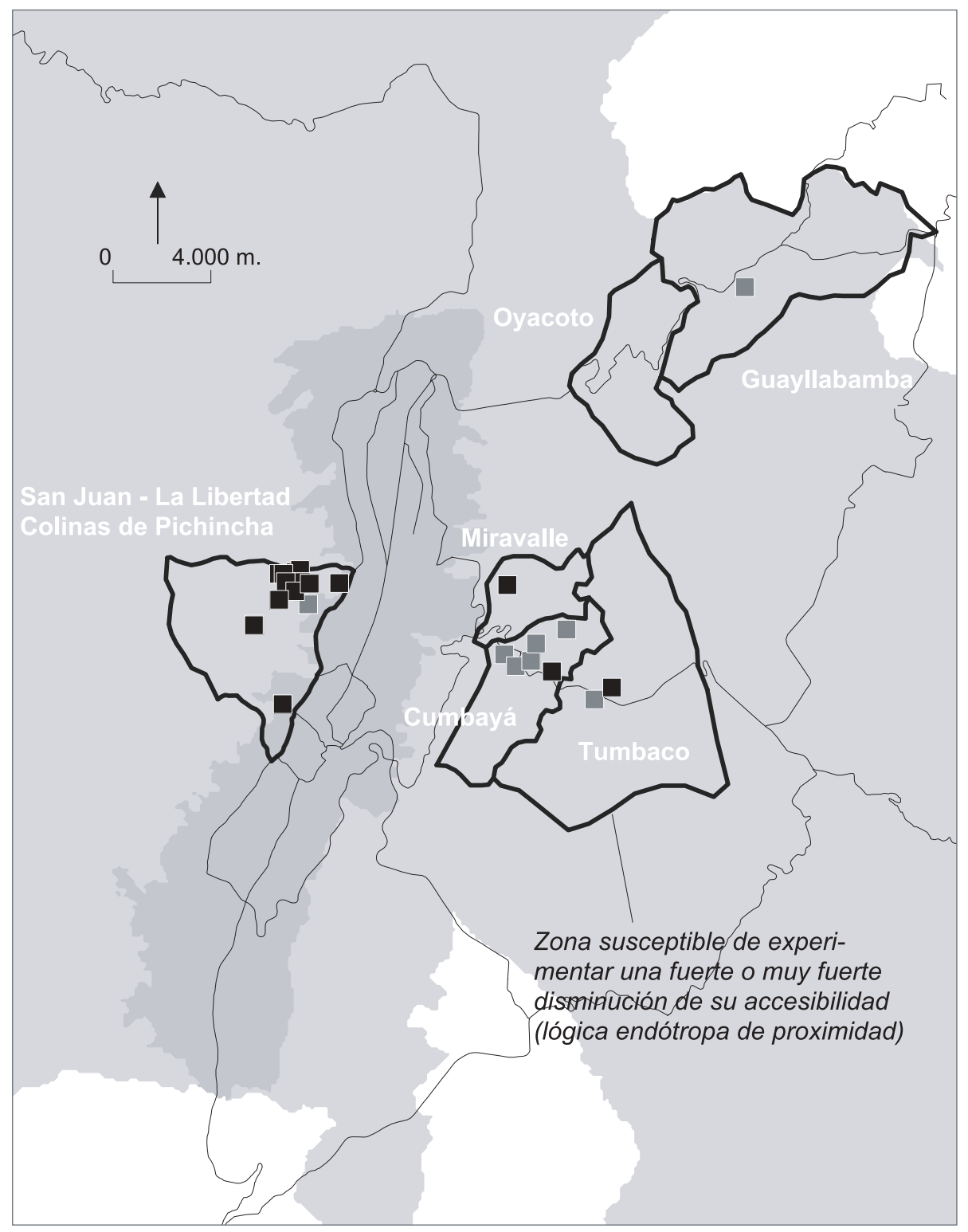

Indica las incidencias espaciales previsibles del disfuncionamiento de las instalaciones esenciales para el funcionamiento del DMQ y las incidencias de la imposibilidad de a c ceder a estas instalaciones en las zonas más susceptibles de experimentar una fuerte disminución de su accesibilidad

Incidencia en todo el Distrito

Incidencia en una parte del Distrito

DMQ

Ciudad de Quito

Ejes viales mayores

195 


\section{Desvíos, instalaciones urbanas esenciales, dependencia de las comunicaciones y riesgos para el DMQ}

\section{Principio, método y cartografía}

En esta sección, se identificó algunas instalaciones esenciales para el funcionamiento del DMQ localizadas en las zonas más vulnerables, es decir aquellas que serían más afectadas (debido a los desvíos) en caso de cierre simultáneo de los cinco ejes más vulnerables previamente identificados (Véase mapa 8-4). Se consideró únicamente las zonas con alta y muy alta vulnerabilidad. Cubren cerca de $396 \mathrm{Km}^{2}$, o sea alrededor del 10 por ciento del total de la superficie del Distrito y corresponden al espacio central, el norte de Quito y los valles de Pomasqui y Cumbayá.

Entre las instalaciones esenciales se consideró únicamente las que parecían particularmente dependientes de las comunicaciones terrestres procedentes del exterior del DMQ o de los valles orientales y cuya reducción o pérdida de operatividad afectaría el funcionamiento del Distrito.

Se consideró cuatro tipos de instalaciones esenciales en los siguientes ámbitos:

1. Abastecimiento y distribución de alimentos.

2. Distribución de combustibles (gasolina y gas).

3. Transporte de personas y mercaderías.

4. Economía.

El mapa 9-4 representa las instalaciones esenciales estudiadas en las zonas más vulnerables.

\section{Reflexiones sobre los riesgos asociados}

En caso de cierre simultáneo de los cinco ejes viales esenciales más vulnerables, los desvíos necesarios para acceder a la ciudad desde las periferias serían muy problemáticos para el Distrito. En efecto, la hipercentralidad de la aglomeración, asociada a un gran número de funciones urbanas estratégicas estaría directamente afectada. Las dos zonas más vulnerables agrupan 80 de las 90 grandes empresas de vanguardia para la economía del Distrito, es decir, 26.000 empleados. En base a entrevistas ${ }^{92}$ realizadas en el marco del programa de investigación, se concluye que de estas 80 empresas, 62 son extremadamente dependientes de la red vial. También en esta zona se censa un 60 por ciento de las 8.600 industrias $^{93}$ en especial en los sectores de Carapungo y Santa Lucía, cerca del intercambiador de Carcelén. Ahora bien, el sector industrial manufacturero del Distrito contribuye en un 20 por ciento al PIB nacional ecuatoriano (Véase primera parte). El incremento de las distancias desde el exterior para llegar a estas empresas e industrias provocaría retrasos en las entregas, problemas de abastecimiento de materias primas, dificultades para repartir los productos hacia las provincias, lo que implicaría de modo general incremento de gastos y pérdida significativa de competitividad.

Siguiendo en el ámbito de la economía, los desvíos también afectarían gravemente la lucrativa actividad

92. Las entrevistas a gerentes de empresas las realizaron Alex Tupiza y Alexandra Mena. En cuanto a las comunicaciones terrestres, se hizo la siguiente interrogante: Para el funcionamiento de su empresa, la dependencia en relación con la red vial es: muy fuerte, bastante fuerte, bastante baja o muy baja?

93. Localizadas en base a los medidores de la Empresa Eléctrica Quito (EEQ). 
Mapa 9-4

Localización de las instalaciones esenciales muy dependientes del transporte terrestre en las zonas más vulnerables, debido a los desvíos

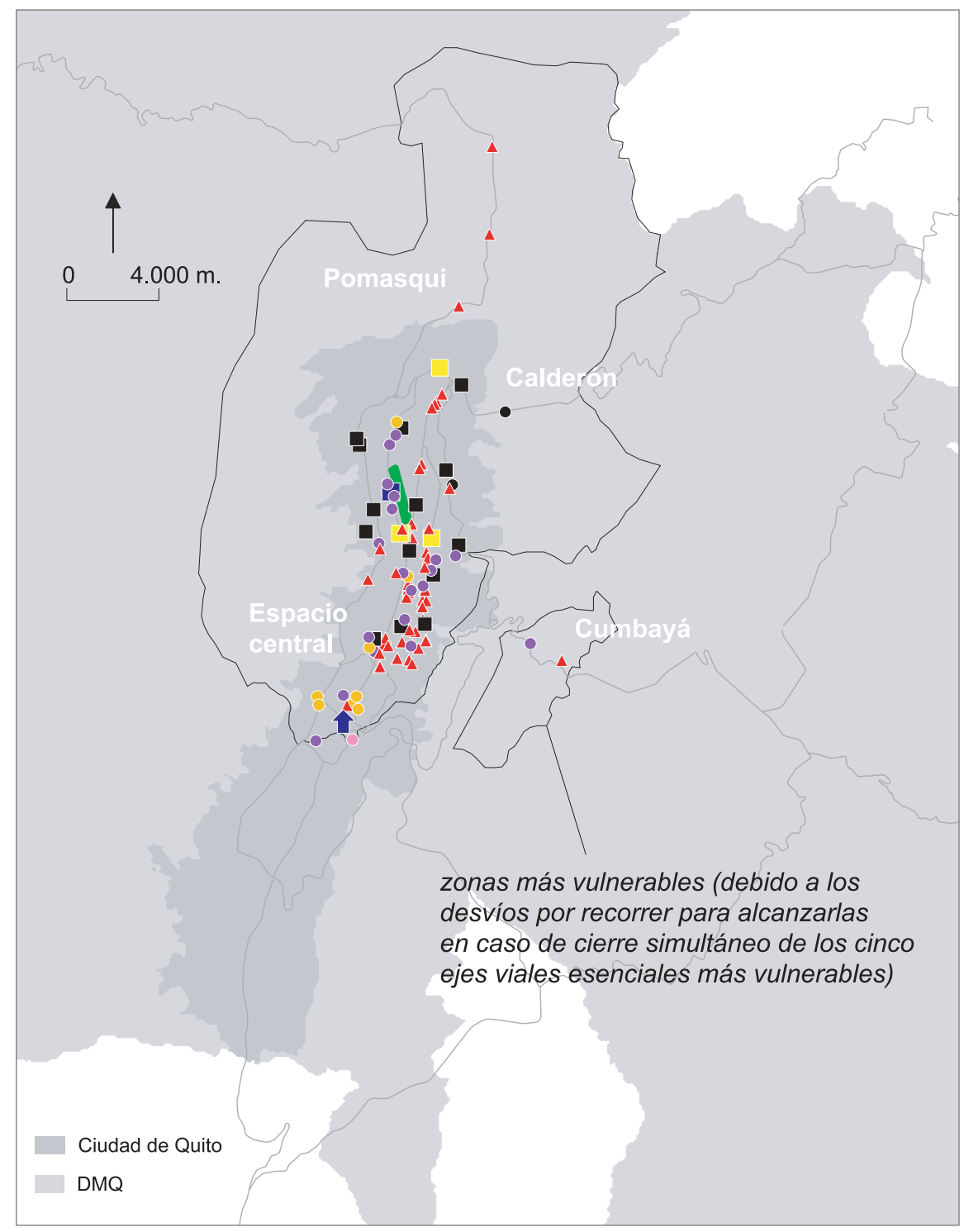

Abastecimiento y distribución de alimentos

- Supermercado

Principales mercados cubiertos y al aire libre

Depósito de productos alimenticios

Fábrica de pasteurización y de envase de leche

Distribución de combustibles

Depósito de carburantes del aeropuerto

Grandes centros de almacenamiento y de venta de gas doméstico en tanques

Estaciones de servicio con más de cinco surtidores

\section{Transporte de personas y} de mercaderías

Terminal terrestre Cumandá

- (transporte inter urbano de personas y encomiendas)

Aeropuerto (exportación de productos nacionales como las flores)

\section{Elementos esenciales para} la economía
Grandes empresas muy dependientes de la red vial

Ejes viales mayores 
florícola ${ }^{94}$. En efecto, el cantón Cayambe, importante zona de producción florícola (900 ha), exporta en flujos constantes los productos, especialmente las rosas, desde el aeropuerto de Quito ubicado en el norte del espacio central. Ahora bien, esta infraestructura esencial podría experimentar una reducción de su accesibilidad en caso de cierre de los principales accesos a la ciudad. El impacto previsible se extiende en este caso mucho más allá de los límites del Distrito o de los cantones circundantes. En efecto, son las cadenas de comercialización de las flores hacia Estados Unidos, Canadá, Europa y Rusia que se verían comprometidas.

Durante la erupción del volcán Reventador en noviembre de 2002, la imposibilidad de exportar las 10.000 cajas dianias de flores desde el aeropuerto de Quito (por la suspensión de los vuelos asociada a la caída de ceniza, más que por problemas de acceso terrestre) obligó a los floricultores a enviar su producción por vía terrestre hacia el aeropuerto de Guayaquil. Este transporte adicional significó un gasto extra y un deterioro de la calidad del producto ya que los medios de transporte refrigerados eran insuficientes.

A más del problema de la transportación de mercadenía, el transporte interprovincial de personas podría experimentar dificultades, porque la terminal terrestre se ubica en el espacio central de la ciudad. Cada día más de 70 líneas de buses brindan un servicio regular desde la terminal hacia el resto del país. Un poco más de 18.000 vehículos, entre los cuales 2.300 buses, llegan cada día al Distrito desde el exterior. La importancia de estos intercambios se debe a su condición de capital y a su dinamismo comercial, segundo en importancia después de Guayaquil.

La reducción de la accesibilidad de la ciudad implicanía profundas perturbaciones de los intercambios que mantiene el Distrito con el resto del país y alterarían su actividad económica. En la misma lógica, muchas cadenas logísticas se verían también afectadas, en especial la distribución de alimentos y combustibles. Sobre un total de 114 principales lugares de venta de alimentos, 64 (56 por ciento) se ubican en las dos zonas más vulnerables donde viven cerca de 220.000 familias (55 por ciento del total de la aglomeración urbana). Entre los diez productos de mayor consumo ${ }^{95}$, por lo menos siete provienen del exterior del Distrito (costa, sierra sur y sierra norte). Si bien es cierto que se producen muchos productos hortelanos en las zonas suburbanas, la mayonía llega del exterior de la aglomeración. El transporte de los productos perecibles podría entonces ser problemático y se podría experimentar desabastecimiento en las zonas en cuestión.

En lo que se refiere a la distribución de carburantes, de los 200.000 vehículos no matriculados en el Distrito, se estimó que más de 110.000 pertenecen a los hogares que viven en las dos zonas más vulnerables. En consecuencia, la demanda en carburantes es muy alta en estos sectores y no es casual encontrar ahí 23 estaciones de servicio de las 36 existentes en la aglomeración Por otro lado, si se observan los circuitos de abastecimiento de combustibles al interior de la aglomeración ${ }^{96}$, se nota que una proporción no despreciable del abastecimiento del norte de la ciudad proviene de la planta de almacenamiento de Itulcachi, ubicada en el

94. Según la Asociación Nacional de Exportadores de Flores (Expoflores) sus exportaciones generan 300 millones de euros al año.

95. Se trata de los siguientes alimentos: arroz, pan, carne, aceite, leche, azúcar, tomate, cebolla, naranja y plátano, según el INEC. 96. Véase R. D'Ercole, P. Metzger, 2002, capítulo 10. 
valle, al este del cerro Ilaló. Por el momento, la distribución también se opera desde la planta de El Beaterio al sur de Quito pero la mayoría de las reservas de combustibles se concentrará próximamente, por razones de seguridad, en Itulcachi. Problemas de acceso a la ciudad generanín rápidamente un desabastecimiento de combustibles en la zona de mayor demanda, consecuentemente se podría experimentar una pérdida general de la movilidad motorizada, tanto en automóvil particular como en transporte colectivo.

A la escala de la aglomeración, los desvíos atribuibles al cierre de los principales accesos a la ciudad afectarían el funcionamiento del Distrito tomando en cuenta la magnitud habitual de los movimientos pendulares (más de 150.000 por día). Esta magnitud se debe a la complementariedad de los diferentes subespacios metropolitanos, sobre todo al carácter atractivo del espacio central asociado a la hipercentralidad, expuesto en la primera parte. Según la encuesta origendestino llevada a cabo por la UPGT en 1998, más de 20.000 personas acceden cada día en transporte colectivo a la ciudad desde el valle de Tumbaco y Cumbayá, y cerca de 10.000 desde el valle de Los Chillos ${ }^{97}$. Más del 41 por ciento de estos desplazamientos se hacen para ir al trabajo, el 16 por ciento para trámites y el 14 por ciento para estudios. Las dos zonas más vulnerables agrupan 21 universidades de un total de 22 y 104 administraciones públicas de 110. Las dificultades que podría experimentar la población de la periferia para ir a la ciudad ocasionanían entre otros, atrasos o faltas del personal de las empresas, administraciones, universidades y perjudicanía el desenvolvimiento de las actividades y prácticas urbanas.

Resalta del análisis previo, cual sea el caso considerado, los riesgos múltiples previsibles asociados a la re- ducción de la accesibilidad de los diferentes sectores del Distrito los cuales podrían tener proporciones que se incrementarían con la duración de la ruptura parcial o total de los accesos. El impacto esperado es también muy variable. Las incidencias pueden evidenciarse en un barrio, una parroquia o en la totalidad del Distrito. Podrían afectar a Ecuador en su globalidad (producción industrial) e igualmente al mercado internacional (exportaciones, entre ellas de flores).

Estas reflexiones tentativas sobre riesgos posibles tienen límites. Están condicionadas por la validez de la información de los diferentes tipos de instalaciones y actividades esenciales, información que no es siempre exhaustiva, así como por el número reducido de ámbitos abarcados y la incertidumbre de los escenarios.

Si bien se sabe que las comunicaciones son fundamentales para el desenvolvimiento de lasactividades en una ciudad, se consideró en este estudio que es la accesibilidad de los lugares esenciales la que es primordial para el funcionamiento y desarrollo de un territorio urbano. De hecho, la limitación de las posibilidades de acceder a los lugares esenciales, condicionada por la vulnerabilidad de las infraestructuras viales más importantes, conlleva riesgos de diferente índole y de distintas escalas. Considerando este enfoque, se propuso en esta cuarta parte algunas reflexiones sobre los riesgos a los cuales está expuesto el Distrito Metropolitano de Quito.

97. Este segundo valor es subestimado porque la encuesta se refiere únicamente al transporte colectivo urbano e interparroquial. Ahora bien, se sabe que la mayoría de los desplazamientos entre Quito y Los Chillos se realizan en transporte intercantonal. 
CONCLUSIÓN

"La ciencia es el asíntota de la verdad.

Se acerca continuamente pero nunca la toca"
(Víctor Hugo) 
202 
En este libro se presentó una reflexión sobre los riesgos a los cuales está expu esto el DMQ considerando la cuestión de la movilidad de las personas y la cuestión de la accesibilidad. Este análisis de riesgo se funda en un método enfocado en los elementos esenciales de la movilidad y su vulnerabilidad. A continuación se presenta un balance de los principales resultados y se resalta la metodología implementada, suslimitaciones, así como la utilidad del estudio para los gestores urbanos. Finalmente se reflexiona sobre la reproductibilidad del método y los aportes conceptuales.

\section{Recapitulación de los principales resultados del análisis}

\section{Movilidad de las personas en el DMQ}

Se analizó los desplazamientos a tres escalas: entre el Distrito Metropolitano de Quito y el resto del país, entre la ciudad y su periferia y al interior de la ciudad; se fundamenta esencialmente en los viajes realizados en transporte colectivo que traslada cerca del 80 por ciento de la demanda diaria. Por otro lado el transporte colectivo es utilizado por la mayoría de personas para movilizarse entre provincias debido a la baja tasa de motorización nacional (cinco vehículos por cada 100 habitantes en el 2001).

El DMQ mantiene relaciones importantes con el sur del país en donde se ubican muchos centros urbanos importantes entre los cuales Guayaquil. Los intercambios entre el Distrito y las ciudades cercanas (Cayambe, Otavalo, Machachi) son abundantes, lo que de- muestra la influencia de la capital a una escala regional. Todos los días se registran cercan de dos millones de desplazamientos en transporte colectivo en la aglomeración capitalina, de los cuales 150.000 corresponden a movimientos pendulares (valor subestimado porque no se contabiliza el transporte intercantonal con el cantón Rumiñahui).

Por otro lado, el análisis de la lógica y fundamentos de la movilidad respecto a la repartición de las funciones en el DMQ resaltó la muy alta concentración de las actividades en el espacio central y dependencias funcionales; la periferia suburbana depende de una manera no despreciable de la ciudad de Quito y al interior de la ciudad, los espacios norte y sur aparecen muy dependientes respecto al espacio central.

\section{Sistema de transporte metropolitano (actores, red, oferta)}

Tanto en el tema de la vialidad como del transporte, varios actores intervienen a distintas escalas dentro del DMQ. El sistema de actores que intervienen en el ámbito de la vialidad corresponden a una superposición complementaria de poderes municipal, provincial (HCPP) así como central (MOP). Si bien las competencias en el ámbito del transporte colectivo son claras con dos actores principales, Municipio (DMT, EMSAT) y Policía Nacional (CNT, CPTP) se advierte, en cambio, una cierta ambigüedad en las atribuciones relacionadas con la gestión y control del tráfico. Ello se debe a la falta de claridad jurídica y al carácter relativamente reciente de la transferencia de competencias a favor del Municipio. Este cambio explica la permanencia de un doble sistema de semaforización que impide una gestión óptima del tráfico en la ciudad. 
Se levantó una tipología tentativa de la red vial y se individualizó así los ejes estructurantes, los ejes principales y la vialidad secundaria. De su lado, la repartición de las obras viales (puentes, túneles) indica una alta concentración en la mitad norte de la ciudad que se encontraba en el 2003 en una profunda reestructuración con la ejecución de varios intercambiadores y camiles exclusivos previstos en el Plan Maestro de Transporte y Vialidad del Municipio del DMQ. Quito cuenta también con un conjunto de instalaciones en las que se sustenta el transporte colectivo (terminal terrestre Cumandá, terminales de transportes urbanos, interparroquiales, intercantonales, tres grandes estaciones de transferencia del trolebús, y ahora la estación norte de transferencia de la ecovía). La parte norte de la ciudad concentra también la mayoría de la estaciones de servicio por la alta frecuentación diurna asociada a su posición de hipercentralidad. Es también en la parte norte de la ciudad que el parque automovilístico es mayor. El uso de un medio de transporte motorizado es hoy en día imprescindible en la ciudad de Quito. De hecho, se calculó que un ciudadano recorre aproximadamente, en promedio, once kilómetros en bus entre su domicilio y su trabajo (una ida simple). En el 2001, los 2.340 buses urbanos transportaban el 77 por ciento de la demanda diaria registrada en transporte colectivo, el trolebús trasladaba un 11 por ciento.

En cuanto a la organización del transporte colectivo, el sector privado poseía en el 2001 cerca del 95 por ciento de las unidades. Adicionalmente, el transporte de personas en Quito se caracteriza por una repartición en múltiples operadores. Se contabilizaron 59 operadores urbanos y 29 interparroquiales en el 2001. Además, la existencia de una diferencia de estatuto jurídico (cooperativa y compañía) tiene implicación directa en cuanto a la calidad del servicio brindado y contribuye a la competencia entre choferes que provoca falta de seguridad y contaminación atmosférica. Para remediar este problema, la municipalidad ha impulsado desde 1996 la agrupación de los operadores en compañías privadas y desde el 2002 ha impuesto una renovación de la flota con buses de mayor capacidad.

En lo que atañe a las redes de transporte colectivo, su configuración responde a una lógica esencialmente norte-sur en la ciudad de Quito y en torno a los ejes centro-periferia en las partes suburbanas. A partir de 1993, la municipalización de la gestión del transporte urbano e interparroquial, anteriormente a cargo de la Policía Nacional, transformó profundamente la ciudad. De hecho, se implementó el sistema de trolebús en carril exclusivo y el sistema integrado de transporte colectivo, actualmente en proceso de ampliación. Este sistema inspirado en el de Curitiba (Brasil), ha aportado varias mejoras tales como un transporte más rápido, transferencias más fáciles y reducción de las emanaciones de gases de escape. Si bien el transporte colectivo traslada todavía al 80 por ciento de la demanda diaria, el uso del automóvil fue creciendo en el DMQ desde los años 70 y se duplicó el parque automotor en el transcurso de la década de los 90 para llegar alrededor de 200.000 vehículos, en el 2001. Es así como más de 40 por ciento del parque nacional ecuatoriano en el 2001, circulaba en el Distrito, cuando apenas concentra el 15\% de la población total del país.

\section{Identificación de los elementos esenciales de la movilidad}

Los elementos eseciales son de diferentes categorías, materiales o inmateriales, localizables en el espacio o no. En el marco de este estudio se enfocó en los ele- 
mentos ante todo materiales y los lugares en donde se encuentran, con el fin de evaluar posteriormente su vulnerabilidad que integra en especial la exposición a las amenazas y su nivel de accesibilidad. Se trata de infraestructuras viales y equipamientos de transporte en las que se basan las conexiones de primera relevancia y la mayor cantidad de flujos.

En la categoría de los ejes viales esenciales, se consideró dos de los cuatro accesos al Distrito (Panamericanas norte y sur), tres de los cuatros ejes centro-periferia (vía a Calderón, vía a Tumbaco, autopista Rumiñahui). En la ciudad, se consideró la mayoría de los principales bulevares de norte a sur, es decir las avenidas Mariscal Sucre, Prensa, Galo Plaza Lasso, 10 de Agosto, Shyris, América, Velasco Ibarra, Napo, Maldonado, Teniente Hugo Ortiz. Algunas arterias transversales (este-oeste) forman también parte de los ejes viales esenciales. Se trata de las avenidas Diego de Vásquez, Granados, Eloy Alfaro (tramo sur), Universitaria, Patria, Pichincha, Rodrigo de Chávez. Los tres túneles (San Juan, San Roque y San Diego) son también elementos esenciales para las comunicaciones como 43 puentes ubicados a lo largo de los ejes viales esenciales. Se incluyó como esenciales siete nodos de las redes de transporte colectivo, como el intercambiador El Trébol, la Plaza Argentina, el playón La Marín, la terminal terrestre Cumandá y tres estaciones de transferencia del trolebús. A excepción de los ejes, la mayoría de los elementos esenciales de la movilidad se concentra en el espacio central y específicamente en la periferia del centro histórico hasta la Avenida Patria, al norte.

\section{Vulnerabilidad de los elementos esenciales}

Para tomar en cuenta su complejidad, se analizó la vulnerabilidad de los elementos esenciales de la movilidad considerando seis formas: intrínseca, dependencia respecto a otros sistemas o elementos, exposición a amenazas, alternativas de funcionamiento, capacidad de control, preparación a las crisis. La lectura cruzada de las diferentes formas permitió resaltar los elementos esenciales particularmente vulnerables (alta vulnerabilidad y baja compensación) para los cuales se formularon ideas de mitigación. El análisis de acumulación de las seis formas permite discernir los elementos que cuentan con la mayor vulnerabilidad sintética, es decir los que tienen la mayor probabilidad de ya no funcionar o desempeñar su papel y por tanto alterar considerablemente la movilidad y la accesibilidad. Se cartografió la vulnerabilidad acumulada de los elementos esenciales de la movilidad. Los centros de transporte son globalmente menos vulnerables porque no cuentan con niveles "altos" o "muy altos" de vulnerabilidad acumulada. En cambio, entre los elementos esenciales de la red vial, se alcanza los niveles "alto" y "muy alto" para los accesos a la ciudad y para los túneles. Se identificó así 13 elementos esenciales de la movilidad con una vulnerabilidad muy alta (tabla 6-4).

\section{Accesibilidad y riesgos}

El impacto del cierre de un eje esencial y las consecuencias de la suspensión de un servicio de transporte en un corredor principal serían perjudiciales para la ciudad, sobretodo si estas infraestructuras permiten acceder a los lugares esenciales para su funcionamien- 
to y desarrollo. Los lugares esenciales son espacios que concentran múltiples instalaciones urbanas estratégicas de diferente índole (salud, educación, economía) que requieren ser accesibles para garantizar su funcionamiento. Estas instalaciones estratégicas para la actividad cotidiana normal del Distrito fueron identificadas, localizadas y presentadas en el libro: "Los lugares esenciales del Distrito Metropolitano de Quito" (R. D’Ercole, P. Metzger, 2002). Se evaluó los riesgos en base a esta información.

En el DMQ, la accesibilidad habitual es heterogénea y limitada en algunos sectores lo que provoca dificultades diarias. Aún mayores serían estas dificultades en el caso de reducción de la accesibilidad debido a la pérdida de operatividad de los elementos esenciales de la movilidad. Ello conllevaría por ejemplo, el aislamiento de ciertas zonas o desvíos considerables en algunos casos.

Para discernir las zonas cuya accesibilidad podría resultar muy comprometida, se consideró la localización de los elementos esenciales de la red vial particularmente expuestos a fallos debido a su "alta" o "muy alta" vulnerabilidad acumulada. Se identificó (1) las zonas expuestas al aislamiento al menos parcial y (2) las zonas cuya accesibilidad podría resultar muy reducida debido al incremento de las distancias por recorrer para alcanzarlas (desvíos). Las zonas expuestas al aislamiento, al menos parcial, son Oyacoto, Cumbayá, Miravalle, San Juan, Colinas del Pichincha. Las zonas cuya accesibilidad podría quedar muy reducida debido a los desvíos son la mitad norte de la ciudad, los sectores de Pomasqui, Calderón y Cumbayá.

Para evaluar los riesgos a los cuales está expuesto el DMQ, se consideró tres casos:
- La vulnerabilidad de la población evaluada en base a la insuficiencia de funciones vitales de proximidad en las zonas susceptibles de experimentar una alta disminución de su accesibilidad.

- La localización de actividades e instalaciones urbanas esenciales para el funcionamiento del DMQ que se localizan en las zonas susceptibles de experimentar una alta disminución de su accesibilidad.

- La localización de funciones e instalaciones urbanas esenciales, particularmente dependientes de los intercambios procedentes del exterior del DMQ o de los valles orientales, que se localizan en zonas que podrían resultar accesibles únicamente mediante desvíos considerables.

A través del primer caso, se evidencia el riesgo de aparecimiento de epidemias y una alta mortalidad debido a la insuficiencia de agua, falta de capacidades médicas y de atención de emergencias en los sectores de Oyacoto, Cumbayá, Miravalle y San Juan, Colinas del Pichincha.

A través del segundo caso se evidencia que los riesgos previsibles corresponden a perturbaciones del régimen educativo, despidos coyunturales, pérdidas económicas y de competitividad, desabastecimiento. Los riesgos de cortes eléctricos, disfuncionamientos en las telecomunicaciones y en los servicios de transporte (trole), así como problemas de información a la población sobre la adopción de medidas de emergencia (debido a fallos en las antenas de Cruz Loma), podrían resultar de esta situación.

A través del tercer caso, se evidencia que la hipercentralidad de la aglomeración capitalina, asociada a un gran número de actividades e instalaciones estratégicas para el funcionamiento del sistema territorial, se 
encuentra en las zonas que podrían experimentar graves problemas de acceso debido a los desvíos. Los riesgos esperados corresponden a problemas de abastecimiento en materias primas, dificultades de distribución de los productos hacia otras provincias. Esta situación conllevaría gastos adicionales y una pérdida significativa de competitividad. La exportación de flores podría igualmente experimentar dificultades por problemas para acceder al aeropuerto y podría ocurrir un desabastecimiento de productos perecibles y de combustibles. Por último, debido a la gran magnitud habitual de movimientos pendulares, el desenvolvimiento de las actividades económicas y de las prácticas urbanas serían alteradas.

\section{Síntesis del método}

Se presenta un balance sobre las principales etapas y articulaciones del método (Véase figura 1). El punto de partida es el análisis de las características de la movilidad en base a la cual es posible identificar los elementos esenciales, para posteriormente analizar su vulnerabilidad. La última etapa abarca la evaluación de los riesgos en base a las enseñanzas logradas en las tres primeras partes. En cada etapa, el uso de un SIG fue necesario aunque no suficiente.

\section{Aportes para los gestores}

En una perspectiva de planificación preventiva, esta investigación propone una base de reflexión para los diferentes actores urbanos, brinda pistas para la reducción de la vulnerabilidad y propone orientaciones generales para la gestión de las emergencias.

En el ámbito de la movilidad, la explotación de la encuesta origen-destino llevada a cabo en los buses ur- banos e interparroquiales por la UPGT en 1998 y sobretodo la cartografía de los desplazamientos de personas, afluencias, motivos constituye un aporte muy significativo para los gestores. También la digitalización de las redes de transporte colectivo (líneas de bus) en toda la ciudad fue una gran novedad.

Los resultados fueron recibidos con satisfacción e integrados en el diagnóstico del Plan Maestro de Transporte y Vialidad de 2002. Paralelamente, la constitución de la base de datos georeferenciados llamada "Mobilité" ha servido de base para la gestión y planificación del transporte urbano. Integra a más de los datos municipales, otras informaciones actualizadas, validadas, compatibilizadas, algunas de las cuales provienen de estudios del equipo de investigación del programa o de otros organismos (Policía, SRI). Por ejemplo, es a través de la Empresa Eléctrica Quito (EEQ) que se recuperó la base de datos sobre la localización de los diferentes tipos de medidores eléctricos. Con esta información se levantó un mapa de uso dominante de los suelos por manzana (Véase mapa 1$12 \mathrm{C}$ ). De modo general, este primer trabajo permitió considerar el transporte y las redes a una escala que abarca la totalidad de la aglomeración y ya no solamente la escala de la ciudad de Quito en lo que se solía trabajar. Adicionalmente, la base de datos "Mobilité" en la actualidad sirve para la implementación de un observatorio sobre la movilidad en el DMQ llevada a cabo por la DMT conjuntamente con la cooperación suiza (DIAE, Ginebra).

En el tema de la vulnerabilidad, el método usado presenta la ventaja de fundamentarse en gran medida en informaciones proporcionadas por técnicos y gestores a cargo del transporte y vialidad. Se intentó guardar sus términos, y el análisis abarca elementos claves 
Figura 1

Recapitulación de las cuatro etapas del análisis

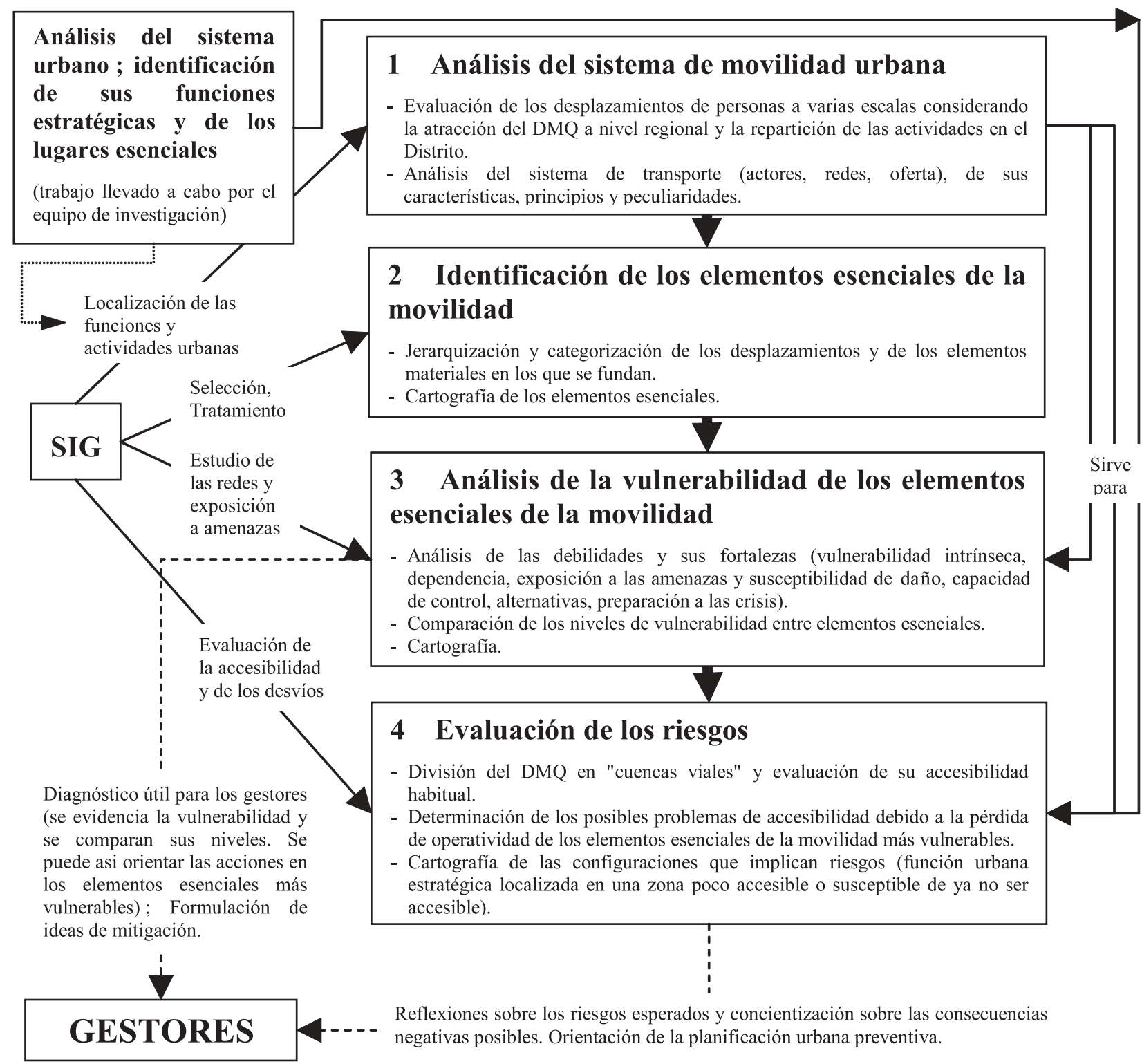


(una vía primordial, un puente estratégico, una terminal esencial) muy conocidos por los gestores y sobre los cuales intervienen directamente; en este sentido, pueden apropiarse fácilmente del análisis. De otro lado, se presentó las distintas formas de vulnerabilidad y se las cartografió. Los mapas ofrecen y permiten una lectura simple por niveles de vulnerabilidad (de la más baja a la más alta) y permite la comparación de los elementos en la totalidad de la aglomeración. Siendo el objetivo ayudar a los gestores urbanos para la toma de decisión con el fin de mitigar la vulnerabilidad y riesgos, los mapas elaborados permiten identificar los elementos que son a la vez más importantes y vulnerables, elementos sobre los cuales las acciones deberán ser prioritarias.

Si bien ciertas formas de vulnerabilidad son difíciles de resolver, se podría empezar ya a reducir otras. Por ejemplo, la instalación de una docena de cámaras de video o la creación de unos puentes de observación adicional (Central de Control de Operación, CCO) en las lomas entre la ciudad y los valles, permitiría monitorear a distancia las condiciones de tráfico en los ejes periféricos mayores, bastante vulnerables, e informar rápidamente a los equipos de intervención adecuados en caso de problema, lo que acortaría el tiempo para el envío de ayuda. La implementación de desvíos señalizados, en caso de cierre de un eje esencial, mejorańa las condiciones de tráfico; se podría incluso determinar con anticipación alternativas viales en caso de cierre de los tramos viales esenciales. El transporte de productos inflamables podría ser reglamentado; cabría una ordenanza municipal que prohíba la entrega de combustibles durante el día o durante las horas pico.
En lo que se refiere a los puentes, a pesar de que el costo de una estructura de hormigón presforzado sea superior al de una estructura de hormigón armado, la resistencia del primero es mejor frente a los sismos. Además implica un menor tiempo de ejecución de la obra (ensamblaje de elementos prefabricados). Se podría plantear un cambio en la manera de otorgar los contratos de ejecución de obras viales, esto es, contratar únicamente a las empresas que utilicen la tecnología del hormigón presforzado y que construyan bajo las normas de sismoresistencia.

Adicionalmente, un mantenimiento regular poco costoso de las obras aumentaría su resiliencia frente a las amenazas. La consolidación de las infraestructuras cuya vulnerabilidad intrínseca es alta, en especial las que se ubican en las vías de acceso al Distrito, es también una tarea factible a corto plazo. Por último, se podría plantear la constitución de un equipo especial para intervenir rápidamente, en caso de daño de las infraestructuras, organizar las potencialidades actuales (inventariando, por ejemplo, la maquinaria que poseen algunas constructoras) y realizar simulacros.

Si bien en el plan de contingencia de la erupción del volcán Pichincha se había pensado, por precaución, en el cierre de los túneles, no se proponía ningún otro itinerario de descongestión señalizado. Tomando en cuenta las observaciones previas, se podría implementar alternativas viales para mitigar los problemas de tránsito en caso de cierre de los túneles; definir y señalizar las alternativas posibles desde las entradas de la ciudad o en intersecciones estratégicas, mucho antes de desembocar en los túneles; organizar simulacros con el fin de probar la eficiencia de las vías de descongestión. Los bomberos podrían aprovechar el cierre de los túneles durante su limpieza para practi- 
car ejercicios de entrenamiento. Por último, la adquisición de trajes especiales y de máscaras de oxígeno mejoraría claramente su seguridad y eficacia en caso de incendio en los tubos.

En el ámbito de los riesgos, el análisis muestra el impacto de los fallos o de la pérdida de operatividad de los elementos esenciales de la movilidad en la accesibilidad. En base a ello, se pueden evaluar las consecuencias negativas previsibles. Los mapas propuestos (9-1, 9-2, 9-3 y 9-4) resaltan un cierto número de riesgos esperados y las escalas asociadas. Esta reflexión permite orientar las medidas a seguir, en caso de crisis. En caso de sismo, considerando el estudio que se realizó en colaboración con la Facultad de Ingenienía Civil de la Escuela Politécnica Nacional, se identificó los puentes que tienen la mayor probabilidad de colapsar en función de la aceleración máxima esperada a nivel del suelo. El desplome de las obras ocasionanía graves perturbaciones de las comunicaciones y afectaría también los intercambios y flujos estratégicos. Ello permite prionizar el restablecimiento de las conexiones esenciales, el levantamiento de puentes temporales, en determinados lugares. En la misma óptica, la identificación de las zonas que son a la vez muy pobladas, expuestas al aislamiento y poco provistas en funciones vitales de proximidad, permite en caso de emergencia orientar el envío de socorro hacia estos sectores.

Las reflexiones sobre los riesgos esperados brindan también pistas en cuanto a planificación preventiva. Se podría remediar la falta de equipamiento que sirve para afrontar una crisis (centro de salud, reserva de agua o de alimentos) en los pocos sectores más expuestos a un aislamiento. Podría plantear también algunas inversiones en vialidad para mejorar la accesi- bilidad de los sectores más expuestos al aislamiento. En este sentido, la construcción de la vía de acceso al nuevo aeropuerto de Puembo permitirá reducir considerablemente en el valle de Tumbaco y Cumbayá las posibilidades de aislamiento, lo que mitigaría la vulnerabilidad y los riesgos asociados.

\section{Limitaciones del estudio}

La movilidad evoluciona constantemente, aún más en una ciudad en la que la población se duplica cada veinte años. Las redes de transporte también cambian mucho. Los resultados presentados en este documento corresponden a los años 2001 y 2002, con cifras que podrían estar desactualizadas al presente, en algunos ámbitos.

En cuanto al volumen de desplazamientos realizados en transporte colectivo, los datos provienen de la encuesta origen-destino del año 1998. La situación ha evolucionado desde entonces (en especial con el cierre de la vía Interoceánica, cerca de la Plaza Argentina) pero tampoco un estudio actualizado ha sido llevado a cabo. Por otro lado, el análisis abarca sobre todo el transporte de las personas en bus (sin considerar el transporte intercantonal con el cantón Rumiñahui). Por último, el análisis de los desplazamientos en automóvil fue considerado únicamente en base a algunos conteos puntuales de aforos vehiculares.

En el ámbito de la vulnerabilidad, el diagnóstico se funda en gran medida en las entrevistas llevadas a cabo a los actores y gestores a cargo de los elementos esenciales. Aunque se intentó validar esta información, preguntando a otros responsables, no siempre fue posible. Algunas dudas existen todavía en cuanto 
a la calidad del asfalto utilizado para la repavimentación de los ejes viales esenciales. El asfalto puede ser de mala calidad, derretirse bajo el efecto del calor, provocar que la calzada se vuelva resbaladiza y peligrosa, sobre todo en los tramos empinados. El análisis de vulnerabilidad se fundamenta en un método innovador aún no comprobado en otras ciudades, el cual se sustenta en una serie de variables consideradas pertinentes en el contexto de Quito. Por último, el método de cálculo de la vulnerabilidad "acumulada" no es más que un método tentativo.

En lo que atañe a las amenazas, la cartografía presenta algunos vacíos y evidencia diferencias importantes para un mismo fenómeno, en función de la fuente considerada. Los tratamientos efectuados para lograr los grados sintéticos de amenaza plasmados en los mapas, no brinda, en consecuencia, sino una aproximación de la realidad, considerando la escala de los mapas iniciales (la mayonía son a 1:50.000). Sin embargo, al no existir otra información, era imposible levantar un diagnóstico más preciso. Para los elementos esenciales que cuentan a la vez con una alta exposición y alta susceptibilidad de daño, siempre se puede plantear estudios de peligro más localizados.

Sobre los riesgos, el análisis se fundamenta en las instalaciones y actividades estratégicas para el funcionamiento del territorio urbano identificadas dentro del programa "Sistema de información y riesgos en el Distrito Metropolitano de Quito". Esta información también tiene sus límites y tampoco pretende ser exhaustiva. Para formular escenarios se planteó una situación excepcional que hasta ahora afortunadamente no se ha producido pero que no es imposible, en la medida en que fenómenos susceptibles de ocasionar daños de gran magnitud amenazan el área metropolitana (laha- res, sismos). Por ejemplo, un fuerte temblor podría ocasionar el cierre de los principales accesos debido al desplome de los puentes. Los cuatro accesos (la Panamericana norte, la vía Interoceánica, la autopista Rumiñahui y la Panamericana sur) podrían quedar fuera de servicio. El acceso sería probablemente mantenido por la antigua vía a Conocoto (desde el valle de Los Chillos). Para el análisis, se consideró este escenario pero hubiese sido interesante poder tomar en cuenta los demás efectos inducidos por un terremoto (además del desplome de los puentes), es decir los deslizamientos, caídas de escombros en las calzadas, pero no se disponía de datos suficientes.

\section{Reproductibilidad del método}

Este estudio fue posible por la contribución del Municipio que puso a disposición la información de sus diferentes dependencias y ayudó a conseguir datos de otras instituciones.

En el trabajo se identificó los elementos esenciales gracias a un método detallado, en base al análisis previo de las características de la movilidad y del sistema de transporte, tarea que toma mucho tiempo. Dependiendo de la información disponible en otros lugares, una simplificación es posible. Se podría considerar únicamente algunos criterios y no todos, o usar otros criterios que pueden ser pertinentes en función del contexto local. Se podría plantear adaptaciones al método, en especial, la identificación de los elementos esenciales.

En otras ciudades, otros modos de transporte colectivo existen (metro, tren ligero, tranvía) y los elementos esenciales (y su vulnerabilidad) son en consecuencia diferentes. Si bien se puede buscar los elementos 
esenciales de la movilidad alrededor del transporte colectivo, en otras ciudades los elementos esenciales de la movilidad están asociados al automóvil (en Los Angeles, por ejemplo). Es decir, además de las vías, intercambiadores, túneles, otros elementos pueden ser esenciales (parqueadero con varios pisos, subterráneo).

\section{Elemento esencial, vulnerabilidad y accesibilidad: tres nociones esenciales para la evaluación de los riesgos}

Este análisis de riesgo en medio urbano, que parte del análisis de la movilidad, se basa en tres nociones claves: elemento esencial, vulnerabilidad y accesibilidad y en sus articulaciones.

La identificación de los elementos esenciales constituye la base del análisis de riesgo en medio urbano. En una perspectiva de optimización de la mitigación del riesgo, rápida y a bajo costo, parece pertinente enfocarse en las estructuras esenciales, aquellas cuya pérdida de operatividad, daño o destrucción perjudicańa gravemente el sistema urbano en su globalidad, aquellas que se debe resguardar, proteger o reforzar a toda costa. Es entonces prioritario dirigir los análisis de vulnerabilidad hacia los elementos esenciales. Así mismo, de manera prioritaria, se debería dirigir la atención a los elementos esenciales más vulnerables, en la medida en que son éstos los que tienen la mayor probabilidad de experimentar graves fallos o sufrir daños. El concepto de vulnerabilidad se posiciona entonces como complemento del concepto de elemento esencial en un análisis de riesgo en medio urbano.
En el análisis de riesgo llevado a cabo, la movilidad interviene en dos ocasiones. Primero como reto mayor del sistema urbano. En efecto, la movilidad para el medio urbano representa algo imprescindible que se basa en elementos esenciales es decir, en aquellas infraestructuras claves identificables y localizables. Segundo, a través de la movilidad se plantea también la noción de accesibilidad, de igual modo indispensable para la evaluación de los riesgos a escala de un sistema territorial como el del DMQ. En base a la noción de accesibilidad es posible determinar las consecuencias posibles de la pérdida de operatividad de un elemento esencial de la movilidad. Este fallo es tanto más probable cuanto que el elemento acumula diversas formas de vulnerabilidad y pocas fortalezas. Como se vio, el acceso a los lugares esenciales del sistema territorial, lugares que reúnen instalaciones estratégicas para su funcionamiento y desarrollo, puede verse afectado. La reducción de la accesibilidad conlleva una serie de consecuencias que pueden dificultar el funcionamiento del sistema territorial estudiado y también los niveles superiores, en especial cuando el sistema territorial en cuestión es la capital de un país.

Las tres nociones elemento esencial, vulnerabilidad y accesibilidad son entonces indisociables y el objeto de este estudio fue mostrar sus articulaciones y analizarlas. El estudio constituye en este sentido un aporte metodológico. A partir de estas nociones y del análisis espacial que supone, el geógrafo puede entonces, en una perspectiva de planificación urbana preventiva y de gestión de crisis, aportar reflexiones útiles para los gestores urbanos. 


\section{Bibliografía}

APPERT M., CHAPELON L., 2003, Variabilité de la performance des réseaux routiers: application à la région urbaine de Londres", in: MATHIS Ph. (Ed), Graphes et réseaux: modélisation multiniveau. $\mathrm{Pa}-$ ris: Hermès. pp. 49-76.

ARIAS C., 1997, El sistema de Trolebús de la ciudad de Quito-Ecuador, Banco Interamericano de Desarrollo, Simposio: La ciudad latinoamericana y del Caribe en el nuevo siglo - Intercambio de experiencias de gestión urbana, Barcelona, 27p.

ASCHAN-LEYGONIE Ch., 2000, Vers une analyse de la résilience des systèmes spatiaux, in l'Espace Géographique, 29 (1), pp. 64-77.

ASAMBLEA NACIONAL CONSTITUYENTE, 1998, Constitución Política de la República del Ecuador, Ed. Gonzalo Arias Barriga, 2da Edición, 123p.

ASTÉ J.-P., 1994, Les outils d'aide à la prévention et à la gestion du risque en milieu urbain, in RGA, 1994, No 4, pp. 125-129.

ATC, 1991, Seismic Vulnerability and Impact of Disruption of Lifelines in the Conterminous United States, Applied Technology Council - 25, Federal Emergency Management Agency (FEMA), Redwood City, CA, 439p.

ATIAGA G., DEMORAES F., 2002 y 2003, Vulnerabilidad estructural de los puentes del Distrito Metropolitano de Quito frente al peligro sísmico - Apli- cación y adaptación de la metodología HAZUS®99 al contexto ecuatoriano - Presentación de la metodología, resultados y mapas. Direcciones Metropolitanas de Territorio y Vivienda y de Transporte y Vialidad, Municipio del Distrito Metropolitano de Quito, Escuela Politécnica Nacional, IRD. Quito, Ecuador, 127p. y 67p.

BARBIEUX C., GREGOIRE B., 1998, Les transports publics urbains dans les pays en développement: Crises et perspectives, in La politique de déplacements urbains - Outil du développement durable, Actes du congrès international CODATU VIII. Le Cap, 21-25 septembre 1998, pp. 21-26.

BAUD P., BOURGEAT S., BRAS C., 1997, Dictionnaire de Géographie, 2ème édition, Coll. Initial, Hatier, Paris, 509p.

BAVOUX J-J., (bajo la dirección de), 1998, Introduction à l'analyse spatiale, Coll. "Synthèse", série "Géographie", Armand Colin, Paris, 96p.

BEAUCIRE F., 1996, Les transports publics et la ville, Editions Milan, 63p.

BEAUJEU-GARNIER J., 1995, Géographie urbaine, 4ème édition, Armand Colin, 349p.

BEGUIN M, PUMAIN D., 2000, La représentation des données géographiques - Statistiques et cartographie, Coll. Cursus Géographie, Armand Colin, Paris, 192p. 
BERDICA K., 2002, An introduction to road vulnerability: what has been done, is done and should be done, Transport Policy 9 (2), pp. 117-127.

BLAIKIE P., CANNON T., DAVIS I., WISNER B., 1996, Vulnerabilidad, El entorno social, político y económico de los desastres, La RED, 374p.

BOCK M. S., GODARD H., de MAXIMY R., 1992, La red vial: un elemento que marca el espacio de manera diferenciada. Accesibilidad y aislamiento: una visión de los modos de composición urbana. Lámina 40: los modos de composición urbana en Atlas Infográfico de Quito, 41 láminas bilingües (español, francés).

BONDOUX F., DEMORAES F., 2002, Determinación de la demanda en transporte interparroquial e informal del corredor Quito - El Quinche mediante una encuesta Ascensos Descensos - Síntesis - (système FINDEM). Quito, Noviembre 2002, 81p.

CAI J-S., 1994, Urban transport strategies for sustainable development of large cities in the developing countries, in Les transports dans les villes du Sud, La recherche de solutions durables, Editions Karthala, CODATU / INRETS, pp. 313-322.

CAMARA A. P. R. 1994, Rio de Janeiro public transportation provision - Characteristics and spatial inequalities, in Les transports dans les villes du Sud, La recherche de solutions durables, Editions Karthala, CODATU / INRETS, pp. 31-45.

CARRIÓN D., 2002, A municipality behind reality - Urban-Spatial Transformations in Quito (1990-2000), $\mathrm{PhD}$ Thesis, Netherland, (borrador), 136p (salvo ilustraciones y anexos).
CARRIÓN F., 2000, Transporte urbano: el caso de Quito en el nuevo urbanismo, 11p.

CARRIÓN F., ARCOS C., PALOMEQUE A., TERÁN A., 2001, Diagnóstico sobre seguridad ciudadana en Ecuador: un paso hacia la definición de políticas públicas, Revista Iconos N ${ }^{\circ} 11$, FLACSO, QuitoEcuador, pp. 68-79.

CARRIÓN F., VALEJO R, 2000, Quito, Capítulo 16, en Metrópolis en movimiento, una comparación internacional, bajo la dirección de DUREAU F. et al, Colección Villes, Ed. Economica, IRD, pp. 603-611.

CERTU, 2002, Vulnérabilité des réseaux urbains et gestion de crise, Exemple de l'inondation de mars 2001 à Lyon et Mâcon, Centre d'études sur les réseaux, les transports, l'urbanisme et les constructions publiques, Ministère de l'Écologie et du Développement Durable (DPPR), 81p. http://www.certu.fr

CHADULE (Groupe), 1997, Initiation aux pratiques statistiques en géographie, Armand Colin, Collection U, série géographie, Paris, 203p.

CHATELAIN J.L., et al. 1994, Les scénarios sismiques comme outils d'aide à la décision pour la réduction des risques: projet pilote à Quito, Equateur, in RGA, No 4, pp. 131-150.

CHATELAIN J.L, GUILIER B., YEPES H., et al., 1996, Projet pilote de scénario sismique à Quito (Equateur): méthode et résultat, Bull. IFEA., 1996, Tome 25, No 3, pp. 553-588.

CIUDAD / CIID, 1990, El transporte colectivo en Quito, en Proyecto de Investigación: Urbanización y Políticas en el Ecuador, CIUDAD - Centro Interna- 
cional de Investigaciones para el Desarrollo - Canadá, 198p.

CONAM, 2001, Taller de identificación y análisis de las alternativas de delegación del sistema trolleybus del Distrito Metropolitano de Quito, José Núñez Cristiansen, Director Unidad de Infraestructura Comisión Nacional de Modernización del Estado. Taller 12 al 16 de Marzo de 2001, Quito - Ecuador, $7 \mathrm{p}$.

CORREA HOUSE C., 2002, Relación entre la tectónica y la erosión en el borde oriental de la cuenca de Quito, Universidad Central del Ecuador, Facultad de Ingeniería en Geología y Minas, Petroleros Ambientales, Tesis de diploma de ingeniero geólogo, 280p.

COSINSCHI M., RACINE J.-B., 1995, Géographie urbaine, in Les concepts de la géographie humaine, Masson, pp. 96-116.

COVA T.J., CONGER S., 2004, Transportation hazards, in Transportation Engineers' Handbook, M. Kutz (Ed.), (en prensa).

CUSSET, J-M, 1993, Dynamique des systèmes de transport urbain dans les pays en développement: convergence et singularités, in la Recherche-Transports-Sécurité, revue INRETS, $n^{\circ} 37$, pp. 23-32.

DAUPHINÉ A., 2001, Risques et catastrophes: Observer, spatialiser, comprendre, gérer, Coll. U, Armand Colin, 288p.

De AQUINO PEREIRA W. A., 2001, Informe final - Estudios de demanda y oferta del Sistema Trolebús del Distrito Metropolitano de Quito, 80p.
DEMORAES F., D'ERCOLE R, 2001, Cartografía de las amenazas por cantón en el Ecuador - Reporte y cartografía realizadas para COOPI / OXFAM en el marco del proyecto "Cartografía de riesgos y capacidades en el Ecuador". Agosto 2001, Quito - Ecuador, 65p.

DEMORAES, F. 2002a, Metodología de identificación de los elementos de mayor interés del transporte urbano. Aplicación a la ciudad de Quito y representación espacial a través de un SIG, Seminario "GIS Ecuador 2002". Julio 2002, Escuela Politécnica Nacional, Quito, Ecuador, CD-ROM.

DEMORAES, F. 2002b, Vulnerabilidad de la movilidad en Quito inducida por la exposición a las inundaciones de un medio de transporte clave: el trolebús. Congreso Panamericano de Ingeniería de Tráfico y Transportes (Panam XII). Noviembre 2002, Quito, Ecuador, CD-ROM.

DEMORAES F., 2002c, Situación del transporte y de las comunicaciones frente a los lahares relacionados con una enupción del volcán Cotopaxi - Distrito Metropolitano de Quito. Comité de Operaciones de Emergencia, MDMQ, Defensa Civil, Cruz Roja, Consejo Provincial, Bomberos, 911. Febrero 2002, Quito, Ecuador, 7p.

DEMORAES F., BONDOUX F., SOURIS M., NÚÑEZ H, 2004, Innovaciones tecnológicas aplicadas al transporte colectivo en Quito - Optimización en la evaluación de la demanda con GPS y SIG, Bulletin de l'Institut Français d'Etudes Andines, 33 (1), Lima, Pérou, pp. 193-212. 
D'ERCOLE R, 1991, Vulnérabilité des populations face au risque volcanique. Le cas de la région du volcan Cotopaxi (Equateur) - Thèse de doctorat, Université Joseph Fourier, Grenoble, 460p.

D'ERCOLE R, 1998, Approches de la vulnérabilité et perspectives pour une meilleure logique de réduction des risques - Pangea, ${ }^{\circ} 29-30$, p.20-28.

D'ERCOLE R, PIGEON P., BAUSSART O., CAMBOT V., GNEMMI L., WATTEZ J., 2000, Analyse du système urbain d'Annecy et définition de ses enjeux, Département de Géographie - Université de Savoie, 52p. + figures.

D'ERCOLE R, METZGER P., 2000, La vulnérabilité de Quito face à l'activité du Guagua Pichincha. Les premières leçons d'une crise durable, in Cahiers Savoisiens de Géographie, CISM, Vol III, pp.39-52.

D'ERCOLE R, METZGER P., 2002, Los lugares esenciales del Distrito Metropolitano de Quito, colección Quito Metropolitano, IRD/DMTV-MDMQ, QuitoEcuador, 216p.

D'ERCOLE R, METZGER P., 2004 - La vulnerabilidad del Distrito Metropolitano de Quito, colección Quito Metropolitano, IRD/DMTV-MDMQ, Quito-Ecuador, $512 \mathrm{p}$.

DIMTRIOU H. T., 1994, Responding to the transport needs of the urban poor, in Les transports dans les villes du Sud. La recherche de solutions durables, Editions Karthala, CODATU / INRETS, pp. 323-338.

DOURTHE A., WITYK M., MALBRAN H., FIGUEROA O., 1998, Déréglementation et re-réglementation du transport public urbain: les cas de Santiago du Chili, in La politique de déplacements urbains CODATU VIII, pp. 815-819.
DUBOIS-MAURY J., CHALINE C., 2002, Les risques urbains, Coll. U, Armand Colin, 208p.

DUPONT Y. (sous la direction de), 2003, Dictionnaire des risques, Armand Colin, 421p.

ECH-UPGT, 1998, Estudios de gestión integral de tránsito y transporte del centro histórico de Quito, Informe 2, Diagnóstico de la situación actual, Louis Berger International, 100p.

EPN - GeoHazards International - MDMQ - ORSTOM - OYO Corp., 1995, Proyecto para el manejo del riesgo sísmico de Quito, Síntesis, colección Quito Metropolitano, Vol. 4, 33p. + un mapa.

ESTACIO J., 2001, Almacenamiento, transporte y peligrosidad de combustibles, productos químicos y radioactivos en el Distrito Metropolitano de Quito, (coordinadores R. D’Ercole y P. Metzger), Reporte, Programa de investigación "Sistema de información y riesgos en el Distrito Metropolitano de Quito", IRD-MDMQ, Quito, 62p.

ESTACIO J., D'ERCOLE R, 2003, Memorias sobre la erupción del volcan Reventador, Consecuencias y experiencias vividas la semana de emergencia del 3 al 11 de noviembre en el DMQ, IRD / Unidad De Prevención de Desastres - Dirección Metropolitana de Seguridad Ciudadana, 51p.

FERNÁNDEZ M.A (bajo la dirección de), 1996, Ciudades en Riesgo. Degradación ambiental, riesgos urbanos y desastres en América Latina, La Red USAID, 190p.

GLEYZE J.-F., 2001, Les dommages induits par les coupures du réseau routier, Colloque "Risque d'accidents et risques environnementaux dans les transports routiers", Octobre 2001, 15p. 
GODARD H., de MAXIMY R, VEGA J., 1992, Transportes y red vial. Lámina 24, en Atlas Infográfico de Quito, 41 láminas bilingües (español, francés).

GODARD X., 1997, La mobilité dans les villes en développement, repères comparatifs, in "Mobilité et politiques de transport dans les villes en développement", Journées spécialisées INRETS, 30-31 janvier 1997, Actes n55, juin 1997, pp. 135-143.

HALL L. M. (coordinador), 2000, Los terremotos del Ecuador del 5 de Marzo del 1987, Deslizamientos y sus efectos socioeconómicos, en Estudios de Geografía, Vol. 9, 146p.

HENRY E., 1993, Autotransporte urbano colectivo en desarrollo: el abanico de las empresas, in EURE, Revista latinoamericana de Estudios Urbanos Regionales, Instituto de Estudios Unbanos, Pontificia Universidad de Santiago de Chile, Vol. XIX, pp. 7178.

HENRY E., FIGUEROA O., 1985, Transports urbains et services en Amérique Latine, Actes de l'Atelier de Recherche, Quito, 8-12 juillet 1985, Tome 1: Transports et citadins, INRETS-CIUDAD, 367p.

HENRY E., FIGUEROA O., 1987, Transports urbains et services en Amérique Latine, Actes de l'Atelier de Recherche, Quito, 8-12 juillet 1985, Tome 2, Le service public, INRETS-CIUDAD, 352p.

HUSDAL J., 2004, Reliability and vulnerability versus costs and benefits, proceedings of the 2nd International Symposium on Transport Network Reliability, New Zealand, August 2004, pp. 180-186.

IIDA Y., 1999, Basic concepts and future directions of road network reliability analysis, in: Journal of Advanced Transportation, vol. 33, No2, 125-134.
IMQ, UET, 1991, Estudio de factibilidad técnica, económica y financiera para el proyecto Trolebús, Quito, 75p.

INEC 2001., VI Censo de Población y V de Vivienda. Instituto Nacional de Estadísticas y Censos. Ecuador.

INRETS, 1997, Mobilité et politiques de transport dans les villes en développement, Journées spécialisées INRETS, 30-31. Janvier 1997, Actes n55, juin 1997, 281p.

JPTP, 1993, Estadísticas de las organizaciones de transporte de pasajeros y de carga urbano e intraprovincial en la Provincia de Pichincha, Jefatura Provincial de Tránsito de Pichincha, Quito, 22p.

KOLBERG, MARTÍNEZ, WHYMPER, WOLF, ITURRALDE et al., 2000, Historia de los terremotos y las enupciones volcánicas en el Ecuador, Siglos XVI XX, Crónicas y relatos, Talleres de Estudios Andinos, Fundación Felipe Guamán Poma, Quito, 202p.

LAHOUSSE Ph., PIEDANNA V., 1998, L'outil statistique en géographie, Tome I, Les distributions à une dimension, Série Synthèse Géographie, Armand Colin, Paris, 96p.

LERAS-ECHEVERRI G., SANCHEZ-SILVA M., 2001, Vulnerability analysis of highway networks, methodology and cases study, Transport 174 (4), pp. 223230.

LOPEZ C., TUPIZA A., 2002, Economía urbana y riesgos. Contribución al conocimiento de la geografía económica del DMQ para la mitigación de los riesgos, (coordinadores R. D’Ercole y P. Metzger), Reporte, Programa de investigación "Sistema de infor- 
mación y riesgos en el Distrito Metropolitano de Quito", IRD-MDMQ , Quito, 92p.

LUTOFF C., 2000, Le système urbain niçois face à un séisme - Analyse des enjeux et des dysfonctionnements potentiels, thèse de doctorat en géographie, Université de Savoie, 361p.

MDMQ, 1998, Plan de Contingencia / Erupción Guagua Pichincha, 84p.

MDMQ/DGP, 1998, Estudio del plan de mejoramiento del transporte en la ciudad de Quito, Informe preliminar realizado por el Arq. Hidalgo Núñez como solicitud a la Cooperación Japonesa. Marzo de 1998, Ministerio de Construcción - Instituto de Desarrollo de la Infraestructura de Japón, 47p.

MDMQ/DMTV, 2000, Plan General de Desarrollo Teritorial - Distrito Metropolitano de Quito 2000 2020, Dirección Metropolitana de Territorio y Vivienda, Quito, CD interactivo y folleto.

MDMQ/UOST, 2001, Estudio de la demanda del Sistema Integrado - Encuesta Ascenso-Descenso en el Trolebús, Subdirección de Operaciones - Planificación y Programación Operacional, febrero-marzo 2001, 7p.

MDMQ/UPGT, 1996, Plan de racionalización del Transporte de la ciudad de Quito, Quito, 80p.

MDMQ/DMT, 2002, Plan Maestro de Transporte para el Distrito Metropolitano de Quito (Propuesta), Quito, CD interactivo y folleto.

MENA A., SERRANO T., 2002, Salud y riesgos en el Distrito Metropolitano de Quito. Análisis espacial y vulnerabilidad de los establecimientos de salud, (coordinadores R. D’Ercole y P. Metzger), Reporte,
Programa de investigación "Sistema de información y riesgos en el Distrito Metropolitano de Quito", IRD-MDMQ, Quito, 2 volúmenes, 60 y 104p.

METZGER P., BERMÚDEZ N., 1996, El medio ambiente urbano en Quito, Municipio del Distrito Urbano de Quito, Dirección General de Planificación MDMQ-DGP / ORSTOM, Colección Quito Metropolitano, 186p.

METZGER P., D'ERCOLE R, SIERRA A., 1999, Enjeux et incertitudes dans la gestion du risque volcanique. Le cas de l'alerte jaune à Quito en octobre 1998, in Les Annales de la Recherche Urbaine n83-84, pp. 177-184.

NÚÑEZ H., 1997, El transporte en el Distrito Metropolitano - Problemática, Primer borrador - Documento de Discusión Interna, Septiembre 1997, $\mathrm{MDMQ} / \mathrm{DGP}, 20 \mathrm{p}$.

OEA-UDSMA, 2001, Estudio general sobre los tramos vulnerables a los peligros naturales de la carretera Panamericana y sus corredores complementarios en Centroamérica, Organización de los Estados Americanos, Unidad de Desarrollo Sostenible y Medio Ambiente, Realizado con el apoyo del Departamento de Transporte de los Estados Unidos de América, Washington, D.C., 85p.

PELTRE P., 1989, Quebradas y riesgos naturales en Quito, período 1900-1988, en Riesgos Naturales en Quito, Lahares, aluviones y derrumbes del Pichincha y del Cotopaxi, en Estudios de Geografía, Vol II, Colegio de Geógrafos del Ecuador, Corporación Editorial Nacional, pp. 45-91.

PERRIN J.-L, SIERRA A., FOURCADE B., et al, 1997, Quito face à un risque d'origine naturelle - La lave 
torrentielle du 31 mars 1997 dans le quartier de la Comuna, Programme SISHILAD/EMAAP-Q/INAMHI/ORSTOM, 34p.

PIGEON P., 2002, Réflexions sur la géographie des risques dits naturels, diplôme d'habilitation à diriger des recherches, texte principal, Université de NiceSophia-Antipolis, Nice, 204p.

PUMAIN D. et SAINT-JULIEN Th., 1997, L'analyse spatiale, Coll. Cursus Géographie, Armand Colin, Paris, $167 p$.

PUMAIN D. et SAINT-JULIEN Th., 2001, Les interactions spatiales - Flux et changements dans l'espace géographique, Coll. Cursus Géographie, Armand Colin, Paris, 192p.

REGISTRO OFICIAL, 2000, Ley de Régimen Municipal, Legislación conexa, Corporación de Estudios y Publicaciones, 22 capítulos.

REGISTRO OFICIAL, 2000, Ley de Tránsito y Transporte Terrestres, Reglamento e información básica, Corporación de Estudios y Publicaciones, 14 capítulos.

SIERRA A., 2000, Gestion et enjeux des espaces urbains à risque d'origine naturelle - Les versants et les quebradas de Quito, Equateur, Université Paris VIII, Centre de Recherche en Analyses Géopolitiques, Thèse de doctorat présentée le 21 sept. 2000, 326p.

SOURIS, M., 2002 - La construction d'un système d'information géographique, principes et algorithmes du système SAVANE, Thèse de Doctorat, Université de La Rochelle, 505 p. Une version en format pdf est disponible à la page suivante: www.bondy.ird.fr/cvd/pages_2003/these_marc.
TAMRU, B., 2002, L'émergence du risque d'inondation a Addis-Abeba: pertinence d'une étude des dynamiques urbaines comme révélatrices d'un processus de vulnérabilisation, in Annales de Géographie, $n^{\circ}$ 627-628, Approches géographiques des risques " naturels ", pp.614-636.

TAYLOR M.A.P., D’ESTE G.M., 2003, Concepts of network vulnerability and applications to the identification of critical elements of transport infrastructure, 26th Australasian Transport Research Forum, Wellington, New-Zealand, October 2003, 15p.

THOMSON I., 1992, Análisis de la institucionalidad del transporte urbano latinoamericano: reformas para mejorarla, in EURE, Revista latinoamericana de Estudios Urbanos Regionales, Instituto de Estudios Unbanos - Pontificia Universidad de Santiago de Chile, Vol. XIX, Marzo del 1993, pp. 55-71.

THOURET J.C., 2002, Aléas et risques volcaniques: mieux comprendre pour prévoir et mieux gérer pour durer, in Annales de Géographie, n 627-628, Approches géographiques des risques " naturels ", Armand Colin, pp. 503-523.

VÁSCONEZ M., 1985, La movilidad urbana en los bamios populares de Quito, en Transportes urbanos y servicios en América Latina, Actas del taller de Investigación, Quito, 8-12 julio 1985, Tome 1: Transportes y ciudadanos, INRETS-CIUDAD, pp. 129152.

VILÉ J., 2003, Fiabilité et vulnérabilité des systèmes de transport, Ponts et Chaussées, http://www.equipement.gouv.fr/recherche/incitatif/predit/enjeu24.htm. 
YAÑEZ-THIRÉ E., MÉJEAN C., 1998, Les transports à Caracas: requalifications urbaines à partir de l'insertion d'un transport en commun de type tramway en site propre, in La politique de déplacements urbains - CODATU VIII, pp. 287-292.

YÉPEZ F., 2002, Últimos avances en la evaluación del niesgo sísmico de Quito y futuros proyectos de mitigación, en Gestión de riesgos y prevención de desastres, Memoria del Seminario, Quito, 24-25 de enero de 2001, FLACSO - COOPI - ECHO, pp 1628. 


\section{Listado de siglas y anexos}

CCO: Centro de Control de Operación (EMSAT-MDMQ)

CNT: $\quad$ Consejo Nacional de Tránsito (Ecuador)

CPTP: Consejo Provincial de Tránsito de Pichincha

DMQ: Distrito Metropolitano de Quito (MDMQ)

DNH: Dirección Nacional de Hidrocarburos del Ecuador

DNT: Dirección Nacional de Tránsito (Policía Nacional del Ecuador)

EEQ: $\quad$ Empresa Eléctrica de Quito

EMAAP-Q: Empresa Metropolitana de Alcantarillado y Agua Potable de Quito (MDMQ)

EMOP-Q: Empresa Metropolitana de Obras Públicas de Quito (MDMQ)

EMSAT: $\quad$ Empresa Metropolitana de Servicio y Administración de Transporte (MDMQ)

HCPP: Honorable Concejo Provincial de Pichincha

IGM: Instituto Geográfico Militar (Ecuador)

INAMHI: Instituto Nacional de Meteorología e Hidrología (Ecuador)

INEC: Instituto Nacional de Estadísticas y Censo (Ecuador)

IRD: Institut de Recherche pour le Développement (Instituto Francés de Investigación para el Desarrollo)

MDMQ: Municipio del Distrito Metropolitano de Quito

MOP: $\quad$ Ministerio de Obras Públicas (Ecuador)

SIG: $\quad$ Sistema de Información Geográfico

UPGT: Unidad de Planificación y Gestión del Transporte (MDMQ), hoy EMSAT
No se detalla en el presente libro los demás anexos del trabajo de investigación (cuya lista se indica a continuación). Se los puede consultar en la siguiente dirección (la mayoría están en francés):

http:// www.univ-savoie.fr/labos/ edytem/membres/demoraes/these/these.html

- Organigrama municipal (MDMQ)

- Método de cálculo de las distancias recorridas en TC

- Correlación entre consumo eléctrico de los hogares y la tasa de motorización

- Método de diferenciación de los puentes (ejemplo)

- Listado de los temas del recorte de prensa

- Ejemplos de vulnerabilidades del sistema de construcción de la red vial

- Ejemplo de entrevista a los gerentes de los operadores de transporte colectivo en Quito

- Cuestionario dirigido a los técnicos municipales para la determinación de algunas formas de vulnerabilidad de los elementos esenciales de la movilidad

- Metadatos de la base SIG "Mobilité" (Savane) en castellano

- Matriz de vulnerabilidad de los ejes viales esenciales (por tramo)

- Matriz de vulnerabilidad de los puentes esenciales

- Matriz de vulnerabilidad de los túneles

- Matriz de vulnerabilidad de los centros de transporte esenciales

- Escala de Mercalli 


\section{Listado de mapas}

\section{Capítulo 1}

Mapa 1-1 Principales ciudades de destino desde Quito en bus sin trasbordo............... 31

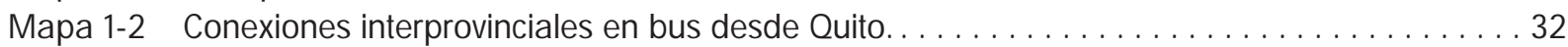

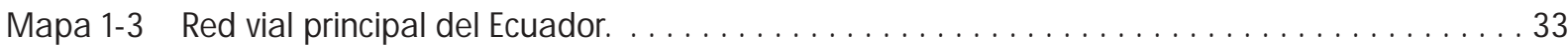

Mapa 1-4 Red vial principal de la provincia de Pichincha y del Distrito Metropolitano de Quito. ....... . 36

Mapa 1-5 Principales desplazamientos de personas entre el DMQ y los cantones vecinos. . . . . . . . . . 38

Mapa 1-6 Principales funciones urbanas y sectores de concentración del empleo en las parroquias suburbanas del DMQ. ..........................41

Mapa 1-7 Densidad de población y uso dominante del suelo en las parroquias

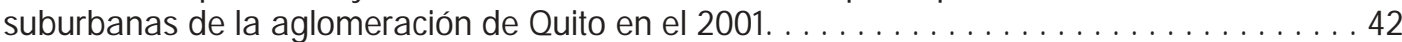

Mapa 1-8 Concentración de la población y del empleo en la zona urbana consolidada de Quito. ......................................46

Mapa 1-9 Concentración de las funciones urbanas y de los servicios a favor de la ciudad de Quito....................................... 47

Mapa 1-10 Volumen y motivos de los desplazamientos de personas realizados a diario en transporte colectivo interparroquial entre la ciudad y

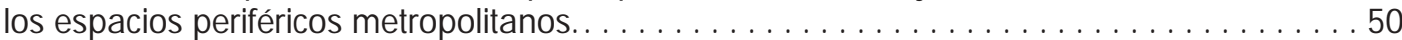

Mapa 1-11 Representación de los dos principales sectores de destino de los movimientos pendulares por zona de procedencia..................... 51

Mapa 1-12 Fuerte concentración de las funciones urbanas al interior del espacio central de Quito. . . . . . . . . . . . . . . . . . . . . . . . . . 54

Mapa 1-13 Desplazamientos de personas realizados cada día en bus urbano e interparroquial con destino al espacio central de la ciudad de Quito................................ 55

Mapa 1-14 Afluencia, salidas y motivos de los viajes de personas efectuados en bus urbano e interparroquial en la ciudad de Quito. . . . . . . . . . . . . . . . . . . 56

\section{Capítulo 2}

Mapa 2-1 Repartición territorial de las competencias institucionales en el ámbito de la vialidad en el Distrito Metropolitano de Quito - Julio de $2003 \ldots \ldots \ldots \ldots \ldots \ldots \ldots$

Mapa 2-2 Estructura, tipología y frecuentación de la red vial de la aglomeración de Quito, 2001 . . . . . 64

Mapa 2-3 Localización de los tres túneles (San Juan, San Roque y San Diego). . . . . . . . . . . . . . . 67

Mapa 2-4 Nomenclatura de las vías principales de Quito y principales hitos. . . . . . . . . . . . 68

Mapa 2-5 Infraestructuras viales y equipamientos para el transporte. Aglomeración de Quito, 2001 . . . . 71

Mapa 2-6 Densidad de líneas de buses urbanos, interparroquiales e intercantonales

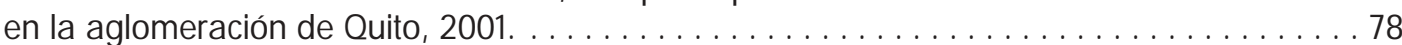


Mapa 2-7 Configuración de las redes de transporte colectivo integrado y frecuentación del eje del trolebús.

Mapa 2-8 Tasa de motorización en el Ecuador, en la Provincia de Pichincha y

en la aglomeración de Quito en el 2001

\section{Capítulo 4}

Mapa 4-1 Síntesis cartográfica de la jerarquización de los ejes suburbanos (accesos al Distrito y ejes centro-periferia).

Mapa 4-2 Detalle del método de identificación de los ejes urbanos más relevantes según las variables consideradas........................ 102

Mapa 4-3 Jerarquización de los ejes de comunicación a nivel de la ciudad de Quito.. . . . . . . . . . . . 103

Mapa 4-4 Accesos al espacio central y arterias de inervación principal. . . . . . . . . . . . . . . . 107

Mapa 4-5 Cuadro A: Jerarquización de los ejes metropolitanos (síntesis).

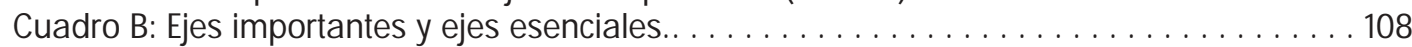

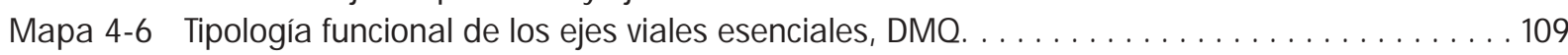

Mapa 4-7 Segmentación de los ejes esenciales respecto a su función y

su posición en la red vial, DM Q.................................... 110

Mapa 4-8 Localización de los puentes viales esenciales, DMQ..................... 114

Mapa 4-9 Localización de los nodos esenciales de las redes de transporte colectivo . . . . . . . . . . . 115

Mapa 4-10 Síntesis de los elementos esenciales de la movilidad, DMQ, 2003 . . . . . . . . . . . . 116

\section{Capítulo 5}

Mapa 5-1 Pendiente de los ejes viales esenciales por tramo..................... 129

Mapa 5-2 Radio de acción del Cuerpo de Bomberos del DM Q, Ciudad de Quito, 2000. . . . . . . . . . 131

Mapa 5-3 Exposición de los elementos esenciales de la movilidad a los aluviones. . . . . . . . . . . . 134

Mapa 5-4 Exposición de los elementos esenciales de la movilidad respecto

a la inestabilidad de los suelos. . . . . . . . . . . . . . . . . . . . . . . . . . . . 135

Mapa 5-5 Exposición de los elementos esenciales de la movilidad a las inundaciones. . . . . . . . . 136

Mapa 5-6 Exposición de los elementos esenciales de la movilidad a la licuefacción

de los suelos y a la amplificación de las ondas en caso de sismo . . . . . . . . . . . . . 137

Mapa 5-7 Exposición de los elementos esenciales de la movilidad a las amenazas volcánicas (lahares, flujos piroclásticos).. . . . . . . . . . . . . . . . . . 138

Mapa 5-8 Exposición a los peligros relacionados con productos inflamables (almacenamiento y transporte) . . . . . . . . . . . . . . . . . . . . . . . . . . . . . . 139

\section{Capítulo 6}

Mapa 6-1 Grados sintéticos de las tres primeras formas de vulnerabilidad de los ejes viales esenciales. . . . . . . . . . . . . . . . . . . . . . . . . 151 
Mapa 6-2 Grados sintéticos de las tres formas de compensación de

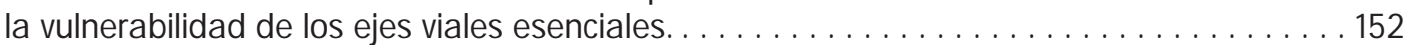

Mapa 6-3 Grados sintéticos de las tres primeras formas de vulnerabilidad de los puentes esenciales.... . 154

Mapa 6-4 Grados sintéticos de las tres formas de compensación de

la vulnerabilidad de los puentes esenciales........................ 155

Mapa 6-5 Grados sintéticos de las tres primeras formas de vulnerabilidad de

los túneles y centros de transporte esenciales .......................... 157

Mapa 6-6 Grados sintéticos de las tres formas de compensación de

la vulnerabilidad de los túneles y centros de transporte esenciales. . . . . . . . . . . 158

Mapa 6-7 Síntesis: Vulnerabilidad acumulada de los elementos esenciales de la movilidad. . . . . . . . . 163

\section{Capítulo 7}

Mapa 7-1 Principales barreras físicas, aglomeración de Quito... . . . . . . . . . . . . . . . 170

Mapa 7-2 Red vial, puntos de entrada y división del Distrito en 14 macrozonas. . . . . . . . . . . . . . 173

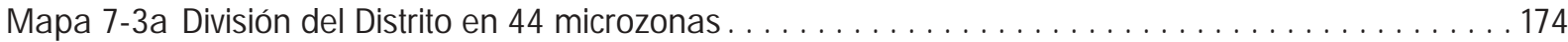

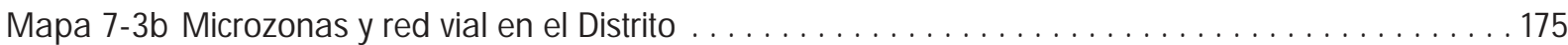

\section{Capítulo 8}

Mapa 8-1 Accesibilidad de las microzonas en período habitual. . . . . . . . . . . . . . . . 179

Mapa 8-2 Reducción posible de la accesibilidad de las zonas en caso

de fallo de los elementos esenciales más vulnerables de la red vial.. . . . . . . . . . . . . . 182

Mapa 8-3 Ejemplo de reducción de la accesibilidad debido al cierre simultáneo

de los ejes esenciales más vulnerables (procedencia desde el norte y el sur). . . . . . . . . . 185

Mapa 8-4 Vulnerabilidad de las zonas asociada a los desvíos que limitarían

su accesibilidad en caso de cierre simultáneo de los cinco ejes

esenciales más vulnerables (síntesis de los seis lugares de procedencia).

\section{Capítulo 9}

Mapa 9-1 Vulnerabilidad de la población debido a la insuficiencia

de funciones vitales de proximidad (agua, alimentos, atención médica)

en zonas susceptibles de quedar aisladas (al menos, parcialmente).

Mapa 9-2 Localización de las instalaciones esenciales para el funcionamiento

del DMQ en las zonas susceptibles de experimentar una fuerte 0

muy fuerte reducción de su accesibilidad. . . . . . . . . . . . . . . . . . . . . . . . 193

Mapa 9-3 Escala de riesgos. ....................................... 195

Mapa 9-4 Localización de las instalaciones esenciales muy dependientes

del transporte terrestre en las zonas más vulnerables, debido a los desvíos. 


\section{Listado de tablas}

\section{Capítulo 1}

Tabla 1-1 Repartición de la población, del empleo y de las funciones urbanas

por conjunto geográfico suburbano .............................. 43

Tabla 1-2 Repartición de la población, del empleo y de las funciones urbanas

entre la ciudad de Quito y su periferia.............................. 45

\section{Capítulo 2}

Tabla 2-1 Volumen de tráfico por sentido en los accesos al Distrito (días hábiles). . . . . . . . . . . 63

Tabla 2-2 Volumen de tráfico por sentido en los ejes centro-periferia (días hábiles). . . . . . . . . 63

Tabla 2-3 Tráfico por sentido en las principales avenidas más transitadas en días hábiles. . . . . . . 66

Tabla 2-4 Características generales de la oferta de transporte colectivo y utilización

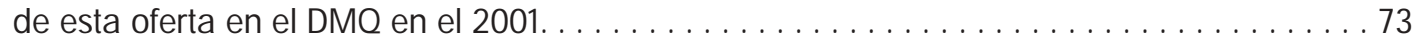

Tabla 2-5 Tasa de motorización por cantón, en el 2001, Provincia de Pichincha................ 86

\section{Capítulo 4}

Tabla 4-1 Variables consideradas para la jerarquización de las vías de acceso al Distrito. . . . . . . . . 96

Tabla 4-2 Variables consideradas para la jerarquización de los ejes centro-periferia. . . . . . . . . . .98

Tabla 4-3 Aforo vehicular en los bulevares más transitados (días hábiles) . . . . . . . . . . . . . . . . . 101

Tabla 4-4 Denominación y localización de los tramos viales homogéneos que resultan

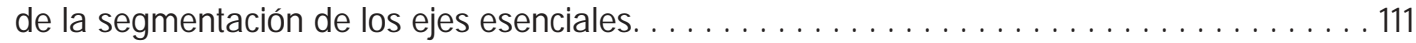

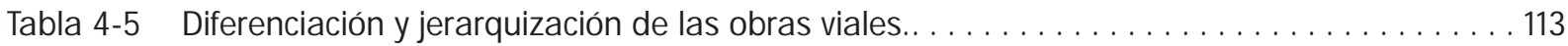

\section{Capítulo 5}

Tabla 5-1 Matriz sinóptica de las variables analizadas para evaluar las tres primeras formas de vulnerabilidad de los elementos esenciales del transporte. . . . 126

Tabla 5-2 Matriz sinóptica de las variables analizadas para evaluar las tres últimas formas de vulnerabilidad de los elementos esenciales del transporte. . . . . . . . . 127

Tabla 5-3 Descripción de los mapas de amenazas considerados y tratamientos realizados para llegar a grados sintéticos de peligro . . . . . . . . . . . . . . . 133

Tabla 5-4 Método de valoración de la vulnerabilidad de los túneles derivada de su dependencia del sistema eléctrico . . . . . . . . . . . . . . . . . . . . . . 142

Tabla 5-5 Exposición de los centros de transporte y de sus accesos inmediatos respecto a las amenazas de origen natural y a los peligros de explosión

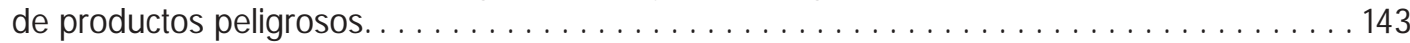


Tabla 5-6 Susceptibilidad de daño de los centros de transporte y de sus vías de acceso. . . . . . . . . . 144

Tabla 5-7 Susceptibilidad de perturbación del servicio del trole y del transporte

interparroquial asociada a fallos en las estaciones.......................... 144

Tabla 5-8 Balance: Exposición de los centros de transporte a las amenazas, susceptibilidad de daño y de perturbación. . . . . . . . . . . . . . . . . . . . . 145

Tabla 5-9 Ejemplo de cálculo del valor máximo de vulnerabilidad que

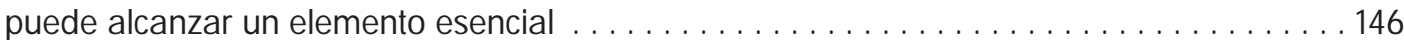

Tabla $5-10$ Cinco grados sintéticos de vulnerabilidad . . . . . . . . . . . . . . . . . . . . . . . . . . . . 146

Tabla 5-11 Suma de las valoraciones de las seis formas de vulnerabilidad y determinación de los grados sintéticos de vulnerabilidad. . . . . . . . . . . . . . . . . . . . . 147

\section{Capítulo 6}

Tabla 6-1 Ponderación de los grados sintéticos de vulnerabilidad (progresión geométrica)......... . 159

Tabla 6-2 Determinación de la vulnerabilidad acumulada de los ejes viales esenciales.. . . . . . . . . . . 160

Tabla 6-3 Equivalencia entre la suma de los grados ponderados y los niveles de vulnerabilidad acumulada . . . . . . . . . . . . . . . . . . . . . . . . . . . . . . . 161

Tabla 6-4 Elementos esenciales entre los más vulnerables (vulnerabilidad acumulada).. . . . . . . . . . . 162

\section{Capítulo 8}

Tabla 8-1 Variables consideradas para medir la accesibilidad de las macrozonas . . . . . . . . . . . . 178

Tabla 8-2 Importancia de los desvíos en función del incremento de la distancia habitual y valoración . . . . . . . . . . . . . . . . . . . . . . . . . 183

Tabla 8-3 Determinación de los niveles de vulnerabilidad de las zonas asociada al incremento de la distancia. . . . . . . . . . . . . . . . . . . . . . . . . . . . . . . 183 


\section{Listado de figuras}

\section{Capítulo 1}

Figura 1-1 Procedencia de los inmigrantes instalados en Quito entre 1996 y 2001 . . . . . . . . . . . 34

Figura 1-2 Repartición del número de medidores eléctricos por categoría y

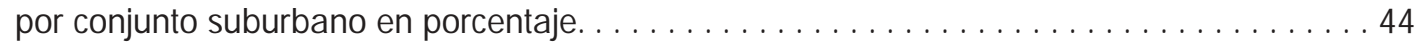

Figura 1-3 Motivos de los viajes diarios realizados en bus entre el centro y la periferia . . . . . . . . . . 48

\section{Capítulo 2}

Figura 2-1 Evolución del parque automovilístico del Distrito Metropolitano de Quito, 1975-2000. . . . . . 85

\section{Capítulo 5}

Figura 5-1 El riesgo, un juego de vulnerabilidad de los elementos esenciales contrabalanceada por factores de compensación....................... 20

\section{Capítulo 7}

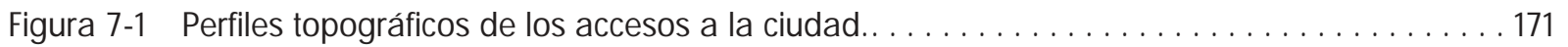

\section{Conclusión}

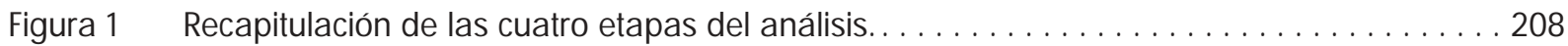




En este libro se presenta una reflexión sobre los riesgos a los cuales está expuesto el Distrito Metropolitano de Quito -DMQ- considerando la cuestión de la movilidad cotidiana de las personas y la accesibilidad, enmarcándose dentro de la filosofía de investigación planteada en el programa "Sistema de información y riesgos en el DMQ", en el marco del convenio de la Dirección Metropolitana de Planificación Territorial y el Institut de Recherche pour le Développmement (IRD, ex ORSTOM).

En una primera parte se analizan los flujos y movimientos de personas y el sistema de transporte vigente. En una segunda parte se identifican y localizan las infraestructuras clave de la movilidad. A continuación se analizan los factores de vulnerabilidad de estas infraestructuras y finalmente, se abordan los riesgos a los cuales está expuesto el Distrito considerando un cierre de las vías clave lo que provocaría una reducción de la accesibilidad de los diferentes espacios metropolitanos.

Esta publicación está dirigida a los planificadores urbanos, especialmente a los encargados del manejo del transporte o riesgos y de manera general a todos los ciudadanos interesados en comprender el funcionamiento de la movilidad de las personas y la vulnerabilidad del DMQ.
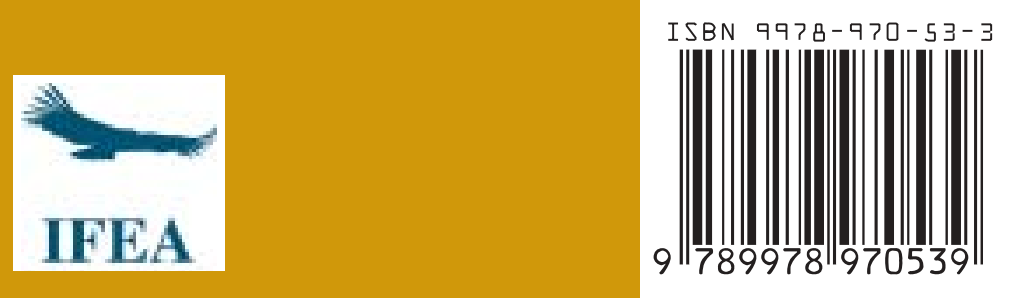